DAVID HENRIQUE RAMOS

AVALIAÇÃO DE ENSAIOS NÃO DESTRUTIVOS APLICADOS AO CONCRETO ARMADO 
DAVID HENRIQUE RAMOS

\section{AVALIAÇÃO DE ENSAIOS NÃO DESTRUTIVOS APLICADOS AO CONCRETO ARMADO}

Dissertação apresentada à Escola Politécnica da Universidade de São Paulo para obtenção do título de Mestre em Ciências 


\section{AVALIAÇÃO DE ENSAIOS NÃO DESTRUTIVOS APLICADOS AO CONCRETO ARMADO}

Dissertação apresentada à Escola Politécnica da Universidade de São Paulo para obtenção do título de Mestre em Ciências

Área de concentração:

Engenharia de Estruturas

Orientador: Prof ${ }^{\circ}$ Dr $^{\circ}$ Túlio Nogueira Bittencourt 


\section{Dedicatória}

Aos meus pais Maria de Fátima e Paulo Alexandre por todos ensinamentos de vida, pela amizade e pela dedicação na educação dos filhos.

Aos meus irmãos André, Paulo e Pedro. À minha namorada Livian. 


\section{Agradecimentos}

Ao meu orientador Prof. Dr. Túlio Nogueira Bittencourt, pelos ensinamentos, pela compreensão nos momentos difíceis e por todo auxílio na dissertação.

Aos engenheiros Paulo Bressaglia e Irving Pizarro Marchena pelo auxílio prestado nos ensaios realizados com GPR na Unicamp.

Ao Prof. Dr. José Tadeu Balbo, Henrique e Eric, por todo auxílio na realização dos ensaios com o ultrassom MIRA.

Ao Prof. Dr. Fernando Rebouças Stucchi, pelo auxílio em conseguir autorização do DNIT/RS e da Secretaria de Obras de São Paulo, para a realização de estudos de caso em campo.

Ao DNIT/RS e à Secretaria de Obras de São Paulo, por fornecer todo suporte e informações necessárias para realização de estudos de caso em campo.

Ao Osmar Manzoli, pelo o auxílio e apoio para realização dos ensaios no laboratório da Poli/USP.

À Wandrea Dantas Moreira por todo auxílio prestado durante a pós-graduação. 


\section{Resumo}

No presente estudo buscou-se avaliar os principais ensaios não destrutivos que são aplicados às estruturas de concreto armado. Para tanto, primeiramente é apresentada uma revisão bibliográfica abordando diversos métodos de ensaios não destrutivos, apresentando seus princípios físicos e aplicações.

Posteriormente são apresentados 4 estudos de caso, onde foram aplicados diversos métodos de ensaio não destrutivo. No primeiro estudo de caso, realizou-se o ensaio com GPR (ground penetration radar) em uma viga de concreto, no Laboratório de Investigações Não Destrutivas (LIND) da Faculdade de Engenharia Civil, Arquitetura e Urbanismo (FEC) da Universidade Estadual de Campinas (UNICAMP). No segundo estudo de caso, realizado no Laboratório de Estruturas e Materiais da Escola Politécnica da USP (EPUSP), uma parede de concreto foi ensaiada, aplicando os seguintes métodos de ensaio não destrutivo: ultrassom MIRA; esclerometria e pacometria. No terceiro estudo de caso, aplicado em campo, em uma ponte em Porto Alegre / RS, foi realizado o ensaio de ultrassom com 2 transdutores para avaliação de ligações da estrutura da ponte. No quarto estudo de caso, aplicado sobre uma ponte em São Paulo, foi realizado ensaio para avaliação do nível de carbonatação e utilizouse a técnica de levantamento com laser scanner para realizar o mapeamento da estrutura. 


\begin{abstract}
The present study aimed to evaluate the main non-destructive tests that are applied to reinforced concrete structures. To do so, a bibliographic review is presented first addressing several methods of non-destructive testing, presenting its physical principles and applications. Subsequently, 4 case studies is presented, where several non-destructive test methods were applied. In the first case study, the GPR (ground penetrating radar) test was carried out on a concrete beam, at the Non-Destructive Investigations Laboratory (LIND) of the Faculty of Civil Engineering, Architecture and Urbanism (FEC) of the State University of Campinas (UNICAMP). In the second case study, carried out in the laboratory LEM of the Polytechnic School of the University of São Paulo, a concrete wall was tested using the following non-destructive test methods: MIRA ultrasonic; sclerometry and pacometry. In the third case study, applied in the field on a bridge in Porto Alegre / RS, the ultrasonic test was carried out with 2 transducers to evaluate the connections of the bridge structure. In the fourth case study, applied on a bridge in São Paulo, a test was carried out to evaluate the carbonation level and the laser scanner technique was used to perform the mapping of the structure.
\end{abstract}




\section{LISTA DE ILUSTRAÇÕES}

FIGURA 2.1 - REPRESENTAÇÃO DO CIRCUITO DE UM PULSO NO ENSAIO DE ULTRASSOM.

FIGURA 2.2 - TIPOS DE CONFIGURAÇÕES POSSÍVEIS PARA APLICAÇÃO DO MÉTODO DO PULSO ULTRASSÔNICO..............................18

FIGURA 2.3 - EXEMPLO DE GRÁFICO ELABORADO A PARTIR DOS RESULTADOS DO ENSAIO DE ULTRASSOM

FIGURA 2.4 - PROCEDIMENTO dE ENSAIO PARA AVALIAÇÃO DO TAMANHO DE UMA FISSURA ATRAVÉS DA VELOCIDADE DO PULSO ULTRASSÔNICO

FIGURA 2.5 - EXEMPLO DE GRÁFICO DE RESISTÊNCIA À COMPRESSÃO EM FUNÇÃO DA VELOCIDADE DO PULSO ULTRASSÔNICO NO MEIO.

FIGURA 2.6 - EXEMPLO DE GRÁFICOS DE VELOCIDADE DO PULSO ULTRASSÔNICO E DE RESISTÊNCIA À COMPRESSÃO EM FUNÇÃO DA IDADE DO CONCRETO.

FIGURA 2.7 - EXEMPLO DE GRÁFICO DE RESISTÊNCIA À COMPRESSÃO DO CONCRETO EM FUNÇÃO DA VELOCIDADE DO PULSO ULTRASSÔNICO, PARA DIFERENTES TIPOS DE AGREGADO.

FIGURA 2.8 - EXEMPLO DE GRÁFICO DE VELOCIDADE DO PULSO ULTRASSÔNICO X RESISTÊNCIA À COMPRESSÃO (PARA DIFERENTES TIPOS DE AGREGADO).......

FIGURA 2.9 - DIFERENTES POSICIONAMENTOS DOS TRANSDUTORES EM RELAÇÃO ÀS BARRAS DE AÇO NA APLICAÇÃO DO ENSAIO DO PULSO ULTRASSÔNICO.

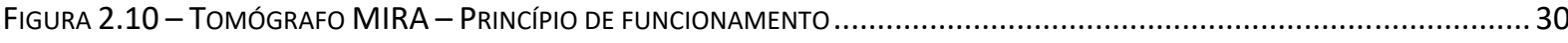

FIgURA 2.11 - TOMÓGRAFO MIRA - MATRIZ DE 4 X 12 TRANSDUTORES DE CONTATO A SECO 30

Figura 2.12 - A) PRIMEIRA FILEIRA EMITINDO PULSOS B) SEGUNDA FILEIRA EMITINDO PULSOS C) TOdAS AS 66 COMBINAÇÕES DE PULSOS.

FiguRA 2.13 - LARGURA dO FEIXE DO TRANSDUTOR NO BLOCO DE TESTE, MOSTRANDO A POSIÇÃO DE INSPEÇÃO EM X ${ }_{1}$ E A POSIÇÃO DO DEFEITO EM $X_{2}$

FIGURA 2.14 - EXEMPLO DE IMAGEM GERADA PELO MIRA

FIGURA 2.15 - EXEMPLO DE APLICAÇÃO DO ENSAIO COM ULTRASSOM MIRA NA EXECUÇÃO DE NOVO PAVIMENTO DE CRCP SOBRE UM PAVIMENTO ANTIGO DE CRCP

FIGURA 2.16 - GRÁFICO MOSTRANDOS MEDIDAS DO MIRA X MEDIDAS DO CORPO DE PROVA.......................................... 34

FIGURA 2.17 - GRÁFICO ILUSTRANDO A DEFINIÇÃO DA FREQUÊNCIA CENTRAL A PARTIR DA LARGURA DA BANDA.............................35

FIGURA 2.18 - PENETRAÇÃO MÁXIMA EM FUNÇÃO DA FREQUÊNCIA CENTRAL DA ANTENA ….............................................36

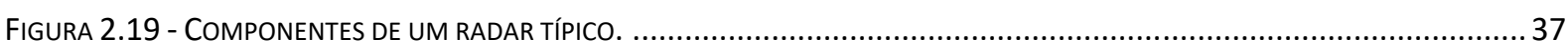

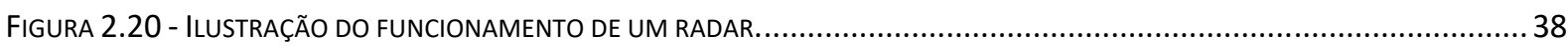

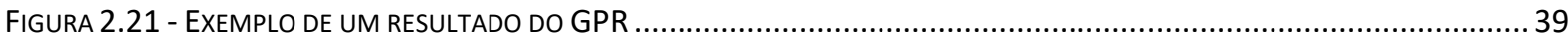

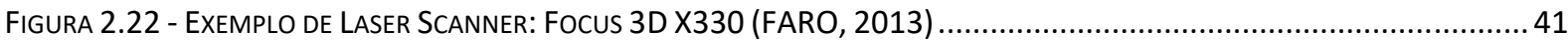

FIGURA 2.23 - EXEMPLO DE MAPEAMENTO COM O FOCUS 3D X330 (FARO, 2013) ........................................................

FIGURA 2.24 - EXEMPLO DE NUVEM DE PONTOS GERADA NO LEVANTAMENTO COM LASER SCANNER .....................................43

FIGURA 2.25 - EXEMPLO dE ESCLERÔMETRO - FUnCIONAMENTO CONSISTE EM PRESSIONAR O ÊMBOLO CONTRA A SUPERFÍCIE E

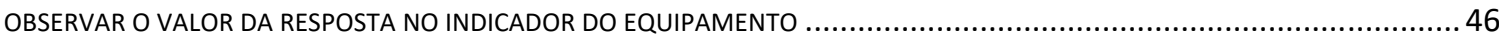

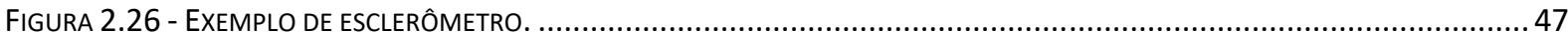


FIGURA 2.27 - EXEMPLO DE APLICAÇÃO DO ENSAIO 47

FIGURA 2.28 - FUNCIONAMENTO DO PACÔMETRO ATRAVÉS DE CAMPO MAGNÉTICO …................................................49

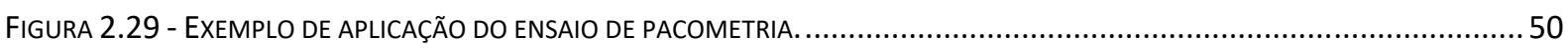

FIGURA 2.30 - EXEMPLO DE ESTRUTURA SUBMETIDA A ENSAIO PARA VERIFICAÇÃO DO NÍVEL DE ATAQUE POR CARBONATAÇÃO.........52

FIGURA 2.31 - EXEMPLO DE ESTRUTURA SUBMETIDA A ENSAIO PARA MEDIR A RESISTIVIDADE ELÉTRICA ..................................54

FIGURA 2.32 - PRINCÍPIO DE FUNCIONAMENTO ATRAVÉS DO MÉTODO DE WENNER .....................................................55

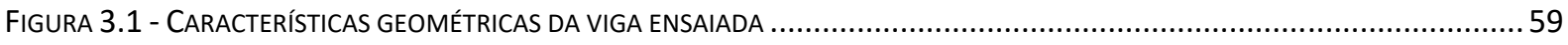

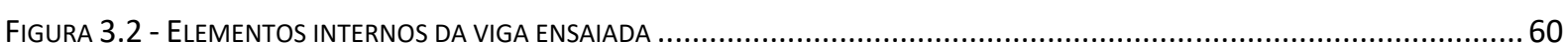

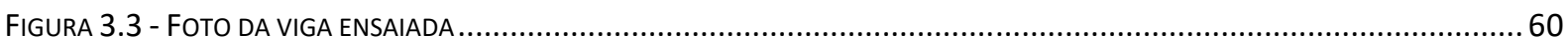

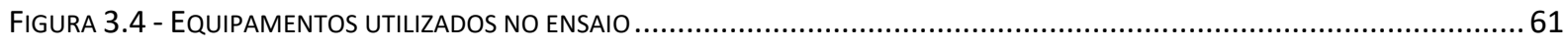

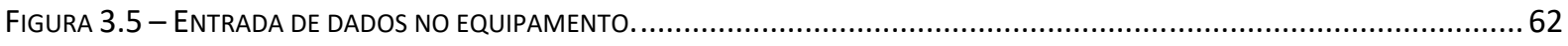

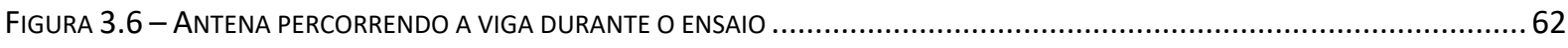

FIGURA 3.7 - ANTENA PERCORRENDO A VIGA DURANTE O ENSAIO E DADOS SENDO AMPLIFICADOS E ARMAZENADOS NA UNIDADE DE CONTROLE

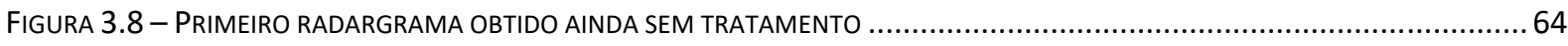

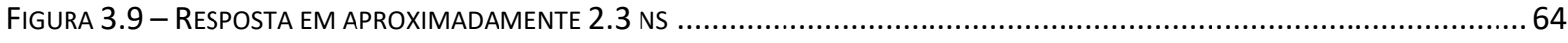

FIGURA 3.10 - RESULTADO DO RADARGRAMA APÓS OPERAÇÃO DE ALTERAÇÃO DO TEMPO ZERO..............................................65

FIGURA 3.11 - RESULTADO DO RADARGRAMA APÓS OPERAÇÃO DE ALTERAÇÃO DO TEMPO ZERO...........................................66

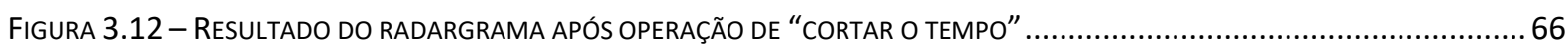

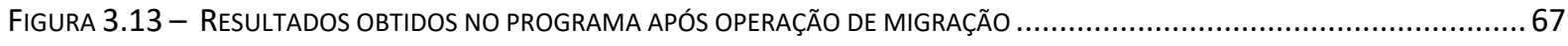

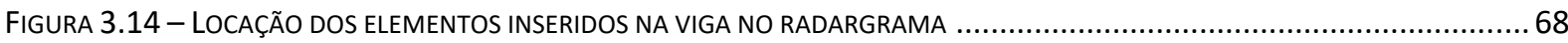

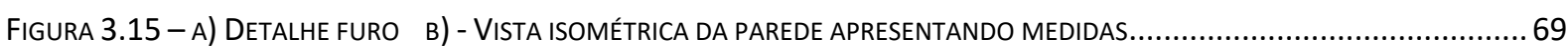

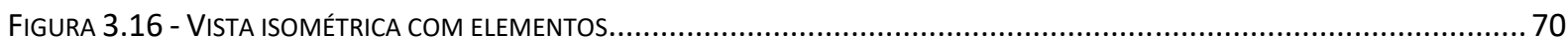

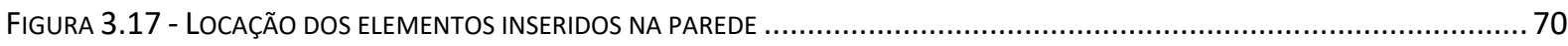

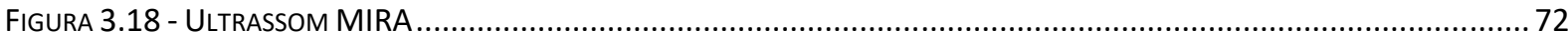

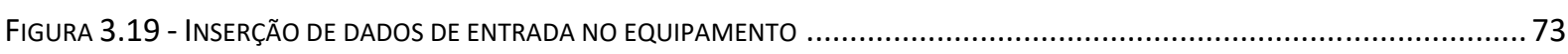

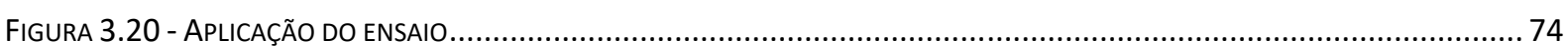

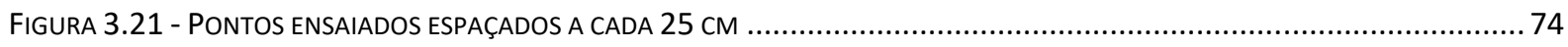

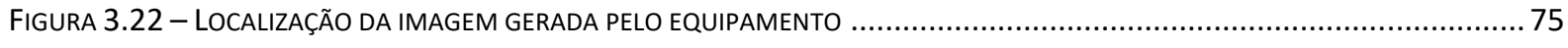

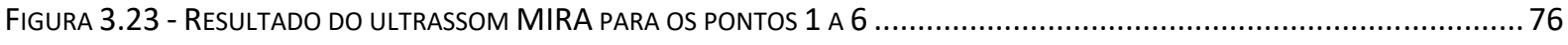

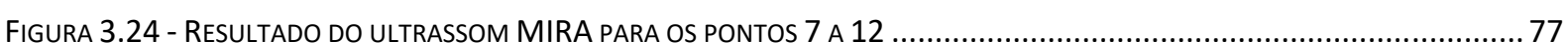

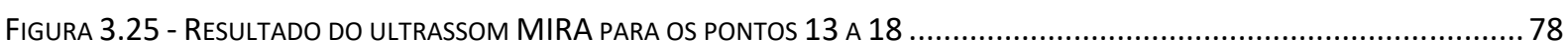

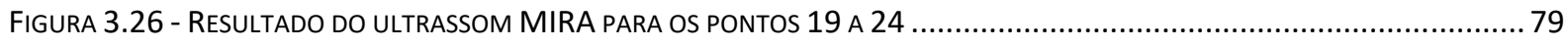

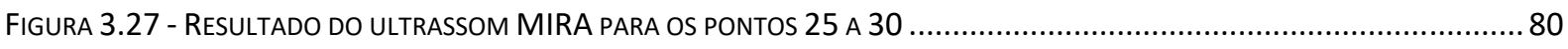

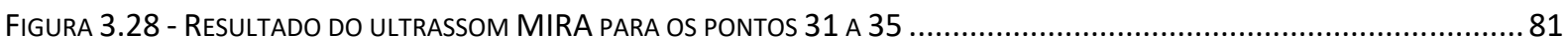

FIGURA 3.29 - LOCAÇÃO DO PONTOS ENSAIADOS E DOS ELEMENTOS INSERIDOS NA PAREDE ..................................................82

FIGURA 3.30 - INTERPRETAÇÃO DOS RESULTADOS DO MIRA NA REGIÃO SEM FURO LONGITUDINAL..........................................83

FIGURA 3.31 - INTERPRETAÇÃO DOS RESULTADOS DO MIRA NA REGIÃO DO FURO LONGITUDINAL .........................................83 
FIGURA 3.32 - INTERPRETAÇÃO DOS RESULTADOS DO MIRA NA REGIÃO DO FURO LONGITUDINAL .84

FIGURA 3.33 - INTERPRETAÇÃO DOS RESULTADOS DO MIRA NA REGIÃO PRÓXIMA À ESFERA DE 5 CM DE DIÂMETRO ....................84

FIGURA 3.34 - ESTIMATIVA DA DIMENSÃO DO FURO LONGITUDINAL NOS PONTOS P3, P8, P13, P18, P23 E P28 ......................85

FIGURA 3.35 - ESTIMATIVA DA DIMENSÃO DO FURO LONGITUDINAL NO PONTO P33 …..................................................86

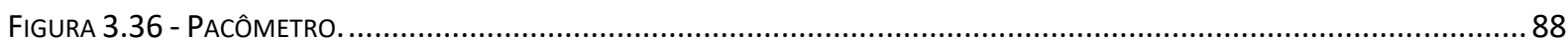

FIGURA 3.37 - RESULTADO NO VISOR DO PACÔMETRO QUANDO NÃO FOI LOCALIZADA ARMADURA: CÍRCULO DESCENTRALIZADO......88

FIGURA 3.38 - RESULTADO NO VISOR DO PACÔMETRO QUANDO LOCALIZA A ARMADURA: CÍRCULO CENTRALIZADO E LUZ VERMELHA ACESA. .89

FIGURA 3.39 - MARCAÇÃO DO POSICIONAMENTO DAS ARMADURAS NA PAREDE COM GIZ ...................................................90

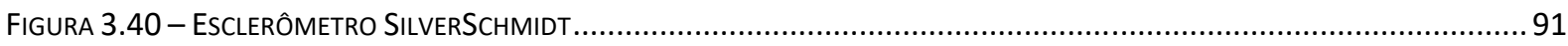

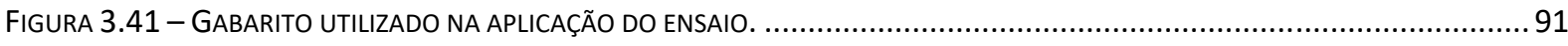

FIGURA 3.42 - DEFINIÇÃO DOS PONTOS ENSAIADOS NO ENSAIO DE ESCLEROMETRIA ................................................... 92

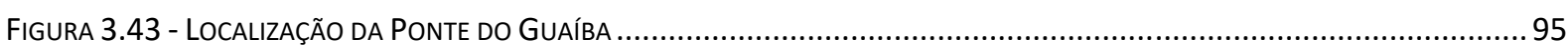

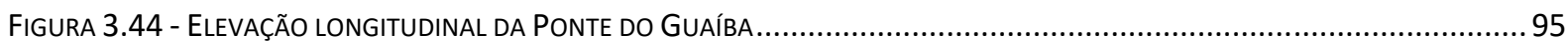

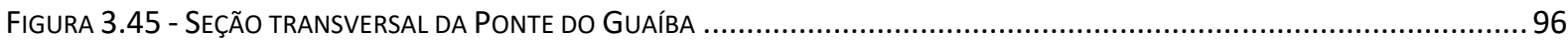

FIGURA 3.46 - ETAPAS DO MÉTOdO CONSTRUTIVO DA PONTE DO GUAÍBA .................................................................97

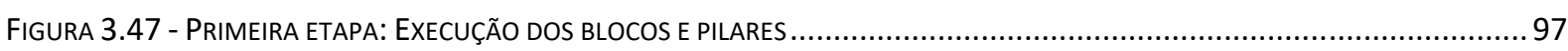

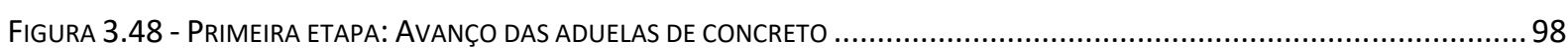

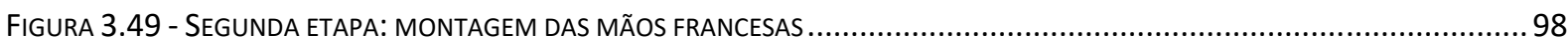

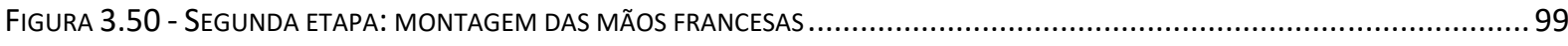

FIGURA 3.51 - DETALHE DA REGIÃO DE ENSAIO: LIGAÇÃO ENTRE MÃO-FRANCESA E ADUELA............................................. 100

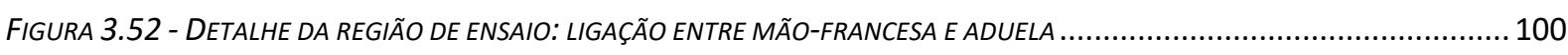

FIGURA 3.53 - DETALHE DO EPÓXI NA REGIÃO DE ENSAIO: LIGAÇÃO ENTRE MÃO-FRANCESA E ADUELA ..................................... 101

FIGURA 3.54 - APLICAÇÃO DO ENSAIO - UM TRANSDUTOR NA ADUELA DE CONCRETO E O OUTRO TRANSDUTOR NA MÃO FRANCESA 102

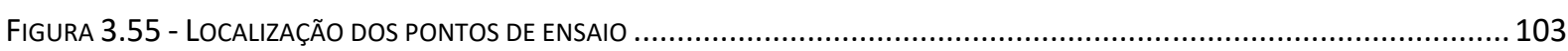

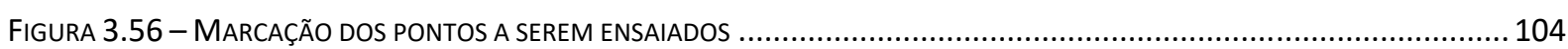

FIGURA 3.57 - REALIZAÇÃO DO ENSAIO COM UM TRANSDUTOR NA ADUELA E O OUTRO NA MÃO FRANCESA...............................105

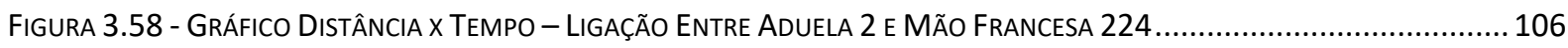

Figura 3.59 - Gráfico DistÂnCIA X Tempo - LigaÇÃo EnTRE AdUela 2 e Mão FranCESA 231 .................................... 106

Figura 3.60 - Gráfico DistÂNCIA X TEMPO - LIGAÇÃo ENTRE AdUELA 10 E MÃo FranCESA 254 .......................................107

Figura 3.61 - Gráfico DistÂnCIA X TEMPO - LIGAÇÃo ENTRE AdUELA 10 E Mão FranCESA 258....................................107

Figura 3.62 - Gráfico DistÂNCIA X TEMPO - LIGAÇÃo ENTRE AdUELA 16 e MÃo FranCESA 259.................................... 108

Figura 3.63 - Gráfico DistÂnCIA X TEMPo - LigaÇÃo ENTRE AdUELA 16 e MÃo FranCESA 255.................................... 109

Figura 3.64 - Gráfico DistÂNCIA X TEMPo - LIGAÇÃo ENTRE AdUELA 5A E MÃo FranCESA 192 ......................................109

Figura 3.65 - Gráfico DistÂnCIA X TEMPO - LIGAÇão ENTRE AdUELA 5A E MÃo FranCESA 202 ....................................110

FigURA 3.66 - GRÁFICO DistÂNCIA X TEMPO - LIGAÇÃo ENTRE AdUELA 11 E MÃo FranCESA 201 ......................................110

Figura 3.67 - GráfICO DistÂNCIA X TEMPO - LIGAÇÃo ENTRE AdUELA 11 E MÃo FranCESA 197 ...................................... 111 
Figura 3.68 - Gráfico DistânCia X TEMPo - Ligação ENTRE AdUela 17 E Mão FranCESA 232.

Figura 3.69 - Gráfico DistânCia X TEMPo - LigaÇÃo Entre Aduela 17 e Mão FranCESA 198.

FIGURA 3.70 - VELOCIDADES DOS PULSOS OBTIDAS NAS DIFERENTES LIGAÇÕES......................................................... 113

FigURA 3.71 - VISTA EM PLANTA DA PONTE EUSÉBIO Matoso SOBRE O RIO PINHEIROS. ................................................ 118

Figura 3.72 - Vista lateral da Ponte EusÉbio Matoso sobre o Rio Pinheiros. ...................................................... 119

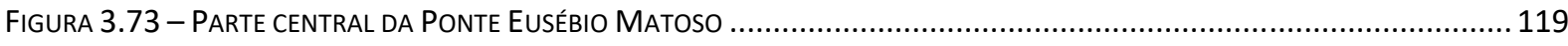

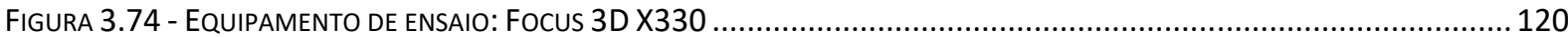

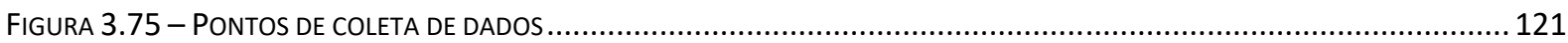

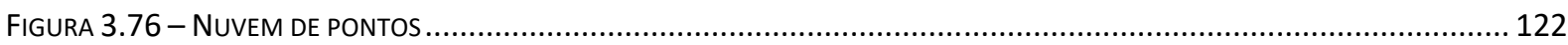

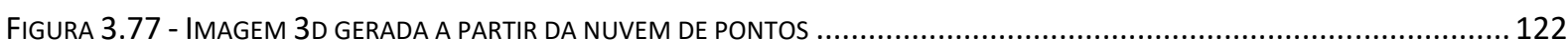

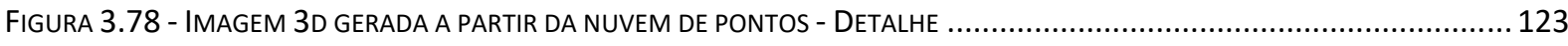

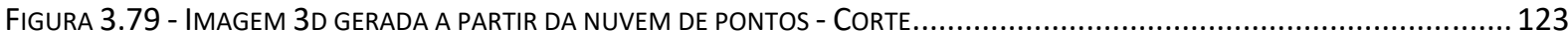

FIGURA 3.80 - IMAGEM 3D GERADA A PARTIR DA NUVEM DE PONTOS - CORTE MOSTRANDO LAJE ...................................... 124

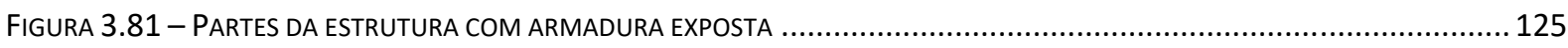

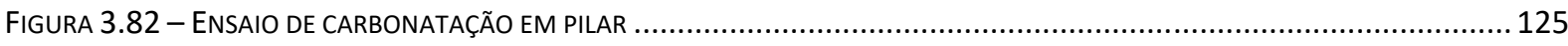

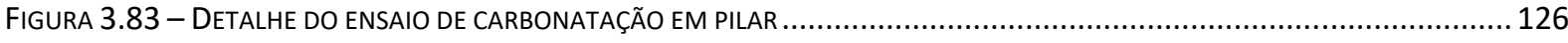

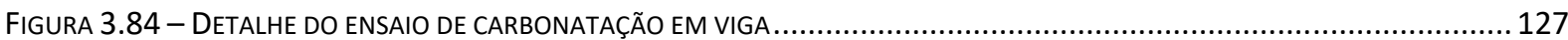




\section{LISTA DE TABELAS}

TABELA 2.1: VALORES PARA CORREÇÃO DA VELOCIDADE DO PULSO ULTRASSÔNICO EM FUNÇÃO DA TEMPERATURA.

TABELA 2.2: INFLUÊNCIA DAS ARMADURAS QUANDO O PULSO ULTRASSÔNICO É PERPENDICULAR ÀS MESMAS.............................28

TABELA 2.3: INFLUÊNCIA DAS ARMADURAS QUANDO O PULSO ULTRASSÔNICO É PARALELO ÀS ARMADURAS. ................................29

TABELA 2.4: CRItÉRIO PARA AVALIAÇÃO do RESULTAdo do ENSAIO dE RESISTIVIDADE SEGUNDO CEB 192 (1989) ......................54

TABELA 3.1: TRAÇO dA PAREDE ENSAIADA

TABELA 3.2: RESULTADOS DE RESISTÊNCIA À COMPRESSÃO E DO MÓDULO DE ELASTICIDADE OBTIDOS EM ENSAIO DE COMPRESSÃO AXIAL E DE DETERMINAÇÃO DOS MÓDULOS ESTÁTICOS DE ELASTICIDADE, RESPECTIVAMENTE. .71

TABELA 3.3: ESTIMATIVA DO VALOR DE MÓDULO DE ELASTICIDADE EM FUNÇÃO DA VELOCIDADE DE CISALHAMENTO..... .87

TABELA 3.4: RESULTADOS DO ENSAIO DE ESCLEROMETRIA E ESTIMATIVA DE RESISTÊNCIA À COMPRESSÃO .93

TABELA 3.5: VELOCIDADES OBTIDAS NO ENSAIO DE ULTRASSOM (MÉDIA, DESVIO PADRÃO E COEFICIENTE DE VARIAÇÃO DAS MEDIDAS)

TABELA 3.6: COMPARAÇÃO ENTRE AS VELOCIDADES OBTIDAS NAS LIGAÇÕES E AS VELOCIDADES DE CALIBRAÇÃO 115

TABELA 3.7 - ESTIMATIVA DO MÓDULO DE ELASTICIDADE DINÂMICO E DA RESISTÊNCIA À COMPRESSÃO. 116

TABELA 3.8 - COMPARAÇÃO ENTRE DA RESISTÊNCIA ESTIMADA PELO ULTRASSOM COM A RESISTÊNCIA OBTIDA NO ENSAIO DE COMPRESSÃO AXIAL. 


\section{SUMÁRIO}

1. INTRODUÇÃO.

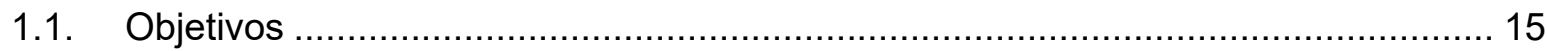

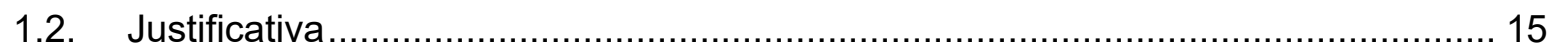

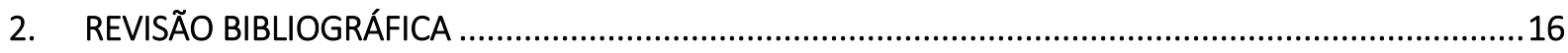

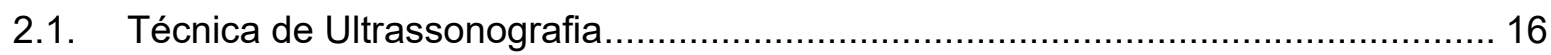

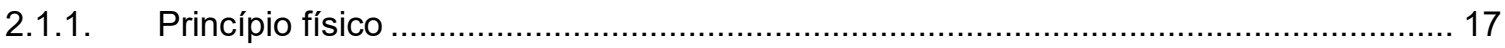

2.1.2. Método da velocidade do pulso ultrassônico ......................................................... 17

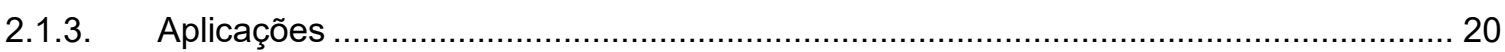

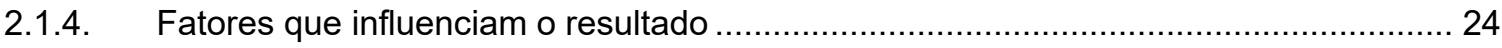

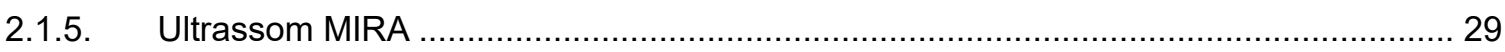

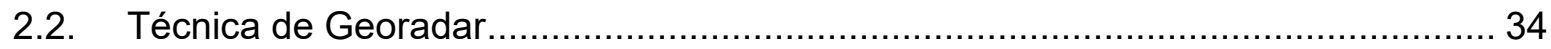

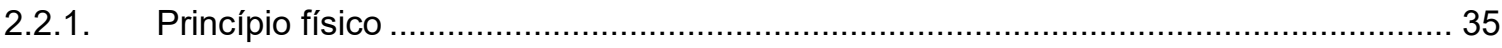

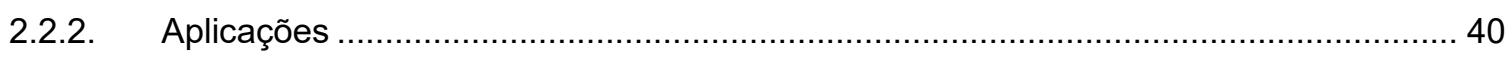

2.2.3. Fatores que influenciam os resultados................................................................ 41

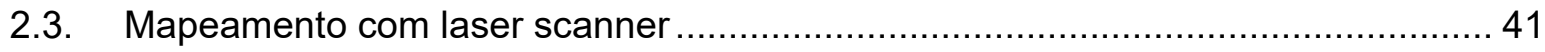

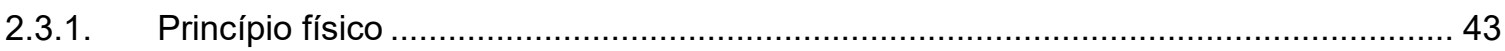

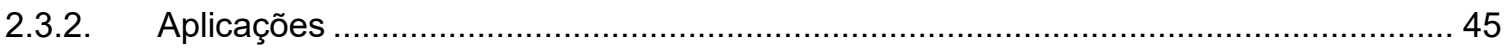

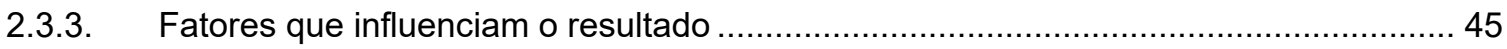

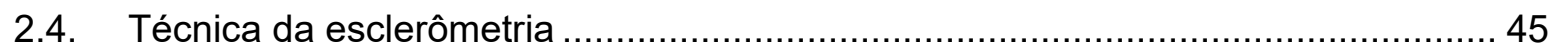

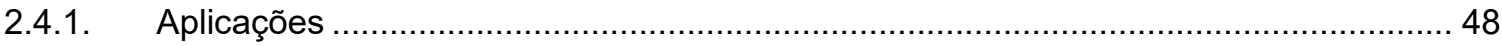

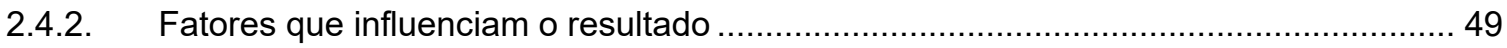

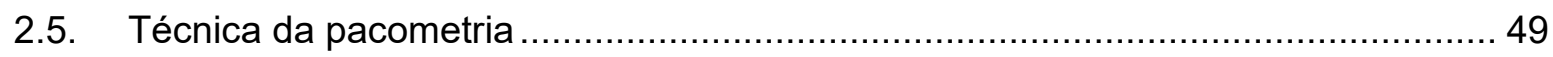

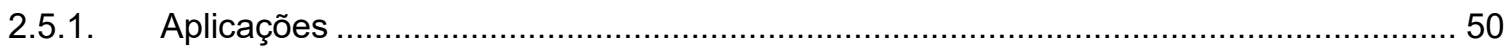

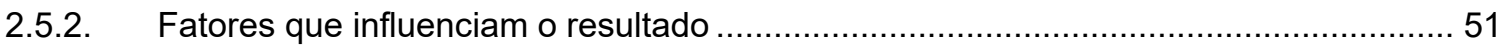

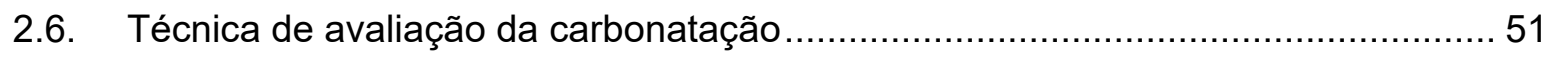

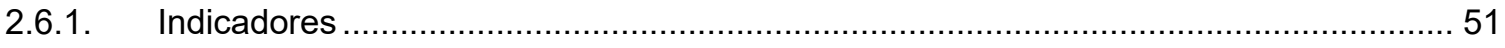

2.6.2. Modelos para estimar profundidade de carbonatação .............................................. 52

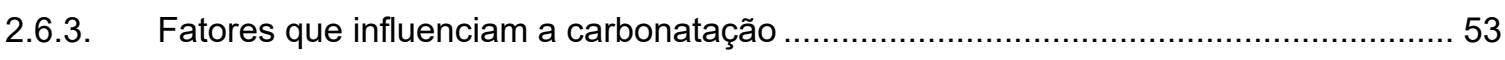

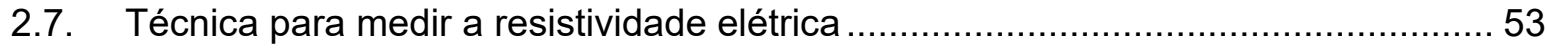

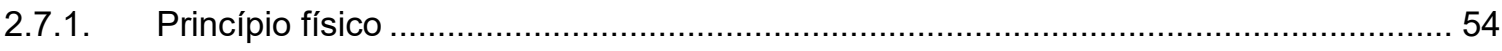

2.7.2. Fatores que influenciam a resistividade elétrica do concreto ...................................... 56 
2.8. Técnica para estimativa do teor de cloretos.................................................... 56

2.8.1. Métodos para estimativa do teor de cloretos …................................................... 57

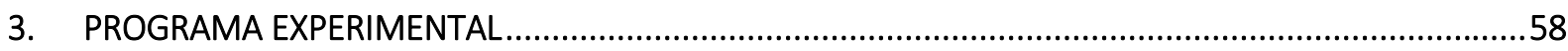

3.1. Descrição do programa experimental ........................................................... 58

3.2. Estudo de caso 1: Ensaio com GPR em uma viga de concreto armado. ...............58

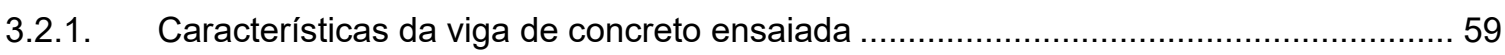

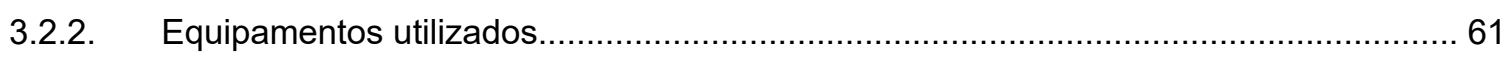

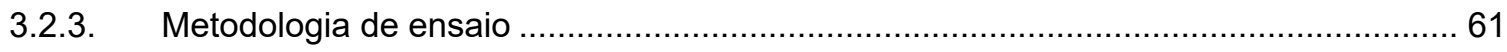

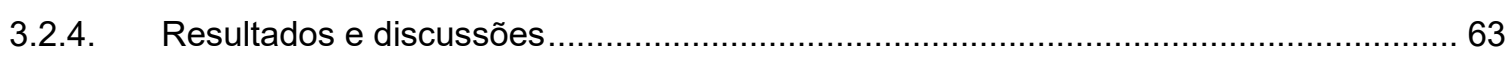

3.3. Estudo de caso 2: Ensaios de ultrassom (MIRA), pacometria e esclerometria em uma parede de concreto armado

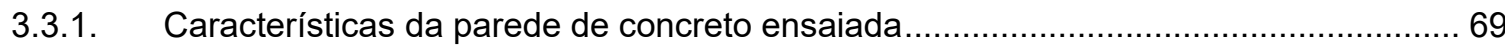

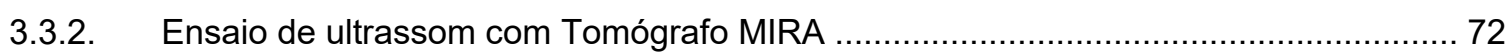

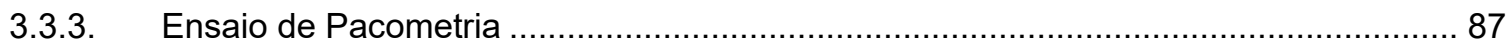

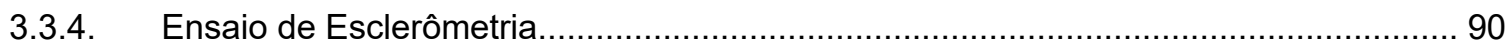

3.4. Estudo de caso 3: Ensaio de ultrassom aplicado na ligação das mãos francesas e das aduelas da Ponte sobre rio Guaíba........................................................................ 94

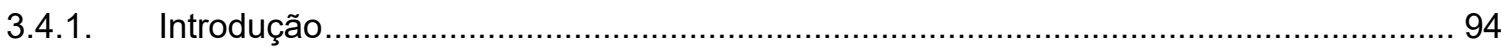

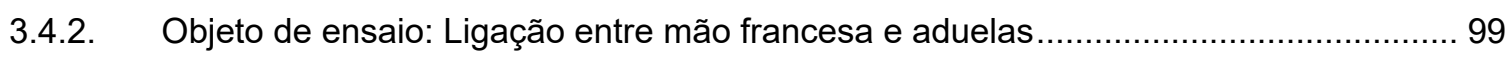

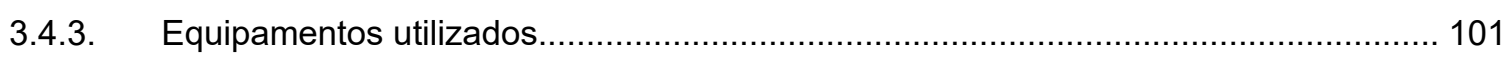

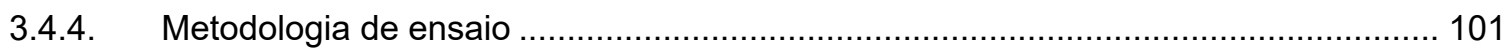

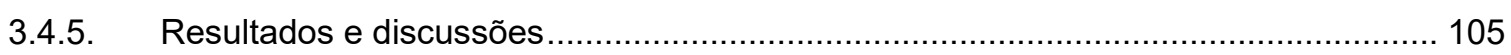

3.5. Estudo de caso 4: Mapeamento com Laser Scanner e e avaliação da carbonatação na Ponte Eusébio Matoso.......................................................................................... 117

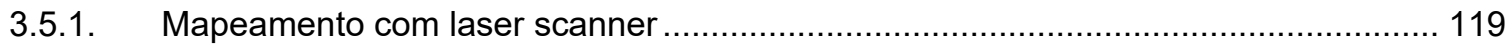

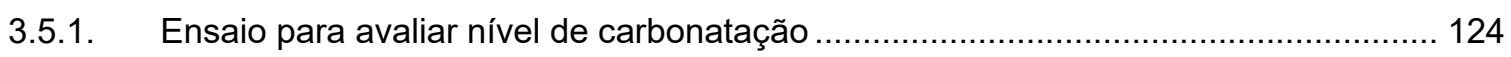

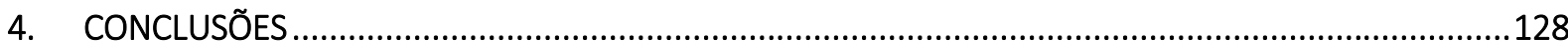

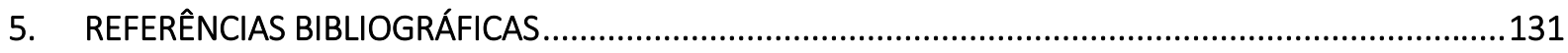

ANEXO 


\section{INTRODUÇÃO}

O monitoramento do comportamento de uma estrutura é importante para garantir que a mesma seja utilizável e garanta segurança aos usuários. Para realizar a avaliação de uma estrutura, existe uma série de ensaios que podem ser aplicados. Estes ensaios podem ser divididos em dois grandes grupos: ensaios destrutivos e não destrutivos.

$\mathrm{Na}$ avaliação de estruturas de concreto, a utilização de ensaios não destrutivos tem como principal vantagem o fato de esses ensaios ocasionarem pouco, ou nenhum dano às estruturas ensaiadas. Por outro lado, muitos resultados dependem de correlações e são baseados em hipóteses para serem obtidos.

O presente estudo pretende avaliar a aplicabilidade e precisão dos resultados apresentados por diferentes ensaios não destrutivos aplicados na avaliação das estruturas de concreto.

\subsection{Objetivos}

O objetivo deste trabalho é apresentar uma síntese da utilização e aplicabilidade de diferentes técnicas de ensaio não destrutivo que são aplicadas às estruturas de concreto. Para tanto, primeiramente é apresentada uma revisão bibliográfica dos principais métodos de ensaio não destrutivos que são aplicados às estruturas de concreto. Posteriormente, no programa experimental, são apresentados 4 estudos de caso, onde foram aplicados diferentes tipos de ensaios não destrutivos.

\subsection{Justificativa}

O monitoramento das estruturas é algo extremamente importante para garantir segurança aos usuários durante a vida útil das mesmas. Com o avanço das tecnologias, novos métodos de ensaio têm surgido.

Desta forma, conhecer com profundidade as peculiaridades destas novas tecnologias é essencial para que se consiga fazer uma avaliação correta dos resultados apresentados. 


\section{REVISÃO BIBLIOGRÁFICA}

Neste capítulo são apresentados alguns dos principais métodos de ensaio não destrutivo aplicados na avaliação de estruturas de concreto.

\subsection{Técnica de Ultrassonografia}

Kaur et al. (2019) afirmam que o ensaio de ultrassom consiste na avaliação da velocidade de propagação de um pulso medida entre dois pontos em um determinado meio. Os pulsos são transmitidos e recebidos por um par de transdutores e a mudança nas características da onda é monitorada. A Figura 2.1 apresenta uma representação do circuito percorrido por um pulso no ensaio de ultrassom.

Figura 2.1 - Representação do circuito de um pulso no ensaio de ultrassom.

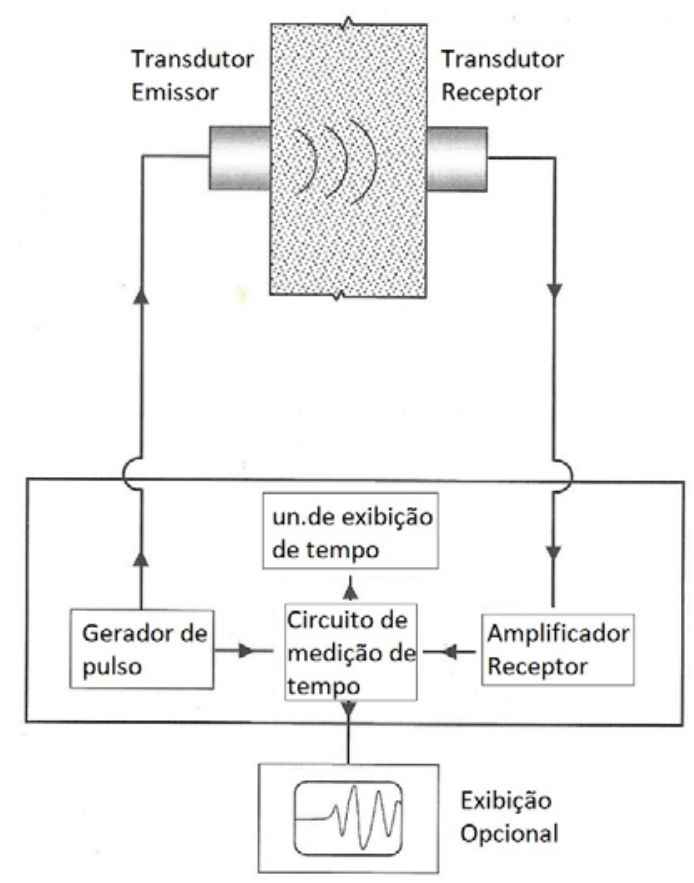

Fonte: Adaptado de Naik, Malhotra e Popovics (2004)

Bompman e Haach (2018) confirmam que o método de velocidade de pulso ultrassônico pode ser utilizado para a determinação das propriedades elásticas de materiais e para a verificação de não-homogeneidades e danos em elementos estruturais.

Internacionalmente este ensaio é normalizado pela ASTM C 597 (2016). No Brasil este ensaio é normalizado pela NBR 8802 (2019). 


\subsubsection{Princípio físico}

Segundo Bungey e Millard (2006), a velocidade de uma onda em um meio depende das propriedades elásticas e da massa do meio em questão. Para um meio infinito, homogêneo e isotrópico a velocidade é definida pela Equação 2.1.

$$
V=\sqrt{\frac{K \times E_{d}}{\rho}}
$$

Onde,

$$
\left\{\begin{array}{l}
V=\text { velocidade da onda }(\mathrm{km} / \mathrm{s}) \\
K=\frac{(1-v)}{(1+v) \times(1-2 v)} \\
E_{d}=\text { módulo de elasticidade dinâmico }\left(\mathrm{kN} / \mathrm{mm}^{2}\right) \\
\rho=\text { densidade }\left(\mathrm{kg} / \mathrm{m}^{3}\right) \\
v=\text { coeficiente de Poisson dinâmico }
\end{array}\right.
$$

Naik, Malhotra e Popovics (2004) afirmam que o fator $\mathrm{K}$ tem pouca influência na velocidade, pois varia em uma faixa estreita de valores. Por exemplo, aumentando o coeficiente de Poisson dinâmico de 0,15 para 0,25 (67\% de aumento), o valor de K irá se alterar de 1,06 para 1,20 (12\% de aumento). Por outro lado, variações na densidade e no módulo de elasticidade dinâmico tem efeitos mais significativos na velocidade de propagação da onda.

\subsubsection{Método da velocidade do pulso ultrassônico}

Bompman e Haach (2018) afirmam que o método da velocidade de pulso ultrassônico baseia-se na emissão de ondas de alta freqüência (acima de $20 \mathrm{kHz}$ ) que se propagam através de um elemento testado.

Kaur et al. (2019) confirma que o ensaio consiste em posicionar os transdutores em distâncias conhecidas e emitir uma onda através de um transdutor emissor e 
receber esta onda, em outro ponto da estrutura, por um transdutor receptor. Ao realizar o ensaio, aparece na tela do osciloscópio o tempo de trânsito do pulso. A velocidade é definida pela Equação 2.2 .

$$
V=\frac{L}{\Delta T}
$$

Onde,

$$
\left\{\begin{array}{l}
V=\text { Velocidade do pulso }(\mathrm{m} / \mathrm{s}) \\
\mathrm{L}=\text { Distância entre transdutores }(\mathrm{m}) \\
\Delta T=\text { Tempo em trânsito }(\mathrm{s})
\end{array}\right.
$$

O ensaio de ultrassom pode ser aplicado através de três formas distintas de transmissão: transmissão direta, indireta e semidireta (EVANGELISTA, 2002). A Figura 2.2 apresenta o posicionamento dos transdutores nestas três formas de aplicação do ensaio de ultrassom.

Figura 2.2 - Tipos de configurações possíveis para aplicação do método do pulso ultrassônico.
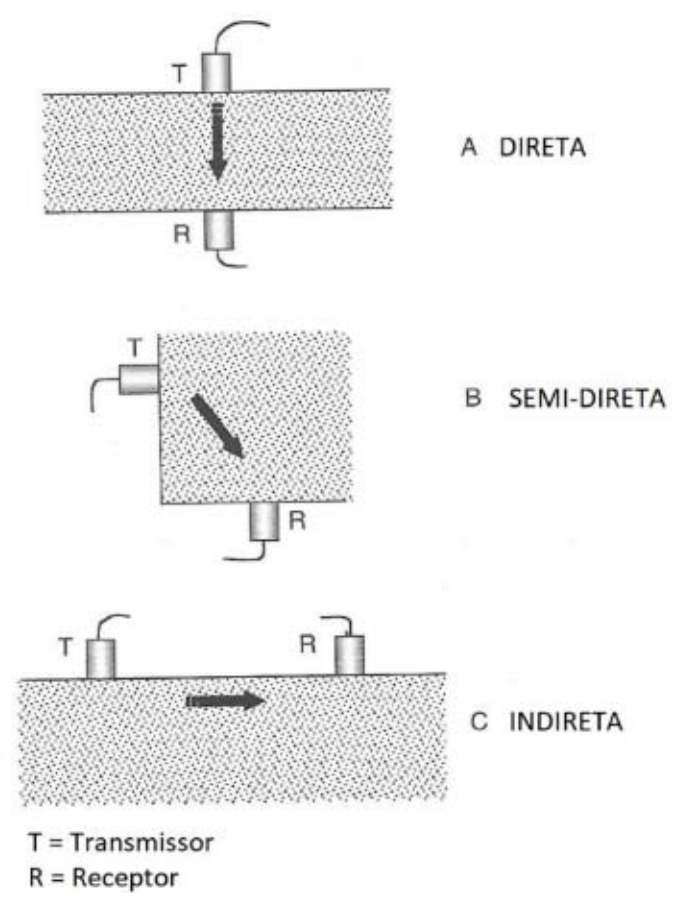

Fonte: Adaptado de Naik, Malhotra e Popovics (2004) 
Segundo a NBR 8802 (2019), na transmissão direta, as ondas são recebidas com maior intensidade e por este motivo é a configuração mais recomendada para determinar a velocidade de propagação de ondas em determinado meio.

A transmissão indireta é utilizada quando não se tem acesso a uma das faces do elemento. Segundo Meneghetti (1999), a determinação da velocidade através da transmissão indireta é menos satisfatória do que através da transmissão direta.

A NBR 8802 (2019) define o procedimento para determinação da velocidade de onda em um meio através do ensaio de ultrassom utilizando transmissão indireta. Segundo a norma, primeiramente deve-se fixar o transdutor emissor em um ponto. Posteriormente deve-se fazer as leituras com os transdutores receptores posicionados em posições equidistantes entre si e sobre uma reta que contenha o alvo. Mede-se o tempo percorrido pelo pulso para cada posição. De posse dos dados obtidos no ensaio, é determinada a curva de distância em função do tempo para as medições realizadas, conforme ilustra a Figura 2.3. Cada ponto do gráfico representa uma posição ensaiada.

Figura 2.3 - Exemplo de gráfico elaborado a partir dos resultados do ensaio de ultrassom

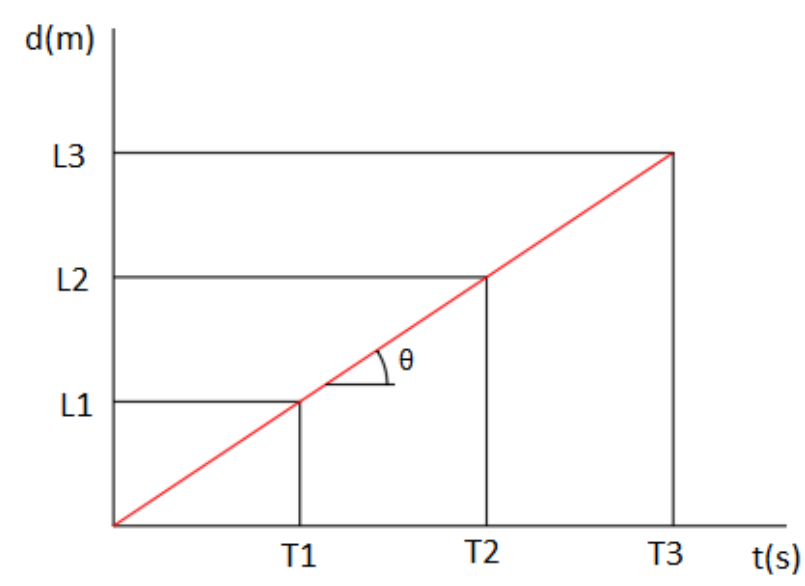

Fonte: Autoria própria

A velocidade do pulso ultrassônico é determinada a partir do gráfico obtido e seu valor é numericamente igual ao valor da tangente do ângulo formado entre a reta obtida e o eixo das abcissas. 


\subsubsection{Aplicações}

\subsubsection{Determinação do Módulo de Elasticidade}

De acordo com Resende (2018), o módulo de elasticidade pode ser correlacionado com a velocidade da onda de cisalhamento através da Equação 2.3.

$$
E=V s^{2} \times 2 \times \rho \times(1+v)
$$

Onde,

$$
\left\{\begin{array}{l}
E=\text { Módulo de elasticidade }(\mathrm{MPa}) \\
V s=\text { Velocidade da onda de cisalhamento }(\mathrm{m} / \mathrm{s}) \\
\rho=\text { Peso específico }\left(\mathrm{kg} / \mathrm{cm}^{3}\right) \\
v=\text { Coeficiente de Poisson }
\end{array}\right.
$$

Segundo Levi (2001) o módulo de elasticidade dinâmico permite estimar melhor as deformações nas estruturas e dessa forma entender melhor o comportamento da mesma. O valor do módulo de elasticidade dinâmico de uma estrutura pode ser determinado conforme a Equação 2.4.

$$
E_{d}=\rho \times V^{2} \times \frac{\left(1+v_{d}\right) \times\left(1-2 v_{d}\right)}{\left(1-v_{d}\right)}
$$

Onde,

$$
\left\{\begin{array}{l}
E_{d}=\text { módulo de elasticidade dinâmico }(\mathrm{MPa}) \\
v_{d}=\text { coeficiente dinâmico de Poisson } \\
\rho=\text { densidade }\left(\mathrm{kg} / \mathrm{cm}^{3}\right) \\
V=\text { velocidade da onda }(\mathrm{m} / \mathrm{s})
\end{array}\right.
$$

Segundo Naik, Malhotra e Popovics (2004), não é recomendado que se utilize o método da velocidade de ultrassom para estimar o módulo de elasticidade dinâmico de uma estrutura por duas razões: imprecisão na determinação do coeficiente de 
Poisson e a utilização da onda de um meio homogêneo em um meio heterogêneo (concreto).

2.1.3.2. Verificar a homogeneidade do concreto e a profundidade de fissuras

As descontinuidades no interior do concreto podem ser detectadas devido às diferenças da velocidade de propagação das ondas (EVANGELISTA, 2002).

De acordo com Bungey e Millard (2006), através do método indireto é possível estimar a profundidade das fissuras. Para tanto deve-se colocar os transdutores que gerarão e receptarão o pulso em posições equidistantes em relação à fissura, conforme ilustra a Figura 2.4.

Figura 2.4 - Procedimento de ensaio para avaliação do tamanho de uma fissura através da velocidade do pulso ultrassônico

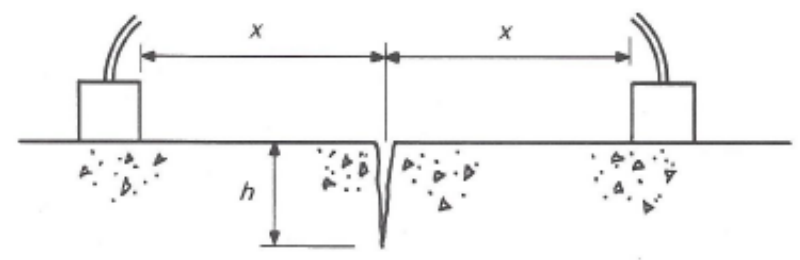

Fonte: BUNGEY e MILLARD (2006).

O tamanho da fissura é determinado pela Equação 2.5 .

$$
h=x \sqrt{\frac{T_{c}^{2}}{T_{s}^{2}}-1}
$$

Onde,

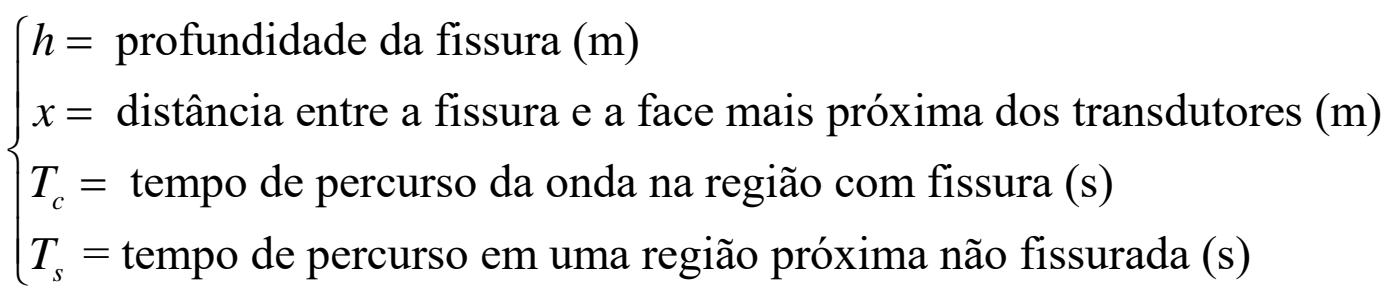

\subsubsection{Estimar a resistência à compressão do concreto}

Naik, Malhotra e Popovics (2004), afirmam que o método de velocidade de ultrassom pode ser utilizado para estimar a resistência à compressão do concreto 
através de correlações. Essas correlações são influenciadas por diversos fatores como: tamanho do agregado, tipo de agregado, relação água/cimento, tipo de cimento. Na seção 2.1.4 são apresentados os fatores que influenciam os resultados. A Figura 2.5 ilustra um exemplo de gráfico de resistência à compressão em função da velocidade de propagação do pulso no meio.

Figura 2.5 - Exemplo de gráfico de resistência à compressão em função da velocidade do pulso ultrassônico no meio.

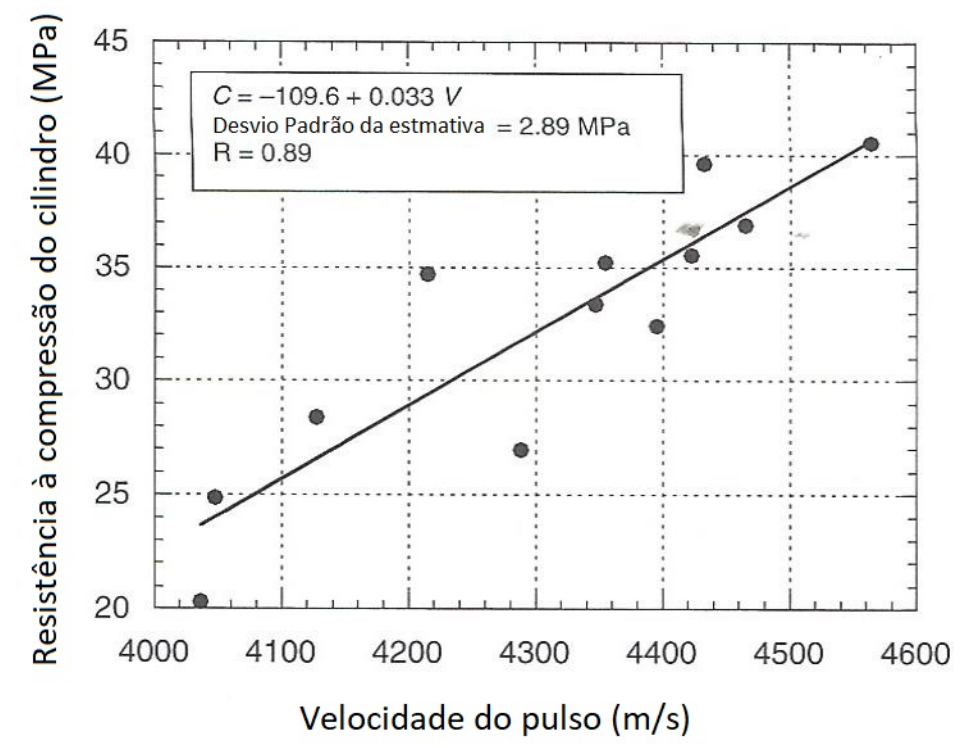

Fonte: Adaptado de Naik, Malhotra e Popovics (2004).

De acordo com Canovas (1988), para concretos normais com módulo de elasticidade entre 20 e $47 \mathrm{MPa}$, é possível calcular a resistência à compressão a partir do módulo de elasticidade dinâmico conforme Equação 2.6.

$$
f_{c}=3,5 \times 10^{-9} \times E_{d}-10^{-3} \times E_{d}+200
$$

Onde,

$$
\left\{\begin{array}{l}
f_{c}=\text { Resistência à compressão }(\mathrm{MPa}) \\
E_{d}=\text { Módulo de elasticidade dinâmico }(\mathrm{MPa})
\end{array}\right.
$$

É possível estimar a resistência à compressão do concreto a partir dos ensaios de ultrassom com um erro na ordem de $10 \%$ para ensaios aplicados em corpos de 
prova. Quando o ensaio é aplicado em estruturas, a imprecisão aumenta, e o erro apresenta-se na ordem de 20\%. (BUNGEY E MILLARD, 2006)

\subsubsection{Estudo da hidratação do cimento}

De acordo com Naik, Malhotra e Popovics (2004), o método de velocidade de ultrassom pode ser utilizado para monitorar a estrutura interna do concreto. Muitos pesquisadores têm publicado resultados satisfatórios no monitoramento do processo de hidratação do cimento, principalmente durante as primeiras trinta e seis horas após a adição da água ao cimento. O efeito da idade do concreto na velocidade do pulso é similar ao efeito de ganho de resistência do concreto. Da mesma forma que a resistência, a velocidade do pulso aumenta bastante nas primeiras horas de vida do concreto, conforme ilustra a Figura 2.6.

Figura 2.6 - Exemplo de gráficos de velocidade do pulso ultrassônico e de resistência à compressão em função da idade do concreto.

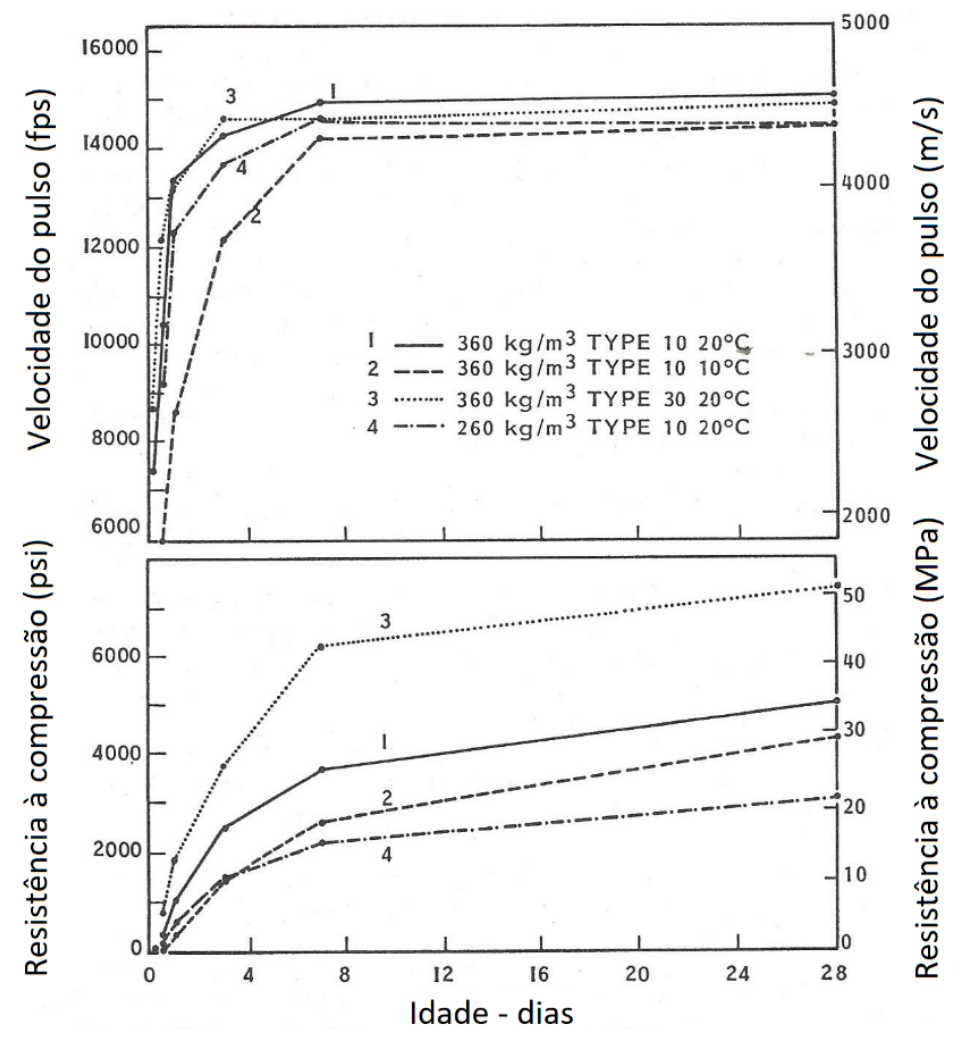

Fonte: Adaptado de Sturrup, Vecchio e Caratin (1984) 


\subsubsection{Avaliação da deterioração do concreto}

Segundo Bungey e Millard (2006), o método de velocidade de ultrassom pode ser utilizado para estimar a extensão e magnitude de deteriorações, sejam mecânicas, químicas ou oriundas de ataque de fogo.

\subsubsection{Fatores que influenciam o resultado}

Os fatores que influenciam os resultados basicamente são os fatores que influenciam na velocidade do pulso. Naik, Malhotra e Popovics (2004) dividem estes fatores em dois grandes grupos:

- Fatores resultantes diretamente das propriedades do concreto: idade do concreto, tamanho e tipo dos agregados, relação água/cimento, tipo de cimento e adição de aditivos.

- Outros fatores (contato do transdutor, temperatura do concreto, umidade, condições de cura, tamanho do percurso, tamanho do corpo ensaiado, nível de tensão da estrutura e a presença de armadura).

\subsubsection{Tipo de cimento}

Segundo Naik, Malhotra e Popovics (2004), o tipo de cimento não tem efeito significativo na velocidade do pulso. Sturrup, Vecchio e Caratin (1984), fizeram um experimento em que testaram a velocidade do pulso para diferentes amostras de concreto, com a mesma quantidade de cimento, porém de diferentes tipos e em diferentes idades. Eles constataram que não há diferença significativa na velocidade do pulso em concretos com cimento de alta resistência e em concretos com cimento comum.

\subsubsection{Idade do concreto}

A idade do concreto tem influência direta na velocidade do pulso. Conforme mostrou-se na Figura 2.6, o efeito da idade do concreto na velocidade do pulso é similar ao efeito de ganho de resistência do concreto. Porém, a velocidade do pulso atinge um valor limite antes de a estrutura de concreto atingir um valor limite para sua resistência (NAIK, MALHOTRA e POPOVICS, 2004). 


\subsubsection{Agregados}

Sturrup, Vecchio e Caratin (1984) afirmam que uma vez que a maior parte em volume do concreto é composta de agregados, a velocidade do pulso neste componente é um importante fator na velocidade final do pulso no concreto.

Segundo Naik, Malhotra e Popovics (2004), muitos pesquisadores já concluíram que a velocidade do pulso no concreto é significativamente afetada pelo tipo e pela quantidade de agregado.

De acordo com Sturrup, Vecchio e Caratin (1984), o efeito da densidade e do formato do agregado é demonstrado na Figura 2.7, onde estão representados quatro tipos de concreto com diferentes tipos de agregados: seixo, brita, ilmenite e cinza volante. Observa-se que a velocidade é bem menor no concreto que apresenta agregado leve (cinza volante). Já nos outros concretos que apresentam agregados convencionais, as velocidades são similares, e o valor mínimo ocorre no concreto que apresenta agregado com formato arredondado (seixo).

Figura 2.7 - Exemplo de gráfico de resistência à compressão do concreto em função da velocidade do pulso ultrassônico, para diferentes tipos de agregado.

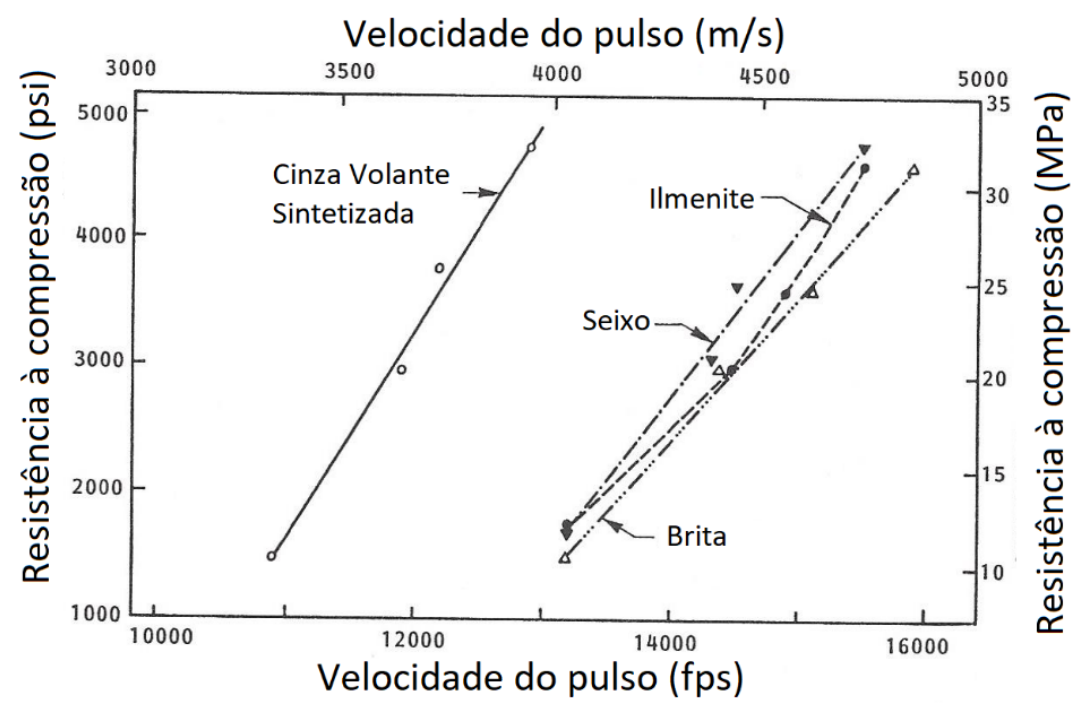

Fonte: Adaptado de Sturrup, Vecchio e Caratin (1984).

Sturrup, Vecchio e Caratin (1984) analisaram dois tipos de concreto (um com agregado de $20 \mathrm{~mm}$ de diâmetro e outro com agregado de $40 \mathrm{~mm}$ de diâmetro) nas idades de 3,7 e 28 dias. Observou-se que nos concretos com agregados de maior 
diâmetro (40mm), a velocidade de propagação do pulso apresentou valores maiores em todas as idades, conforme ilustra Figura 2.8.

Figura 2.8 - Exemplo de gráfico de velocidade do pulso ultrassônico x resistência à compressão (para diferentes tipos de agregado)

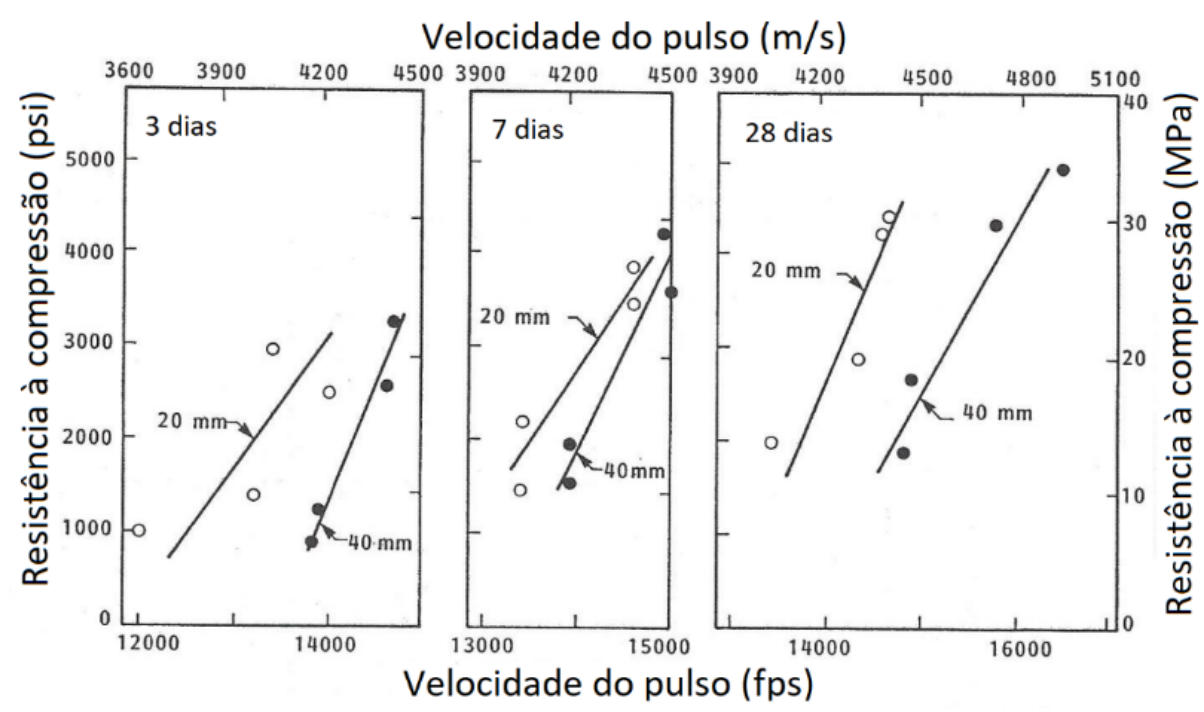

Fonte: Adaptado de Sturrup, Vecchio e Caratin (1984).

2.1.4.4. Relação água/cimento

Segundo Naik, Malhotra e Popovics (2004), à medida que a relação água/cimento aumenta, diminui a resistência à compressão e também a velocidade da onda ultrassônica no concreto.

\subsubsection{Temperatura}

A RILEM NDT (1972) afirma que a velocidade de ondas ultrassônicas é influenciada pela temperatura caso ela seja maior que $30^{\circ} \mathrm{C}$ ou menor que $5^{\circ} \mathrm{C}$. Para valores de temperatura fora destes limites, Naik, Malhotra e Popovics (2004) propõem correções nas velocidades apresentadas em ensaio, conforme ilustra a Tabela 2.1. 
Tabela 2.1: Valores para correção da velocidade do pulso ultrassônico em função da temperatura.

\begin{tabular}{c|cc}
\hline & \multicolumn{2}{|c}{ Correção (\%) } \\
\hline Temperatura do concreto & Concreto seco & Concreto saturado com água \\
60 & +5 & +4 \\
40 & +2 & +1.7 \\
20 & 0 & 0 \\
0 & -0.5 & -1 \\
Under -4 & -1.5 & -7.5
\end{tabular}

Fonte: Adaptado de Naik, Malhotra e Popovics (2004)

\subsubsection{Presença de armadura}

Segundo Santos (2011), a velocidade do pulso em estruturas de concreto armado é maior que em estruturas de concreto simples. O principal motivo é que a velocidade no aço pode chegar ao dobro da velocidade no concreto.

Manjunath (2007) afirma que quanto maior a densidade do concreto ensaiado, maior será a velocidade de propagação do pulso. Por este motivo, a velocidade do pulso é maior em estruturas de concreto armado em relação às mesmas estruturas de concreto, porém sem aço. Isto ocorre, porque, o primeiro apresenta densidade maior que a do segundo.

A presença de armaduras pode alterar significativamente os resultados da medição do pulso, principalmente em barras dispostas longitudinalmente ao pulso (STURRUP, VECCHIO E CARATIN ,1984).

Naik, Malhotra e Popovics (2004) propõem a Tabela 2.2 e a Tabela 2.3 para mostrar a influência que as armaduras e suas disposições causam na velocidade da onda. Na Tabela 2.2, é apresentada a influência da presença de armadura na velocidade do pulso, para diferentes taxas de armadura, quando as armaduras estão dispostas perpendicularmente ao pulso. Observa-se que quanto maior a taxa de armadura, maior é a influência causada na velocidade do pulso. Por exemplo, para um pulso que percorreu um percurso de comprimento $L$ em um concreto de baixa qualidade, e em 50\% deste percurso existiam barras de aço (comprimento Ls), verificou-se que a velocidade do pulso sem armadura é $75 \%$ da velocidade com armadura. Para taxas mais baixas a influência é menor. 
Tabela 2.2: Influência das armaduras quando o pulso ultrassônico é perpendicular às mesmas..

\begin{tabular}{|c|c|c|c|}
\hline \multirow[b]{2}{*}{$\mathrm{Ls} / \mathrm{L}$} & \multicolumn{3}{|c|}{$\frac{c}{V}=\frac{\text { Velocidade do pulso em concreto comum }}{\text { Velocidade do pulso em concreto armado }}$} \\
\hline & $\begin{array}{l}\text { Qualidade baixa } \\
\text { Vc }=3000 \mathrm{~m} / \mathrm{s}\end{array}$ & $\begin{array}{l}\text { Qualdade mediana } \\
\qquad \mathrm{Vc}=4000 \mathrm{~m} / \mathrm{s}\end{array}$ & $\begin{array}{l}\text { Boa qualidade } \\
\text { Vc }=5000 \mathrm{~m} / \mathrm{s}\end{array}$ \\
\hline $1 / 12$ & 0.96 & 0.97 & 0.99 \\
\hline $1 / 8$ & 0.94 & 0.96 & 0.98 \\
\hline $1 / 6$ & 0.92 & 0.94 & 0.97 \\
\hline $1 / 4$ & 0.88 & 0.92 & 0.96 \\
\hline $1 / 3$ & 0.83 & 0.89 & 0.94 \\
\hline $1 / 2$ & 0.75 & 0.83 & 0.92 \\
\hline
\end{tabular}

Fonte: Adaptado de Naik, Malhotra e Popovics (2004)

A Figura 2.9a ilustra o posicionamento dos transdutores em relação às barras de aço, utilizados para apresentar a Tabela 2.2.

Figura 2.9 - Diferentes posicionamentos dos transdutores em relação às barras de aço na aplicação do ensaio do pulso ultrassônico

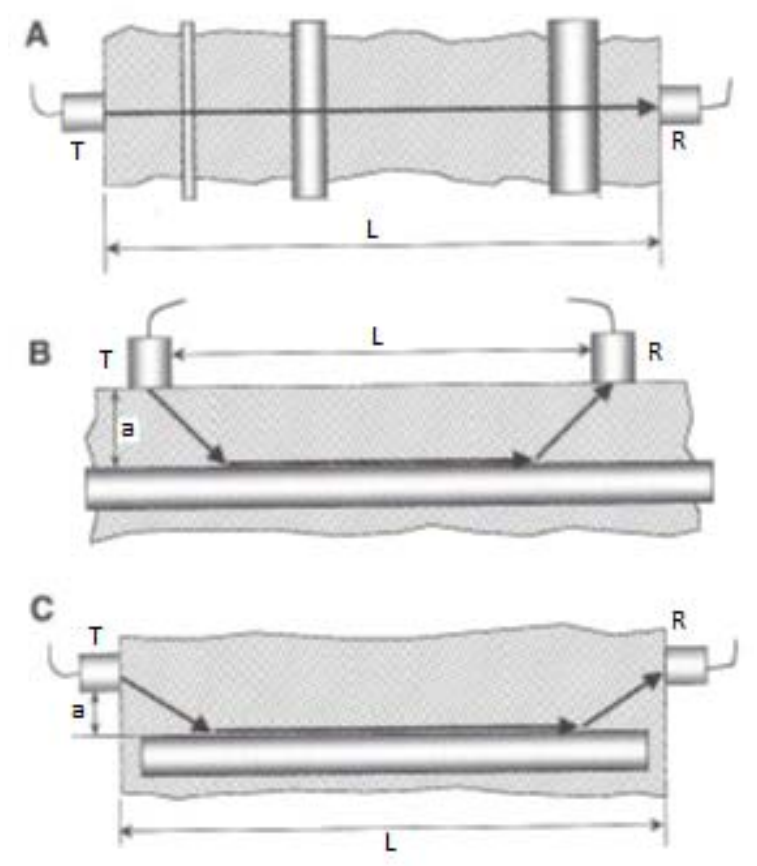

. Fonte: Adaptado de Naik, Malhotra e Popovics (2004)

A Tabela 2.3 apresenta a influência da presença de armadura na velocidade do pulso, para diferentes relações entre velocidade no concreto e velocidade no aço, e para diferentes posicionamentos dos transdutores em relação a barra longitudinal, quando as armaduras estão dispostas paralelas ao pulso 
Tabela 2.3: Influência das armaduras quando o pulso ultrassônico é paralelo às armaduras.

\begin{tabular}{|c|c|c|c|c|}
\hline \multirow[b]{2}{*}{$a / L$} & $\frac{\mathrm{Vc}}{\mathrm{V}}$ & \multicolumn{3}{|c|}{ Velocidade do pulso em concreto comum } \\
\hline & $\frac{V c}{V s}=0.90$ & $\frac{V c}{V s}=0.80$ & $\frac{V c}{V s}=0.71$ & $\frac{V c}{V s}=0.60$ \\
\hline 0 & 0.90 & 0.80 & 0.71 & 0.60 \\
\hline $1 / 20$ & 0.94 & 0.86 & 0.78 & 0.68 \\
\hline $1 / 15$ & 0.96 & 0.88 & 0.80 & 0.71 \\
\hline $1 / 10$ & 0.99 & 0.92 & 0.85 & 0.76 \\
\hline $1 / 7$ & 1.00 & 0.97 & 0.91 & 0.83 \\
\hline $1 / 5$ & 1.00 & 1.00 & 0.99 & 0.92 \\
\hline $1 / 4$ & 1.00 & 1.00 & 1.00 & 1.00 \\
\hline
\end{tabular}

Fonte: Adaptado de Naik, Malhotra e Popovics (2004)

A representação do posicionamento apresentado na Tabela 2.3 está ilustrada na Figura 2.9b e na Figura 2.9c. Observa-se que quanto maior a taxa de armadura, maior é a influência causada na velocidade do pulso. Por exemplo, para um pulso que percorreu um percurso de comprimento $\mathrm{L}$, e em $60 \%$ deste percurso existiam barras de aço (comprimento $L_{s}$ ), verificou-se que a velocidade do pulso sem armadura chega a ser $60 \%$ da velocidade do pulso com armadura, dependendo do posicionamento dos transdutores. Quanto mais próximo das armaduras estiverem os transdutores, maior é a influência ocasionada.

\subsubsection{Ultrassom MIRA}

O ensaio ultrassônico de onda de cisalhamento representa uma das técnicas mais avançadas disponíveis em testes não destrutivos de concreto. MIRA é um sistema multifuncional de baixa frequência $(20-100 \mathrm{kHz})$ baseado no método do pulso ultrassônico, utilizando ondas de cisalhamento, que é capaz de detectar objetos, interfaces e anomalias em estruturas de concreto. (CHOI et al., 2016).

De acordo com o manual da Germann Instruments (2012), o princípio de funcionamento do tomógrafo MIRA consiste no envio de um pulso por um transdutor e o recebimento do pulso refletido por um segundo transdutor. A Figura 2.10 apresenta uma ilustração do princípio de funcionamento do MIRA. 
Figura 2.10 - Tomógrafo MIRA - Princípio de funcionamento

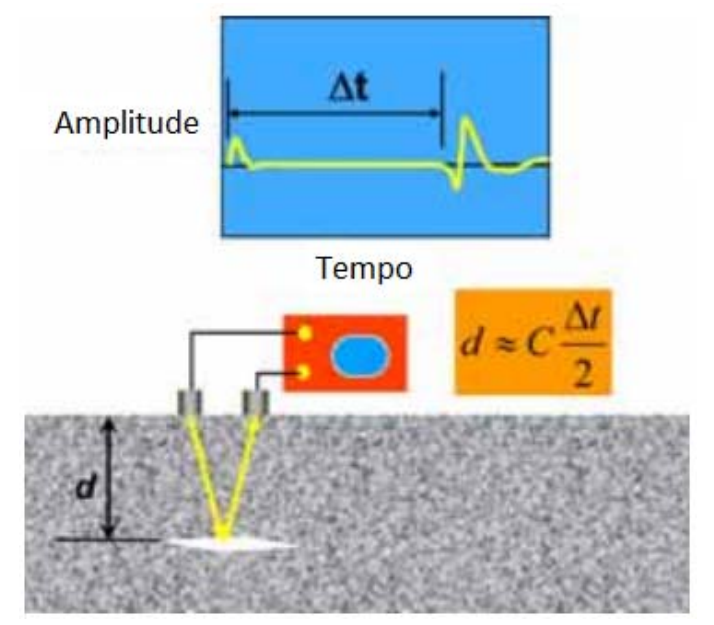

Fonte: Adaptado de Germann Instruments (2012)

O equipamento é composto por uma matriz de 48 transdutores de contato a seco, conforme ilustra a Figura 2.11. Estes transdutores emitem e recebem o pulso ultrassônico.

Figura 2.11 - Tomógrafo MIRA - Matriz de 4 × 12 transdutores de contato a seco

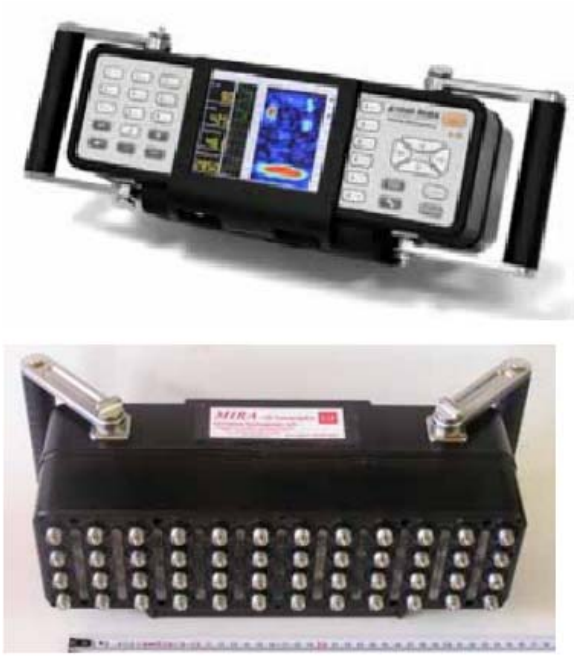

Fonte: (GERMANN INSTRUMENTS, 2012)

O tempo em trânsito é medido pelo equipamento. Sabendo-se a velocidade da onda, a profundidade da interface refletora pode ser determinada pela Equação 2.7.

$$
d \approx C \frac{\Delta t}{2}
$$


Onde,

$\left\{\begin{array}{l}C=\text { Velocidade do pulso ultrasônico }(\mathrm{m} / \mathrm{s}) \\ d=\text { Profundidade do alvo }(\mathrm{m}) \\ \Delta t=\text { Tempo em trânsito }(\mathrm{s})\end{array}\right.$

Para gerar o pulso no equipamento, primeiramente a unidade de controle dentro da antena excita uma fileira de transdutores, que emitem o pulso. As outras fileiras de transdutores atuam como receptores, conforme ilustra a Figura 2.12a. Após excitada esta primeira fileira de transdutores, a próxima fileira é excitada e as demais funcionam como receptoras, conforme ilustra a Figura 2.12b. Este processo é repetido até que cada uma das 12 linhas de transdutores tenham atuado como transmissores, gerando um total de 66 combinações, de acordo com a Figura 2.12c.

Figura 2.12 - a) Primeira fileira emitindo pulsos b) Segunda fileira emitindo pulsos c) Todas as 66 combinações de pulsos

a)

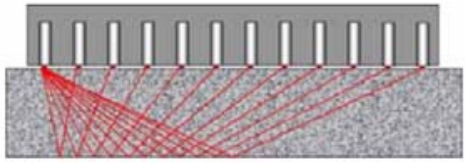

b)

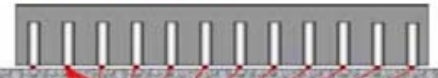

)

c)

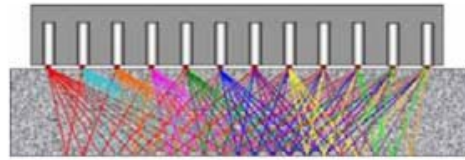

Fonte: (GERMANN INSTRUMENTS, 2012)

De acordo com Haza et al. (2011), depois de emitidos e receptados os pulsos, os dados obtidos são processados utilizando a técnica de abertura de foco sintética (SAFT) para reconstruir, em tempo real, uma imagem bidimensional da seção transversal.

Segundo Elbern e Guimarães (2000), a técnica do foco sintético é baseada na reflexão geométrica (modelo acústico de raios). Neste modelo, o foco do transdutor ultrassônico é assumido como sendo um ponto pelo qual todos os raios sonoros passam antes de divergir em um cone, cujo ângulo é determinado pelo diâmetro do transdutor e pela distância focal, conforme ilustra a Figura 2.13. 
Figura 2.13 - Largura do feixe do transdutor no bloco de teste, mostrando a posição de inspeção em $X_{1}$ e a posição do defeito em $X_{2}$

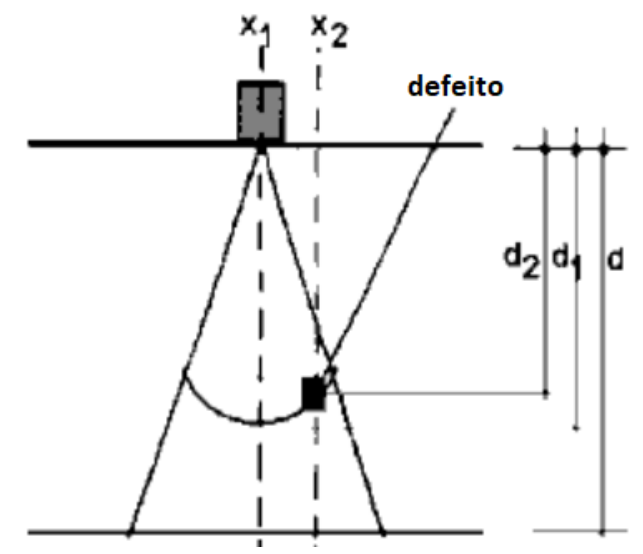

Fonte: Adaptado de Elbern e Guimarães (2000),

Se um alvo estiver localizado abaixo do ponto focal e dentro do cone, é possível calcular o comprimento do caminho e o tempo de trânsito para um sinal viajando ao longo do raio. Com essa informação, é possível construir um conjunto de dados. De acordo com Dinh, Gucunski e Zayed (2019), SAFT é uma técnica poderosa para analisar sinais ultrassônicos. O princípio deste método é baseado na Equação 2.8. Para cada local de levantamento, as formas de onda recebidas são registradas no domínio do tempo, para formar o que é chamado A-scan. Basicamente, O SAFT empilha todos os A-scans coletados para a mesma linha de teste, formando um Bscan.

$$
A(x, d)=\sum_{i=1}^{N} S_{g}^{i}\left(t=\frac{L^{i}}{V}\right)
$$

Onde,

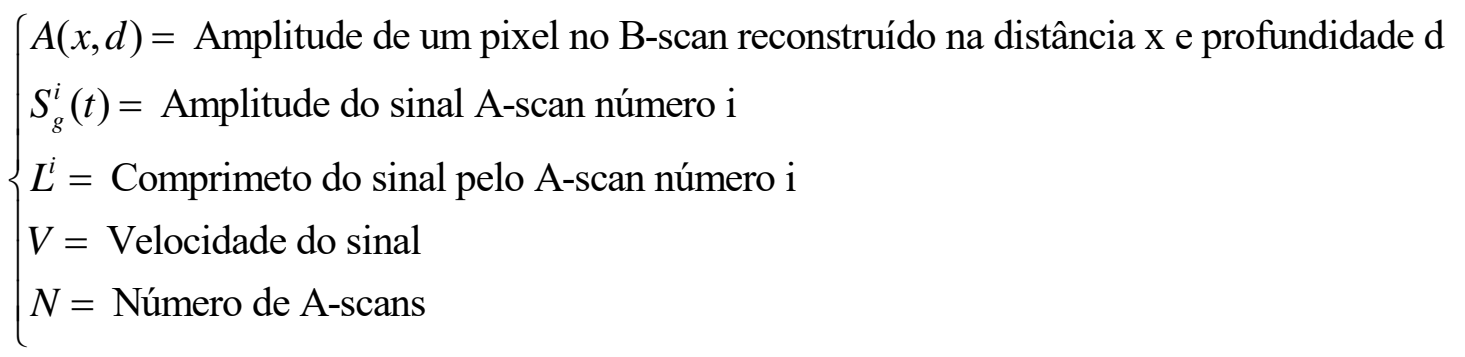

Após o processamento dos dados utilizando a técnica SAFT, são geradas imagens bidimensionais da estrutura ensaiada. A Figura 2.14 apresenta um exemplo 
de imagem gerada. Neste exemplo, é possível observar a reflexão do fundo da laje e das barras de aço.

Figura 2.14 - Exemplo de imagem gerada pelo MIRA

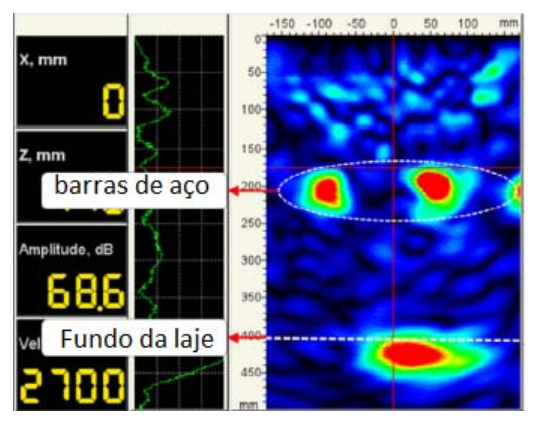

Fonte: Adaptado de Choi et al. (2016)

Choi et al. (2016) afirmam que o ensaio com o ultrassom MIRA pode ser aplicado no monitoramento de pavimentos, realizando avaliações como: detecção de rachaduras horizontais, seleção do limite de reparo e avaliações de seções, conforme ilustra a Figura 2.15.

Figura 2.15 - Exemplo de aplicação do ensaio com ultrassom MIRA na execução de novo pavimento de CRCP sobre um pavimento antigo de CRCP.

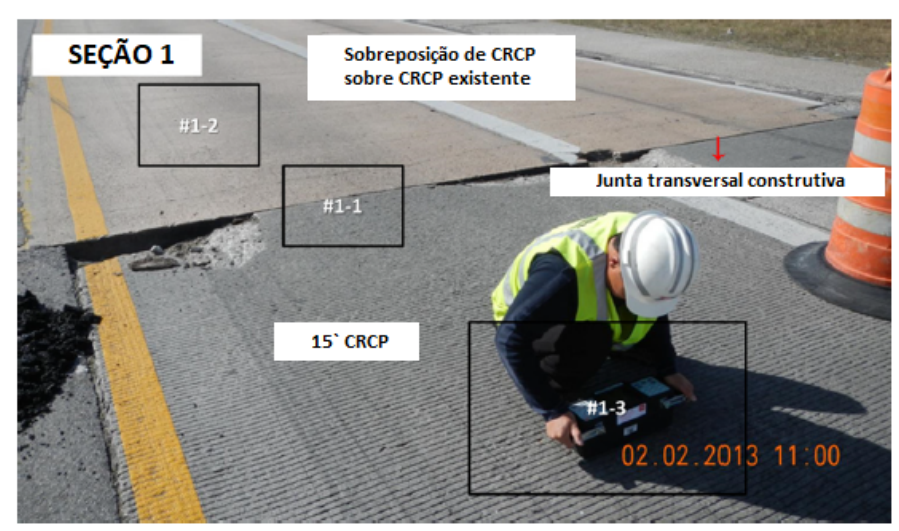

Fonte: Adaptado de Choi et al. (2016)

Uma combinação de vários estudos, coletados por Vancura et al. (2013) certifica os resultados do MIRA na avaliação de medidas de espessura de estruturas, conforme ilustra a Figura 2.16. 
Figura 2.16 - Gráfico mostrandos medidas do MIRA x medidas do corpo de prova.

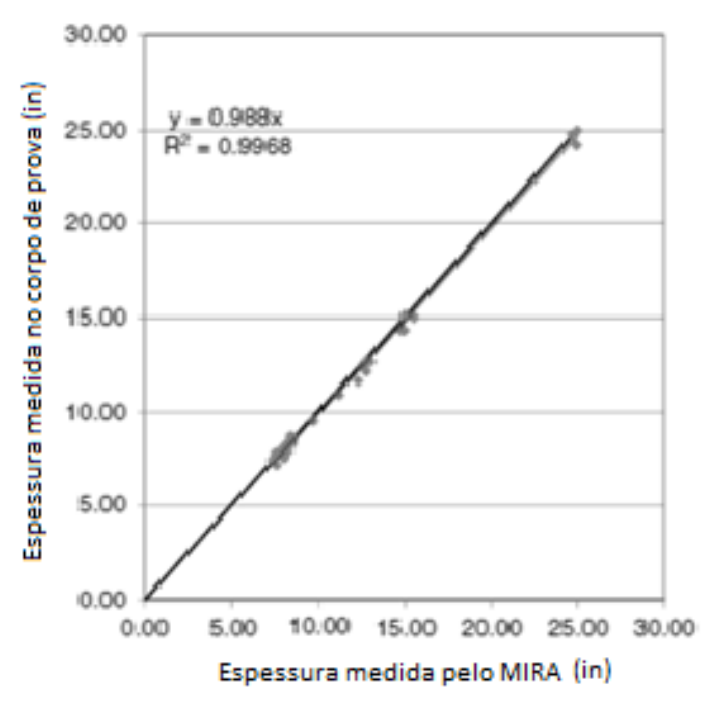

Fonte: Adaptado de Vancura et al. (2013)

Os valores obtidos pelo MIRA foram bastante próximos aos valores medidos nos corpos de prova. O valor do coeficiente de Pearson foi próximo de 1 , indicando grande correlação entre os valores.

\subsection{Técnica de Georadar}

A técnica de georadar, também conhecida como GPR (Ground Penetration Radar), é uma técnica de ensaio não destrutivo que é fundamentada na propagação de sinais eletromagnéticos.

Até meados da década de 70 , as aplicações do GPR resumiam-se basicamente a determinar e mapear espessuras e fissuras em geleiras. (CASAGRANDE et al., 2013). Segundo Pinto (2010), durante a guerra do Vietnã, na década de 70, o exército americano começou a aprimorar o sistema GPR com a intenção de localizar os túneis e rotas de fuga dos vietnamitas. Ainda na mesma década, o sistema GPR foi utilizado pela NASA (National Aeronautics and Space Administration) para pesquisas na superfície lunar.

Com o passar dos anos, o sistema GPR foi se aprimorando e novas aplicações passaram a fazer parte do sistema. Segundo Casagrande et al. (2013) com os avanços tecnológicos e a praticidade dos equipamentos, o GPR se tornou uma das técnicas mais eficazes para investigações rasas de solo. Atualmente o GPR 
apresenta uma série de aplicações em diversas áreas, que serão apesentadas na seção 2.2.2.

\subsubsection{Princípio físico}

Segundo Lai, Dérobert e Annan (2018), os sistemas GPR típicos operam na faixa de freqüência de 10 a $5.000 \mathrm{MHz}$. As antenas que são usadas para emitir e detectar os sinais devem ter dimensões compatíveis com os comprimentos de onda dos sinais que definem o tamanho do instrumento GPR. As operações do GPR na faixa de 10 a $100 \mathrm{MHz}$ são adequadas para imagens de fundações profundas na escala de dezenas de metros. As operações na faixa dos 100 a $1000 \mathrm{MHz}$ são usadas para investigar pavimentos de estradas, revestimentos de túneis e utilitários na escala de medidores. Já as aplicações na faixa dos 1000 a $5000 \mathrm{MHz}$ são usadas para avaliação de revestimentos de túneis e estruturas de edifícios na escala de centímetros.

Um dos principais fatores que determinam a escolha das antenas, é a frequência central. A largura da banda é definida pela frequência central. Geralmente a largura da banda tem um valor mínimo, que corresponde a 0,5 vezes o valor da frequência central e um valor máximo que corresponde a 1,5 vezes esse valor, conforme ilustra a Figura 2.17(ANNAN, 1992).

Figura 2.17 - Gráfico ilustrando a definição da frequência central a partir da largura da banda
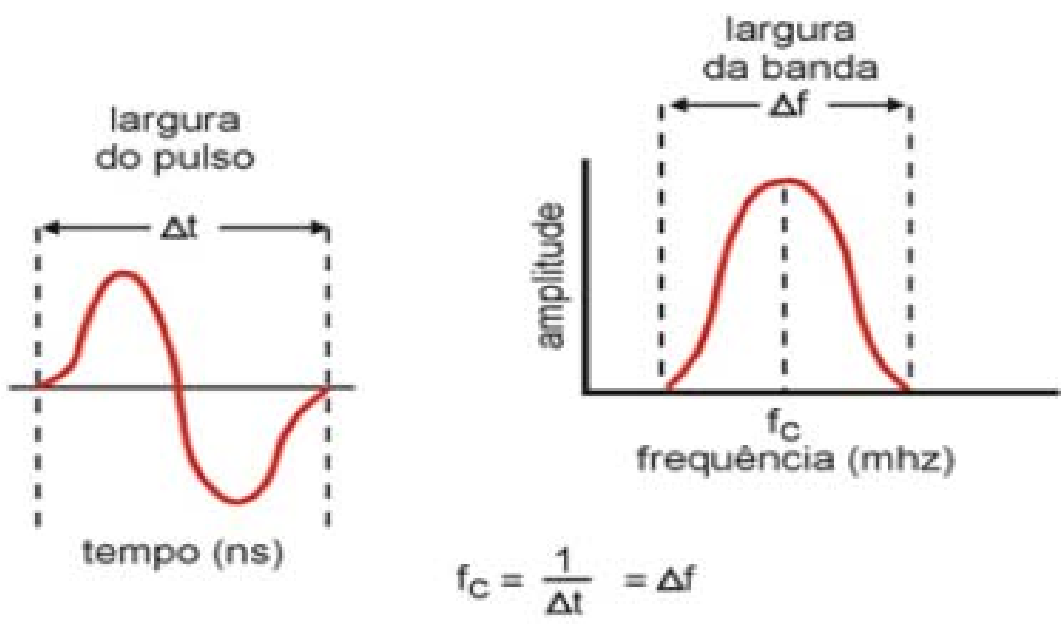

Fonte: (ANNAN ,1992) 
De acordo com Porsani (1999), as profundidades máximas de penetração atingidos por diferentes frequências centrais da antena é apresentada na Figura 2.18. Observa-se que antenas com frequência central de menores valores atingem profundidades maiores.

Figura 2.18 - Penetração máxima em função da frequência central da antena

\begin{tabular}{|c|c|}
\hline $\begin{array}{c}\text { Frequência central } \\
\text { (MHz) }\end{array}$ & $\begin{array}{c}\text { Profundidade Máxima } \\
\text { de Penetração }(\mathbf{m})\end{array}$ \\
\hline 1000 & 1 \\
\hline 400 & 2 \\
\hline 200 & 4 \\
\hline 100 & 25 \\
\hline 50 & 30 \\
\hline 25 & 40 \\
\hline 10 & 50 \\
\hline
\end{tabular}

Fonte: Adaptado de Porsani (1999)

De acordo com Clemeña (2004), os radares operam pela transmissão de um único pulso seguido por um tempo morto, no qual o sinal é refletido e retorna ao receptor.

Silva (2014) afirma que o sistema do GPR é composto basicamente por: uma unidade de controle, um conjunto de antenas transmissora e receptora e uma unidade de armazenamento de dados (computador). A Figura 2.19 apresenta os componentes do sistema GPR. 
Figura 2.19 - Componentes de um radar típico.

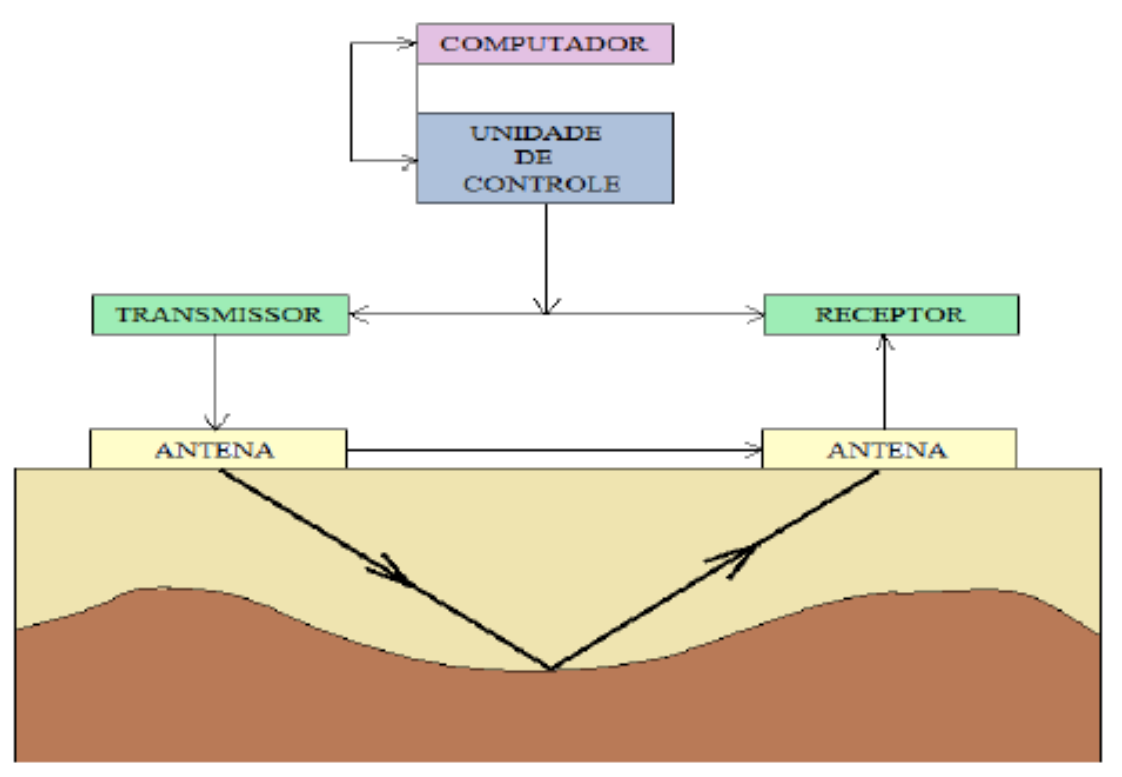

Fonte: BORGES (2013).

Kaplanvural, Peksen e Ozkap (2018) afirmam que a velocidade de propagação de uma onda eletromagnética em um bloco de concreto pode ser caracterizada pela permissividade dielétrica (constante dielétrica) e pela permeabilidade magnética, de acordo com a Equação 2.9.

$$
v=\frac{1}{\sqrt{\varepsilon \times \mu}}=\frac{1}{\sqrt{\varepsilon_{0} \times \varepsilon_{r} \times \mu_{0} \times \mu_{r}}}
$$

Onde,

$$
\left\{\begin{array}{l}
v=\text { velocidade da onda eletromagnética } \\
\varepsilon=\text { Permissividade dielétrica do meio } \\
\varepsilon_{0}=\text { Permissividade dielétrica ao ar livre } \\
\varepsilon_{r}=\varepsilon / \varepsilon_{0}=\text { Permissividade dielétrica relativa do meio } \\
\mu=\text { Permeabilidade magnética do meio } \\
\mu_{0}=\text { Permeabilidade magnética ao ar livre } \\
\mu_{r}=\mu / \mu_{r}=\text { Permeabilidade magnética relativa }
\end{array}\right.
$$

De acordo com Kaplanvural, Peksen e Ozkap (2018), na maior parte dos meios, como concreto e solos, as propriedades magnéticas são negligenciáveis, e a 
permeabilidade magnética relativa fica próxima de 1, resultando na Equação 2.10 para a velocidade da onda.

$$
v=\frac{c}{\sqrt{\varepsilon_{r}}}
$$

Onde,

$$
\left\{\begin{array}{l}
v=\text { velocidade da onda eletromagnética } \\
c=\text { velocidade da luz } \\
\varepsilon=\text { Permissividade dielétrica do meio } \\
\varepsilon_{0}=\text { Permissividade dielétrica ao ar livre } \\
\varepsilon_{r}=\varepsilon / \varepsilon_{0}=\text { Permissividade dielétrica relativa do meio }
\end{array}\right.
$$

Casagrande et al. (2013) afirmam que quando um pulso é emitido pelo equipamento e atinge uma interface que separa dois meios de propriedades eletromagnéticas diferentes, uma parte do pulso continua se propagando até ser absorvida pelo meio, e a outra parte sofre reflexão e difração. Esta segunda parte que sofre reflexão e difração é captada por uma antena receptora que detecta os sinais e envia para uma unidade de controle, conforme ilustra a Figura 2.20.

Figura 2.20 - Ilustração do funcionamento de um radar.

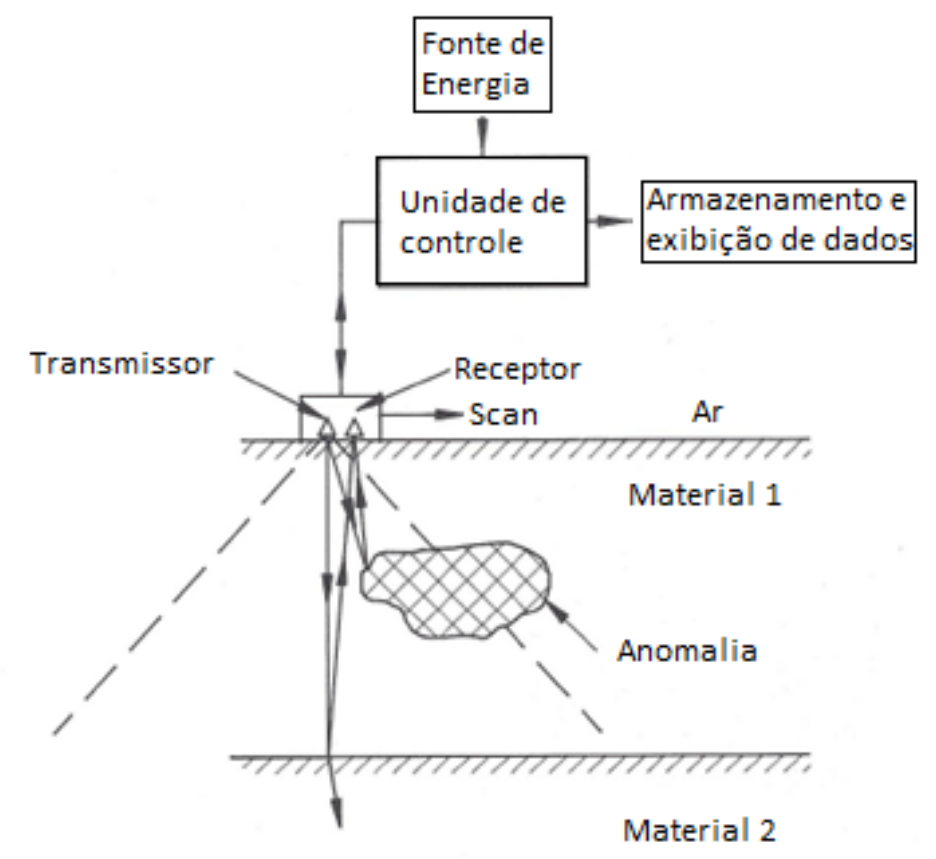

Fonte: Adaptado de Bungey e Millard (2006). 
$\mathrm{Na}$ unidade de controle o sinal é amplificado e posteriormente é armazenado em unidade de processamento.

Basicamente o processamento envolve as etapas de edição dos dados, processamento do sinal e apresentação da imagem processada. A etapa básica de processamento inclui a filtragem dos dados e a aplicação de ganhos. A filtragem é uma das técnicas mais simples e mais potentes para análise dos dados obtidos com o GPR. O correto uso do filtro pode melhorar a razão sinal/ruído, permitindo delimitar uma frequência de banda que seja atingível pela antena. Já a aplicação de ganhos busca equalizar todas as amplitudes de cada traço, com o intuito de compensar a atenuação que ocorre no sinal a medida que ele se propaga.

No processamento avançado ocorrem as etapas de migração e deconvolução. A etapa de migração permite reconstruir uma imagem que representa melhor o meio, uma vez que as reflexões podem ser colocadas em suas posições corretas. A "deconvolução" permite remover "ringing" dos dados que são causados pela ressonância de energia do radar.

Atualmente existe no mercado uma série de programas que podem ser usados para tratamento dos dados obtido com o GPR, entre eles: RADAN, REFLEXW, GRADIX, RADPRO, GROUNDVISION

A Figura 2.21 apresenta um exemplo de radargrama obtido após a etapa de processamento dos dados.

Figura 2.21 - Exemplo de um resultado do GPR

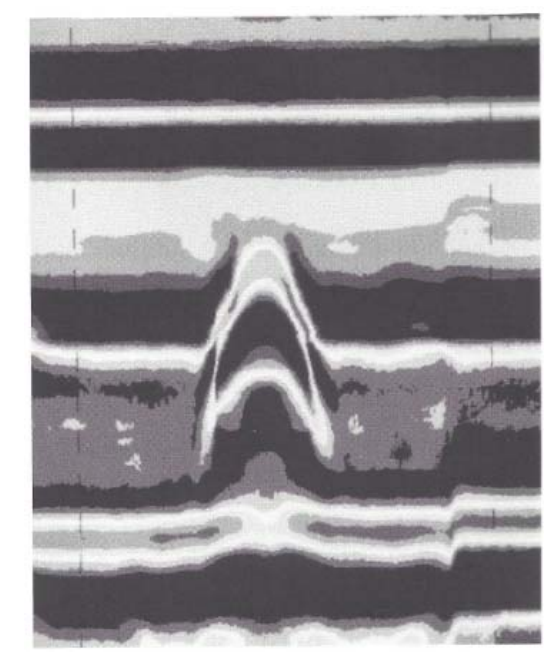

Fonte: BUNGEY E MILLARD (2006). 
Algumas características importantes deste processo devem ser ressaltadas. Segundo Casagrande et al. (2013), quando a antena atravessa um objeto em ângulo reto, a imagem resultante se assemelha a uma hipérbole. Isto ocorre porque a radiação do feixe de antena tem formato de um cone. Desta forma o equipamento permite fazer verificações não somente quando o objeto está em uma posição perpendicular ao alvo, mas também em outras posições. $O$ formato de hipérbole, portanto, revela a antena se aproximando ou se distanciando do objeto. O cume da hipérbole revela exatamente quando a posição da antena está em cima do alvo.

\subsubsection{Aplicações}

De acordo com Casagrande et al. (2013) algumas das áreas em que se têm utilizado a técnica do GPR são: pavimentos rodoviários e de aeroportos, aplicações militares, estudo dos solos, arqueologia, planejamento urbano, hidrogeologia, exploração mineral.

No ramo da geologia, o GPR apresenta uma série de aplicações. A estimativa da umidade do solo é a aplicação mais frequente dos levantamentos de solo de GPR, uma vez que o conteúdo de água influencia a propagação de sinal eletromagnético. O uso do GPR, aplicado na avaliação dos solos, pode ser utilizado no estudo da estratigrafia (composição das camadas do solo) e na avaliação da salinidade e textura do solo (ZAJIKOVA e CHUMAN, 2019).

$\mathrm{Na}$ avaliação de estruturas de concreto, o GPR permite aplicações como: detectar fissuras, determinar grau de hidratação, medir espessuras, detectar armaduras e eletrodutos. Segundo Lai, Dérobert e Annan (2018), existem três áreas principais de foco quando o GPR é usado para inspecionar edifícios. A primeira é localizar objetos e estruturas, a segunda é o mapeamento da deterioração e a terceira é a avaliação de danos estruturais

$\mathrm{Na}$ construção de pavimentos, existe um rigoroso controle para garantir uma espessura mínima de laje. Muitas vezes são extraídos corpos de prova para garantir que se tenha esta espessura mínima e consequentemente uma vida útil longa para novos pavimentos. Segundo Clemeña (2004), a utilização da técnica de radar é uma alternativa não destrutiva possível de se aplicar para solucionar este tipo problema. 
2.2.3. Fatores que influenciam os resultados

Segundo Clemeña (2004), o sucesso na medição utilizando radar depende de uma razoável reflexão do pulso da parte inferior da estrutura de concreto ensaiada pois desta forma consegue-se ter uma identificação precisa da reflexão e posteriormente ter mais exatidão no tempo de trânsito do pulso.

A interpretação dos resultados é bastante subjetiva e depende muito de cada interpretação.

\subsection{Mapeamento com laser scanner}

De acordo com Suchocki e Katzer (2018), o Laser Scanner Terrestre (TLS) é um instrumento que utiliza um feixe de laser para medições remotas não destrutivas. Ele realiza várias medições durante uma varredura e adquire conjuntos de dados.

De acordo com Dalmolin e Santos (2004), o sistema de laser scanner é capaz de gerar as coordenadas tridimensionais de pontos sobre uma superfície. $O$ equipamento gera pulsos de laser que são emitidos e atingem vários pontos da superfície com o auxílio de um espelho de varredura. Os pontos atingidos refletem o pulso incidente e parte do pulso retorna para o equipamento, onde é possível determinar informações do objeto. A Figura 2.22 apresenta um exemplo de laser scanner.

Figura 2.22 - Exemplo de Laser Scanner: Focus 3D X330 (FARO, 2013)

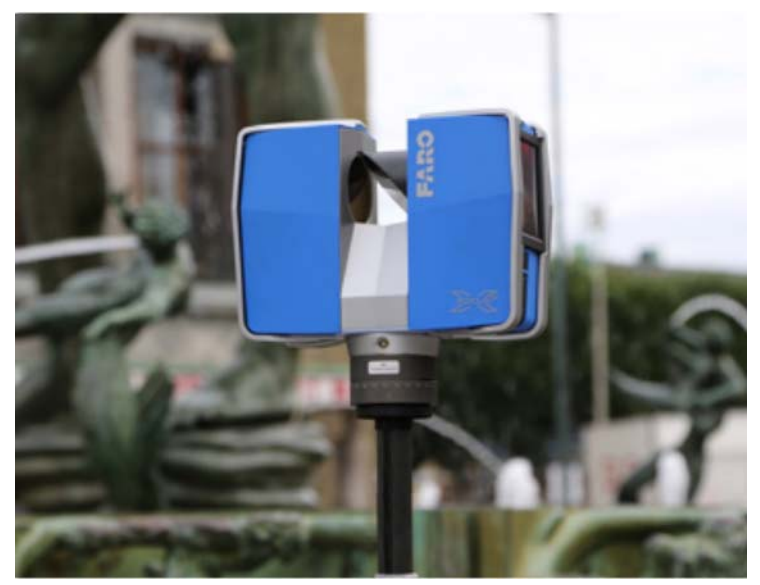

Fonte: FARO (2013) 
Suchocki e Katzer (2018) afirmam que a cada ponto varrido, o equipamento TLS coleta um conjunto de dados dos objetos, que compreende: o ângulo vertical, o ângulo horizontal, a distância e a intensidade relativa do sinal capturado. A Figura 2.23 apresenta um exemplo de aplicação do mapeamento em campo.

Figura 2.23 - exemplo de mapeamento com o Focus 3D X330 (FARO, 2013)

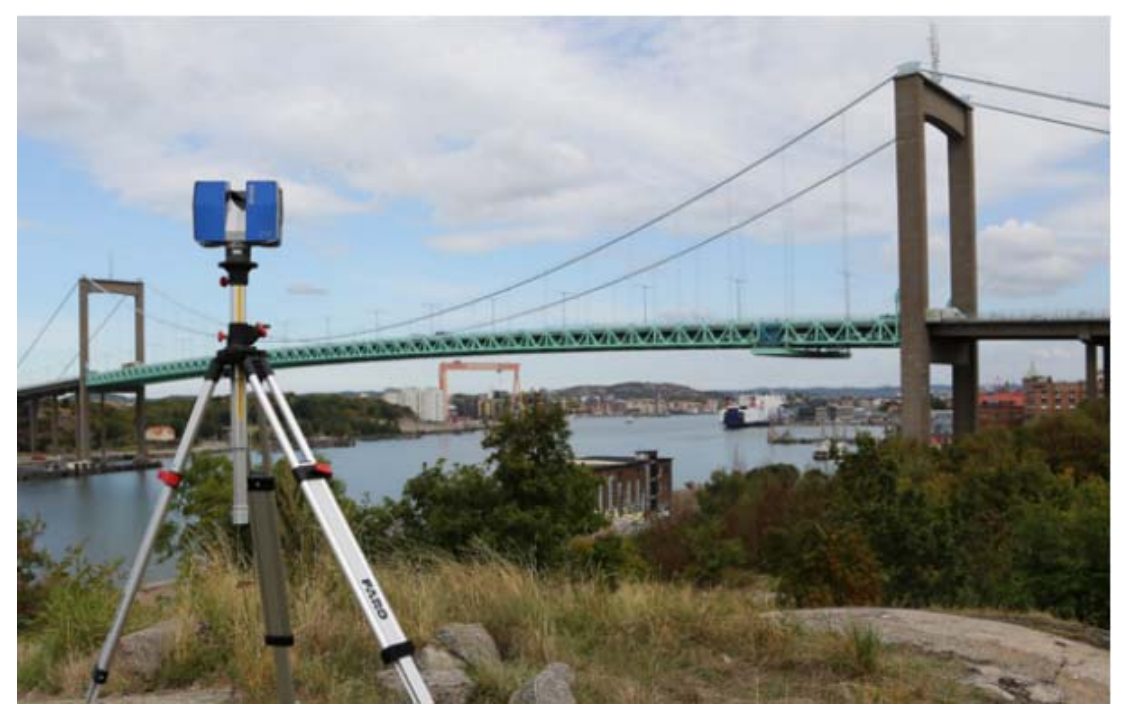

Fonte: FARO (2013)

Segundo Xilian et al. (2016), O TLS mede automaticamente o espaço tridimensional circundante usando milhões a bilhões de pontos. Suchocki e Katzer (2018) afirmam que esse conjunto de pontos são utilizados para criar modelos digitais bidimensionais e tridimensionais. A Figura 2.24 ilustra, como exemplo de resultado de levantamento, a nuvem de pontos obtida no mapeamento de uma ponte. 
Figura 2.24 - Exemplo de nuvem de pontos gerada no levantamento com laser scanner

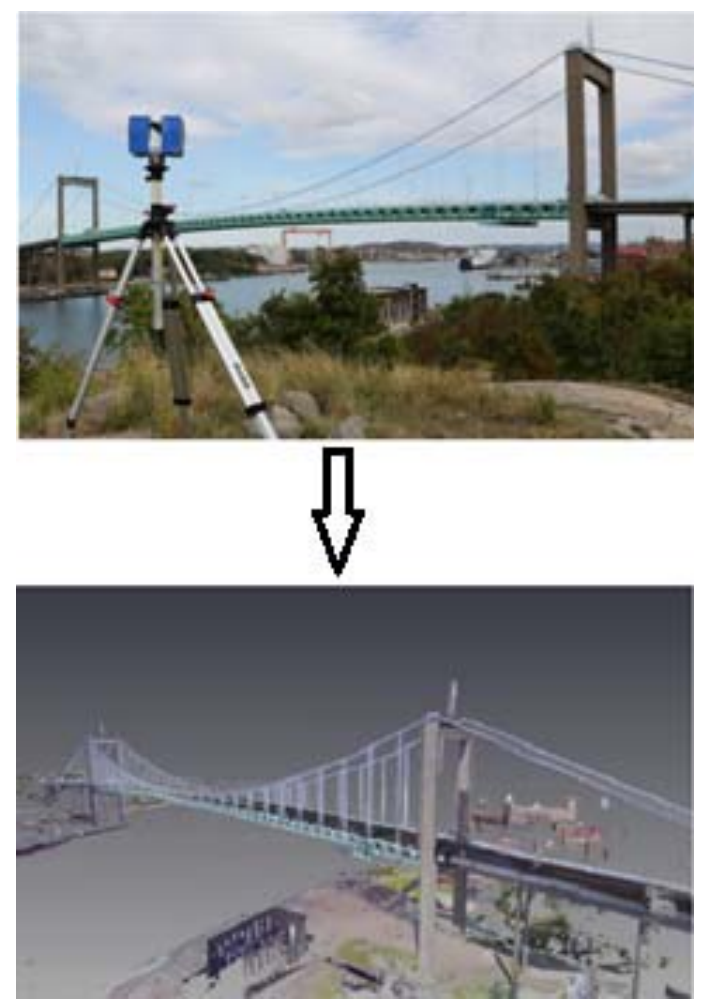

Fonte: Adaptado de FARO (2013)

\subsubsection{Princípio físico}

De acordo com Maia (1999), em função do princípio de funcionamento, os sistemas de varredura de lasers estáticos podem ser classificados em três grupos.

O primeiro grupo, corresponde aos sistemas baseados no princípio da triangulação. Segundo Tommaselli (2003), neste método, o pulso de laser é emitido pelo sistema e a luz refletida pelo objeto é captado por sensores do equipamento. Estes sensores transformam a luz recebida em sinais elétricos, que são convertidos em bits. Neste processo, o ângulo de varredura dos pulsos é registrado no equipamento a cada pulso. Com estes dados, é possível determinar a posição dos pontos refletidos.

O segundo grupo, corresponde àqueles baseados no princípio "time of flight" ou intervalo de tempo desde o instante da emissão do pulso até o momento da recepção do mesmo. Neste sistema, também conhecido como LIDAR (Light Detection And Ranging), são emitidos milhares de pulsos por segundo. A distância do objeto é estimada através do tempo de percurso do pulso. O pulso é refletido pelo objeto e parte dele retorna ao sistema, onde os dados são coletados. 
No terceiro grupo, estão os sistemas baseados no método de diferença de fase, onde a distância é calculada através da diferença de fase da onda modulada. (MAIA, 1999).

Segundo Suchocki e Katzer (2018), o sistema TLS opera com o sistema de varredura "time of flight", também conhecido como LIDAR (Light Detection And Ranging).

No sistema LIDAR, as medições são baseadas em uma equação geral de alcance a laser, apresentada pela Equação 2.11.

$$
\mathrm{P}_{R}=\frac{\mathrm{p}_{t} \times \mathrm{D}^{2} \times \sigma}{4 \pi \times R^{4} \times \beta_{t}^{2}} \times \eta_{\text {ATM }} \times \eta_{\text {SYS }}
$$

Onde,

$$
\left\{\begin{array}{l}
\mathrm{P}_{R}=\text { Intensidade do sinal recebido }(\mathrm{W}) \\
p_{t}=\text { Intensidade do sinal recebido }(\mathrm{W}) \\
D=\text { Diâmetro de abertura do receptor }(\mathrm{m}) \\
\sigma=\text { Efetiva seção transversal do alvo }\left(\mathrm{m}^{2}\right) \\
R=\text { Distância do sistema ao alvo }(\mathrm{m}) \\
\beta_{t}=\text { Largura do feixe do laser }(\mathrm{m}) \\
\eta_{\text {ATM }}=\text { Fator de transmissão atmosférica } \\
\eta_{\text {SYS }}=\text { Fator de transmissão do sistema }
\end{array}\right.
$$

A relação entre a largura do feixe de laser $\left(\beta_{t}\right)$, a constante de iluminação de abertura $\left(K_{a}\right)$, o comprimento de onda da luz do laser $(\lambda)$ e o diâmetro da abertura (D) é dada pela Equação 2.12

$$
\beta_{t}=\frac{K_{a} \times \lambda}{D}
$$

Onde, 


$$
\left\{\begin{array}{l}
\beta_{t}=\text { Largura do feixe do laser }(\mathrm{m}) \\
K_{a}=\text { Constante de abertura } \\
\lambda=\text { Comprimento de onda do pulso }(\mathrm{m}) \\
D=\text { Diâmetro de abertura }(\mathrm{m})
\end{array}\right.
$$

A seção transversal efetiva do alvo (também conhecida como seção transversal de retrodifusão), é definida pela Equação 2.13

$$
\sigma=\frac{4 \times \pi \times \rho \times A_{s}}{\Omega}
$$

Onde,

$$
\left\{\begin{array}{l}
\sigma=\text { Efetiva seção transversal do alvo }\left(\mathrm{m}^{2}\right) \\
\rho=\text { Reflectância do alvo } \\
A_{\mathrm{s}}=\text { Área do alvo }\left(\mathrm{m}^{2}\right) \\
\Omega=\text { Espalhamento sólido do alvo }
\end{array}\right.
$$

\subsubsection{Aplicações}

Segundo Suchocki e Katzer (2018), a tecnologia TLS é utilizada em algumas aplicações de engenharia civil, como: monitoramento de pontes; deformações de estruturas; deslizamentos de terra; monitoramento de barragens; deformação de túneis e análise de fachadas.

\subsubsection{Fatores que influenciam o resultado}

Segundo Suchocki e Katzer (2018), os resultados são afetados principalmente pela refletividade do alvo, pelo ângulo de incidência e pelo alcance do alvo.

\subsection{Técnica da esclerômetria}

Segundo Malhotra (2004), o método de ensaio utilizando esclerômetro consiste em submeter uma determinada estrutura a um impacto de uma massa conhecida, 
com uma energia cinética também conhecida e avaliar a resposta da estrutura a este impacto padronizado.

De acordo com o ACI 228 (2003), o valor da resposta (rebote) depende do valor da energia cinética antes de ocorrer o impacto, e de quanto dessa energia é absorvida entre a barra de percussão e o concreto. Esta energia absorvida está relacionada aos parâmetros de rigidez do concreto.

Segundo Bungey (1989), os primeiros testes para avaliar a dureza superficial do concreto ocorreram em 1930. Nestes primeiros testes, foi utilizada uma bola de aço fixa em um pêndulo ou atirada de uma pistola. Em 1948, o engenheiro suíço Ernst Schmidt desenvolveu um martelo para testar a dureza superficial do concreto pelo princípio do rebote mecânico. Os resultados deste estudo foram apresentados ao Instituto Experimental de Zurich e ao centro federal suíço de teste de materiais, onde o martelo foi construído e extensivamente testado. A representação deste aparelho e de seu funcionamento está apresentada na Figura 2.25.

Figura 2.25 - Exemplo de Esclerômetro - Funcionamento consiste em pressionar o êmbolo contra a superfície e observar o valor da resposta no indicador do equipamento

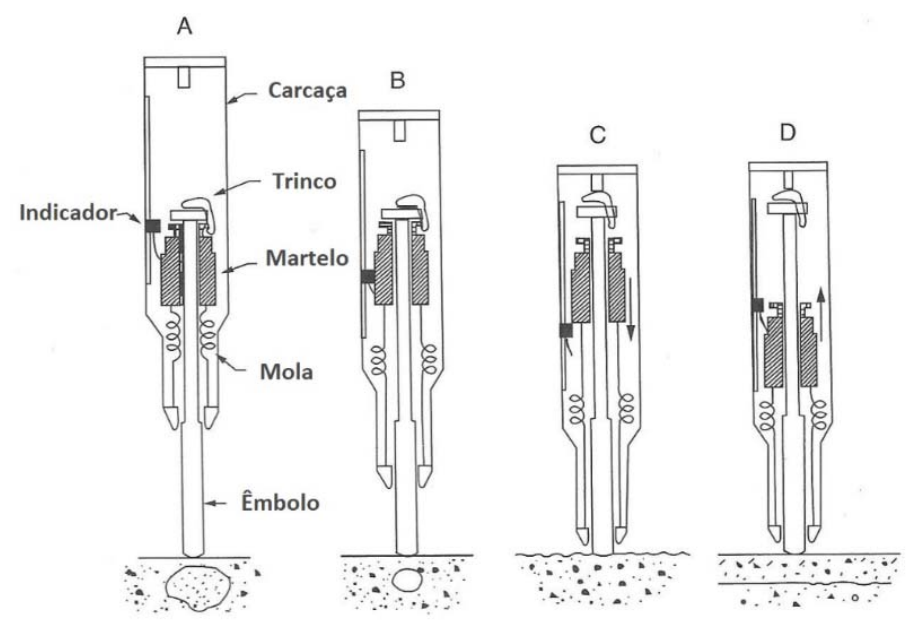

Fonte: Adaptado de Bungey (1989)

A Figura 2.26 ilustra um exemplo do ensaio sendo aplicado. Durante a execução do teste, o martelo deve ser empurrado contra a superfície com velocidade moderada até que seja efetuada a medição (MALHOTRA, 2004). 
Figura 2.26 - Exemplo de esclerômetro.

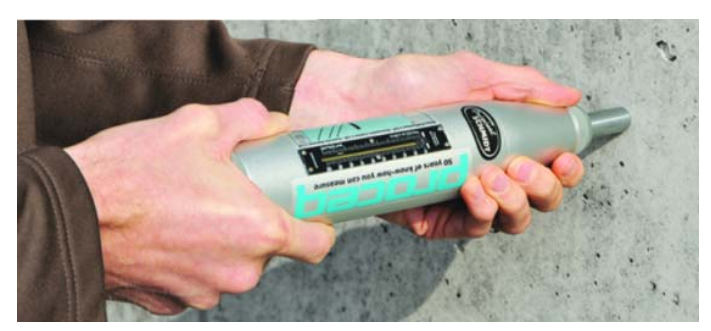

Fonte: PROCEQ (2016)

No Brasil o ensaio é normalizado pela NBR 7584 (2012) e internacionalmente pelas normas EN 12504-2 (2012), RILEM NDT 3 (1984), BS1881:Part202 (1986) e ASTM C805 (2008).

De acordo o manual da PROCEQ (2016), para a realização do ensaio, primeiramente deve-se utilizar uma pedra de esmeril para alisar a superfície e homogeneizar a mesma. Alisada a estrutura, antes de executar o teste, deve-se realizar alguns testes de impacto na superfície, para depois iniciar as medições. A Figura 2.27 apresenta um exemplo em que a superfície foi homogeneizada antes dos testes.

Figura 2.27 - Exemplo de aplicação do ensaio
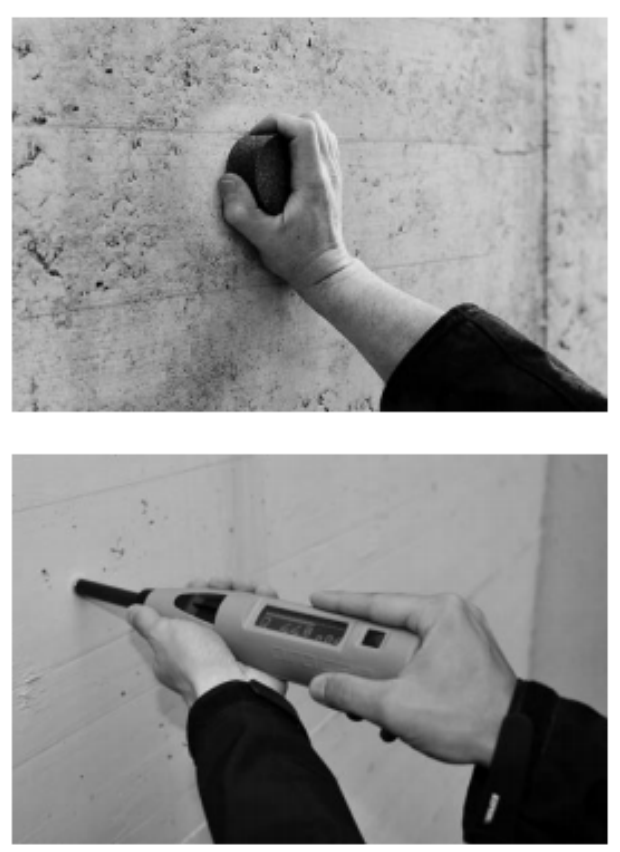

Fonte: Manual da PROCEQ (2016) 


\subsubsection{Aplicações}

Este método permite avaliar a dureza superficial de uma determinada superfície de concreto. Desta forma, é possível avaliar a uniformidade de uma determinada superfície.

Outra aplicação, segundo Meneghetti (1999), é realizar a avaliação da resistência à compressão de uma determinada estrutura, através de correlações existentes.

De acordo com a norma NM78 (1996), o procedimento para a determinação da correlação entre o índice esclerométrico e a resistência à compressão está descrito a seguir.

- Preparar concretos com relação água/cimento variando de 0,40 a 0,70, com intervalos de 0,05, para obter diferentes pontos da curva de correlação.

- Para cada valor da relação água/cimento recomenda-se moldar no mínimo dois corpos de prova. Determinar inicialmente o índice esclerométrico médio e a resistência à compressão para cada corpo de prova.

- Recomenda-se a utilização de corpos de prova cilíndricos de $15 \mathrm{~cm}$ de diâmetro e $30 \mathrm{~cm}$ de altura.

- O corpo de prova deve estar superficialmente seco (deixar 48 horas em ambiente de laboratório antes do ensaio).

- Os impactos devem ser aplicados na direção normal ao plano tangente do corpo de prova. Devem ser escolhidas três geratrizes separadas em aproximadamente 120 graus e serem efetuadas três determinações a diferentes alturas em cada uma delas.

De Acordo com Malhotra (2004), cada fabricante de esclerômetro desenvolve curvas de correlação se baseando em corpos de prova ensaiados. Entretanto, não é recomendado que se utilize essas curvas, uma vez que o material e as condições de teste podem não ser os mesmos de quando o fabricante fez os ensaios para gerar as curvas de correlação. O ideal é fazer ensaios com o esclerômetro em corpos de prova, submeter estes corpos de prova ao ensaio de compressão axial e depois realizar as correlações. 


\subsubsection{Fatores que influenciam o resultado}

Malhotra (2004) alerta que apesar de este método ser de fácil e barata aplicação, vários fatores influenciam o seu resultado e devem ser observados com atenção durante a aplicação do teste, entre eles: rugosidade da superfície, tamanho, formato e rigidez da estrutura ensaiada, idade da estrutura ensaiada, composição do concreto, tipo e tamanho de agregados, tipo de cimento e a carbonatação da superfície avaliada.

Segundo o manual do equipamento da PROCEQ (2016), o fenômeno da carbonatação faz com que uma camada dura apareça na superfície do concreto, causando uma sobrevalorização do valor obtido no ensaio, chegando a aumentar em $50 \%$ a resposta dada pelo martelo. Por este motivo saber a espessura da camada carbonatada é importante para avaliar os resultados.

\subsection{Técnica da pacometria}

De acordo com Rathod et al. (2019), a técnica da pacometria utiliza o campo magnético para identificar as barras de aço no concreto, utilizando a tecnologia de indução de impulsos eletromagnéticos, conforme ilustra a Figura 2.28. Neste método, as bobinas são carregadas usando os pulsos de corrente, gerando campo magnético ao redor da superfície de concreto eletricamente não condutora.

Figura 2.28 - Funcionamento do pacômetro através de campo magnético

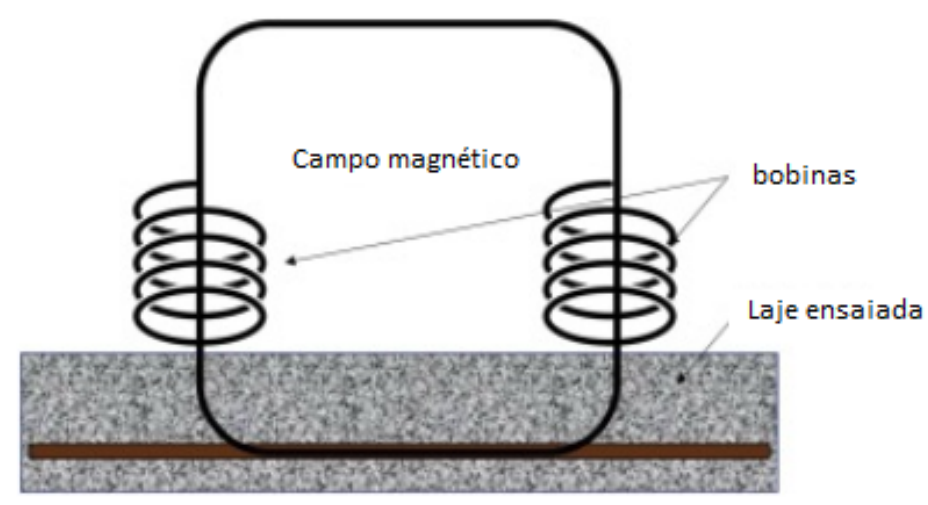

Fonte: Adaptado de Rathod et al. (2016)

O principal objetivo do ensaio de pacometria é localizar a posição das armaduras no interior do concreto, e determinar seus respectivos cobrimentos. Seu 
uso baseia-se no arrasto do equipamento sobre a estrutura de concreto e observação dos resultados no visor do equipamento. Quando a armadura é localizada, o círculo do visor fica centralizado na tela e acende-se uma luz vermelha indicando a localização da armadura, conforme ilustra a Figura 2.29. No canto inferior direito do visor aparece o valor do cobrimento estimado pelo aparelho.

Figura 2.29 - Exemplo de aplicação do ensaio de pacometria.

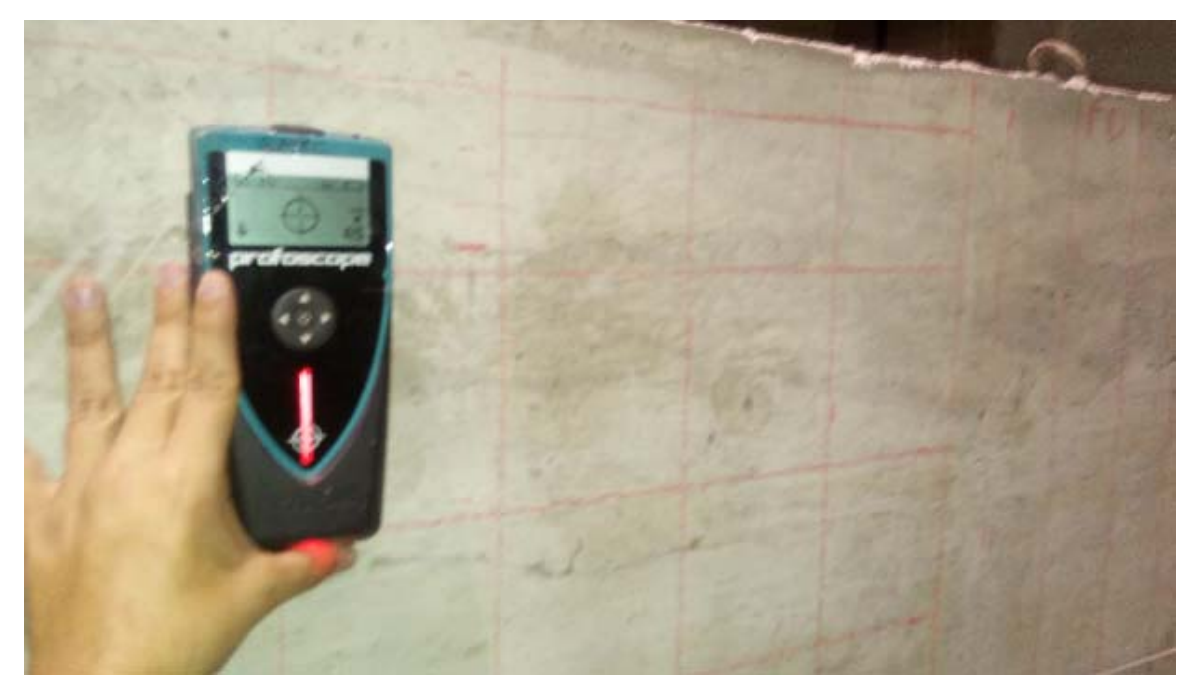

Fonte: Autoria própria

Pela facilidade de uso do equipamento, a recomendação para a realização de medidas precisas baseia-se na repetição do arrasto por diferentes alturas do corpo em estudo, e pela observação da linearidade da resposta para essas diferentes alturas.

Este ensaio é recomendado pela norma BS 1881:part 204 (1988).

\subsubsection{Aplicações}

As principais aplicações do ensaio de pacometria são: localização de armaduras em uma estrutura de concreto e a determinação do cobrimento das mesmas. 


\subsubsection{Fatores que influenciam o resultado}

Os principais fatores que afetam os resultados do ensaio de pacometria são: rugosidade da estrutura ensaiada, taxa de armadura da estrutura e a presença de impurezas na região de aplicação do ensaio.

\subsection{Técnica de avaliação da carbonatação}

Segundo Sahuinco (2011), a causa mais importante da corrosão da armadura, que é a principal causa de deterioração precoce do concreto, é a carbonatação.

De acordo com Pauletti (2004), a carbonatação é um fenômeno físico-químico em que ocorre a substituição dos compostos do cimento através de reações com o dióxido de carbono $\left(\mathrm{CO}_{2}\right)$ e outros gases ácidos, como o dióxido de enxofre $\left(\mathrm{SO}_{2}\right)$. A reação principal que rege este processo é apresentada na Equação 2.14. Neste processo, o $\mathrm{pH}$ do concreto é reduzido de algo em torno de 13 para um valor inferior a 9.

$$
\mathrm{Ca}(\mathrm{OH})_{2}+\mathrm{CO}_{2} \rightarrow \mathrm{CaCO}_{3}+\mathrm{H}_{2} \mathrm{O}
$$

De acordo com Andrade (1992), a espessura superficial carbonatada denomina-se "profundidade de carbonatação". O ensaio para avaliar a profundidade de carbonatação consiste em submeter a estrutura ensaiada a indicadores químicos e observar as cores resultantes (SAHUINCO, 2011).

Este ensaio é recomendado pela RILEM CPC 18 (1988).

\subsubsection{Indicadores}

O principal indicador químico utilizado no ensaio de carbonatação é a fenolftaleína. Este indicador apresenta coloração rosa para meios com $\mathrm{pH}$ maiores que 9,5. Não existe um consenso entre pesquisadores em que faixa de $\mathrm{pH}$ a coloração se altera de incolor para rosa (PAULETTI, 2004).

De acordo com Sahuinco (2011), em função da cor apresentada após aplicar a solução de fenolftaleína na estrutura, é possível estimar o pH: cor violeta mostra um $\mathrm{pH}$ maior que 13 e ausência de cor indica um $\mathrm{pH}$ menor que 9. 
Além da fenolftaleína, outros indicadores químicos também podem ser utilizados no ensaio de carbonatação. De acordo com Pauletti (2004), alguns indicadores que também podem ser utilizados são: timolftaleína, o amarelo de alizarina $\mathrm{R}$ e o Napthol green B. A Figura 2.30 mostra um exemplo de resultado após aplicação do ensaio.

Figura 2.30 - Exemplo de estrutura submetida a ensaio para verificação do nível de ataque por carbonatação.

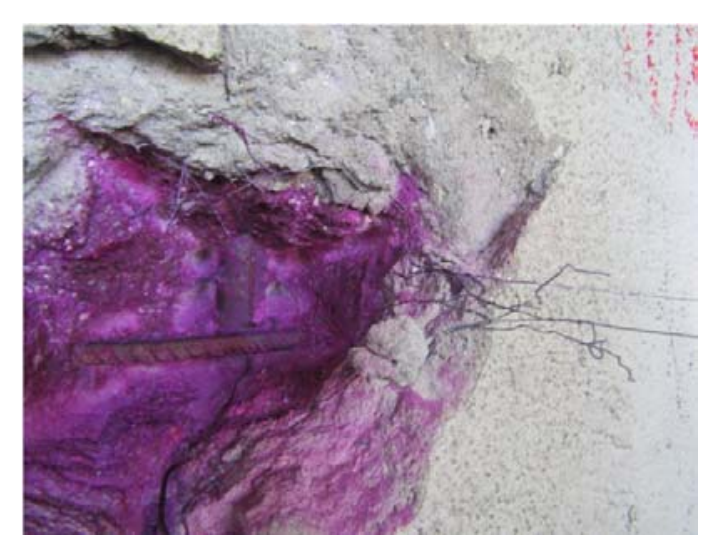

Fonte: Secretaria de Obras da cidade de São Paulo (2019)

2.6.2. Modelos para estimar profundidade de carbonatação

Alguns autores fizeram estudos e propuseram modelos para estimativa da espessura da camada de carbonatação. De acordo com Carmona (2005), dos vários modelos utilizados para se fazer esta avaliação, o modelo apresentado por Tuuti (1982) é o que parece ser mais adequado. A Equação 2.15 apresenta a formulação para cálculo da espessura da camada carbonatada segundo este modelo.

$$
e=k \sqrt{t}
$$

Onde,

$$
\left\{\begin{array}{l}
k=\text { Coeficiente de carbonatação }\left(\mathrm{m} / \mathrm{s}^{1 / 2}\right) \\
e=\text { Espessura da camada de concreto carbonatada }(\mathrm{m}) \\
t=\text { Tempo }(\mathrm{s})
\end{array}\right.
$$


De acordo com o fib Model Code (2010), a propagação de carbonatação na superfície de concreto é representada pela Equação 2.16.

$$
x_{c}=\sqrt{2 \times k_{e} \times k_{c} \times R_{N A C}^{-1} \times C S} \times \sqrt{t} \times W
$$

Onde,

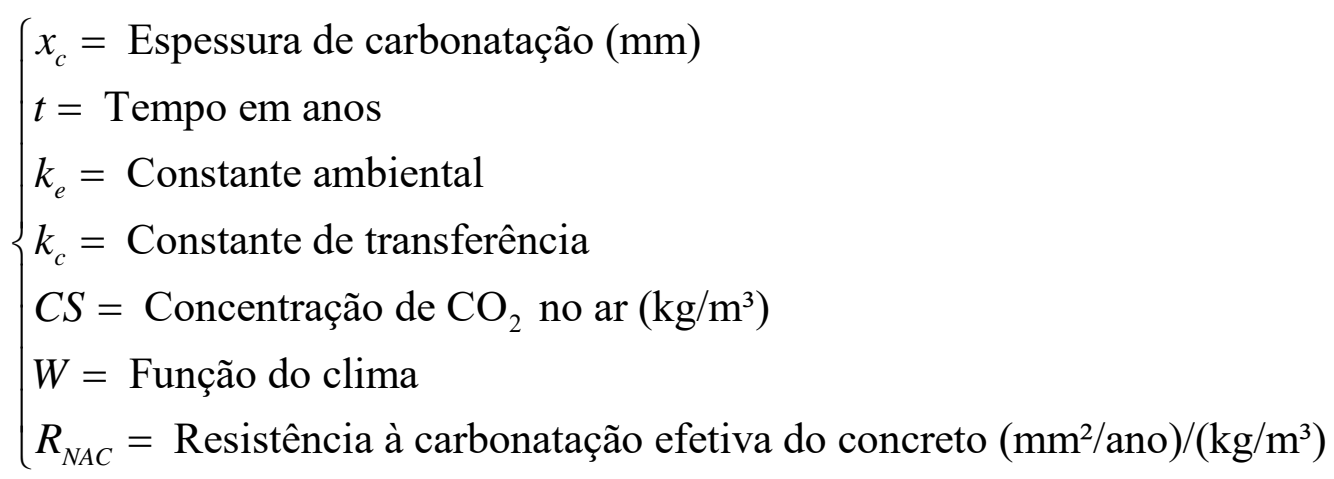

\subsubsection{Fatores que influenciam a carbonatação}

Os principais fatores que influenciam o processo de carbonatação são: presença de $\mathrm{CO}_{2}$ e a umidade relativa do meio. Em ambientes fechados, geralmente, a carbonatação é maior que em ambientes abertos, onde ocorre a circulação do ar (PAULETTI, 2004).

\subsection{Técnica para medir a resistividade elétrica}

De acordo com Sahuinco (2011), a resistividade do concreto é um parâmetro importante na avaliação da durabilidade da estrutura, uma vez que concretos com alta resistividade elétrica apresentam menor pré-disposição para a corrosão das armaduras. Mehta e Monteiro (2008) afirmam que uma vez removida a camada passivadora, serão a resistividade elétrica e a disponibilidade de oxigênio que controlarão a taxa de corrosão da armadura.

O ensaio consiste em medir-se a resistividade do concreto e avaliar o potencial de corrosão em função dos valores obtidos. A Figura 2.31 mostra um exemplo de aplicação do teste utilizando o equipamento RESIPOD. 
Figura 2.31 - Exemplo de estrutura submetida a ensaio para medir a resistividade elétrica

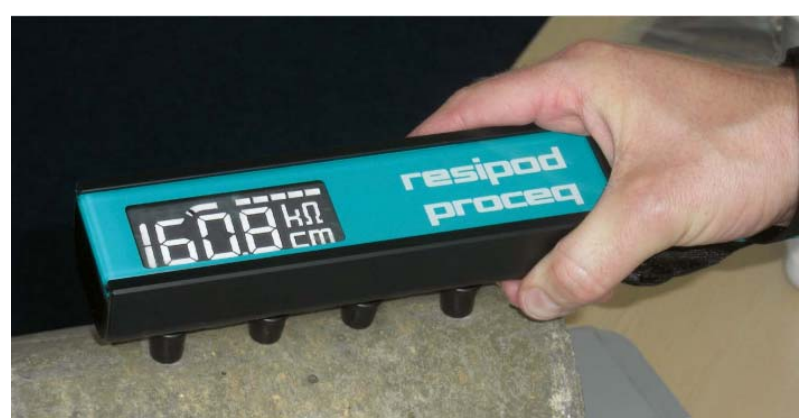

Fonte: PROCEQ (2017)

Cascudo (2005) afirma que existem duas formas para determinação da resistividade elétrica: o método de quatro eletrodos (método de Werner) e o método dos três eletrodos, que é o método adotado pela norma brasileira NBR 9204 (2012). O método de Werner é normalizado pela ASTM G57 (2012).

Abreu (1998) apresentou a Tabela 2.4 como critério proposto pelo CEB 192 (1989) para avaliação do resultado do ensaio para medir a resistividade elétrica no concreto. Para resistividades maiores que 200 Ohm.m, o risco de corrosão é desprezível, ao passo que para resistividades menores que 50 Ohm.m, o risco de corrosão é muito alto.

Tabela 2.4: Critério para avaliação do resultado do ensaio de resistividade segundo CEB 192 (1989)

\begin{tabular}{|c|c|}
\hline Resistividade elétrica (Ohm.m) & Risco de corrosão \\
\hline$>200$ & desprezível \\
\hline 100 a 200 & baixa \\
\hline 50 a 100 & alta \\
\hline$<50$ & muito alta \\
\hline
\end{tabular}

Fonte: ABREU (1998)

\subsubsection{Princípio físico}

De acordo com manual da PROCEQ (2017), através do método de Wenner, a resistividade elétrica é medida aplicando uma corrente às duas sondas nas extremidades do aparelho e medindo-se a diferença de potencial entre as sondas internas, conforme ilustra a Figura 2.32 
Figura 2.32 - Princípio de funcionamento através do método de Wenner

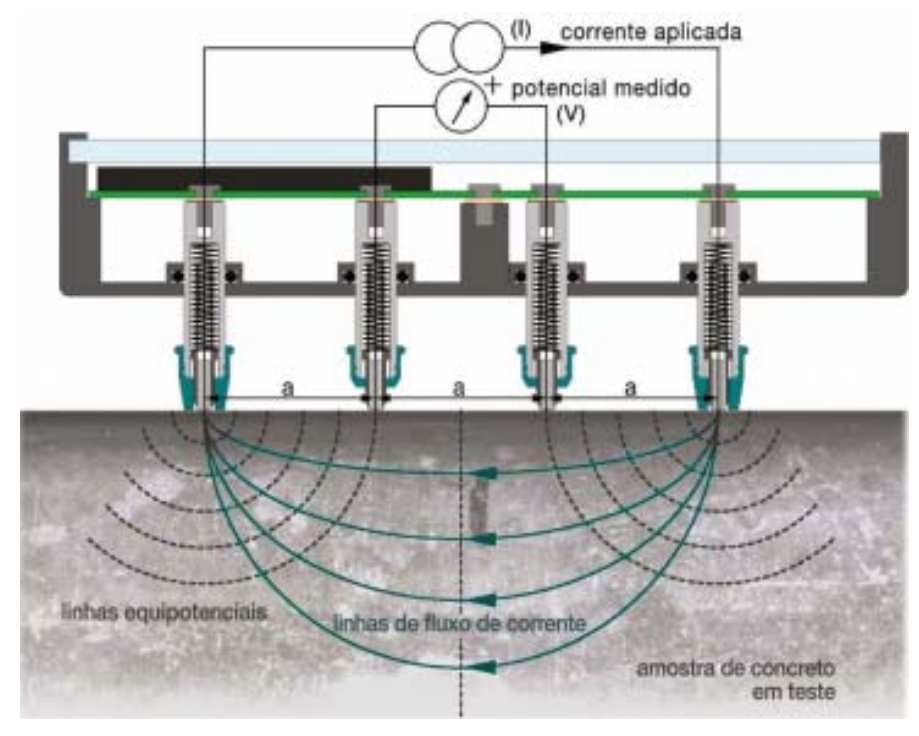

Fonte: PROCEQ (2017)

De acordo com Sahuinco (2011), a resistividade elétrica é uma grandeza que está relacionada com a resistência do material. Mais precisamente, a resistividade é a medida da oposição de um material ao fluxo de corrente elétrica. Quanto maior for a resistividade de um material, maior será a sua resistência e menor será a sua corrente. A relação entre diferença de potencial, corrente e resistência é dada pela lei de Ohm, conforme apresentada na Equação 2.17.

$$
I=\frac{V}{R}
$$

Onde,

$$
\left\{\begin{array}{l}
V=\text { Diferença de potencial }(\mathrm{V}) \\
\mathrm{I}=\text { Corrente }(\mathrm{A}) \\
\mathrm{R}=\operatorname{Resistência~}(\Omega)
\end{array}\right.
$$

A relação entre resistividade e resistência é apresentada na Equação 2.18.

$$
R=\frac{\rho \times L}{A}
$$


Onde,

$$
\left\{\begin{array}{l}
\rho=\text { Resistividade elétrica }(\Omega \cdot \mathrm{m}) \\
\mathrm{L}=\text { Comprimento da amostra }(\mathrm{m}) \\
\mathrm{R}=\text { Resistência elétrica }(\Omega) \\
\mathrm{A}=\text { Área da seção transversal da amostra }\left(\mathrm{m}^{2}\right)
\end{array}\right.
$$

\subsubsection{Fatores que influenciam a resistividade elétrica do concreto}

De acordo com a RILEM TC 154 (2003), entre os fatores que influenciam na resistividade elétrica do concreto estão: temperatura, umidade, teor de carbonatação, presença de íons agressivos.

Sahuinco (2011) afirma que a resistividade é inversamente proporcional ao aumento de temperatura. Desta forma, em temperaturas mais elevadas, a resistividade do concreto é menor.

De acordo com Lubeck (2008), o teor de umidade tem influência indireta na resistividade do concreto, alterando a estrutura da matriz dos poros e, consequentemente, a composição aquosa do meio, e assim influenciando a resistividade.

Hoppe (2005) afirma que a presença de íons agressivos no concreto, faz com que aumente a concentração iônica nos poros e, consequentemente, aumente sua condutividade e reduza a sua resistividade.

\subsection{Técnica para estimativa do teor de cloretos}

De acordo com Pereira e Cincotto (2001), a alta alcalinidade da camada de cobrimento das armaduras, com pH acima de 12, faz com que seja criada uma película de passivação do aço que o protege contra a corrosão. Na presença de cloretos, esta película é rompida. Quando o teor de cloretos livres no concreto atinge um certo limite, que é o teor limite do início da corrosão, inicia-se a corrosão eletroquímica.

Sahuinco (2011) afirma que os cloretos presentes em ambientes agressivos podem penetrar no concreto e atingir as barras de aço que compõem a estrutura do concreto armado, diminuindo o $\mathrm{pH}$ do concreto e rompendo a película passivadora 
que protegia o aço. Em presença de umidade e oxigênio, inicia-se um processo de corrosão eletroquímica.

A própria estrutura do concreto também contém cloretos. Cada componente do concreto pode contribuir com um dado teor de cloreto em sua estrutura e o teor global de cloreto depende da dosagem do concreto.

Em regiões tropicais como no Brasil, onde não existem sais de degelo, a principal fonte de cloretos é oriunda das águas dos mares ou das impurezas dos seus componentes (Pereira e Cincotto, 2001).

A NBR6118 (2014) enfatiza que não é permitido utilizar aditivos que contenham cloreto em sua composição.

\subsubsection{Métodos para estimativa do teor de cloretos}

Pereira e Cincotto (2001) afirmam que os principais métodos para estimativa do teor de cloretos em laboratório são aplicados por via úmida. Entre os principais métodos estão: gravimetria; titulometria; potenciometria e métodos microanalíticos.

De acordo com Pereira e Cincotto (2001), o método gravimétrico consiste em pesar a quantidade de cloreto de prata precipitado da solução de cloreto. Esse método não é adequado para baixos teores de cloreto como o que ocorre no concreto.

A titulometria, consiste na análise quantitativa, realizada através da determinação do volume de uma solução, de concentração conhecida, requerida para reagir quantitativamente com a solução da substância a ser determinada. A solução conhecida é denominada solução padrão e geralmente ela é adicionada com uma bureta até o ponto onde ocorre o término da titulação, denominado ponto de equivalência ou ponto final teórico. Este ponto final da titulação é determinado pela mudança visual do indicador, ao qual a solução está sendo titulada.

Pereira e Cincotto (2001) afirmam que o método de potenciometria consiste em medir a diferença de potencial entre dois eletrodos, sendo um eletrodo de referência, com potencial conhecido, e o outro eletrodo com potencial em função da concentração de íons cloreto.

A NBR 9917 (2009) descreve o método para a determinação do teor de cloretos. Internacionalmente as normas ASTM C 114 (2007) e ASTM C 1152 (2012) discorrem sobre o tema. 


\section{PROGRAMA EXPERIMENTAL}

\subsection{Descrição do programa experimental}

Para avaliação da aplicação de alguns ensaios não destrutivos e semidestrutivos, foram realizados quatro estudos de caso: dois estudos de caso em laboratório e dois estudos de caso em campo.

No primeiro estudo de caso em laboratório, foi realizado o ensaio não destrutivo utilizando o georadar GPR em uma viga de concreto armado, com características conhecidas, moldada no Laboratório de Investigações Não Destrutivas (LIND) da Faculdade de Engenharia Civil, Arquitetura e Urbanismo (FEC) da Universidade Estadual de Campinas (UNICAMP).

O segundo estudo de caso de laboratório foi realizado em uma parede de concreto armado, com características previamente conhecidas, moldada no Laboratório de Estruturas e Materiais Estruturais (LEM) da Escola Politécnica da USP. Foram aplicados os ensaios não destrutivos de: ultrassom (MIRA), pacometria e esclerometria.

O terceiro estudo de caso, realizado em campo, foi aplicado em uma ponte sobre Rio Guaíba, em Porto Alegre/RS. Com o intuito de avaliar a integridade entre a ligação das mãos francesas e das aduelas da ponte, foram feitos ensaios não destrutivos com ultrassom. Os resultados do ensaio foram fornecidos pelo DNIT/RS e no estudo de caso são apresentadas análises dos resultados, bem como estimativas de resistência.

O quarto estudo de caso, realizado em campo, foi aplicado na Ponte Eusébio Matoso, em São Paulo/SP. Com o intuito de fornecer melhores informações para avaliação da estrutura da ponte, foi realizado mapeamento da estrutura com laser scanner. Também foi aplicado o ensaio para avaliação do nível de carbonatação das estruturas da ponte.

\subsection{Estudo de caso 1: Ensaio com GPR em uma viga de concreto armado.}

O primeiro estudo de caso foi realizado no Laboratório de Investigações Não Destrutivas (LIND) da Faculdade de Engenharia Civil, Arquitetura e Urbanismo (FEC) da Universidade Estadual de Campinas (UNICAMP). Aplicou-se o ensaio não 
destrutivo com o equipamento GPR em uma viga de concreto armado. Esta viga está moldada no laboratório para fins experimentais, apresenta em seu interior barras de ferro, tubos de PVC e uma esfera de plástico vazia (bola de tênis de mesa).

\subsubsection{Características da viga de concreto ensaiada}

A Viga ensaiada apresenta largura de $21 \mathrm{~cm}$, comprimento de $85 \mathrm{~cm}$ e $16 \mathrm{~cm}$ de altura, de acordo com a Figura 3.1.

Figura 3.1 - Características geométricas da viga ensaiada

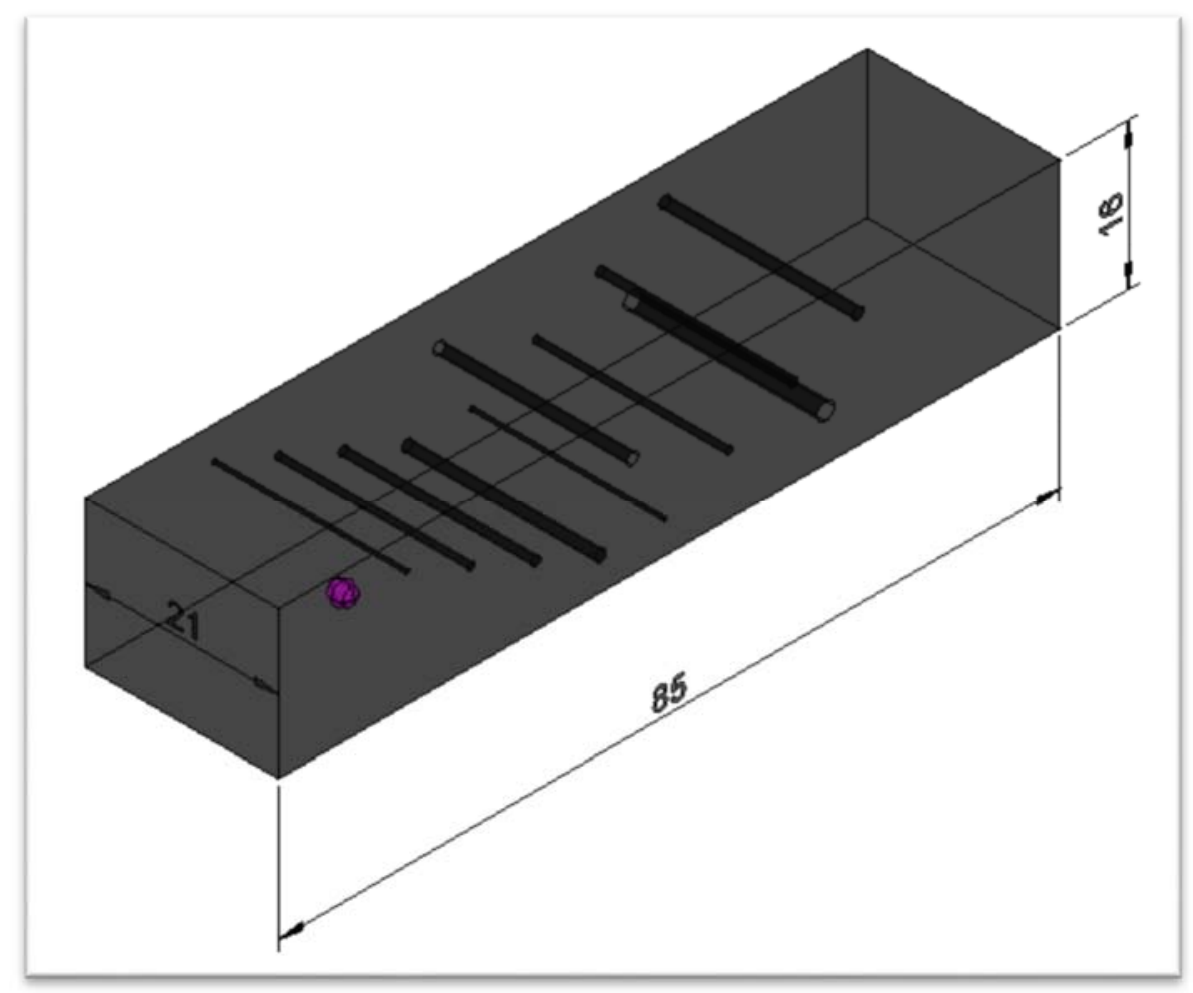

Fonte: Autoria própria.

O interior da viga apresenta 8 barras de ferro de diâmetros variando de $5 \mathrm{~mm}$ a 12,5 mm, 2 tubos de PVC (um de diâmetro de 0,75 polegadas e outro de 0,5 polegadas) e uma esfera de plástico de $25 \mathrm{~mm}$ de diâmetro (bola de tênis de mesa), conforme ilustra a Figura 3.2. 
Figura 3.2 - Elementos internos da viga ensaiada

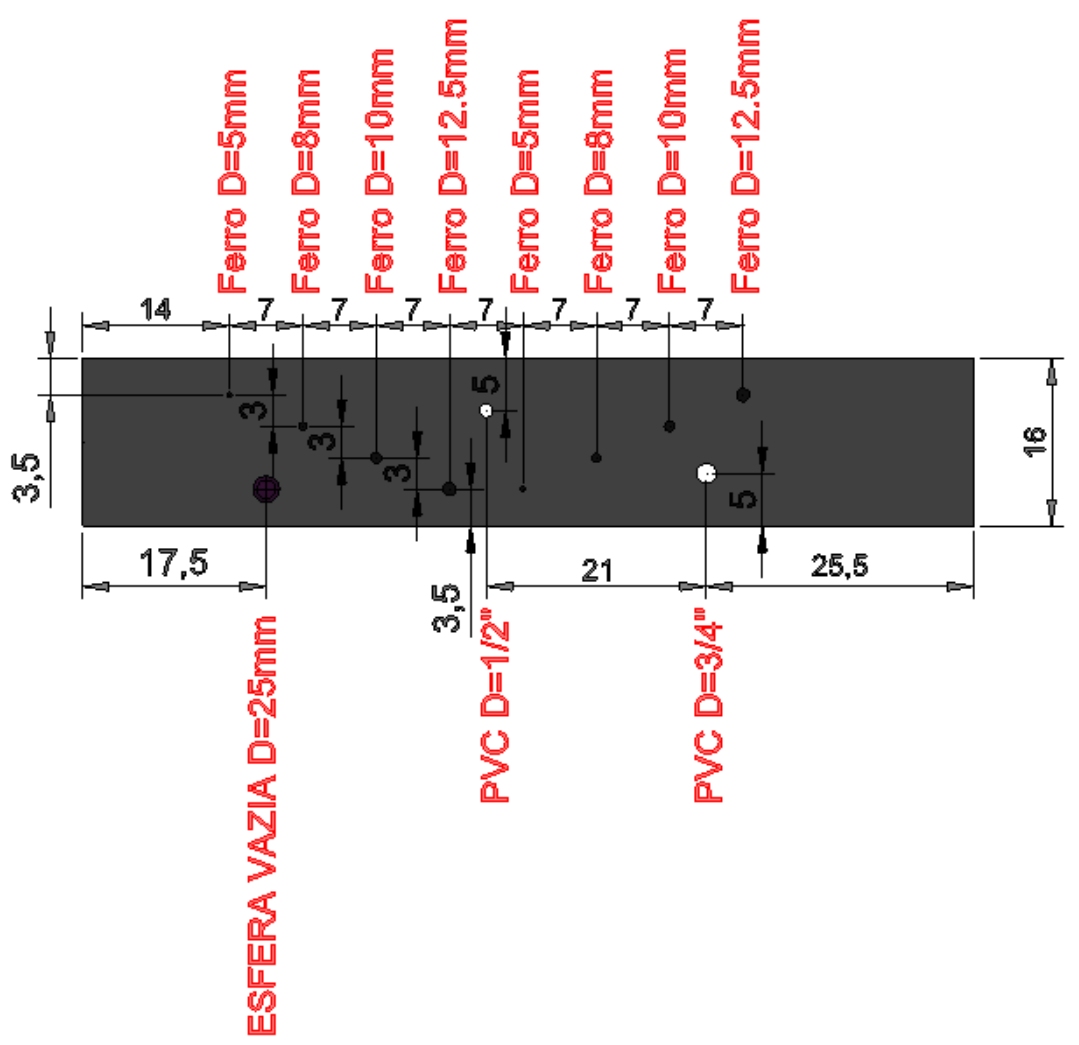

Fonte: Autoria própria.

A Figura 3.3 apresenta uma foto da viga tirada no dia do ensaio.

Figura 3.3 - Foto da viga ensaiada

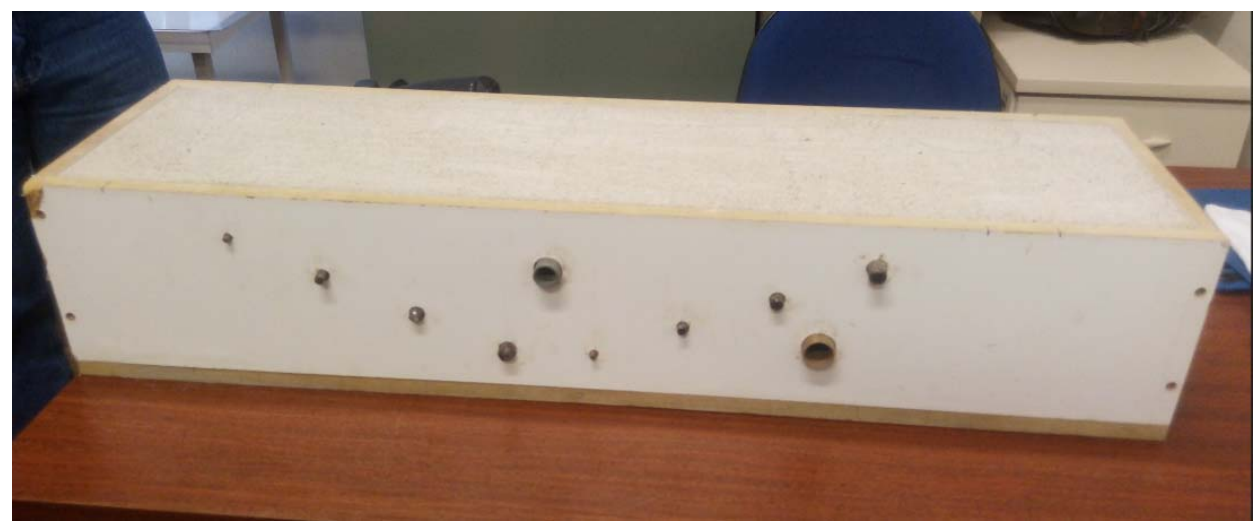

Fonte: Autoria própria. 


\subsubsection{Equipamentos utilizados}

Para aquisição de dados foi utilizado o equipamento comercial de GPR modelo SIR-3000 (antena de 1,6 GHz) da empresa Geophysical Survey Systems (GSSI), conforme ilustra a Figura 3.4. O equipamento é composto pela antena (fica acoplada a um carrinho para facilitar o ensaio), unidade de controle (onde o sinal é amplificado e armazenado), bateria e cabos de ligação, conforme apresenta a Figura 3.4.

Figura 3.4 - Equipamentos utilizados no ensaio

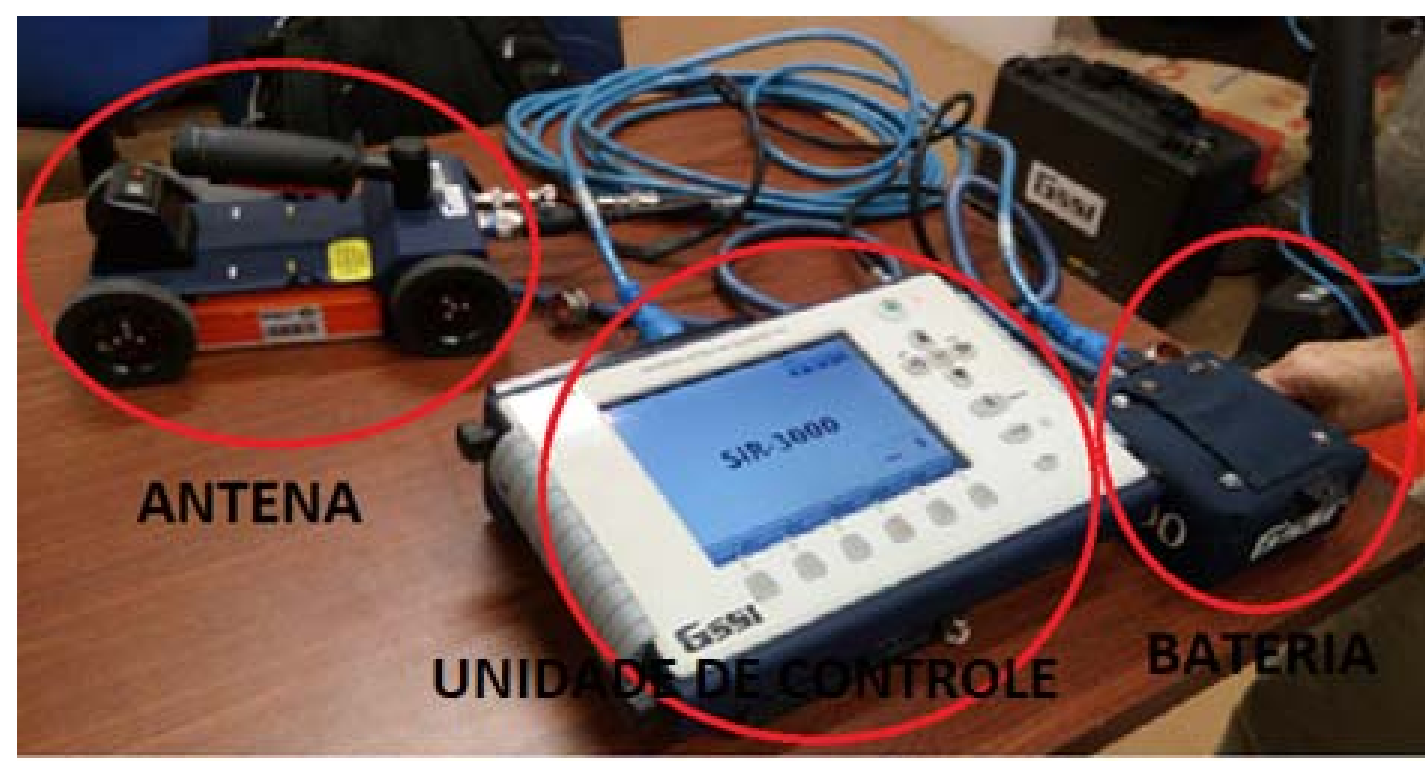

Fonte: Autoria própria.

\subsubsection{Metodologia de ensaio}

Primeiramente foram inseridos os dados de entrada na unidade de controle. Como dados de entrada para realização do ensaio, utilizou-se:

- Permissividade dielétrica relativa igual a 10

- Taxa de aquisição de dados igual a 800 traços por metro

- Janela temporal de 10 nanosegundos (ns).

Os dados foram coletados no modo denominado Struture Scan do equipamento comercial SIR3000 (GSSI, 2014), conforme ilustra Figura 3.5. 
Figura 3.5 - Entrada de dados no equipamento.

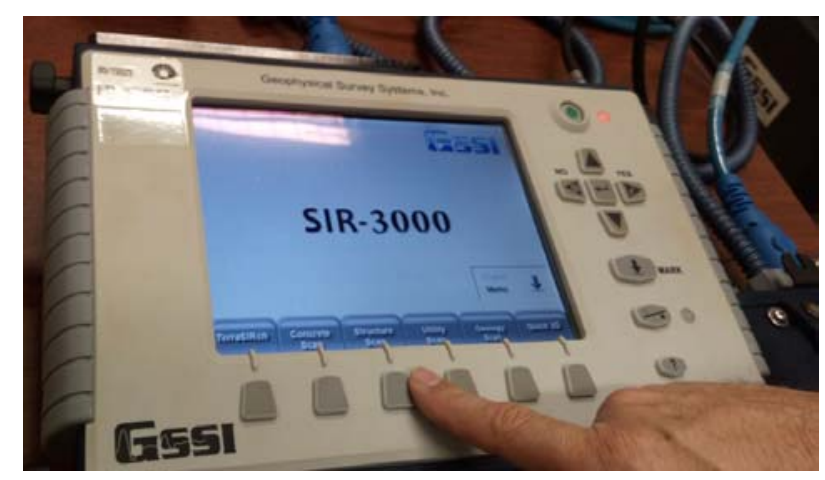

Fonte: Autoria própria.

A antena fica conectada à unidade de controle. O ensaio consiste em percorrer a viga com a antena, que fica acoplada a um carrinho para facilitar o ensaio, e registrar os dados obtidos, conforme ilustra a Figura 3.6.

Figura 3.6 - Antena percorrendo a viga durante o ensaio
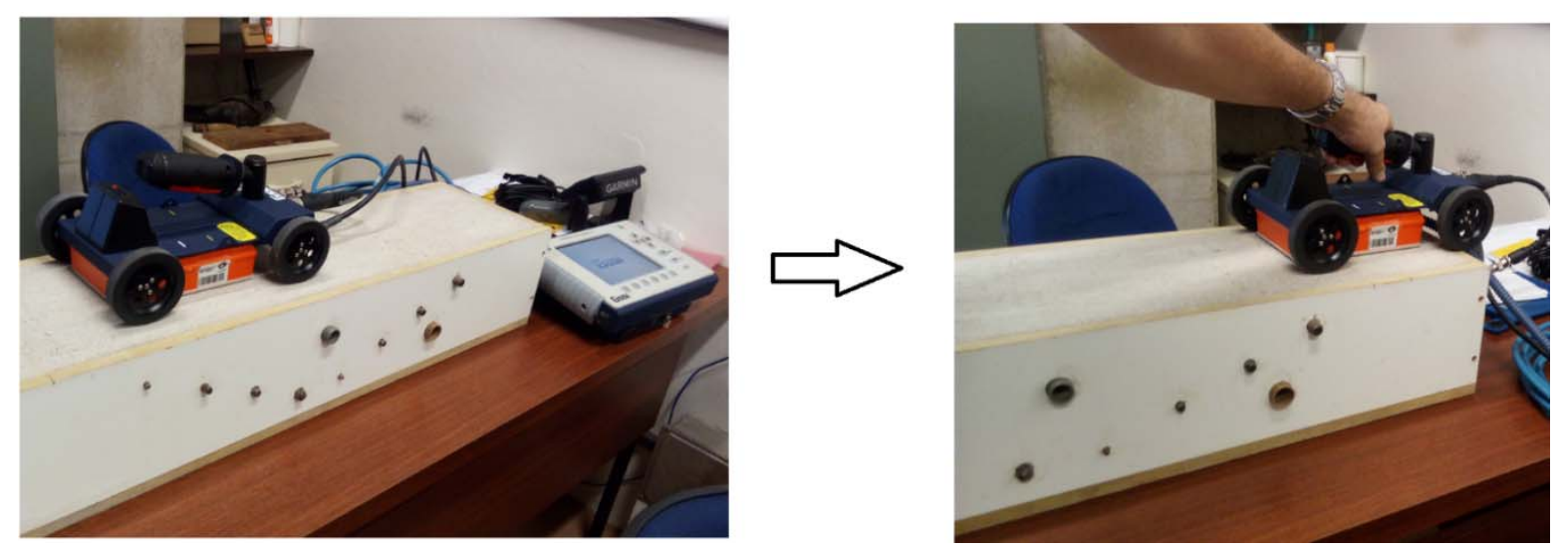

Fonte: Autoria própria.

Os dados coletados são enviados para a unidade de controle, onde o sinal é amplificado e armazenado, conforme ilustra a Figura 3.7. 
Figura 3.7 - Antena percorrendo a viga durante o ensaio e dados sendo amplificados e armazenados na unidade de controle

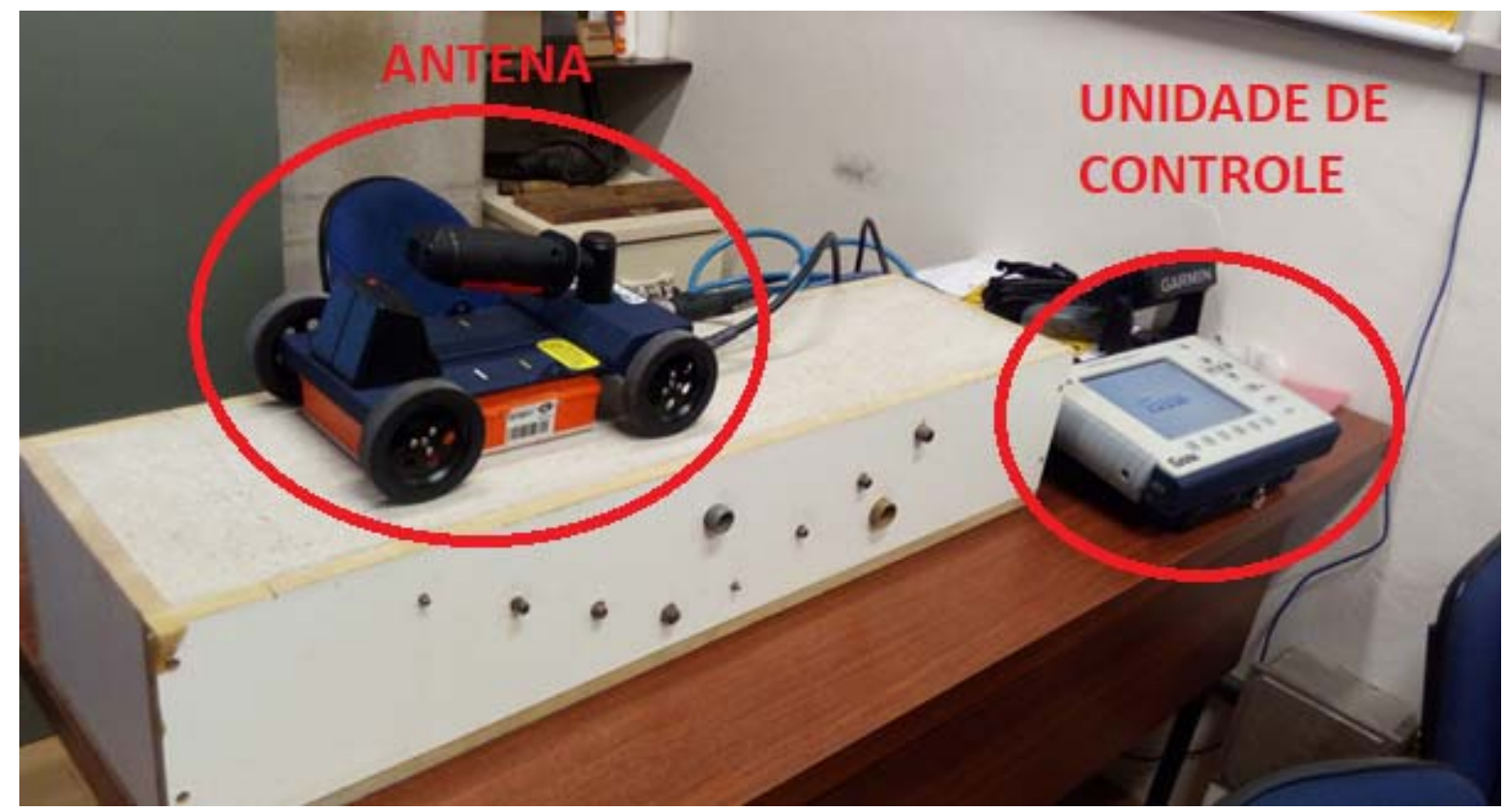

Fonte: Autoria própria.

Realizado o ensaio, os dados obtidos ficaram armazenados na unidade de controle. Estes dados foram transferidos para um computador e foram processados no programa REFLEXW (SANDMEIER, 2010). Como resultado deste processamento no programa, foram gerados os radargramas, que são apresentados nos resultados.

\subsubsection{Resultados e discussões}

Após aplicação do ensaio, os dados foram processados no software REFLEXW (SANDMEIER, 2010), onde foram aplicadas as seguintes operações: ajuste do tempo zero; corte do tempo e migração. Primeiramente os dados obtidos no ensaio foram importados para o software, obtendo-se a primeira imagem ainda sem tratamento, conforme ilustra a Figura 3.8. 
Figura 3.8 - Primeiro radargrama obtido ainda sem tratamento

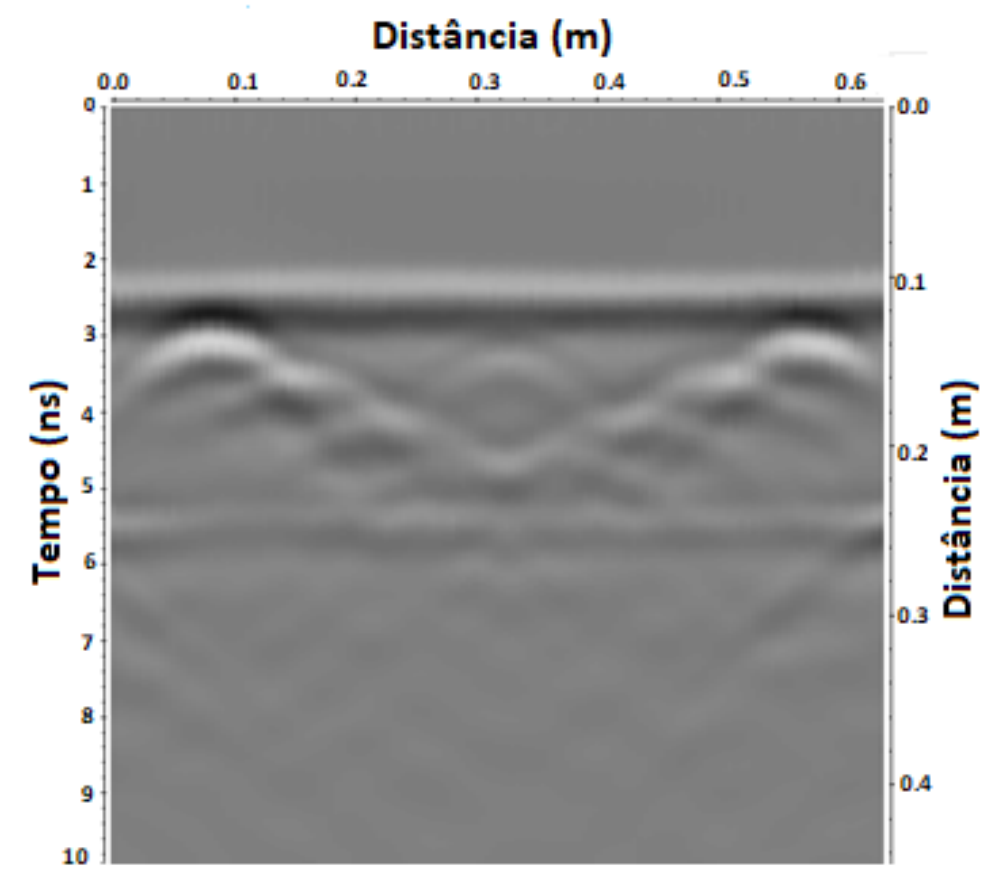

Fonte: Adaptado dos resultados obtidos no programa REFLEXW (SANDMEIER, 2010).

Depois de importados os dados no software, observou-se que o primeiro pico positivo da onda foi dado em aproximadamente 2,3 ns, conforme ilustra a Figura 3.9.

Figura 3.9 - Resposta em aproximadamente 2.3 ns

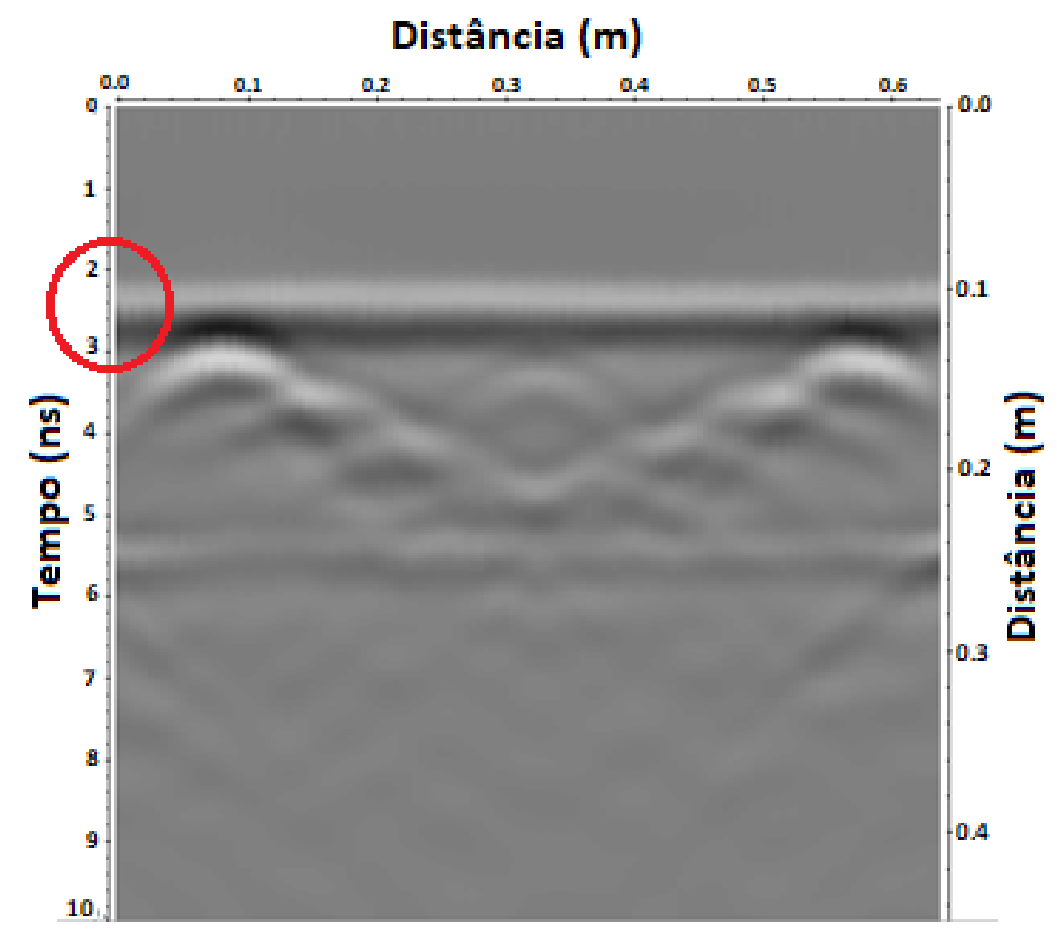

Fonte: Adaptado dos resultados obtidos no programa REFLEXW (SANDMEIER, 2010). 
Desta forma, alterou-se o tempo zero para -2,3 ns. A Figura 3.10 apresenta a imagem resultante após esta alteração do tempo zero.

Figura 3.10 - Resultado do radargrama após operação de alteração do tempo zero

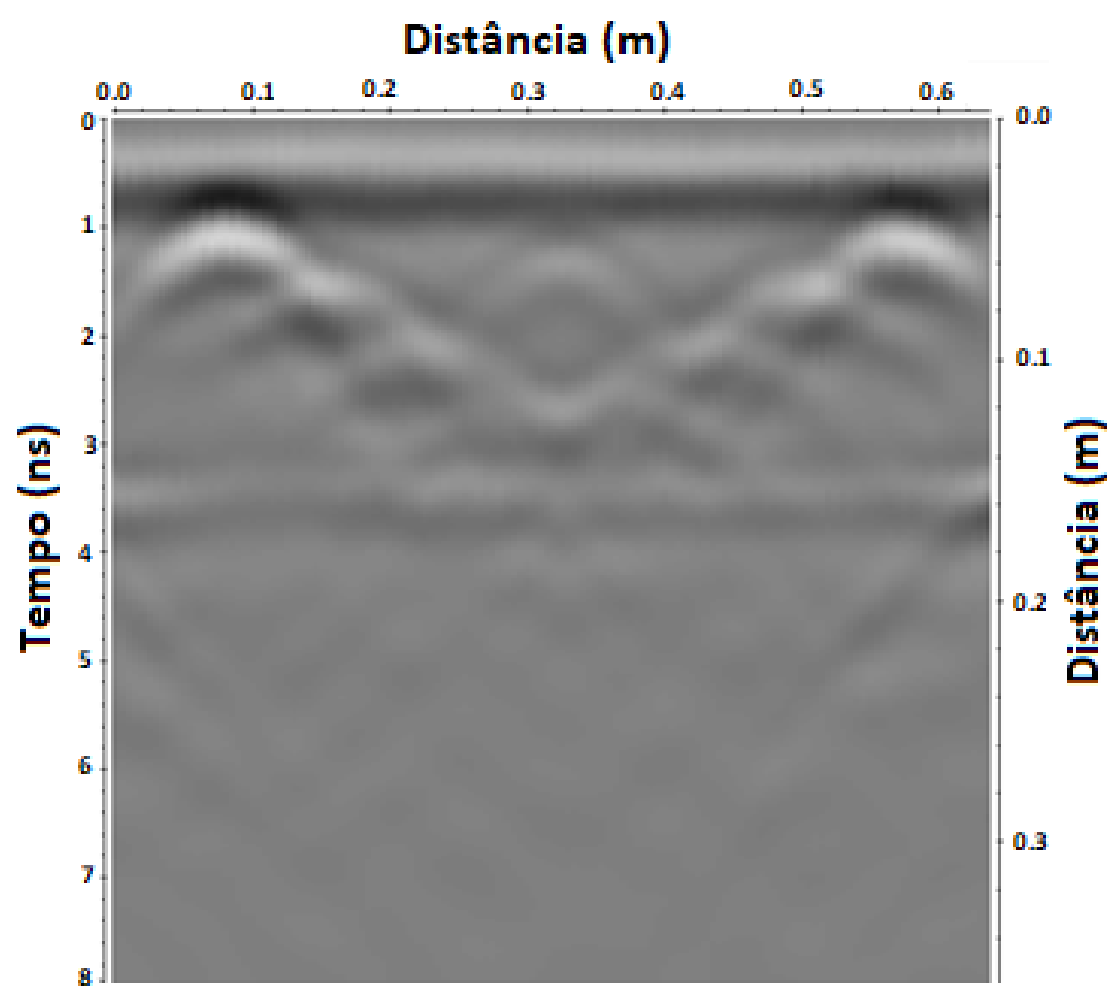

Fonte: Adaptado dos resultados obtidos no programa REFLEXW (SANDMEIER, 2010).

Depois de definido o tempo zero, foi feita a operação de "cortar o tempo". De forma análoga ao que foi feito no tempo zero, o tempo foi cortado no último pico positivo da onda, conforme ilustra a Figura 3.11. 
Figura 3.11 - Resultado do radargrama após operação de alteração do tempo zero

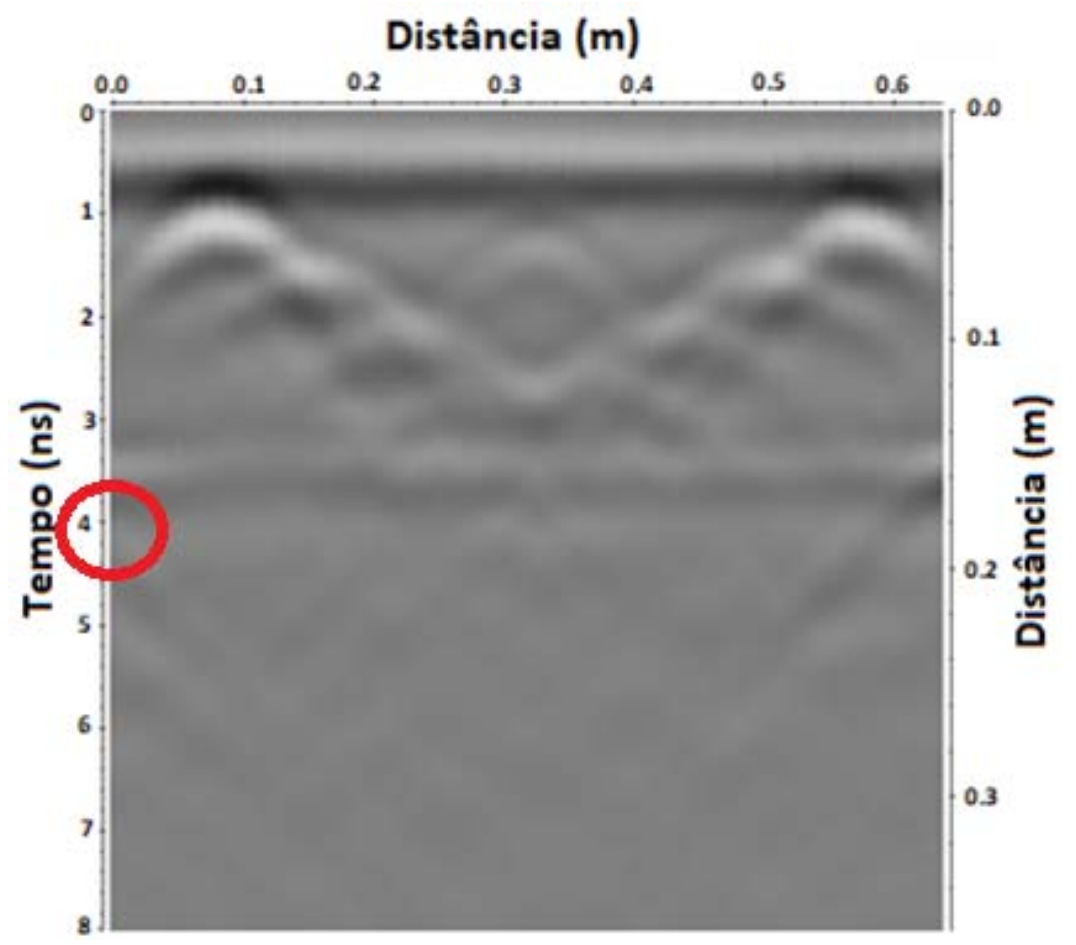

Fonte: Adaptado dos resultados obtidos no programa REFLEXW (SANDMEIER, 2010).

A Figura 3.12 ilustra a imagem resultante após a operação de "cortar o tempo"

Figura 3.12 - Resultado do radargrama após operação de "cortar o tempo"

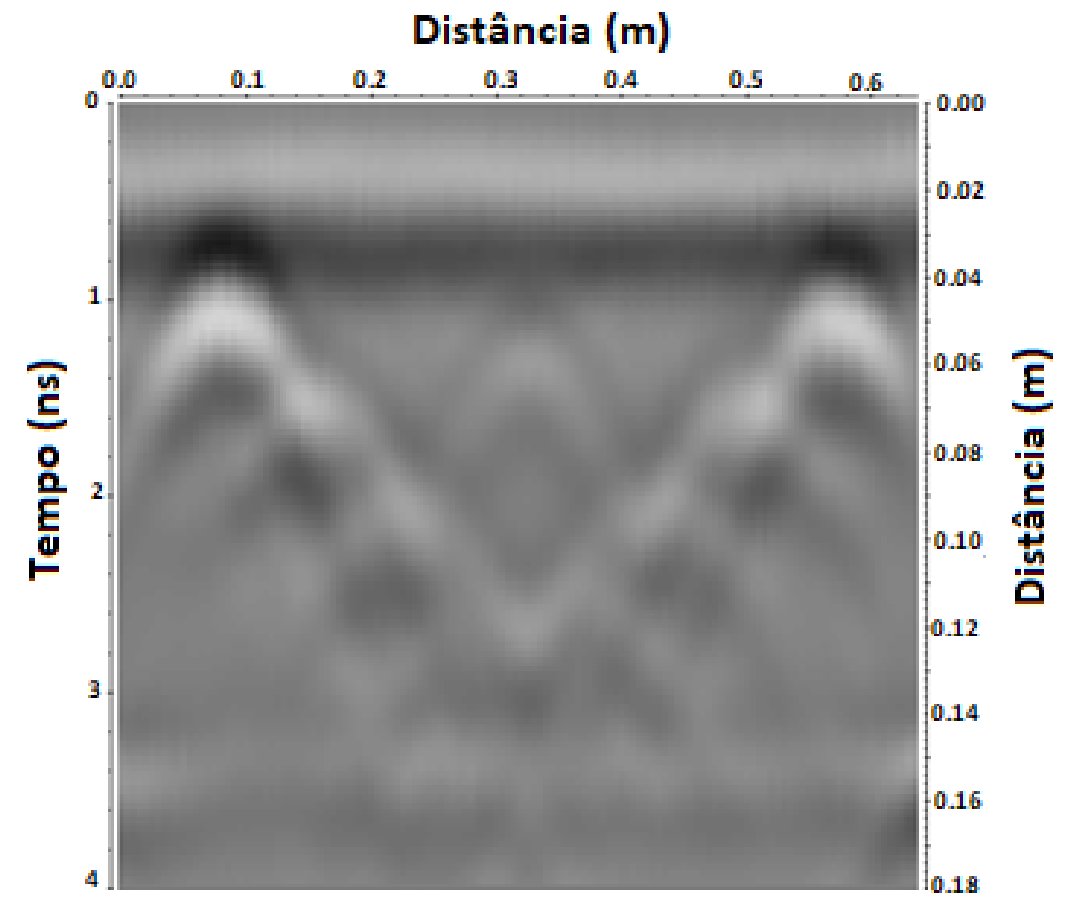

Fonte: Adaptado dos resultados obtidos no programa REFLEXW (SANDMEIER, 2010). 
A última etapa do processamento foi a operação de migração. Esta etapa é utilizada para melhorar a posição de alvos nas seções de GPR. O termo "migração" refere-se ao deslocamento dos alvos para a sua posição correta. Como resultado do processamento foi gerado o radargrama apresentado na Figura 3.13.

Figura 3.13 - Resultados obtidos no programa após operação de migração

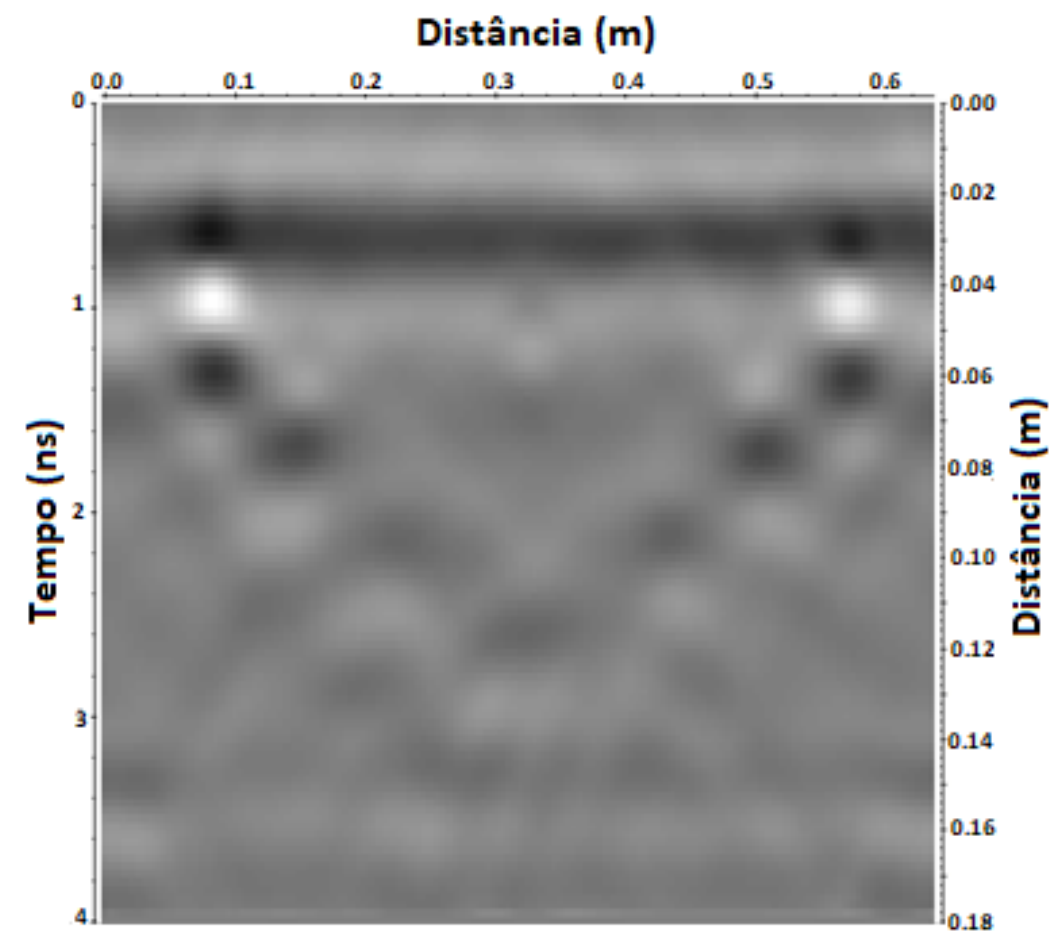

Fonte: Adaptado dos resultados obtidos no programa REFLEXW (SANDMEIER, 2010).

A partir do radargrama obtido após processamento dos resultados do ensaio no programa REFLEXW (SANDMEIER, 2010), locou-se as posições dos elementos que estão inseridos na viga e o fundo da mesma, conforme ilustra Figura 3.14. 
Figura 3.14 - Locação dos elementos inseridos na viga no radargrama

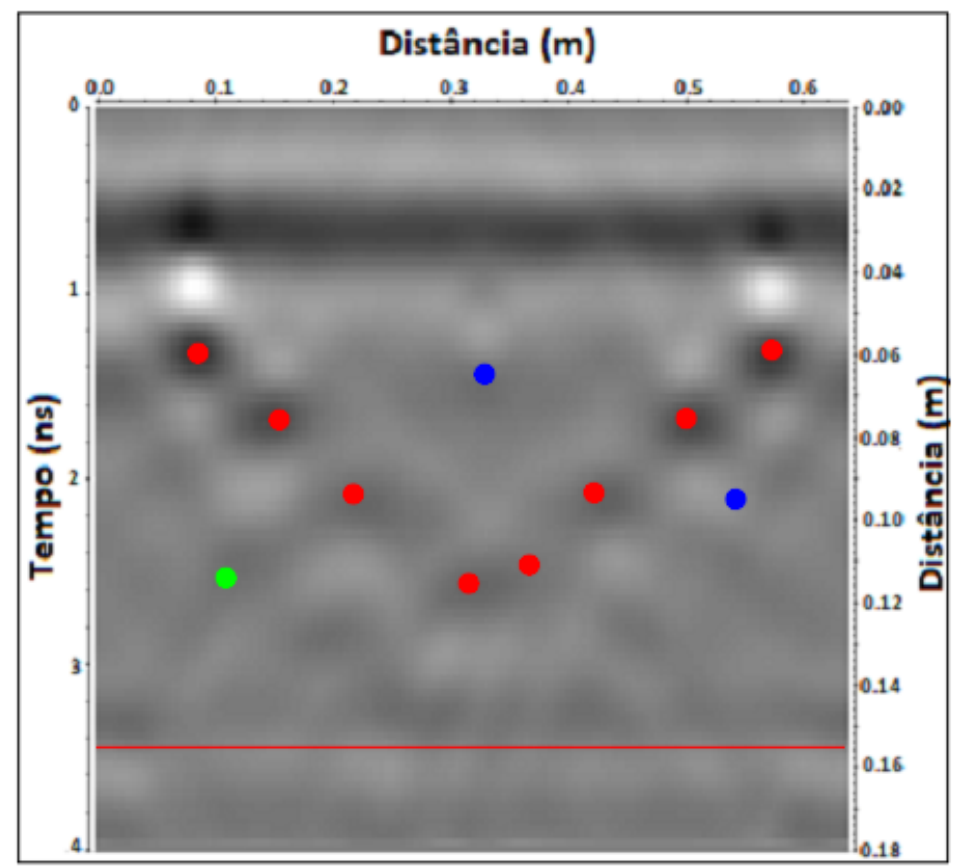

- FERRO

- PVC

- PLÁstico

Fonte: Adaptado dos resultados obtidos no programa REFLEXW (SANDMEIER, 2010).

Observa-se que a as barras de ferro refletem o pulso com maior intensidade se comprado aos tubos de PVC e à esfera de plástico. Isto ocorre pelo fato de os materiais terem propriedades elétricas (permissividade dielétrica, permeabilidade magnética e condutividade elétrica) distintas, refletindo o pulso de maneira distinta. No caso específico do concreto, de acordo com Kaplanvural, Peksen e Ozkap (2018), a permeabilididade magnética relativa é próxima de 1 , sendo o resultado dependente principalmente da permissividade dielétrica do alvo. O Ferro apresenta permissividade dielétrica na ordem de 10 vezes menor que a permissividade dielétrica do PVC. Quanto menor a permissividade, maior a velocidade da onda, conforme Equação 2.10, e maior a intensidade do sinal. Por este motivo as barras de ferro refletem o pulso com maior intensidade se comprado aos tubos de PVC e à esfera de plástico (bola de tênis de mesa).

Também é possível observar que as barras de ferro que estão mais próximas à superfície (e consequentemente da antena), refletem o pulso com maior intensidade se comparado às barras de ferro mais próximas do fundo da peça. Um dos fatores que contribuem para que isso ocorra é a atenuação do sinal ao longo do percurso. 
Observa-se que a reflexão do fundo da peça ocorre aproximadamente na cota $0,155 \mathrm{~m}$. A viga apresenta altura 0,16 m, indicando forte correlação entre o resultado do programa e a altura real.

\subsection{Estudo de caso 2: Ensaios de ultrassom (MIRA), pacometria e esclerometria em uma parede de concreto armado}

O segundo estudo de caso foi realizado no laboratório LEM da Escola Politécnica da USP. Foram aplicados, em uma parede de concreto armado, os seguintes ensaios não destrutivos: ultrassom (MIRA); pacometria e esclerometria.

\subsubsection{Características da parede de concreto ensaiada}

A parede apresenta altura de $150 \mathrm{~cm}$, largura de $50 \mathrm{~cm}$ e comprimento de 200 $\mathrm{cm}$, conforme ilustra a Figura 3.15 b. A parede apresenta um furo longitudinal de 9 $\mathrm{cm}$ de diâmetro, que atravessa a parede ao longo de todo comprimento, de acordo com a Figura 3.15 a.

Figura 3.15 - a) Detalhe furo b) - Vista isométrica da parede apresentando medidas
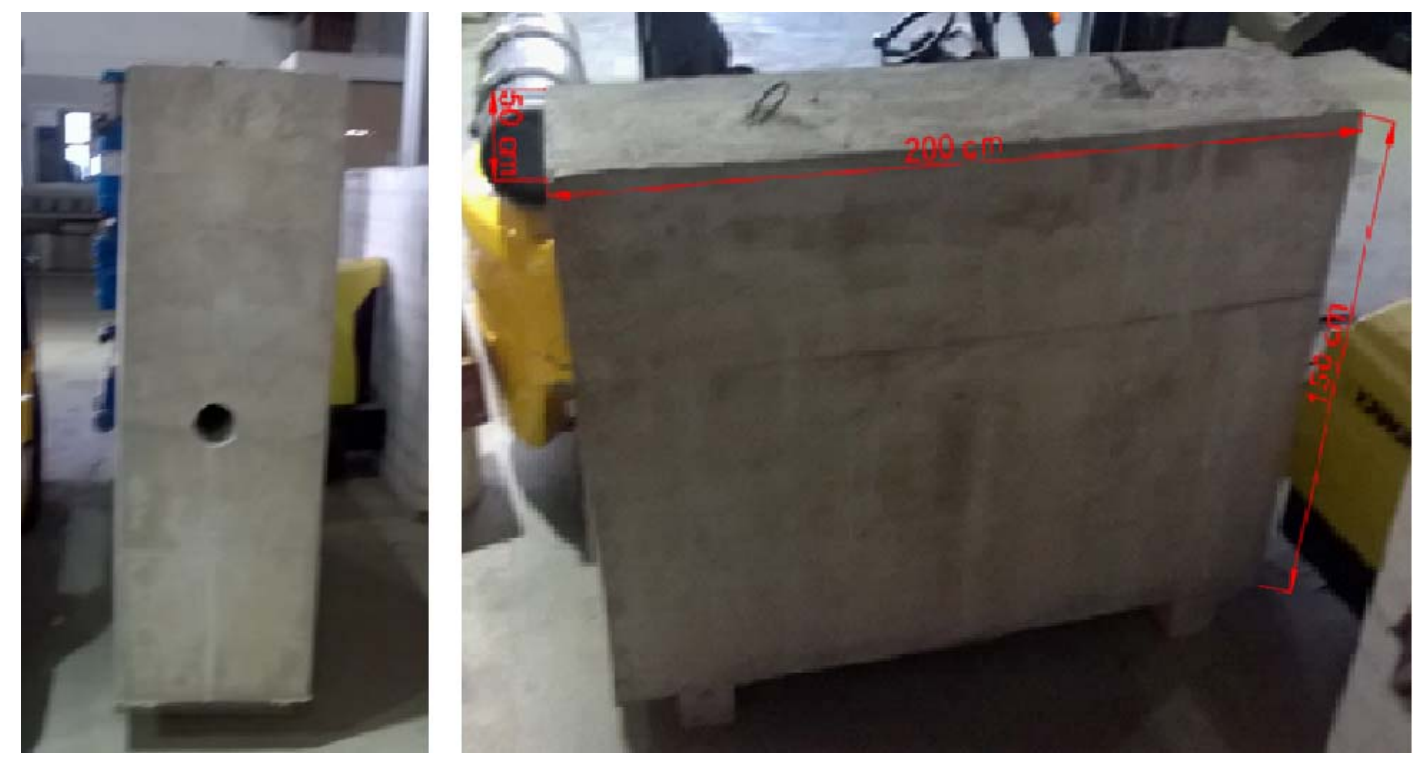

Fonte: Autoria própria.

A Figura 3.16 apresenta uma vista tridimensional da parede mostrando os elementos contidos em seu interior. Os elementos em magenta representam esferas de isopor de diâmetros variando entre $5 \mathrm{~cm}$ e $12,5 \mathrm{~cm}$. Os elementos em amarelo 
representam as barras de aço, que apresentam 12,5 mm de diâmetro. Uma das faces está com as barras espaçadas a cada $8 \mathrm{~cm}$ e a outra face a cada $12 \mathrm{~cm}$. O cobrimento das armaduras é de 4,5 cm. A Figura 3.17 apresenta a locação destes elementos.

Figura 3.16 - Vista isométrica com elementos

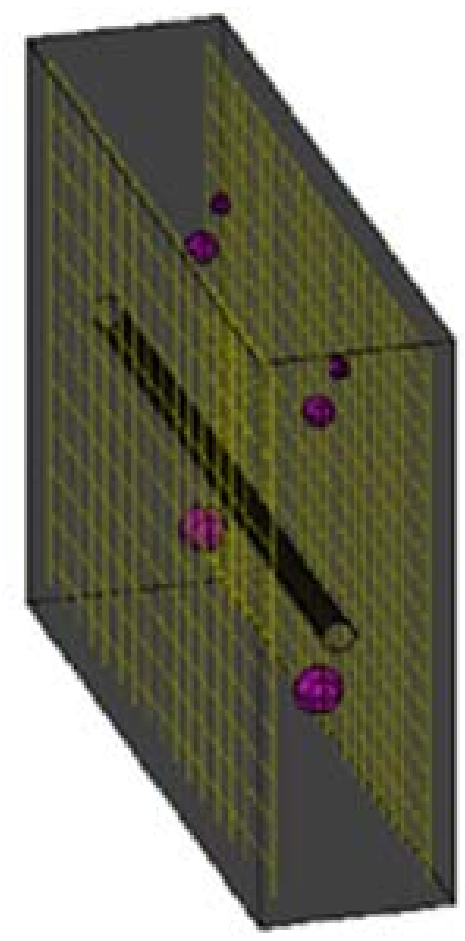

Fonte: Autoria própria.

Figura 3.17 - Locação dos elementos inseridos na parede

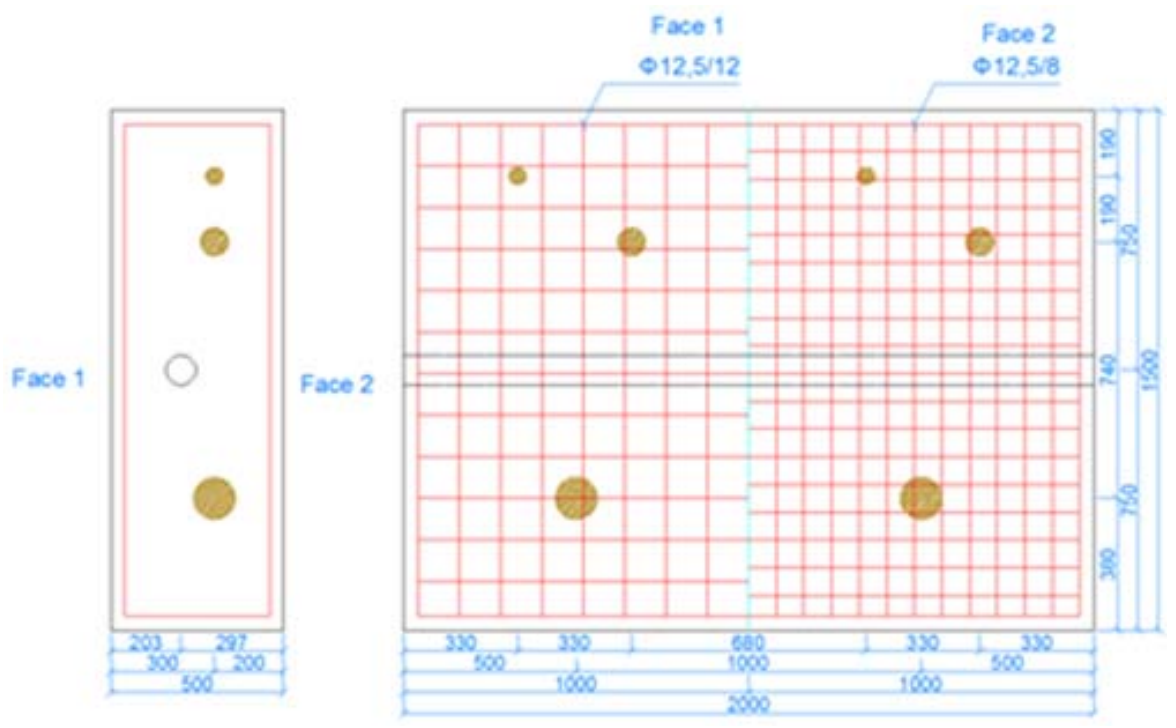

Fonte: GMEC (2018) 
O traço da parede ensaiada está apresentado na Tabela 3.1.

Tabela 3.1: Traço da parede ensaiada

\begin{tabular}{|l|c|}
\hline \multicolumn{2}{|c|}{ Traço - kg / $\mathrm{m}^{3}$} \\
\hline Cimento & 404 \\
\hline Brita 0 (Araça) & 864 \\
\hline Areia Quartzo (Dibloco) & 569 \\
\hline Areia artificial (Araça) & 410 \\
\hline Água & 182 \\
\hline Polifuncional & 2275 \\
\hline Hiperfluidificante & 4551 \\
\hline Massa Total & $2.435,0$ \\
\hline
\end{tabular}

Fonte: GMEC (2018)

$\mathrm{Na}$ Tabela 3.2 estão apresentados os valores do módulo de elasticidade, obtidos de acordo com a NBR 8522 (2017), e de resistência à compressão, obtidos segundo a NBR 5739 (2018), aplicando ensaios de compressão axial em corpos de prova que foram moldados juntamente com a concretagem da parede. O valor médio da resistência à compressão apresentado foi de 74,7 MPa e o valor médio do módulo de elasticidade apresentado foi de 37,5 MPa. Estes valores são comparados com os valores do módulo de elasticidade e da resistência à compressão estimados nos ensaios realizados.

Tabela 3.2: Resultados de resistência à compressão e do módulo de elasticidade obtidos em ensaio de compressão axial e de determinação dos módulos estáticos de elasticidade, respectivamente.

\begin{tabular}{|c|c|c|}
\hline Nomenclatura & Resistência compressão & Módulo de elasticidade \\
\hline (caminhão 1_-ou 2_) & (MPa) & (GPa) \\
\hline CP $1\left(2_{-}^{0}\right)$ & 72 & - \\
\hline CP $2\left(2_{-}^{0}\right)$ & 71.4 & - \\
\hline CP $3\left(2_{-}^{0}\right)$ & 81.9 & 37.3 \\
\hline CP $4\left(2_{-}^{0}\right)$ & 75.8 & 36.6 \\
\hline CP $5\left(2_{-}^{0}\right)$ & 76.1 & 37.5 \\
\hline CP $6\left(2_{-}^{0}\right)$ & 79.4 & 37.3 \\
\hline $\mathrm{CP} 7\left(2_{-}^{0}\right)$ & 71.6 & 37.3 \\
\hline CP $8\left(2_{-}^{0}\right)$ & 69.6 & 38.7 \\
\hline Média & 74.7 & 37.5 \\
\hline Desvio Padrão & 4 & 0.6 \\
\hline Coef. De Variação & $5.40 \%$ & $1.70 \%$ \\
\hline
\end{tabular}

Fonte: GMEC (2018) 
3.3.2. Ensaio de ultrassom com Tomógrafo MIRA

\subsubsection{Equipamentos utilizados}

O equipamento utilizado para realizar o ensaio foi o tomógrafo MIRA de segunda geração. Uma imagem do equipamento é apresentada na Figura 3.18.

Figura 3.18 - Ultrassom MIRA
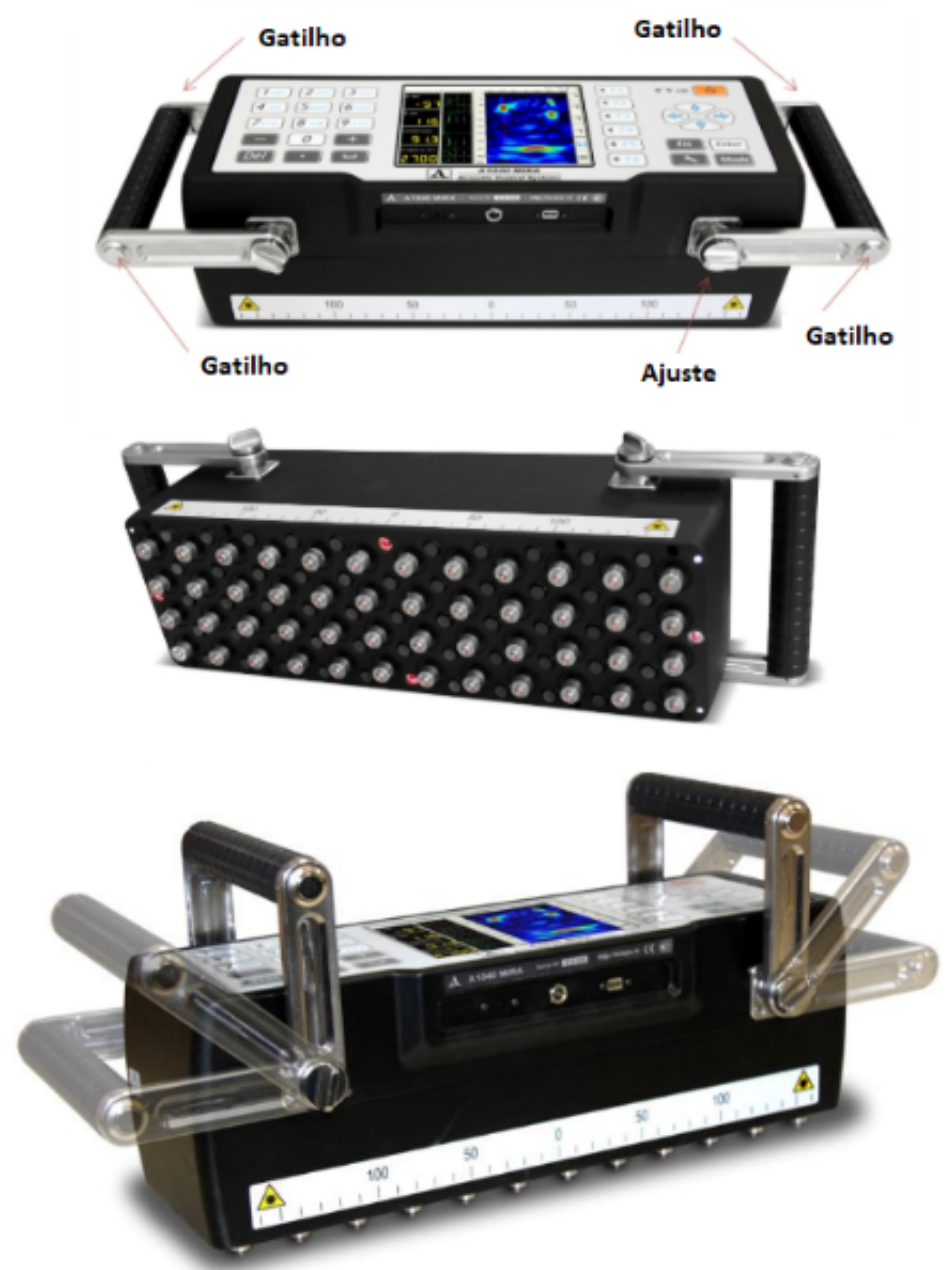

Fonte: (GERMANN INSTRUMENTS, 2012)

\subsubsection{Metodologia de ensaio}

Primeiramente foram inseridos os dados de entrada no equipamento, conforme ilustra a Figura 3.19. Como dados de entrada para realização do ensaio, utilizou-se:

- Frequência de operação $\rightarrow 50$ kHz 
- Ganho de cor $\rightarrow 22 \mathrm{~dB}$

- Ganho analógico $\rightarrow 43 \mathrm{~dB}$

- Número de períodos $\rightarrow 1$

- Pausa entre pulsos emissores $\rightarrow$ Não

- Medição de velocidade $\rightarrow \operatorname{Sim}$

- Qualidade da imagem $\rightarrow$ Mediana

Figura 3.19 - Inserção de dados de entrada no equipamento

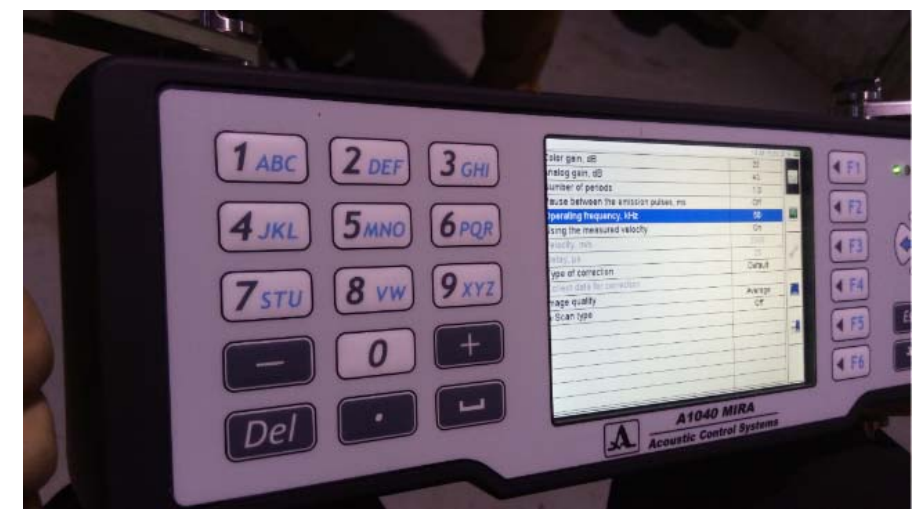

Fonte: Autoria própria

A frequência de operação utilizada foi de $50 \mathrm{kHz}$. De acordo com Vancura et al. (2013), ensaios na faixa de $50 \mathrm{kHz}$ permitem que o sinal transite no concreto, mesmo com suas características heterogêneas. Também foi habilitado o campo para medir a velocidade da onda de cisalhamento, que é utilizada para estimar o valor do módulo de elasticidade.

Depois de inserir os dados de entrada no equipamento, iniciou-se o ensaio nos pontos de interesse. De acordo com Choi et. al. (2016), não existe a necessidade de utilização de gel acoplante para realização dos ensaios, uma vez que os transdutores são de contato a seco.

Para obter a imagem $2 \mathrm{~d}$ nos diversos pontos ensaiados, deve-se pressionar o equipamento contra a superfície e apertar os gatilhos que ficam na alça do equipamento com os polegares direito e esquerdo para gravar a imagem, conforme ilustra a Figura 3.20. Após gravada a imagem, é possível editar o nome da imagem e organizar em pastas no equipamento, facilitando a organização dos resultados. 
Figura 3.20 - Aplicação do ensaio

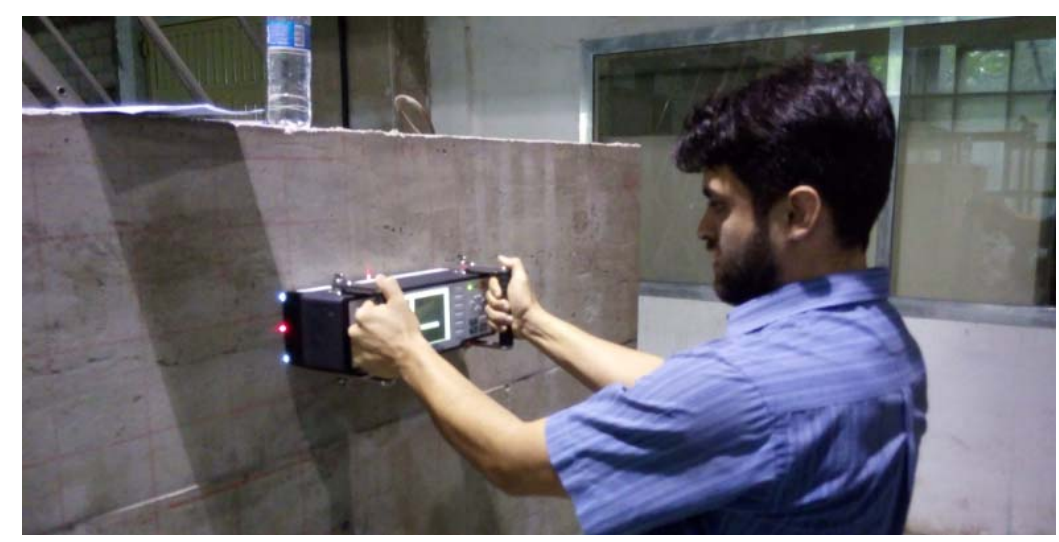

Fonte: Autoria própria

Através deste procedimento, foi realizado o ensaio com o equipamento centrado em diversos pontos da parede, espaçados a cada $25 \mathrm{~cm}$, conforme ilustra a Figura 3.21. A face de aplicação do ensaio foi a face 2, de acordo com a Figura 3.17.

Figura 3.21 - Pontos ensaiados espaçados a cada $25 \mathrm{~cm}$

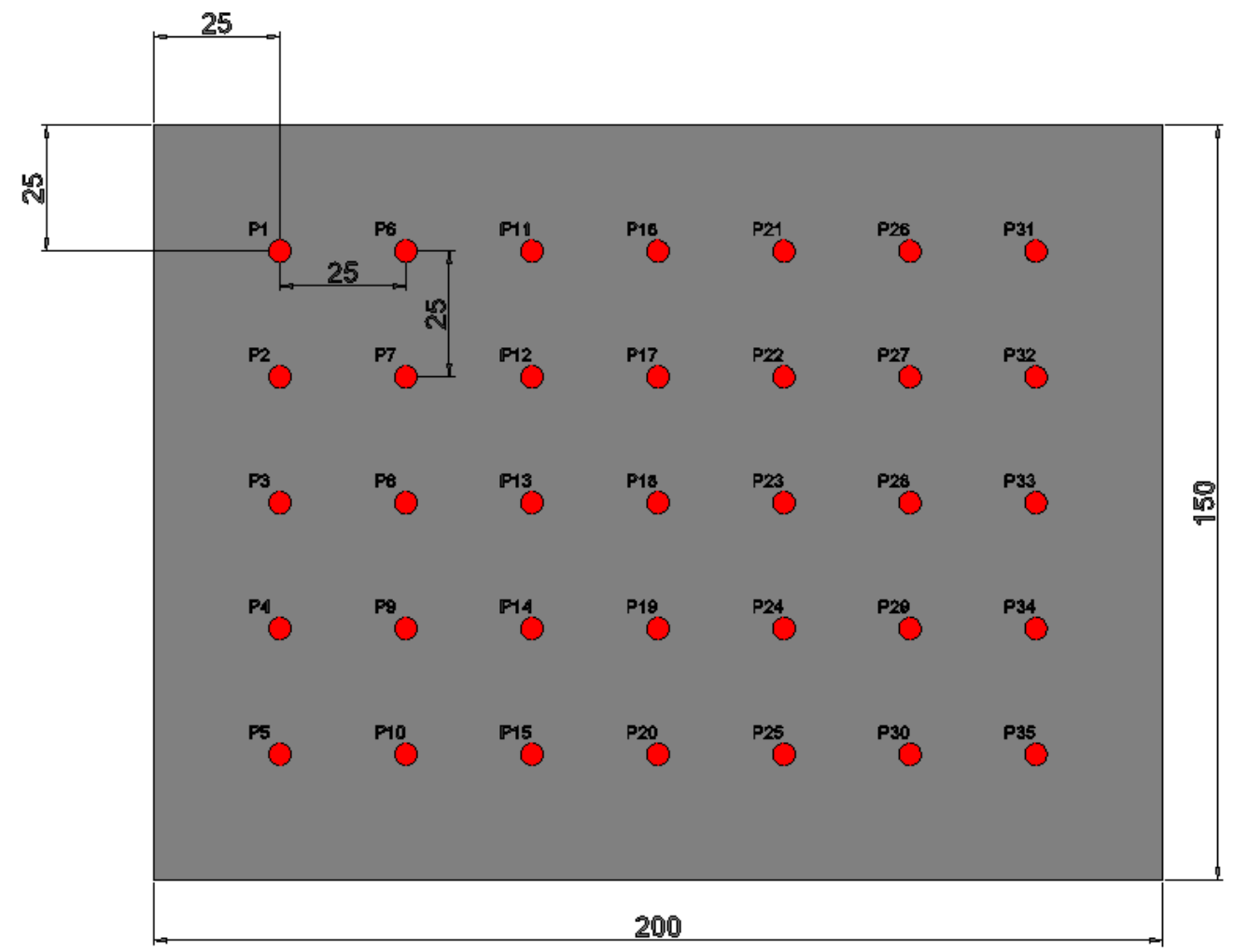

Fonte: Autoria própria 


\subsubsection{Resultados e discussões}

Depois de realizado o ensaio nos 35 pontos de interesse, as imagens gravadas no equipamento foram copiadas em um notebook. Cada ponto foi ensaiado duas vezes durante o ensaio. Como os resultados foram muito similares para cada ponto, é apresentado apenas 1 resultado por ponto.

Antes de apresentar os resultados, destaca-se que as imagens geradas pelo equipamento foram obtidas no modo B-scan. Neste modo, a imagem é gerada no ponto médio da altura do equipamento ao longo de seu comprimento, conforme ilustra a Figura 3.22. Analisando a Figura 3.20, que apresenta o momento da aplicação do ensaio em uma região da parede, observa-se que no momento em que o gatilho é apertado, uma luz vermelha se acende exatamente no ponto médio do equipamento.

Figura 3.22 - Localização da imagem gerada pelo equipamento
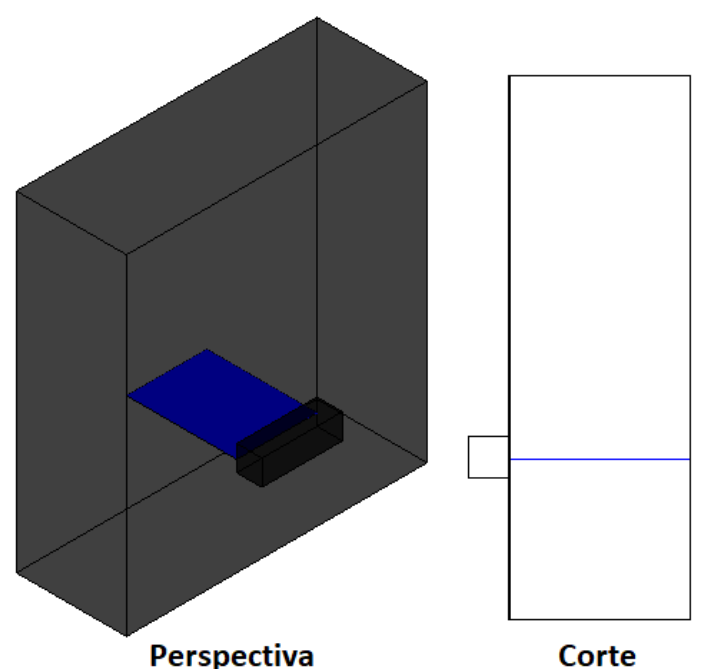

Fonte: Autoria própria

Os resultados obtidos nos 35 pontos estão apresentados da Figura 3.23 a Figura 3.28. 
Figura 3.23 - Resultado do ultrassom MIRA para os pontos 1 a 6
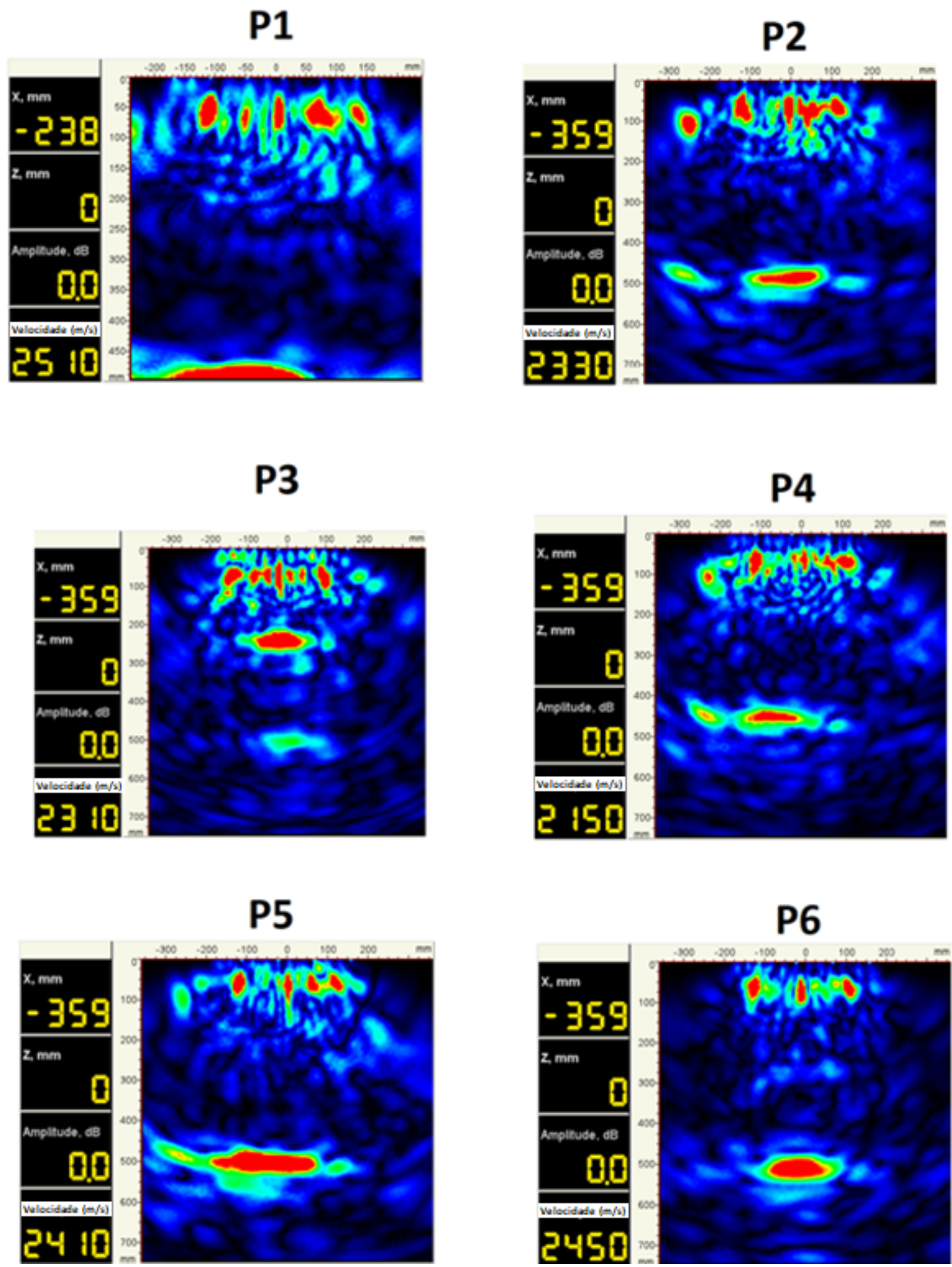

Fonte: Adaptado dos resultados obtidos no programa MIRA (GERMANN INSTRUMENTS, 2012). 
Figura 3.24 - Resultado do ultrassom MIRA para os pontos 7 a 12

P7

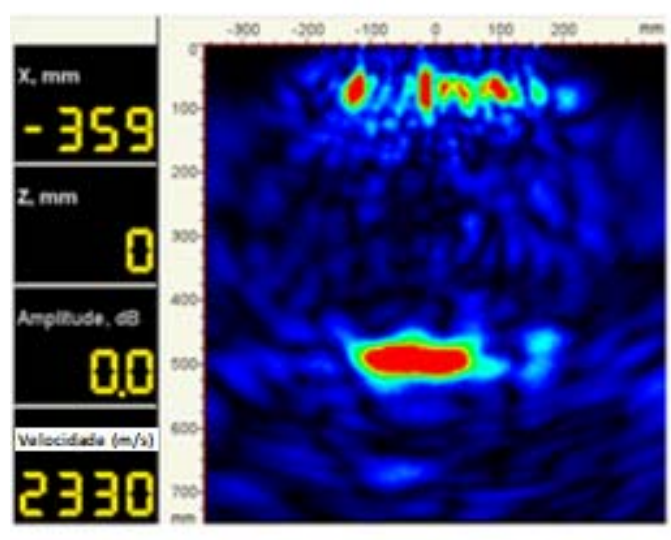

P9

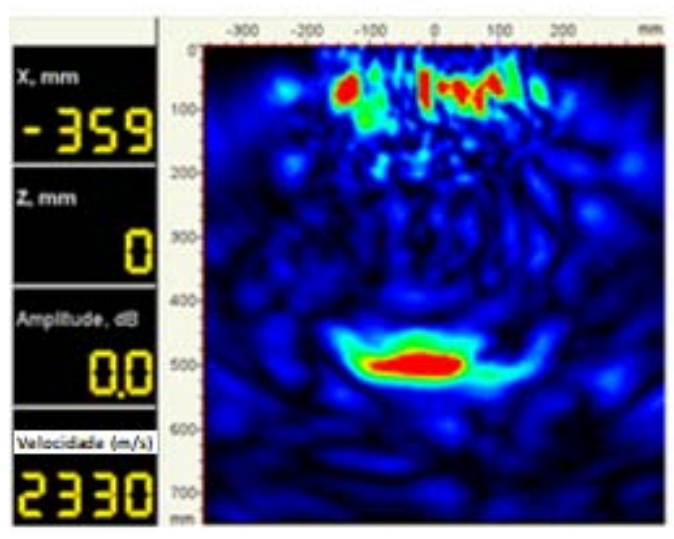

P11

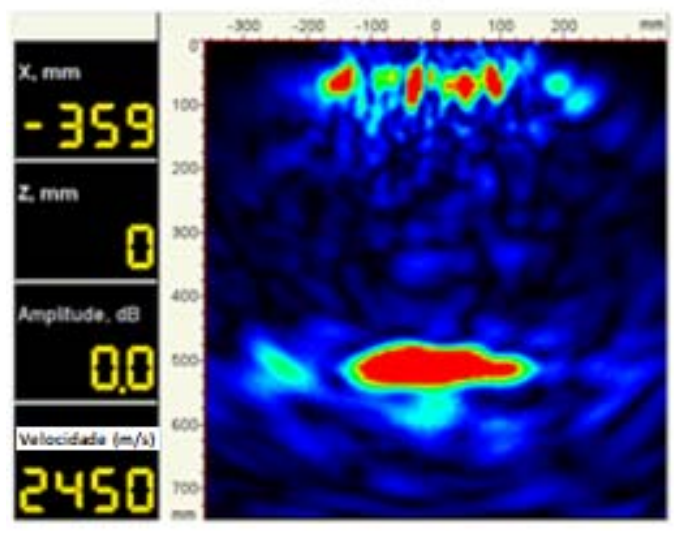

P8

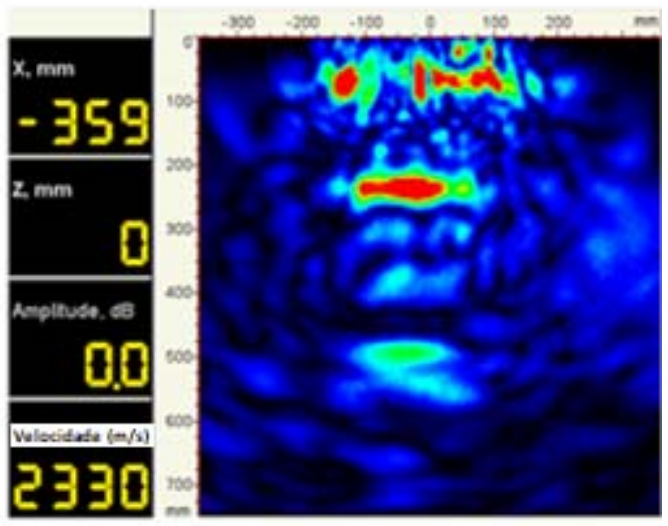

P10

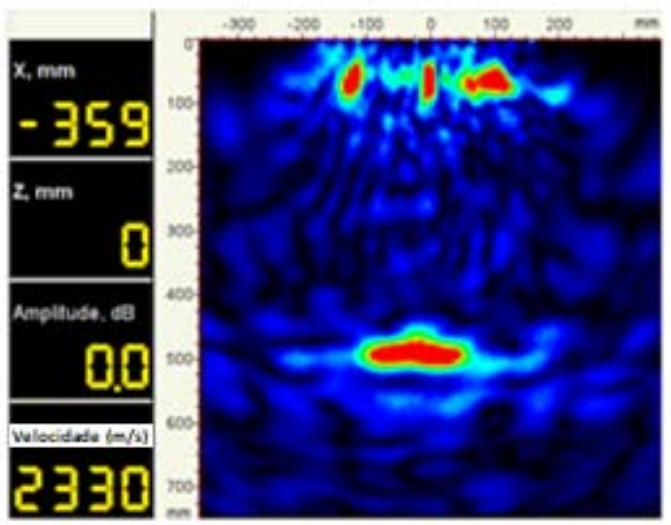

P12

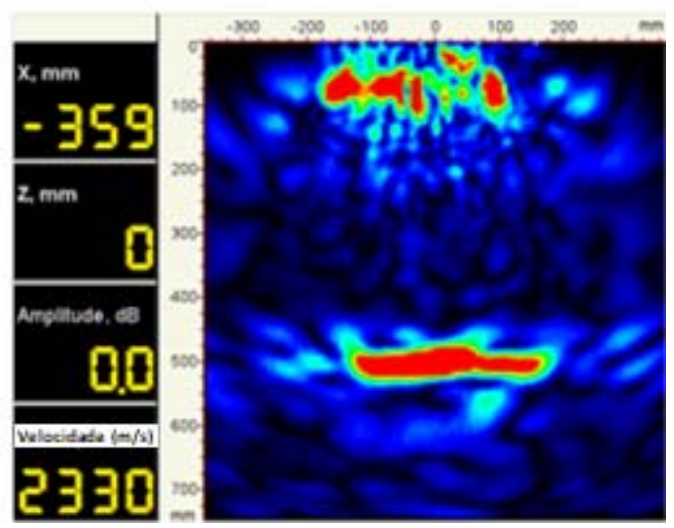

Fonte: Adaptado dos resultados obtidos no programa MIRA (GERMANN INSTRUMENTS, 2012). 
Figura 3.25 - Resultado do ultrassom MIRA para os pontos 13 a 18

\section{P13}

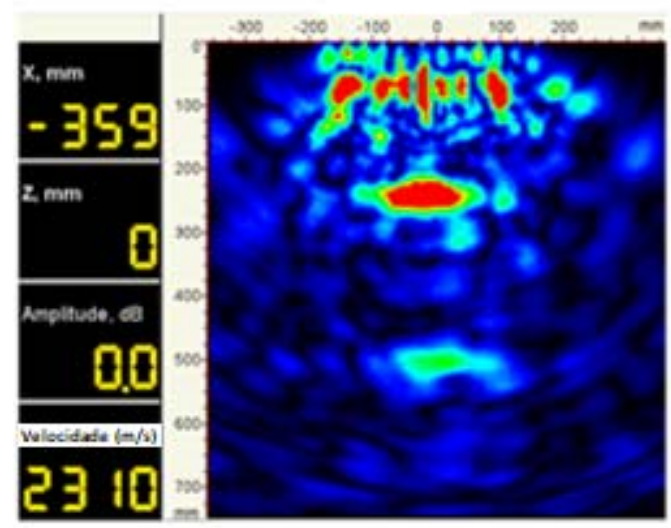

P15

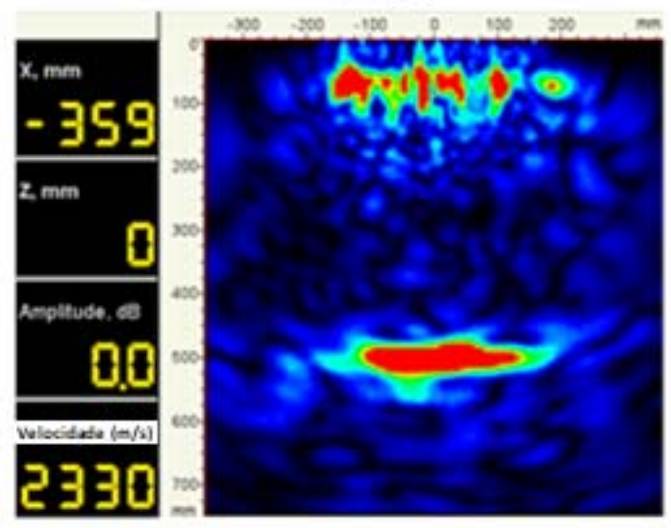

P17

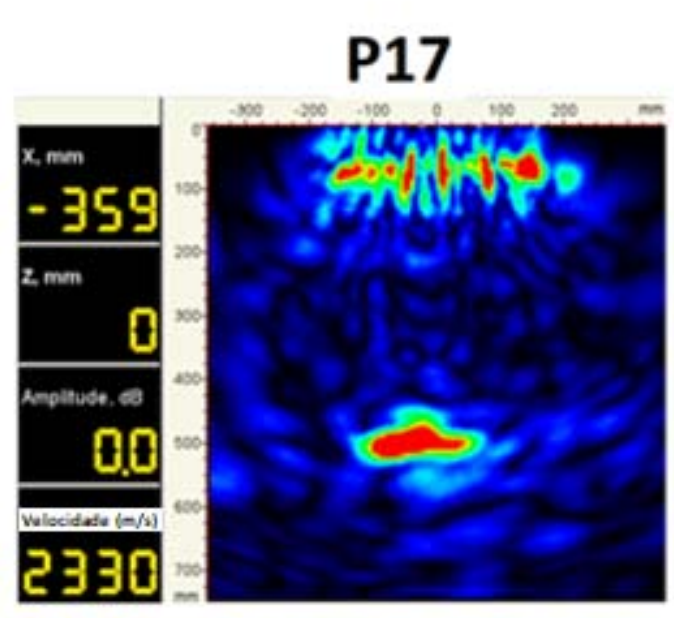

P14

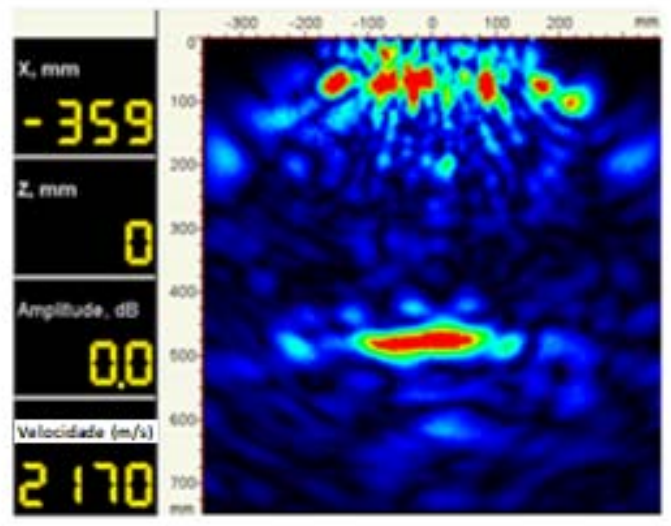

\section{P16}

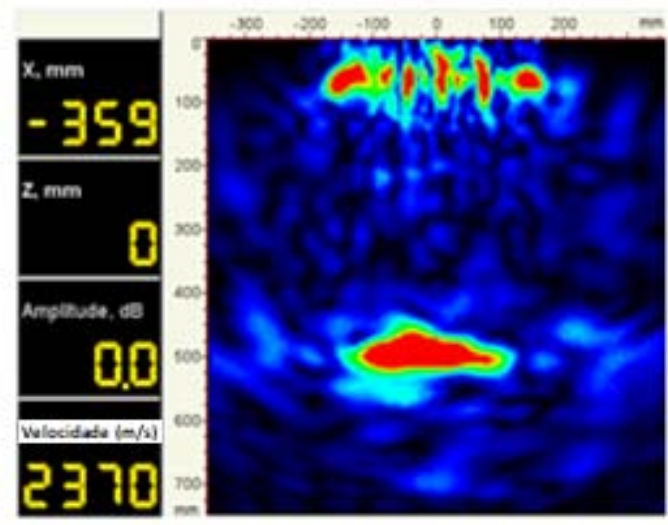

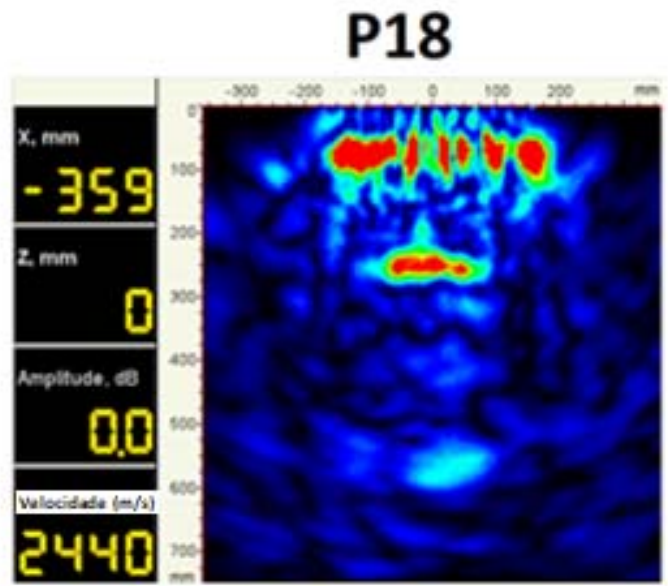

Fonte: Adaptado dos resultados obtidos do programa MIRA (GERMANN INSTRUMENTS, 2012) 
Figura 3.26 - Resultado do ultrassom MIRA para os pontos 19 a 24

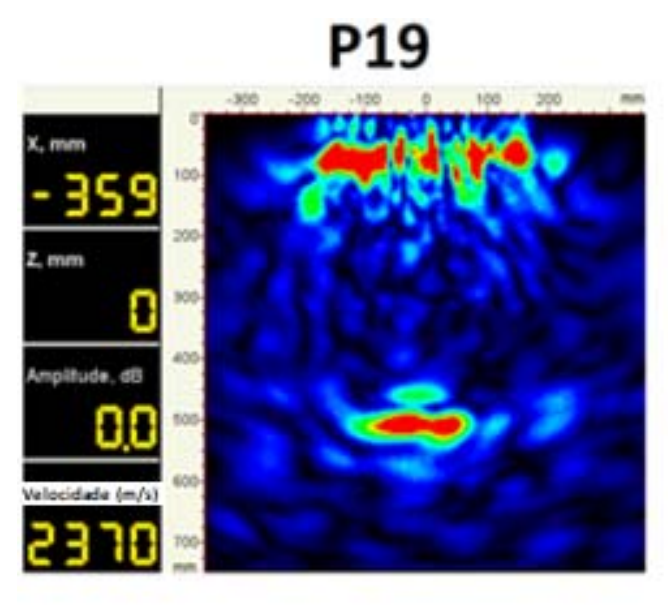

P21

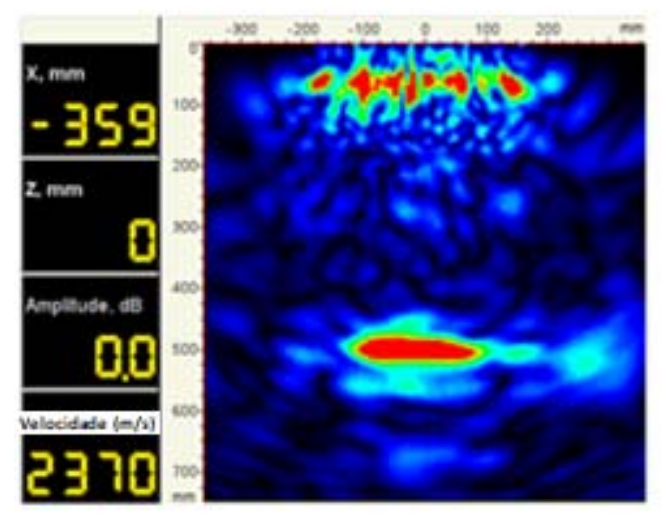

P23

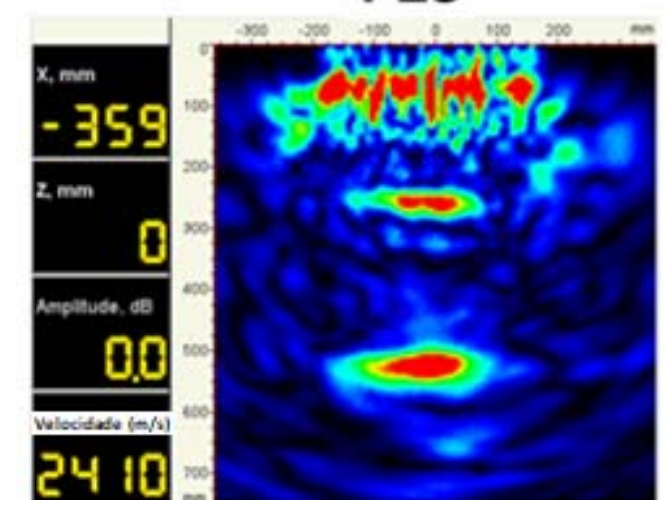

P20

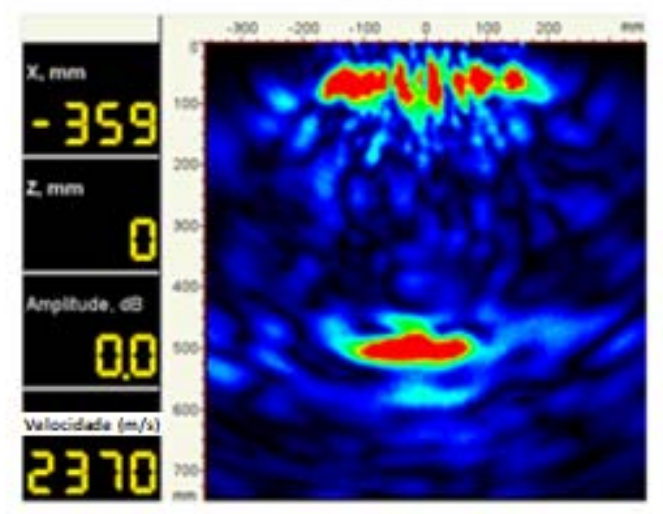

P22

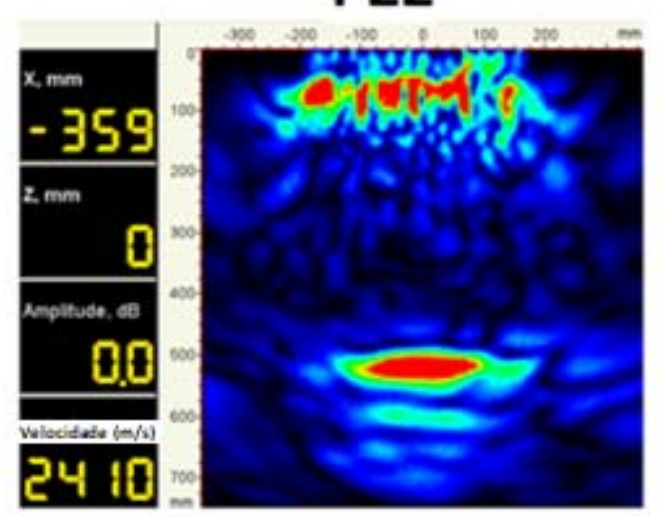

P24

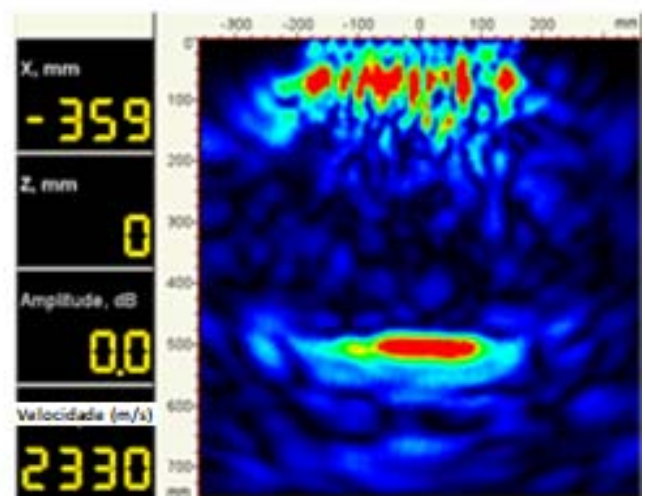

Fonte: Adaptado dos resultados obtidos no programa MIRA (GERMANN INSTRUMENTS, 2012). 
Figura 3.27 - Resultado do ultrassom MIRA para os pontos 25 a 30
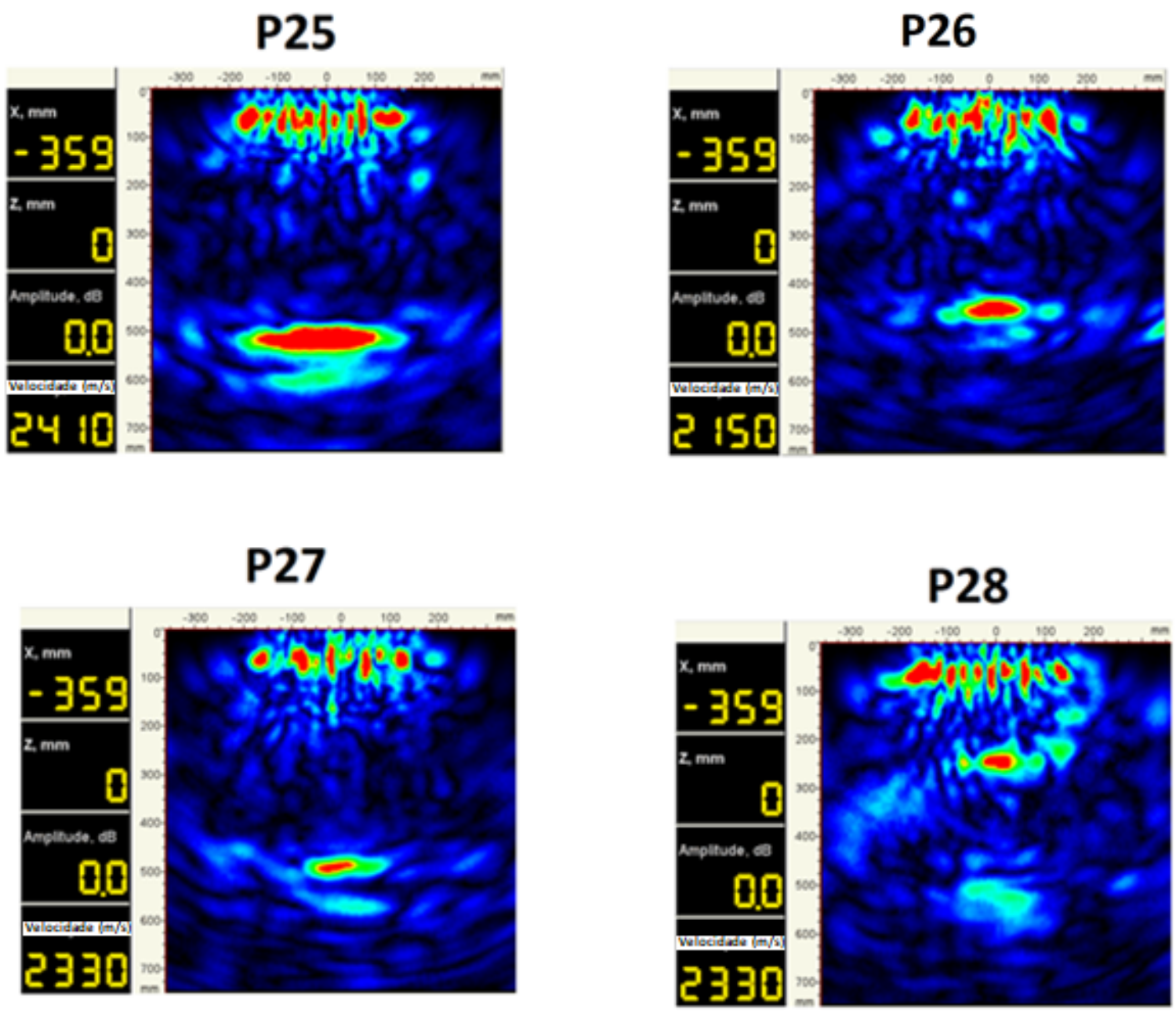

P29

P30
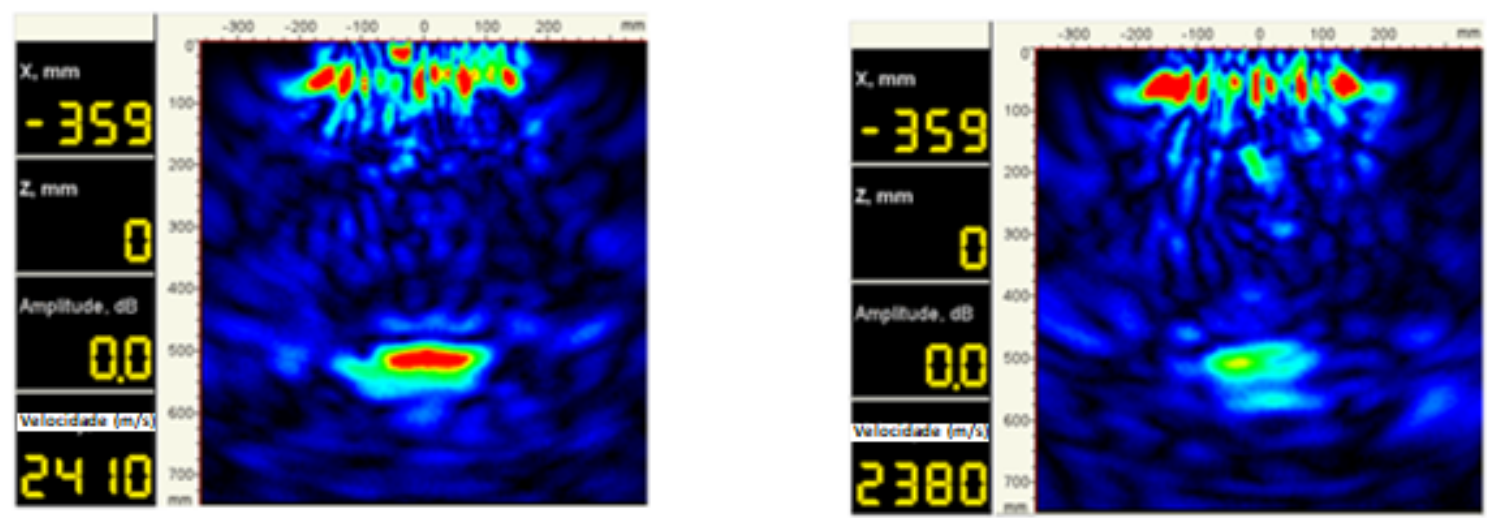

Fonte: Adaptado dos resultados obtidos no programa MIRA (GERMANN INSTRUMENTS, 2012). 
Figura 3.28 - Resultado do ultrassom MIRA para os pontos 31 a 35

P31

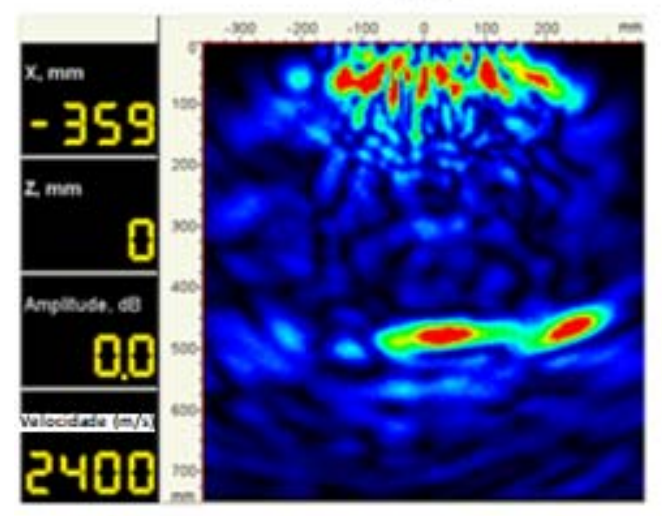

\section{P33}

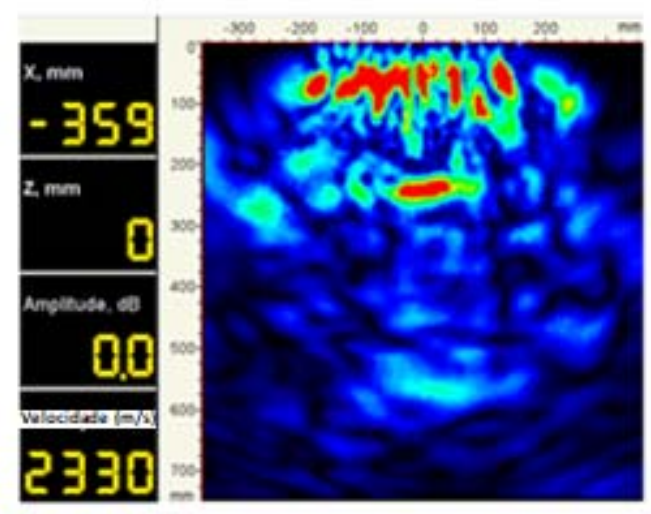

P32

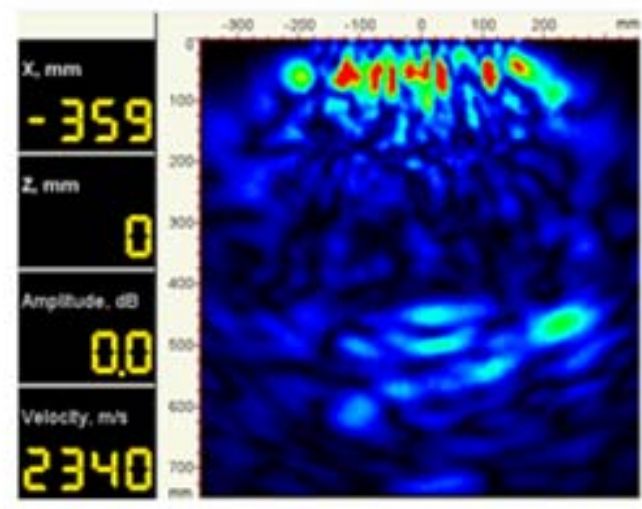

P34

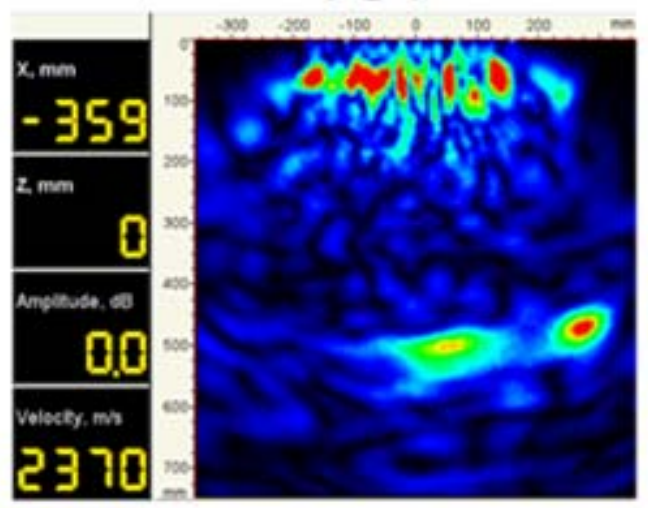

\section{P35}

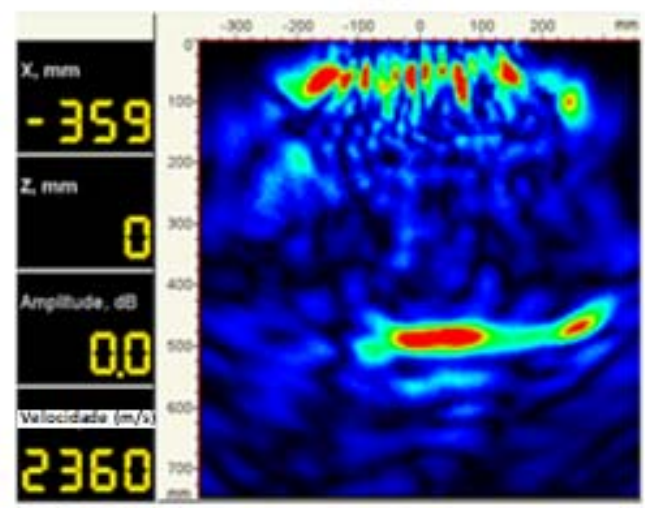

Fonte: Adaptado dos resultados obtidos no programa MIRA (GERMANN INSTRUMENTS, 2012). 
Para facilitar a análise dos resultados, a Figura 3.29 apresenta a locação dos elementos que estão inseridos na parede juntamente com o mapeamento dos pontos ensaiados.

Figura 3.29 - Locação do pontos ensaiados e dos elementos inseridos na parede

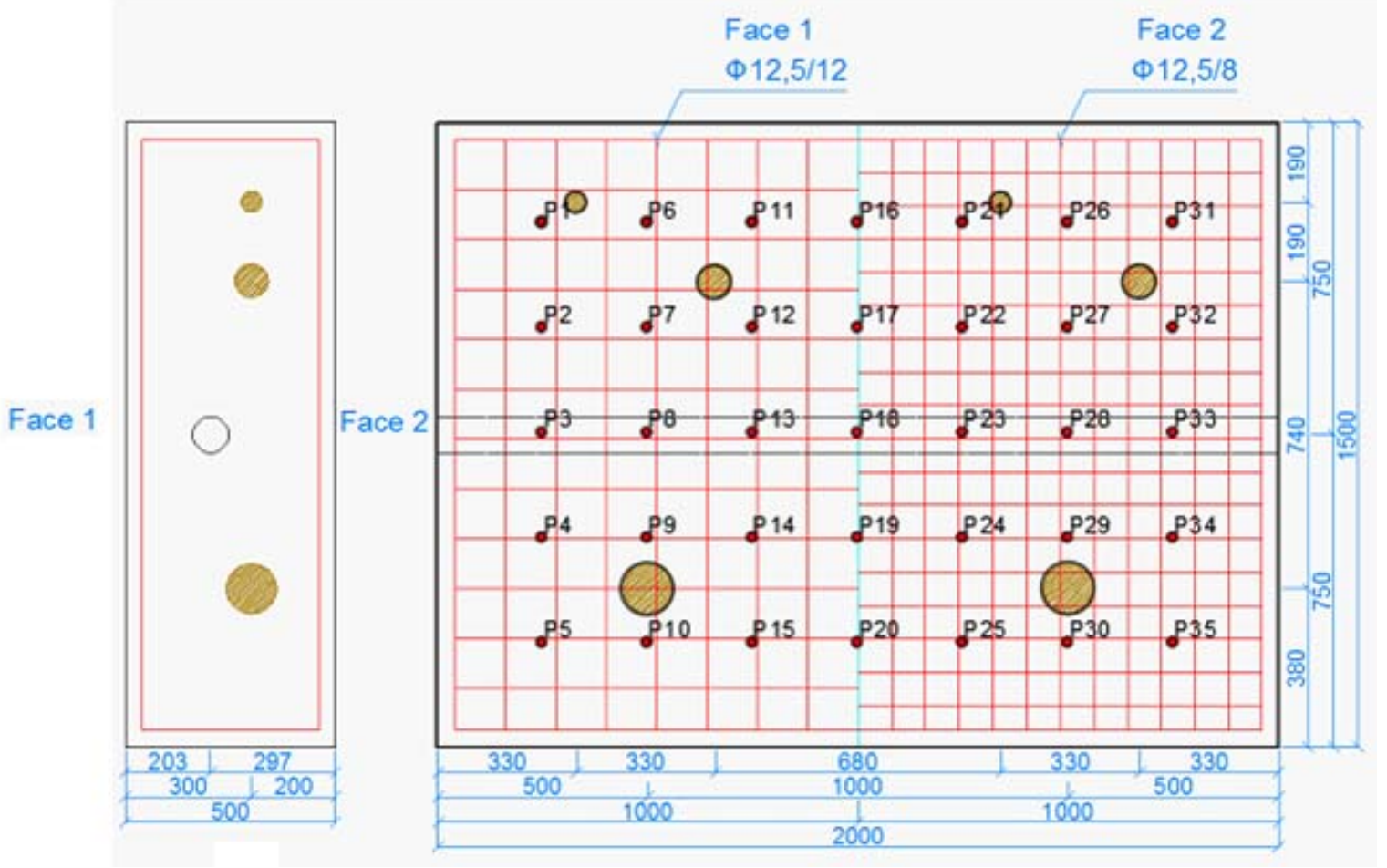

Fonte: Autoria própria

Analisando os resultados apresentados da Figura 3.23 a Figura 3.28, observase que em todos os pontos ensaiados ocorre a reflexão do fundo da parede aproximadamente na cota $500 \mathrm{~mm}$ (eixo das ordenadas das imagens), que corresponde ao fundo da parede, conforme ilustra a Figura 3.30. Em alguns pontos, como nos pontos 30 e 33, a intensidade da reflexão do fundo foi menor. Mais próximo da superfície, observa-se a reflexão das armaduras mais próximas da face ensaiada, aproximadamente na cota $50 \mathrm{~mm}$, além das reflexões ocasionadas pelas ondas de superfície. Não foi possível observar a reflexão das armaduras próximas ao fundo da parede. 
Figura 3.30 - Interpretação dos resultados do MIRA na região sem furo longitudinal

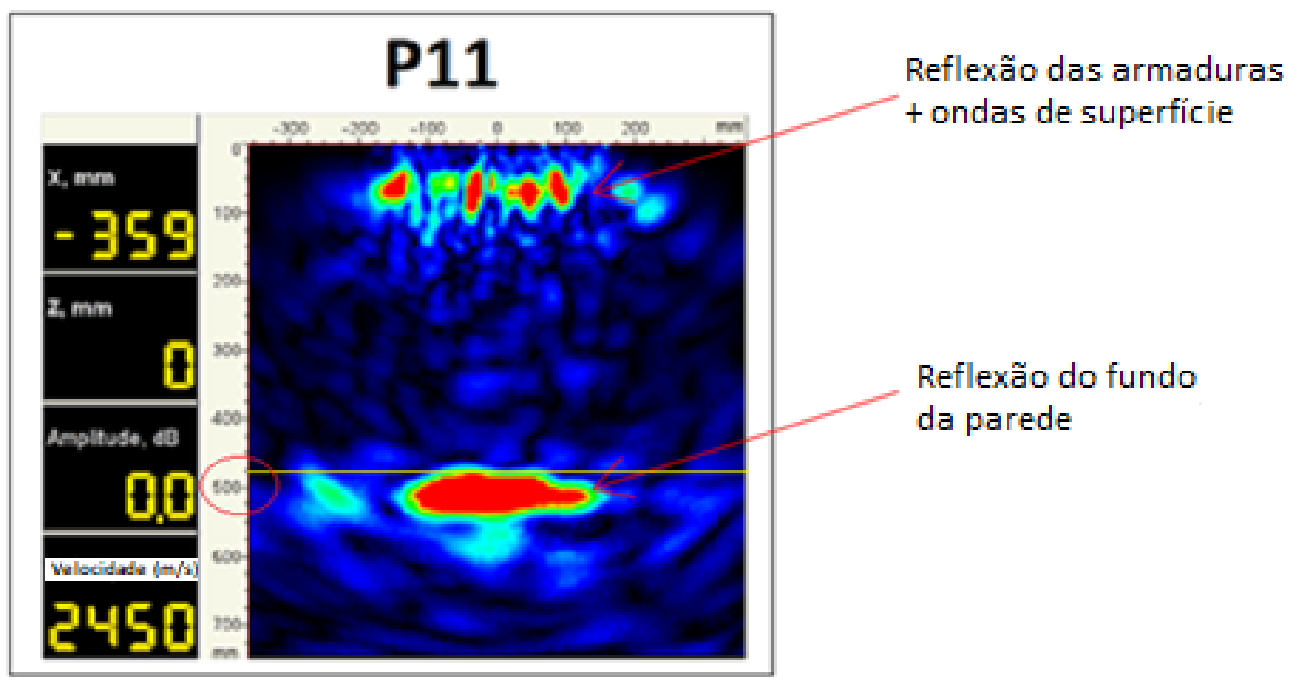

Fonte: Adaptado dos resultados obtidos no programa MIRA (GERMANN INSTRUMENTS, 2012).

Nos pontos de ensaio que estão perpendiculares ao furo longitudinal existente no meio da parede (pontos P3, P8, P13, P18, P23, P28 e P33), além da reflexão do fundo da parede, das armaduras próximas a face de ensaio e das ondas de superfície, ficou evidente a reflexão ocasionada pelo furo que atravessa a parede longitudinalmente, com início da reflexão aproximadamente na cota $250 \mathrm{~mm}$, conforme ilustra a Figura 3.31. Observa-se que o ensaio foi aplicado na face 2 da parede e a distância entre esta face e o início do furo longitudinal é de $247 \mathrm{~mm}$, conforme apresentado na Figura 3.29.

Figura 3.31 - Interpretação dos resultados do MIRA na região do furo longitudinal

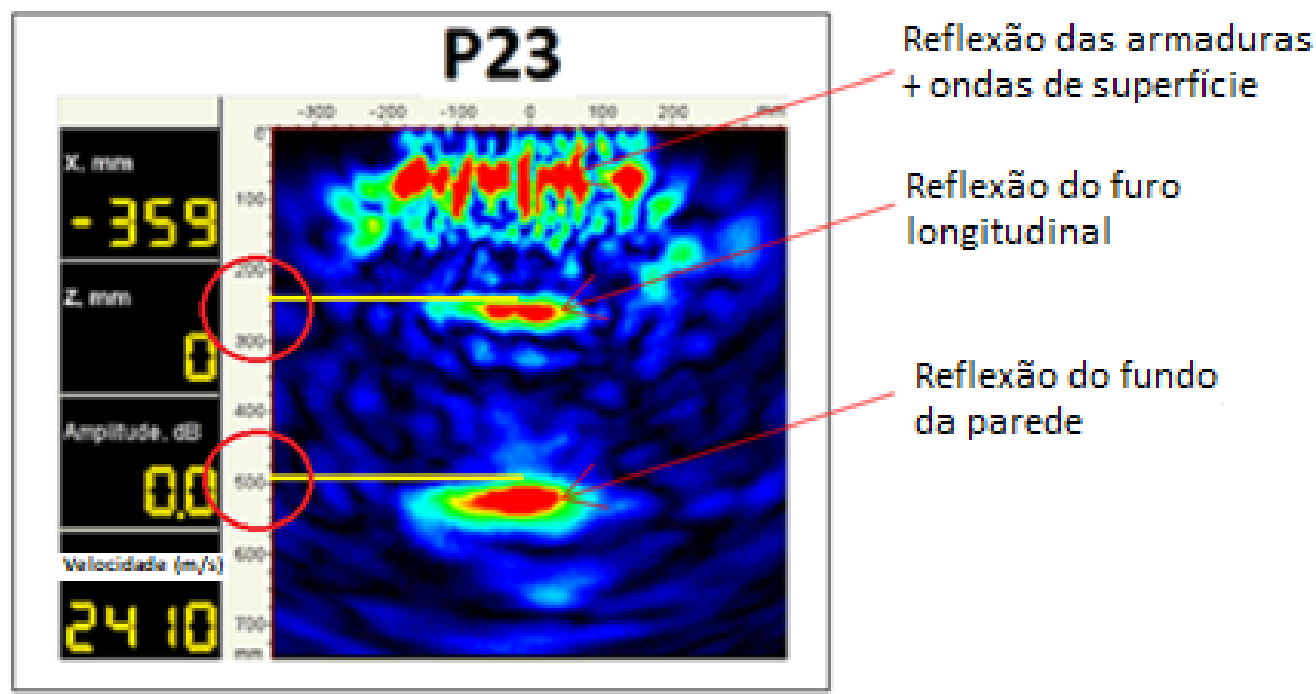

Fonte: Adaptado dos resultados obtidos no programa MIRA (GERMANN INSTRUMENTS, 2012). 
Observa-se no mapeamento realizado (B-scan), que a linha média onde são obtidos os resultados do equipamento, não coincidiu com o centro de nenhuma das esferas de isopor, conforme ilustra a Figura 3.32, que mostra a região próxima do ponto de ensaio 21 .

Figura 3.32 - Interpretação dos resultados do MIRA na região do furo longitudinal

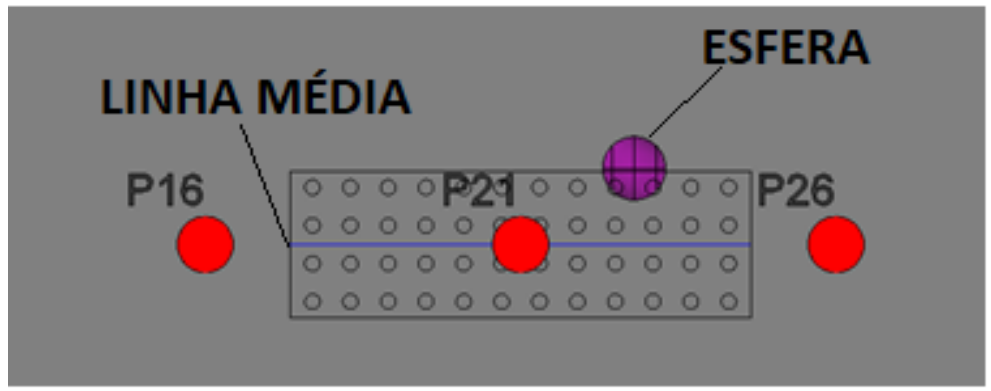

Fonte: Autoria própria

Desta forma, nos pontos ensaiados que estão mais próximos às esferas, não foi possível identificar a reflexão das mesmas, sendo possível identificar apenas a reflexão do fundo da parede, das armaduras e ondas superficiais nestes pontos. A Figura 3.33 apresenta a análise do resultado do ensaio no ponto 21 que está próximo à esfera de isopor de $5 \mathrm{~cm}$ de diâmetro.

Figura 3.33 - Interpretação dos resultados do MIRA na região próxima à esfera de $5 \mathrm{~cm}$ de diâmetro

\section{P21}

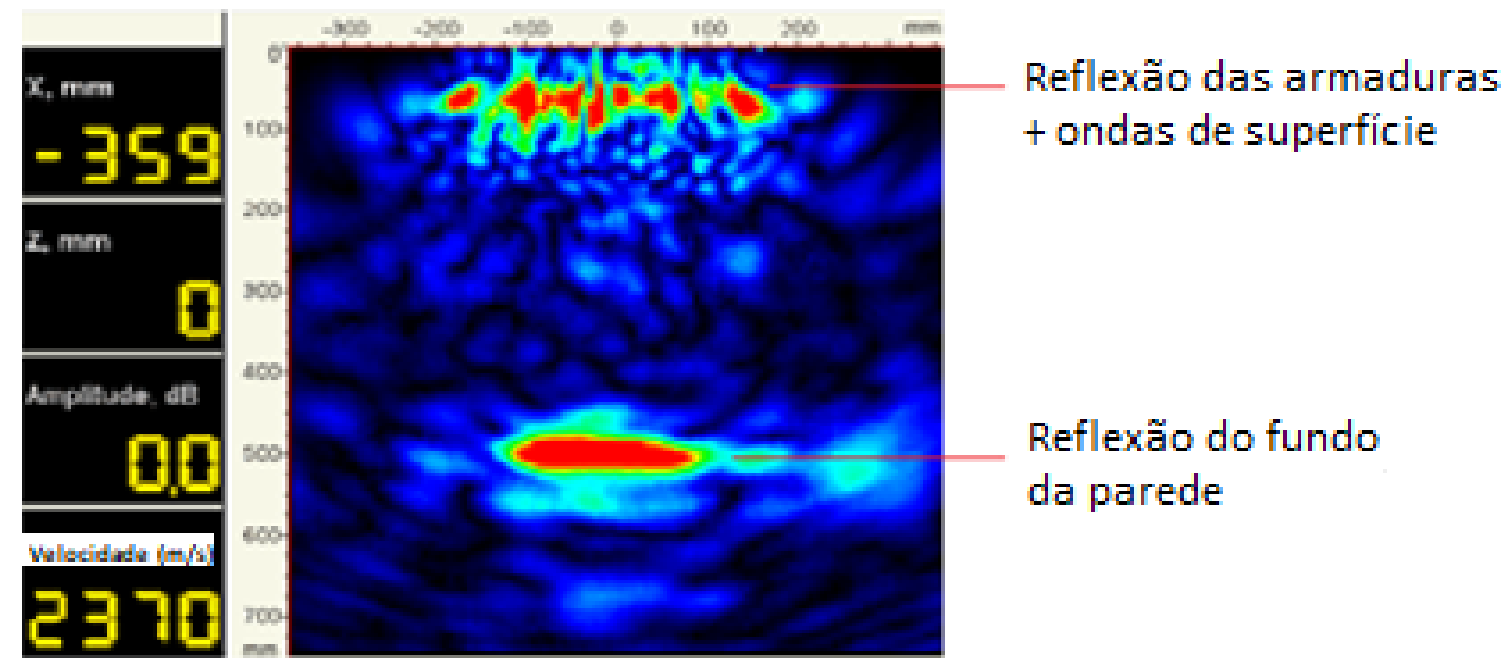

Fonte: Adaptado dos resultados obtidos no programa MIRA (GERMANN INSTRUMENTS, 2012). 
A partir das imagens geradas nos pontos de ensaio que estão perpendiculares ao furo longitudinal existente no meio da parede (pontos P3, P8, P13, P18, P23, P28 e P33), foi realizada uma estimativa da dimensão do furo em função das reflexões geradas nestes pontos, conforme apresentado da Figura 3.34 a Figura 3.35

Figura 3.34 - Estimativa da dimensão do furo longitudinal nos pontos $P 3, P 8, P 13, P 18, P 23$ e $P 28$

P3

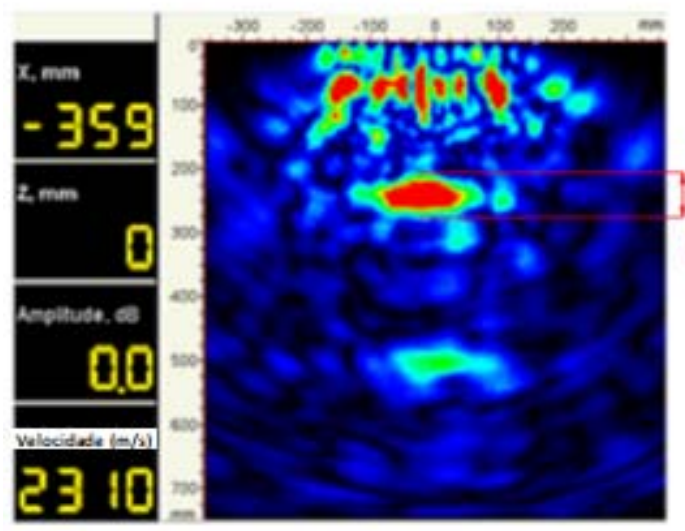

P13

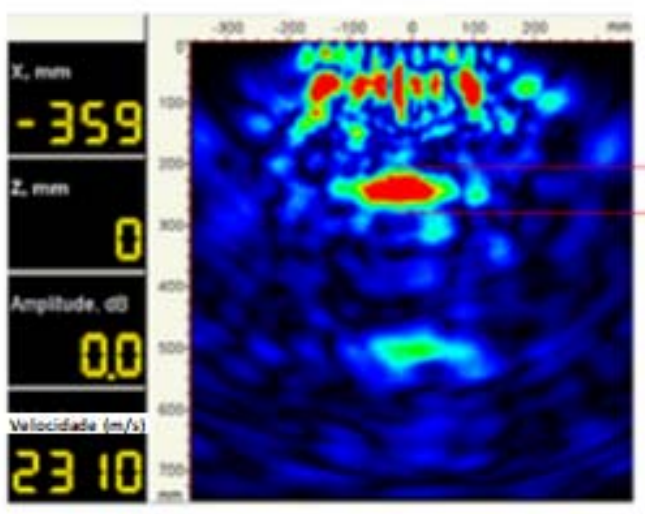

P23

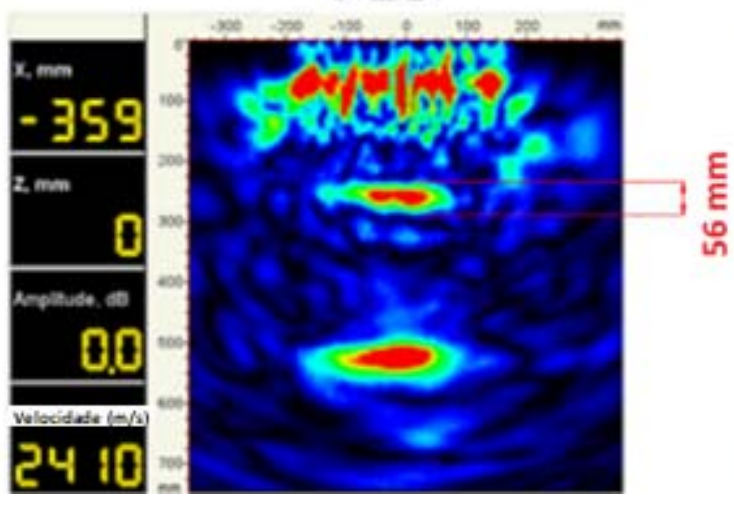

P8

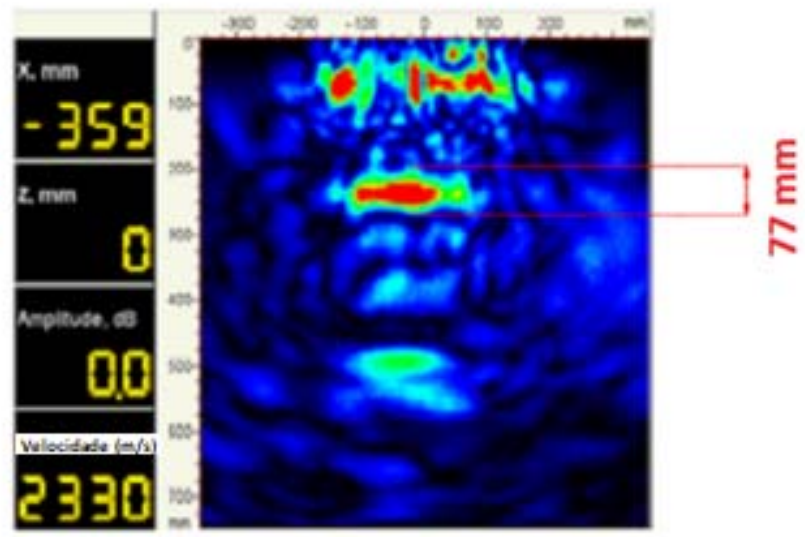

P18

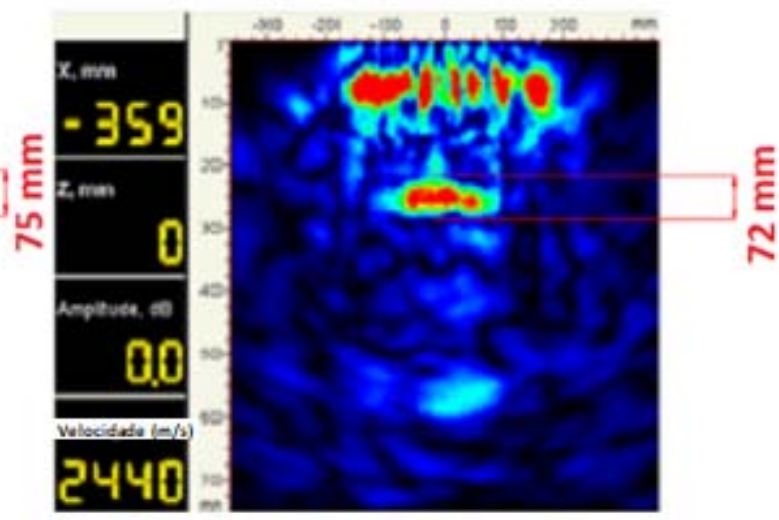

P28

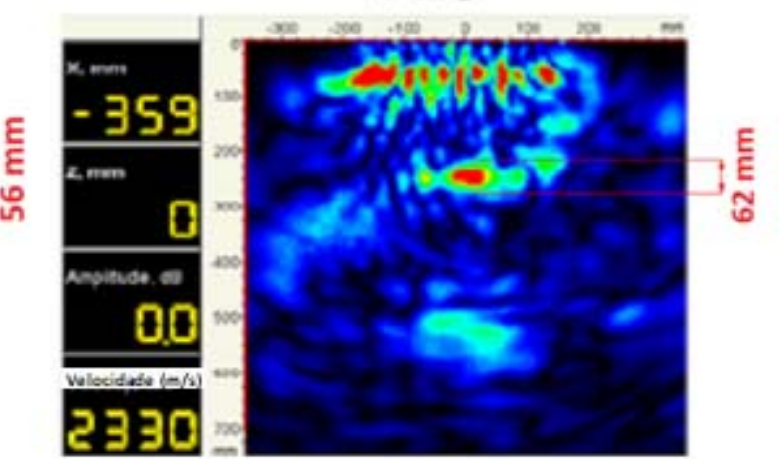

Fonte: Adaptado dos resultados obtidos no programa MIRA (GERMANN INSTRUMENTS, 2012). 
Figura 3.35 - Estimativa da dimensão do furo longitudinal no ponto P33

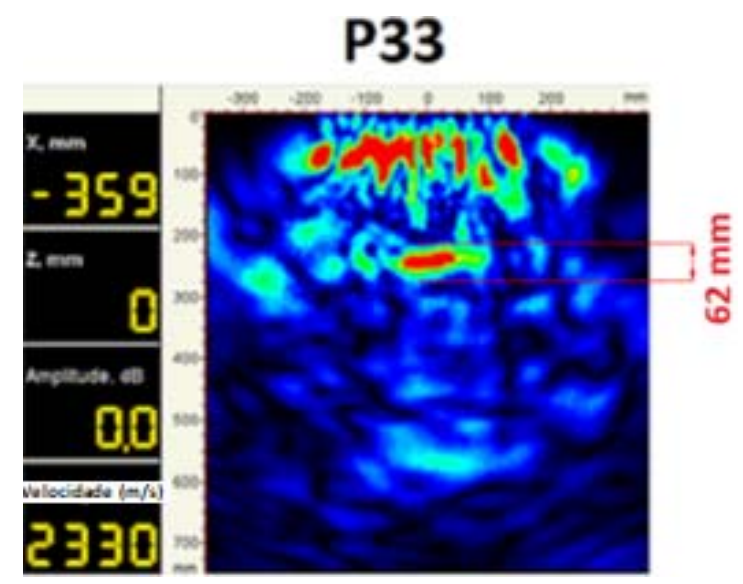

Fonte: Adaptado dos resultados obtidos no programa MIRA (GERMANN INSTRUMENTS, 2012).

Verifica-se que as estimativas das dimensões das reflexões ocasionadas pelo furo longitudinal estão variando entre $56 \mathrm{~mm}$ e $77 \mathrm{~mm}$ nas imagens geradas, e apresentam uma média de $68 \mathrm{~mm}$. O furo apresenta diâmetro de $90 \mathrm{~mm}$. Assim, a estimativa média obtida para o tamanho do furo é $24,4 \%$ menor que o tamanho real do furo.

Analisando a velocidade das ondas de cisalhamento nos diversos pontos ensaiados, observa-se que a média de velocidade nos 35 pontos foi de 2350,9 m/s, com desvio padrão de $75,2 \mathrm{~m} / \mathrm{s}$ e coeficiente de variação de $3,2 \%$, conforme apresentado na Tabela 3.3 
Tabela 3.3: Estimativa do valor de módulo de elasticidade em função da velocidade de cisalhamento

\begin{tabular}{|c|c|c|c|c|c|}
\hline Posição & $\begin{array}{c}\text { Velocidade da onda } \\
\text { tranversal (m/s) }\end{array}$ & $\begin{array}{c}\text { Módulo de } \\
\text { Elasticidade (Gpa) }\end{array}$ & Posição & $\begin{array}{c}\text { Velocidade da onda } \\
\text { tranversal (m/s) }\end{array}$ & $\begin{array}{c}\text { Módulo de } \\
\text { Elasticidade (Gpa) }\end{array}$ \\
\hline P1 & 2510 & 37.4 & $\mathbf{P 1 9}$ & 2370 & 33.4 \\
\hline P2 & 2330 & 32.3 & $\mathbf{P 2 0}$ & 2370 & 33.4 \\
\hline P3 & 2310 & 31.7 & $\mathbf{P 2 1}$ & 2370 & 33.4 \\
\hline P4 & 2150 & 27.5 & $\mathbf{P 2 2}$ & 2410 & 34.5 \\
\hline P5 & 2410 & 34.5 & $\mathbf{P 2 3}$ & 2410 & 34.5 \\
\hline P6 & 2450 & 35.7 & $\mathbf{P 2 4}$ & 2330 & 32.3 \\
\hline P7 & 2330 & 32.3 & $\mathbf{P 2 5}$ & 2410 & 34.5 \\
\hline P8 & 2330 & 32.3 & $\mathbf{P 2 6}$ & 2150 & 27.5 \\
\hline P9 & 2330 & 32.3 & $\mathbf{P 2 7}$ & 2330 & 32.3 \\
\hline P10 & 2330 & 32.3 & $\mathbf{P 2 8}$ & 2330 & 32.3 \\
\hline P11 & 2450 & 35.7 & $\mathbf{P 2 9}$ & 2410 & 34.5 \\
\hline P12 & 2330 & 32.3 & P30 & 2380 & 33.7 \\
\hline P13 & 2310 & 31.7 & P31 & 2400 & 34.2 \\
\hline P14 & 2170 & 28.0 & P32 & 2340 & 32.5 \\
\hline P15 & 2330 & 32.3 & P33 & 2330 & 32.3 \\
\hline P16 & 2370 & 33.4 & P34 & 2370 & 33.4 \\
\hline P17 & 2330 & 32.3 & P35 & 2360 & 33.1 \\
\hline P18 & 2440 & 35.4 & Média & 2350.9 & 32.9 \\
\hline & & & Desvio Padrão & 75.2 & 2.1 \\
\hline
\end{tabular}

Fonte: Autoria própria

Estimou-se o módulo de elasticidade em função da velocidade da onda de cisalhamento, de acordo com a Equação 2.3, adotando o valor de 0,22 para o coeficiente de Poisson e o valor de $2435 \mathrm{~kg} / \mathrm{m}^{3}$ para o peso específico, conforme Tabela 3.1. A média do valor do módulo de elasticidade obtida para os 35 pontos ensaiados foi de 32,9 GPa, com desvio padrão de 2,1 GPa e coeficiente de variação de 6,3\%. Comparando essa média obtida para o módulo de elasticidade através da velocidade da onda de cisalhamento com a média do módulo de elasticidade obtida segundo a norma NBR 8522 (2017), apresentada na Tabela 3.2, observa-se que o valor médio obtido através do ensaio de ultrassom é $12,3 \%$ menor que o valor obtido através do ensaio de compressão axial.

\subsubsection{Ensaio de Pacometria}

\subsubsection{Equipamentos utilizados}

Para a realização do ensaio de pacometria foi utilizado o Pacômetro Profoscope da empresa Proceq, conforme ilustra a Figura 3.36. 
Figura 3.36 - Pacômetro.

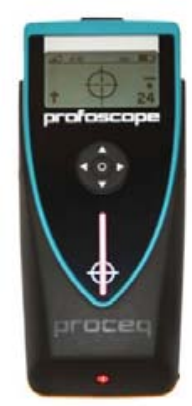

Fonte: PROCEQ (2014)

\subsubsection{Metodologia de ensaio}

O ensaio de pacometria foi realizado para determinação da posição e do cobrimento das armaduras na parede. Primeiramente realizou-se o arrasto do equipamento ao longo da estrutura e observou-se o resultado no visor do mesmo. No visor do equipamento aparece um círculo que serve como guia para a localização da armadura. Quando o equipamento estava distante da armadura, este círculo se deslocava para o canto, ficando descentralizado em relação ao centro do visor, conforme ilustra a Figura 3.37.

Figura 3.37 - Resultado no visor do pacômetro quando não foi localizada armadura: círculo descentralizado

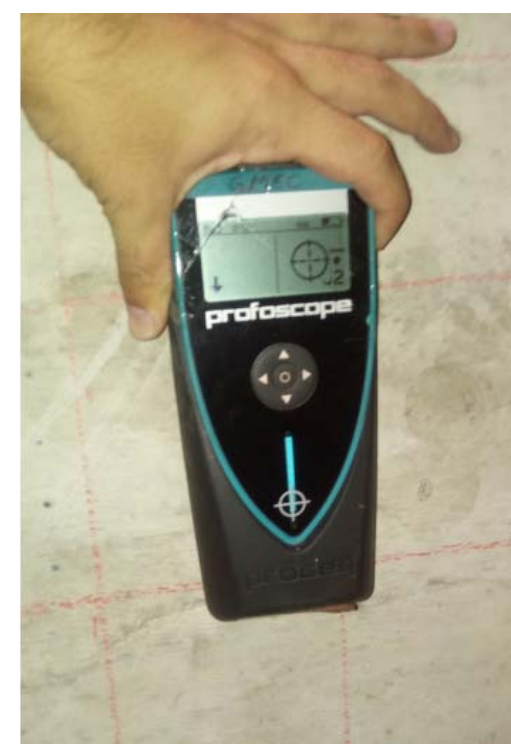

Fonte: Autoria própria 
À medida que o equipamento se aproximava da armadura, o círculo ia se deslocando em direção ao centro do visor. Quando o eixo vertical central do visor do aparelho encontrava-se exatamente em cima da armadura, o círculo ficava centralizado no visor do equipamento e uma luz vermelha se acendia, indicando a localização da armadura, conforme ilustra a Figura 3.38. O cobrimento é mostrado no canto inferior direito do visor do equipamento.

Figura 3.38 - Resultado no visor do pacômetro quando localiza a armadura: círculo centralizado e luz vermelha acesa

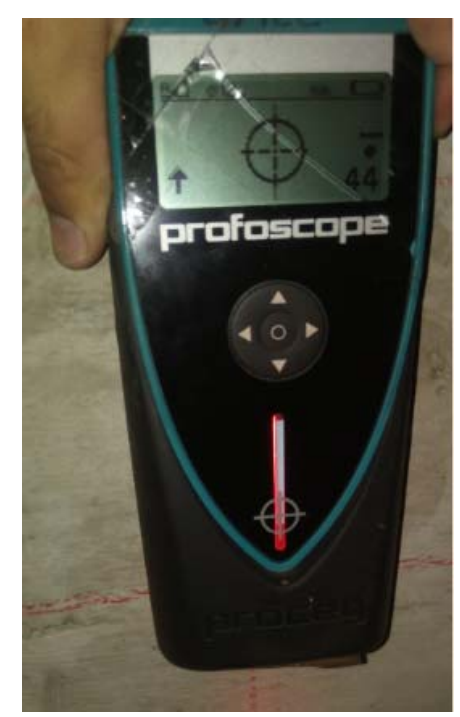

Fonte: Autoria própria

Após localizadas as armaduras, marcou-se com um giz o posicionamento das mesmas na parede.

\subsubsection{Resultados e discussões}

Como resultado do ensaio de pacometria, determinou-se a localização das barras de aço e marcou-se na estrutura com giz de cera o posicionamento das mesmas. A marcação resultou em uma malha quadricular, conforme apresentado na Figura 3.39. 
Figura 3.39 - Marcação do posicionamento das armaduras na parede com giz

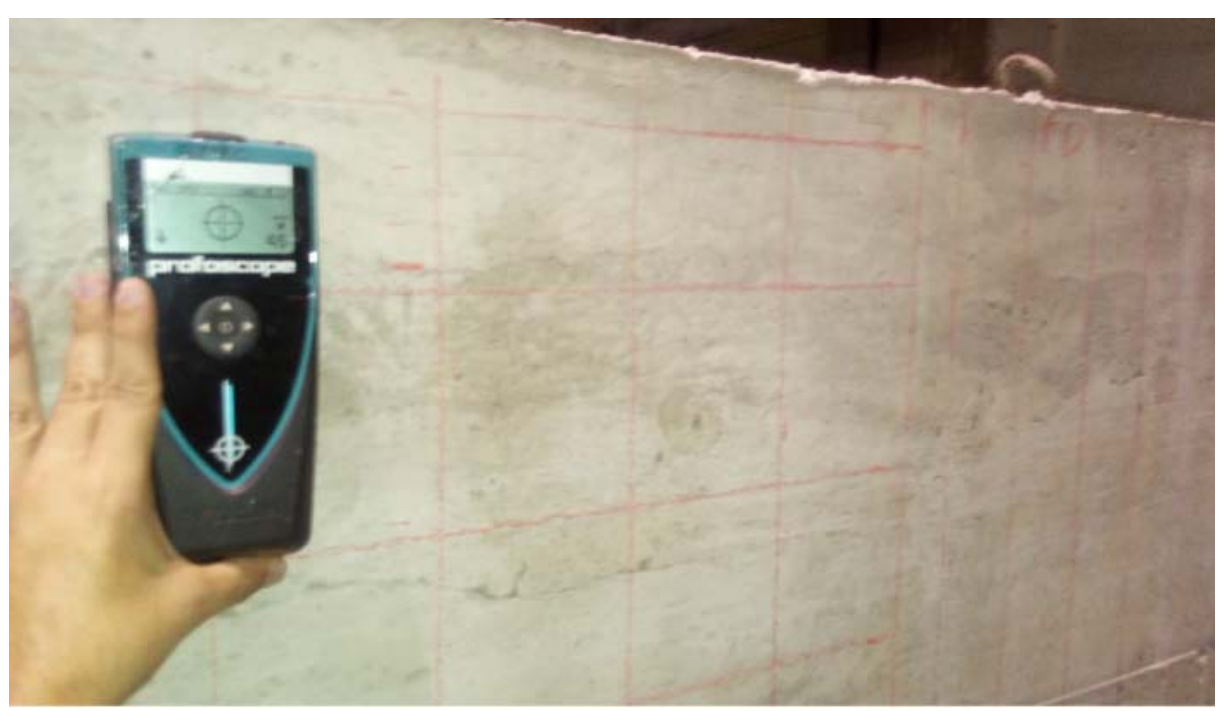

Fonte: Autoria própria

A medida que o equipamento localizava as armaduras, o valor estimado para o cobrimento era mostrado no canto inferior direito do visor. O cobrimento das armaduras estimado no ensaio variou entre $4,1 \mathrm{~cm}$ e $4,7 \mathrm{~cm}$. O cobrimento especificado em projeto é de $4,5 \mathrm{~cm}$. Logo a estimativa teve uma variação máxima de 8,9 \% em relação ao valor especificado em projeto.

\subsubsection{Ensaio de Esclerômetria}

\subsubsection{Equipamentos utilizados}

O equipamento principal utilizado no ensaio foi o esclerômetro Silver Schmidt da empresa Proceq, apresentado na Figura 3.40. Para auxílio na realização do ensaio foi utilizado um gabarito com 16 pontos, com espaçamento de $3 \mathrm{~cm}$, conforme recomendado pela norma NBR 7584 (2012). 
Figura 3.40 - Esclerômetro SilverSchmidt

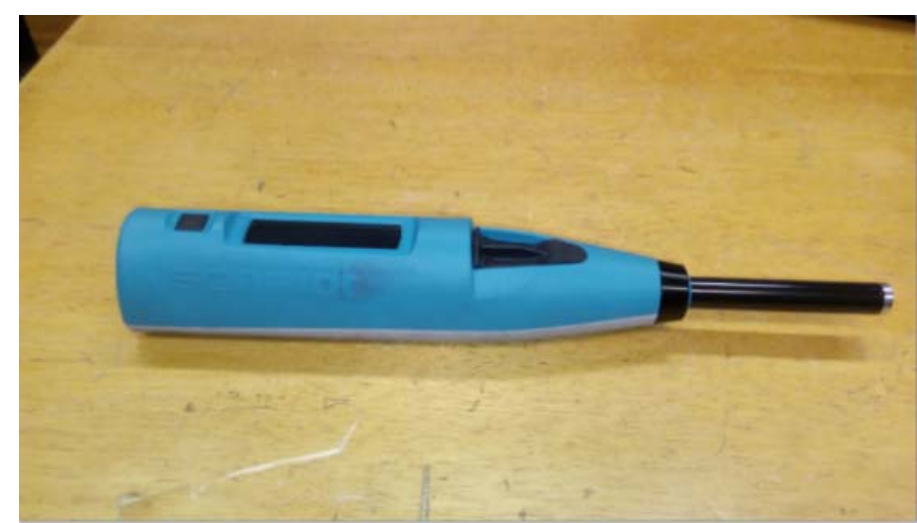

Fonte: Autoria própria

Figura 3.41 - Gabarito utilizado na aplicação do ensaio.

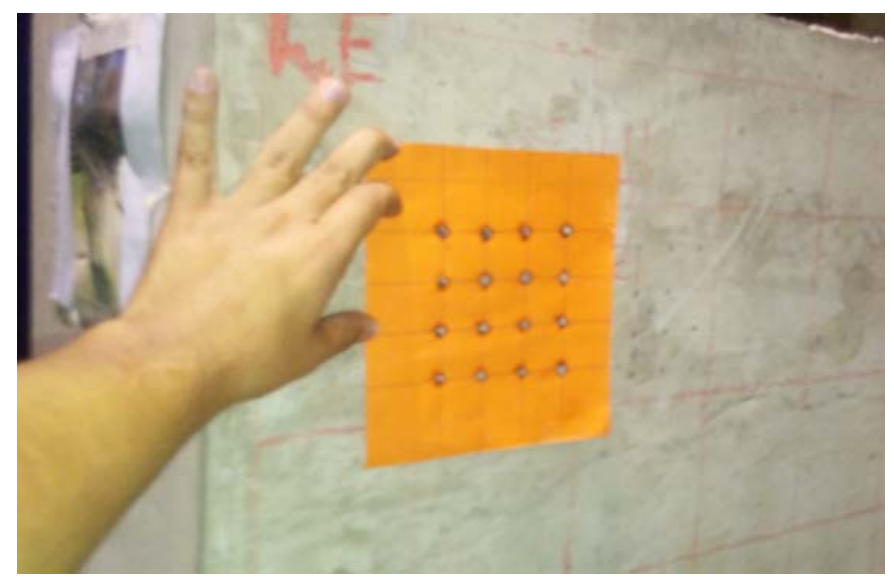

Fonte: Autoria própria

\subsubsection{Metodologia de ensaio}

Para realização do ensaio de esclerometria, primeiramente elaborou-se um gabarito com 16 pontos espaçados a cada $3 \mathrm{~cm}$ para auxiliar na realização do ensaio.

Foram ensaiadas 4 regiões da parede. Os pontos centrais das regiões ensaiadas foram definidos depois da realização do ensaio de pacometria e definição do posicionamento das armaduras. Foram escolhidos 4 pontos entre 0 posicionamento das armaduras, para que as mesmas não influenciassem o resultado, de acordo com a Figura 3.42. 
Figura 3.42 - Definição dos pontos ensaiados no ensaio de esclerometria

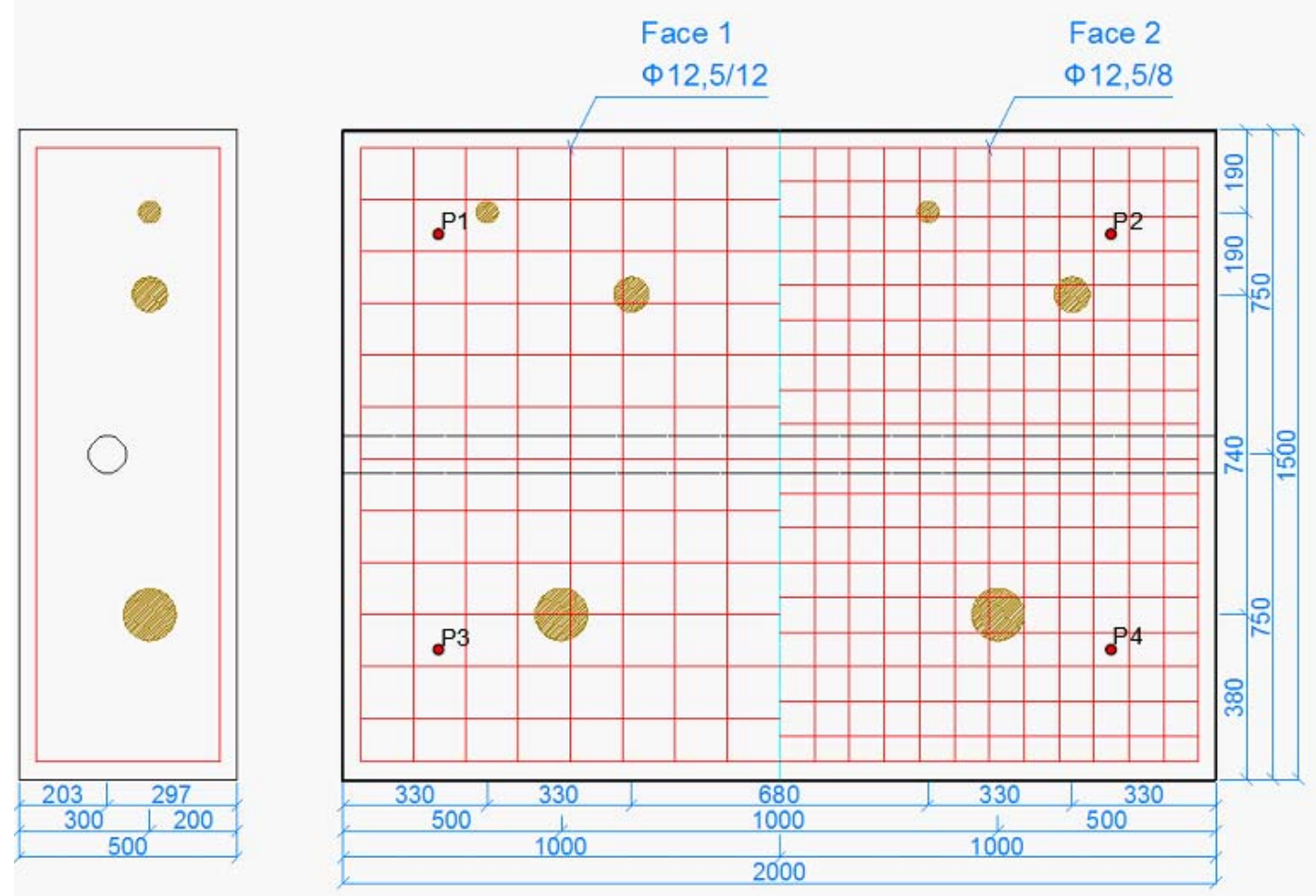

Fonte: Autoria própria

Definidos os pontos a serem ensaiados, iniciou-se o ensaio. Para cada região ensaiada, foi medido o índice esclerométrico para cada um dos 16 pontos do gabarito. $\mathrm{Na}$ realização das medidas, o martelo ficou perpendicular à superfície ensaiada e fezse uma pressão constante no equipamento contra a parede até obter-se os resultados para cada ponto.

Seguindo as recomendações da norma NBR 7584 (2012), depois de realizado o ensaio, foi realizada uma análise dos resultados para eliminar as medidas divergentes e determinar o índice esclerométrico médio da região ensaiada. Para eliminar esses valores divergentes, primeiramente tirou-se a média do índice esclerométrico obtido nos 16 pontos do gabarito e eliminou-se todos valores que divergiam em mais de $10 \%$ da média obtida. Descartando estes valores divergentes da média inicial, fez-se uma nova média com os pontos restantes, e determinou-se o índice esclerométrico da região. 


\subsubsection{Resultados e discussões}

Os resultados obtidos no ensaio de esclerometria para as 4 regiões estudadas estão apresentados na Tabela 3.4. Calculou-se o índice esclerométrico médio dos 16 pontos do gabarito e também o índice esclerométrico corrigido, descartando todos valores que divergiam em $10 \%$ da média inicial dos 16 pontos. Os pontos que foram excluídos para realizar a segunda média corrigida estão destacados em vermelho. A Tabela 3.4 também apresenta a estimativa de resistência à compressão em função do valor do índice esclerométrico corrigido. Segundo o manual da PROCEQ (2014), a resistência à compressão é correlacionada com o índice esclerométrico de acordo com a Equação 3.1 .

$$
f_{c k}=1,8943 \times e^{0,064 \times Q}(\mathrm{MPa})
$$

Onde,

$$
\mathrm{Q}=\text { índice esclerométrico }
$$

Tabela 3.4: Resultados do ensaio de esclerometria e estimativa de resistência à compressão

\begin{tabular}{|l|r|r|r|r|}
\hline Ponto & Região 1 & Região 2 & Região 3 & Região 4 \\
\hline $\mathbf{1}$ & 56 & 58.5 & 56 & 57 \\
\hline $\mathbf{2}$ & 60 & 59.5 & 56.5 & 58 \\
\hline $\mathbf{3}$ & 61.5 & 59.5 & 57 & 60 \\
\hline $\mathbf{4}$ & 57 & 65 & 58 & 58 \\
\hline $\mathbf{5}$ & 59.5 & 58.5 & 59 & 58.5 \\
\hline $\mathbf{6}$ & 60 & 54.5 & 60 & 60 \\
\hline $\mathbf{7}$ & 58 & 57.5 & 61 & 66 \\
\hline $\mathbf{8}$ & 58 & 56.5 & 57 & 62 \\
\hline $\mathbf{9}$ & 61 & 57 & 59 & 59 \\
\hline $\mathbf{1 0}$ & 60 & 61 & 58 & 57 \\
\hline $\mathbf{1 1}$ & 58.5 & 60 & 60 & 58.5 \\
\hline $\mathbf{1 2}$ & 66 & 59 & 58 & 59 \\
\hline $\mathbf{1 3}$ & 62 & 59.5 & 65 & 60 \\
\hline $\mathbf{1 4}$ & 58.5 & 61 & 62 & 52 \\
\hline $\mathbf{1 5}$ & 57.5 & 58.5 & 57 & 58 \\
\hline $\mathbf{1 6}$ & 60 & 58 & 56 & 60 \\
\hline Q médio & 59.6 & 59 & 58.7 & 58.9 \\
\hline Q médio corrigido & 59.2 & 58.6 & 58.3 & 58.9 \\
\hline Estimativa de resistência & 83.6 & 80.4 & 79 & 82.3 \\
\hline
\end{tabular}

Fonte: Autoria própria 
Observa-se que as medidas de resistência variaram entre $79 \mathrm{MPa}$ e 83,6 MPa nas 4 regiões ensaiadas, indicando um concreto de alto desempenho. A média de resistência obtida nas estimativas foi de 81,3 MPa. De acordo com a Tabela 3.2, a resistência média à compressão obtida através dos ensaios de compressão axial foi de 74,7 MPa.

Desta forma os resultados obtidos para estimativa da resistência à compressão da parede tiveram uma variação média de 8,9\% em relação à média de resistência obtida no ensaio de compressão axial. A máxima variação na estimativa de resistência à compressão em relação à média de resistência obtida no ensaio de compressão axial foi apresentada na região 1 , com um valor de $11,9 \%$.

\subsection{Estudo de caso 3: Ensaio de ultrassom aplicado na ligação das mãos francesas e das aduelas da Ponte sobre rio Guaíba}

\subsubsection{Introdução}

Para elaboração do terceiro estudo de caso, foram utilizados dados fornecidos pelo Consórcio da Ponte do Guaíba e autorizado pelo DNIT/RS.

O ensaio de ultrassom foi realizado por uma empresa terceirizada contratada pelo Consórcio da Ponte do Guaíba para avaliação da ligação entre as mãos francesas e as aduelas de concreto da nova ponte sobre o Rio Guaíba.

Neste estudo de caso, é apresentada a análise dos resultados obtidos no ensaio de ultrassom, bem como a estimativa da resistência à compressão e do módulo de elasticidade em função da velocidade do pulso ultrassônico.

A ponte avaliada é parte integrante da construção da nova ponte do Guaíba e acessos, na BR-116/RS no estado do Rio Grande do Sul, conforme apresentado na Figura 3.43 . 
Figura 3.43 - Localização da Ponte do Guaíba

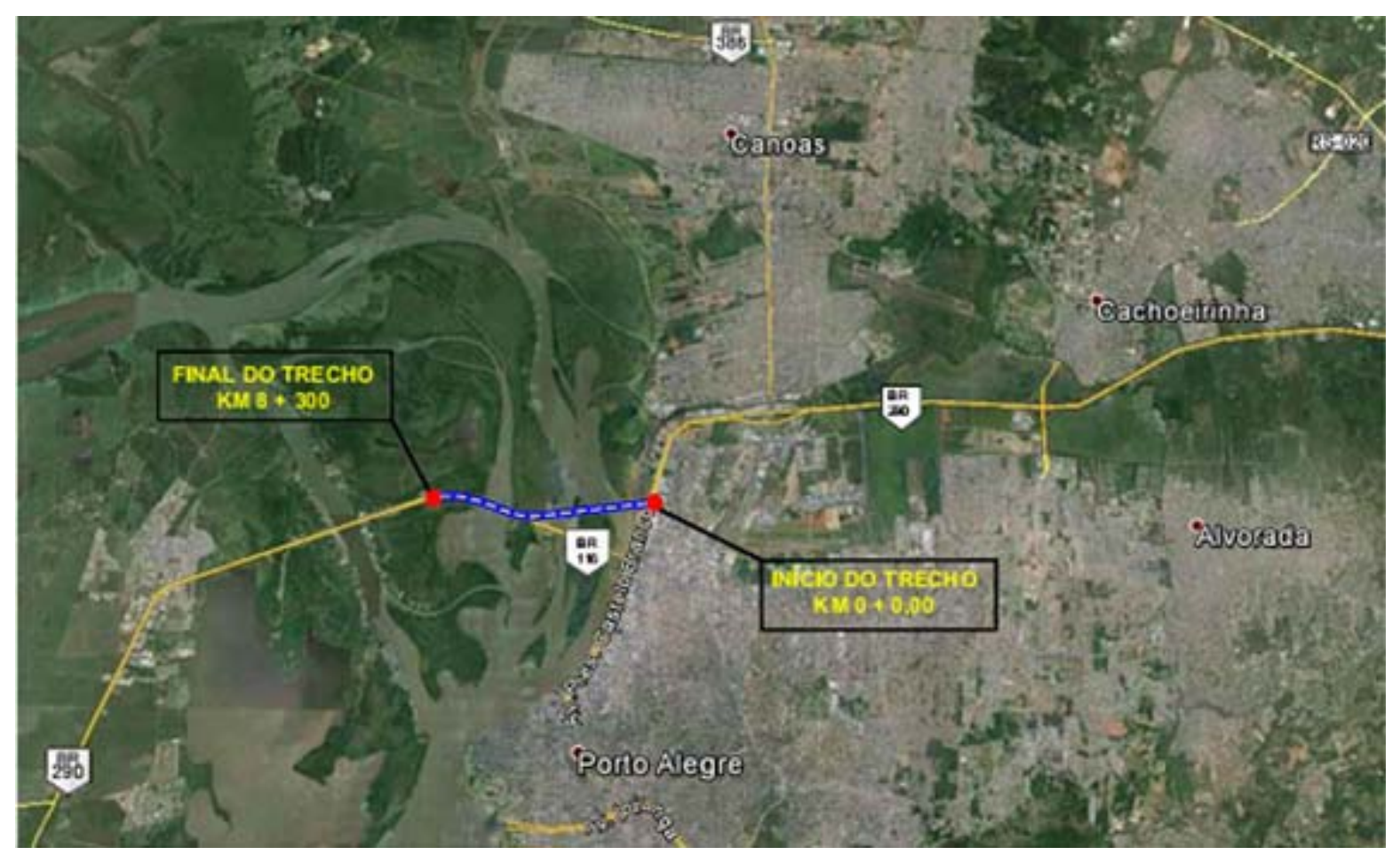

Fonte: Consórcio Ponte do Guaíba (2019)

Trata-se de uma ponte reta com cinco vãos, construída por balanços sucessivos. De acordo com a Figura 3.44, a ponte possui três vão centrais de 140 metros e dois vão laterais de 90 metros. Esses vãos foram definidos de forma a se respeitar os gabaritos de navegação e aéreo. A largura da ponte é de aproximadamente 27 metros.

Figura 3.44 - Elevação longitudinal da Ponte do Guaíba

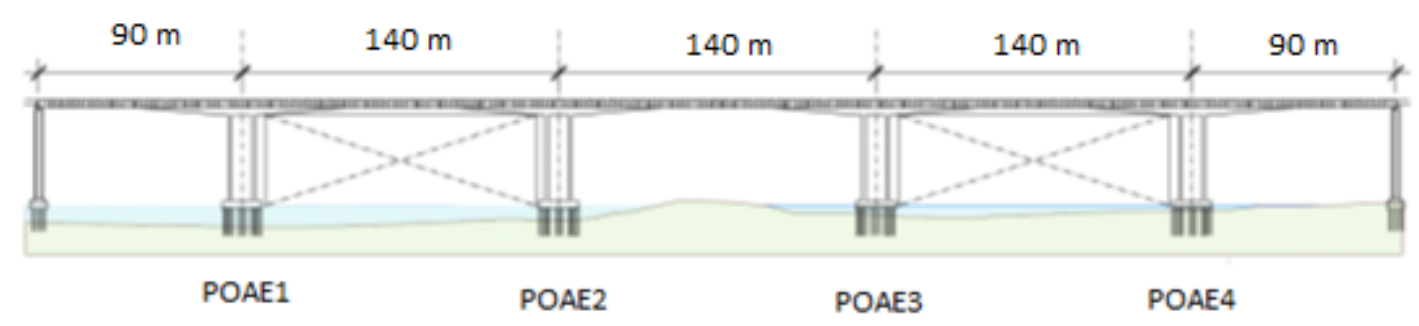

Fonte: Consórcio Ponte do Guaíba (2019) 
A superestrutura foi concebida em seção caixão (unicelular) e, devido à grande largura da ponte, mãos francesas foram utilizadas para reduzir o balanço e permitir a utilização de apenas duas almas, conforme ilustrado na Figura 3.45.

Figura 3.45 - Seção transversal da Ponte do Guaíba

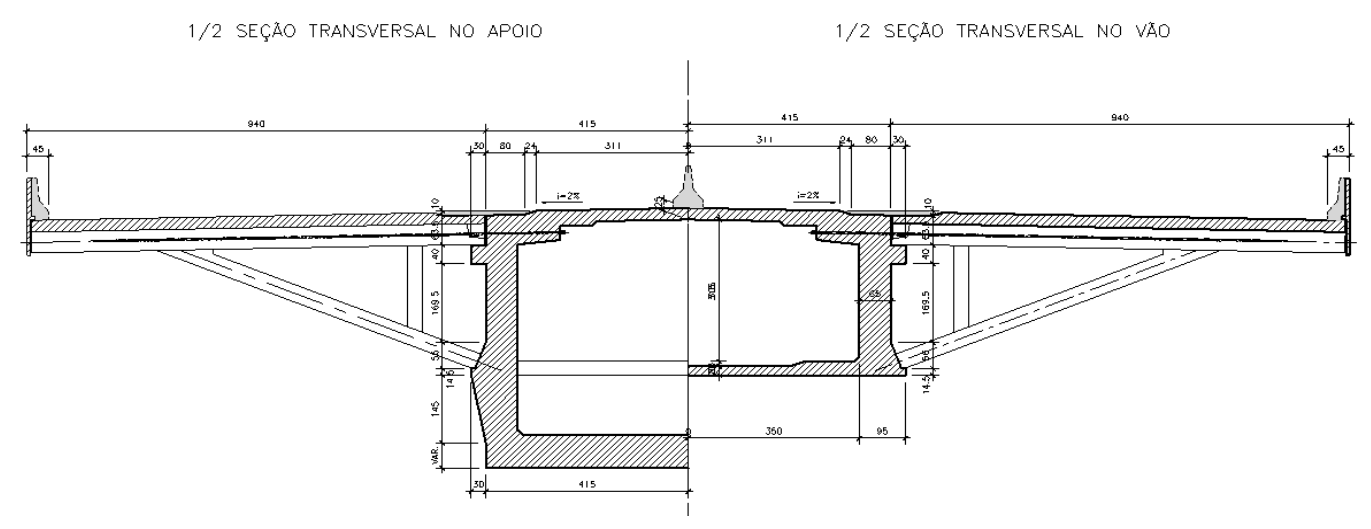

Fonte: Consórcio Ponte do Guaíba (2019)

A altura da seção transversal varia linearmente de 7,5 metros no apoio a 3,6 metros no meio do vão. As seções transversais são compostas por um caixão prémoldado, uma laje complementar pré-moldada e um par de mãos francesas.

O método construtivo da ponte pode ser divido em 4 etapas, conforme ilustra a Figura 3.46 . 
Figura 3.46 - Etapas do método construtivo da Ponte do Guaíba

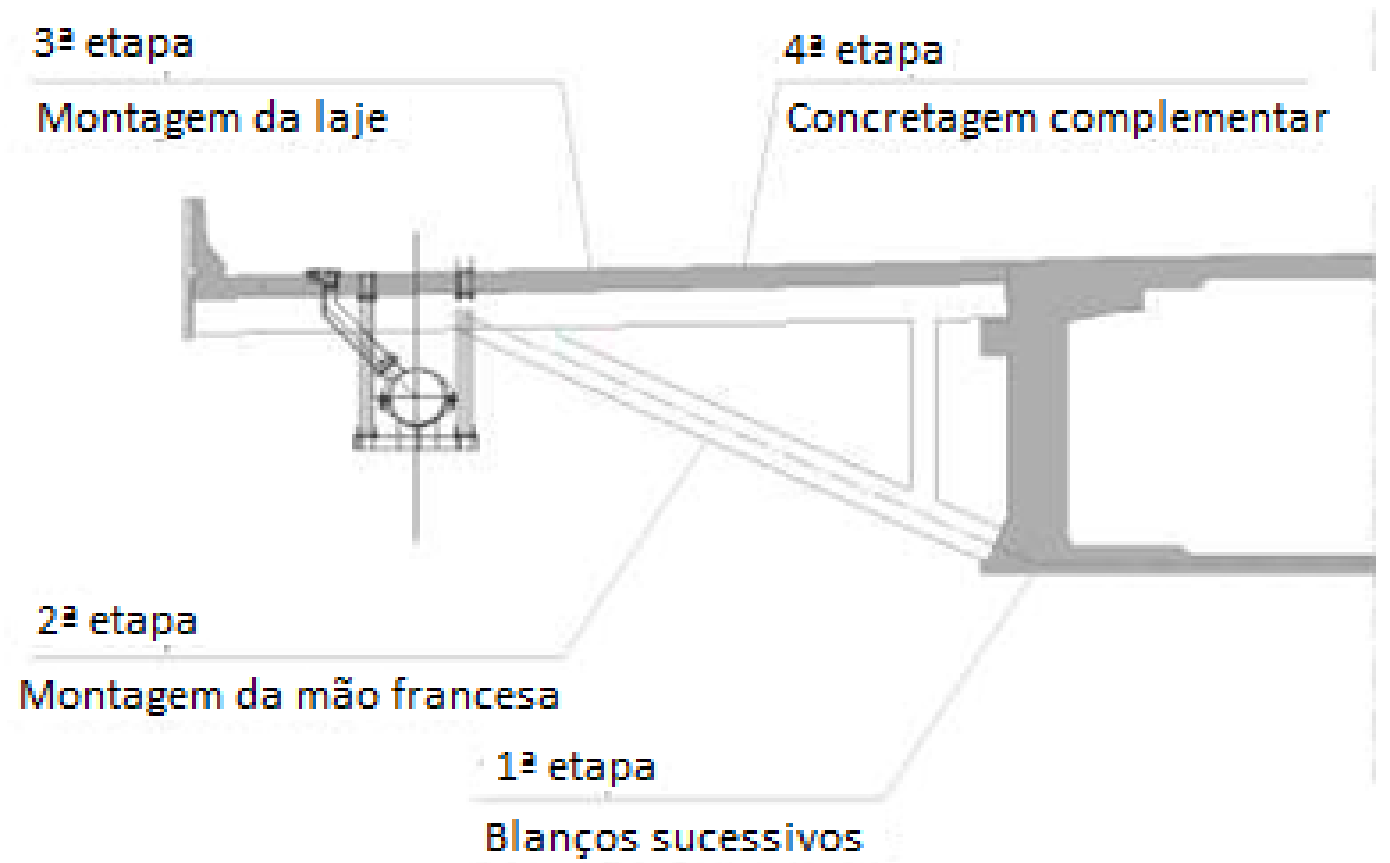

Fonte: Consórcio Ponte do Guaíba (2019)

A primeira etapa corresponde a execução dos blocos de fundação, pilares e da estrutura da ponte em caixão celular através de balanços sucessivos. A Figura 3.47 e a Figura 3.48 ilustram esta primeira etapa.

Figura 3.47 - Primeira etapa: Execução dos blocos e pilares

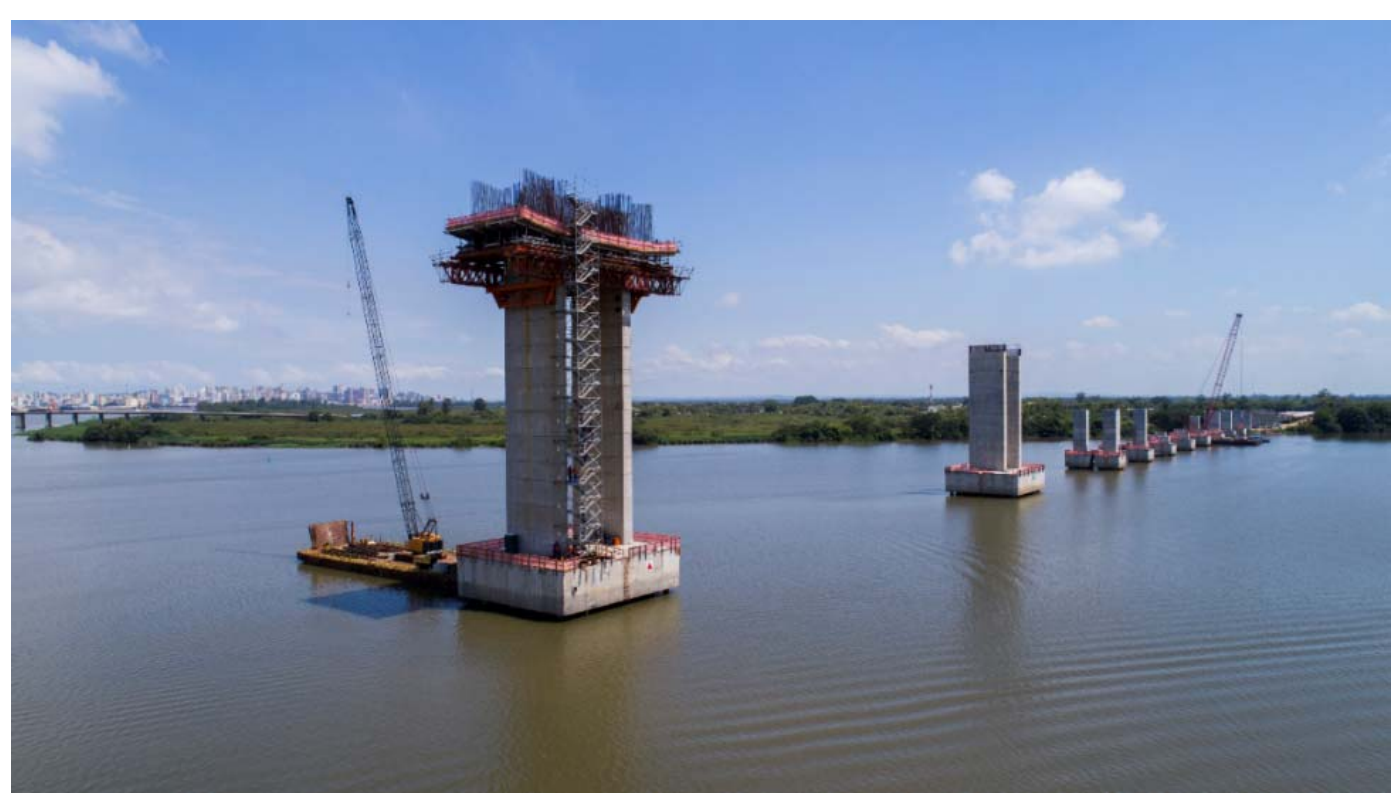

Fonte: Consórcio Ponte do Guaíba (2019) 
Figura 3.48 - Primeira etapa: Avanço das aduelas de concreto

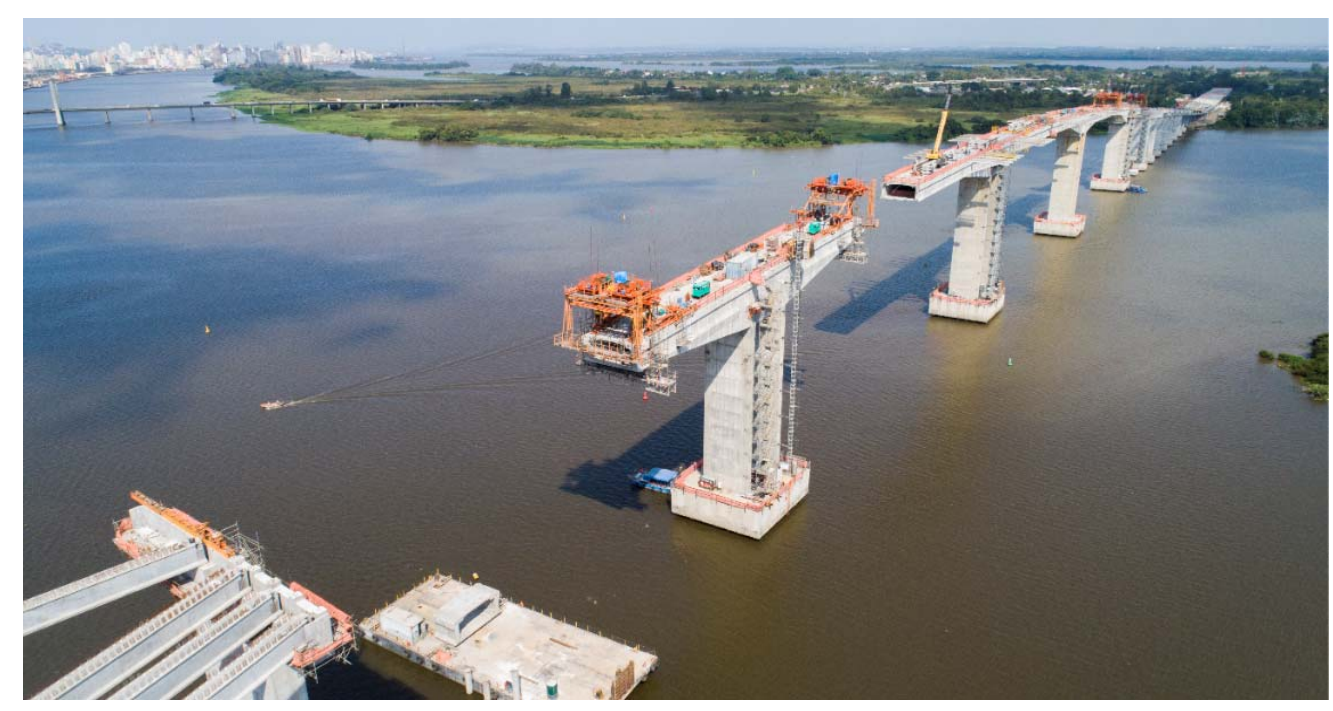

Fonte: Consórcio Ponte do Guaíba (2019)

A segunda etapa corresponde a montagem das mãos francesas pré-moldadas após execução das aduelas de concreto da superestrutura, conforme apresentado na Figura 3.49 e Figura 3.50 .

Figura 3.49 - Segunda etapa: montagem das mãos francesas

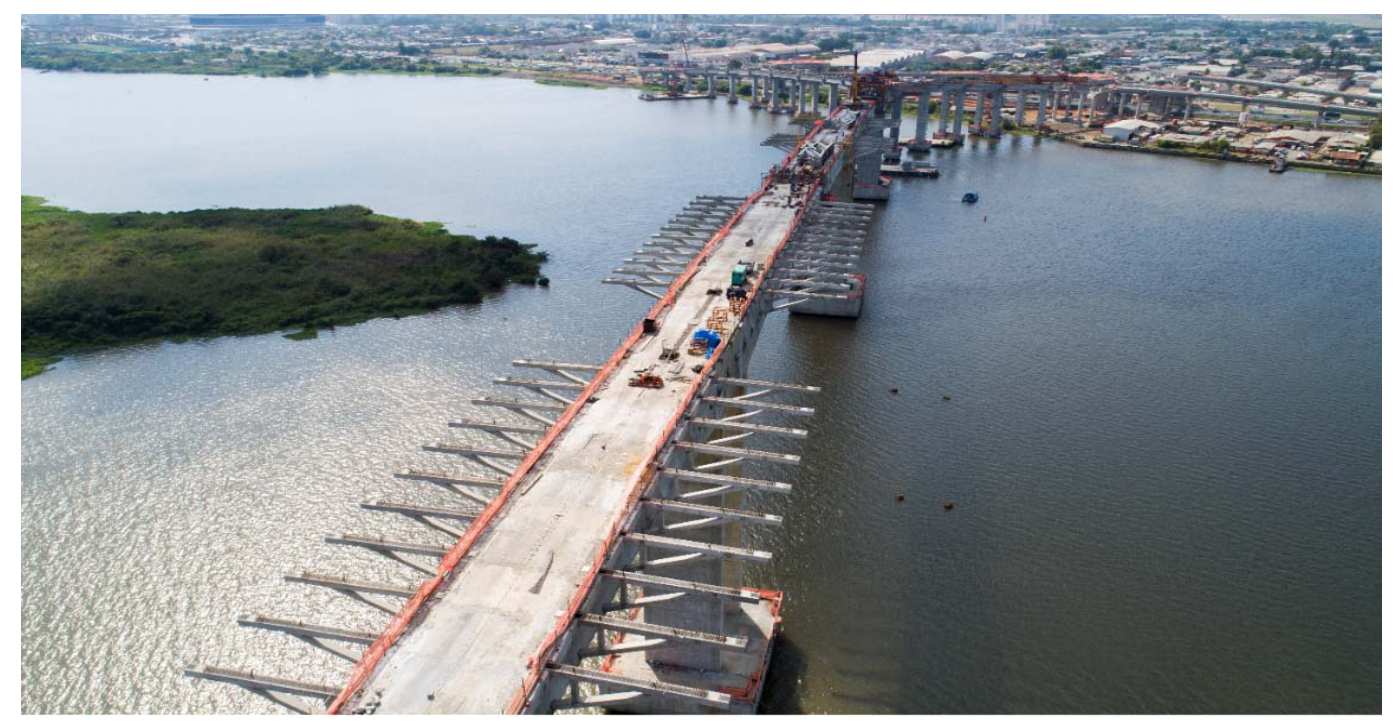

Fonte: Consórcio Ponte do Guaíba (2019) 
Figura 3.50 - Segunda etapa: montagem das mãos francesas

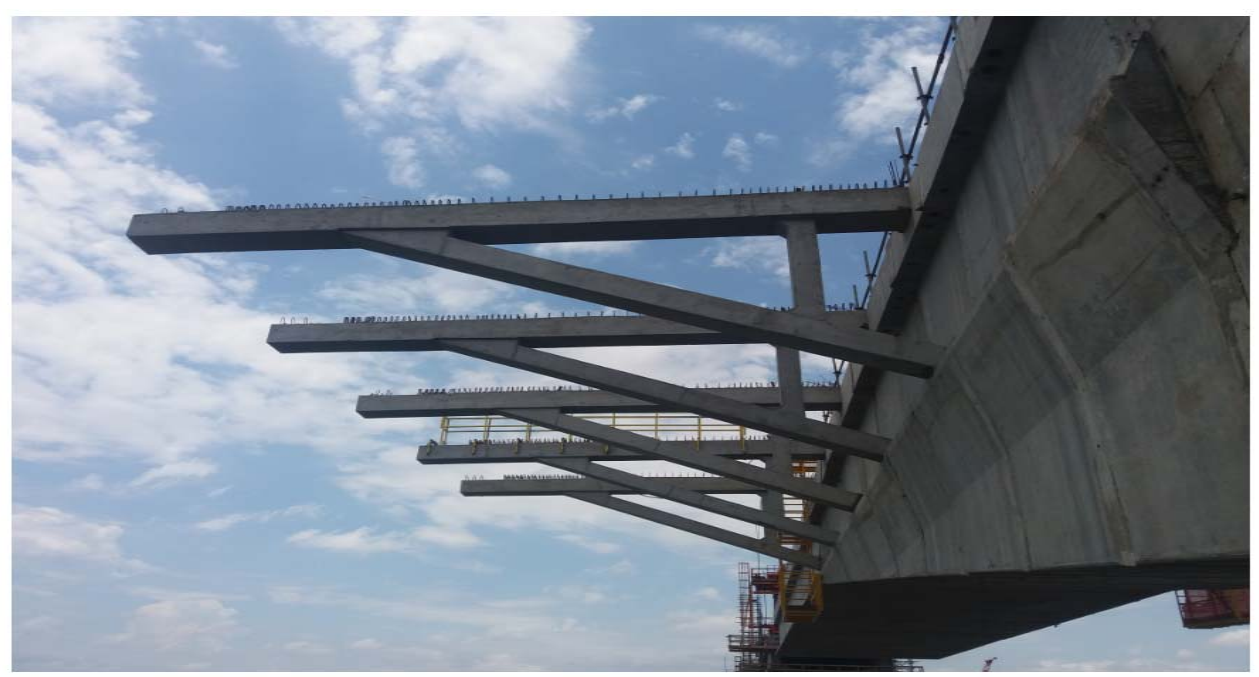

Fonte: Consórcio Ponte do Guaíba (2019)

A terceira etapa é executada após montagem das mãos francesas e corresponde à concretagem das lajes.

A quarta e última etapa corresponde a uma concretagem complementar.

\subsubsection{Objeto de ensaio: Ligação entre mão francesa e aduelas}

O ensaio de ultrassom foi realizado para avaliação da integridade da ligação entre o banzo inferior das mãos francesas e as aduelas de concreto. A Região de ensaio está apresentada na Figura 3.51 e na Figura 3.52. 
Figura 3.51 - Detalhe da região de ensaio: ligação entre mão-francesa e aduela

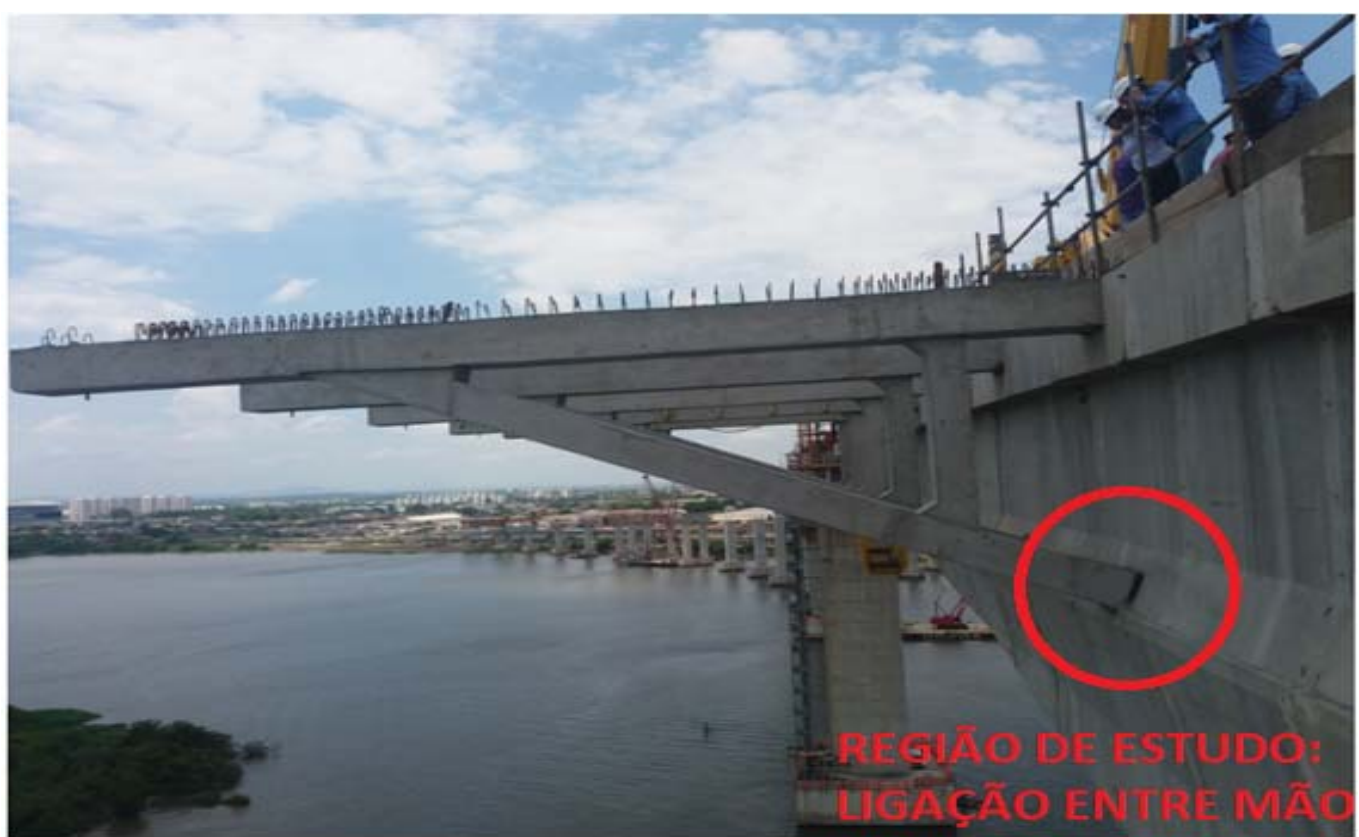

FRANCESA E ADUELA

Fonte: Adaptado de Consórcio Ponte do Guaíba (2019)

Figura 3.52 - Detalhe da região de ensaio: ligação entre mão-francesa e aduela
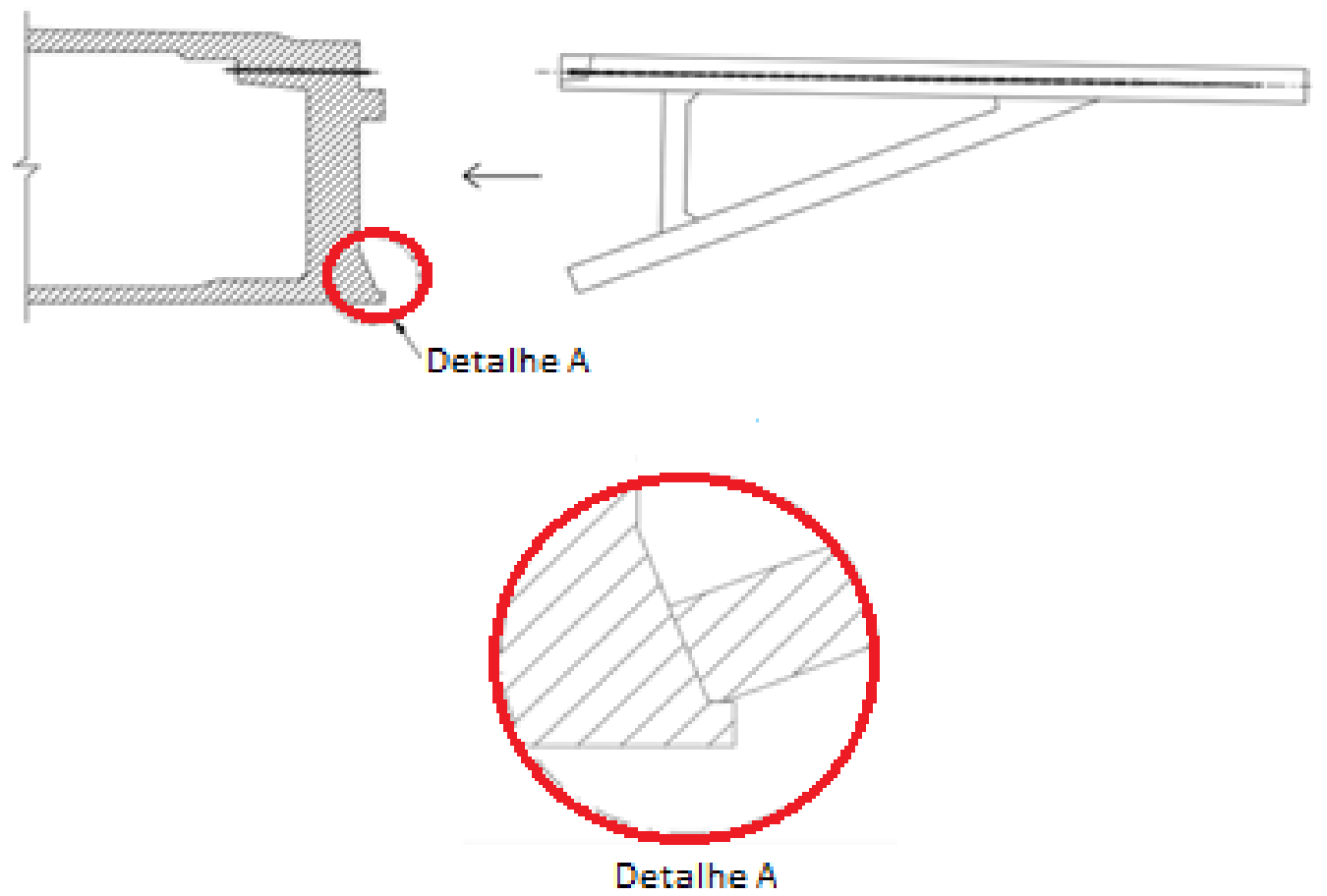

Fonte: Adaptado de Consórcio Ponte do Guaíba (2019) 
As mãos francesas são pré-moldadas. A ligação do banzo inferior da mão francesa com a estrutura da ponte é feita através de resina epóxi, conforme ilustra a Figura 3.53.

Figura 3.53 - Detalhe do epóxi na região de ensaio: ligação entre mão-francesa e aduela

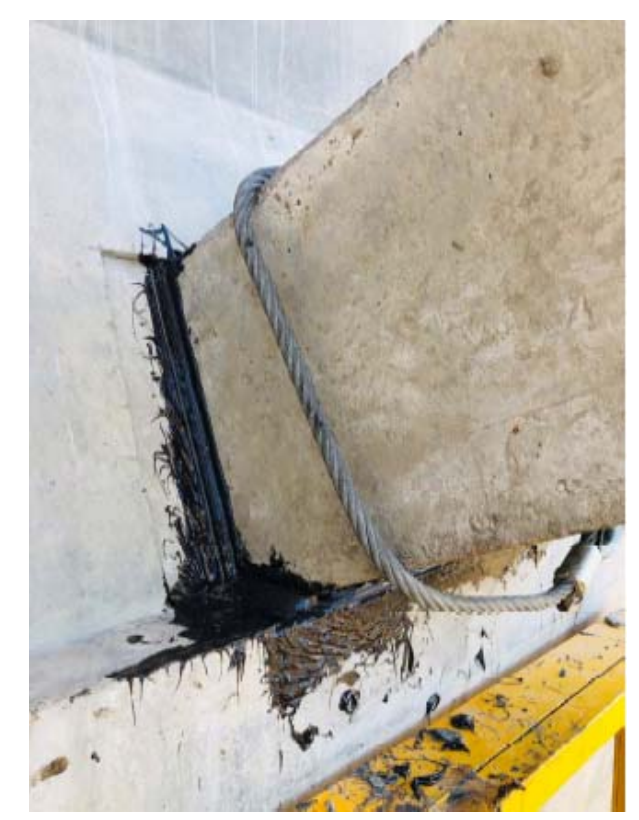

Fonte: Consórcio Ponte do Guaíba (2019)

\subsubsection{Equipamentos utilizados}

Para acessar a região de ensaio montaram-se andaimes metálicos. Para garantir a segurança na realização dos ensaios, utilizou-se capacete e cinto de segurança, que ficava travado à estrutura metálica. $O$ ensaio de ultrassom foi realizado com equipamento PUNDIT LAB+, com transdutor de frequência de $54 \mathrm{kHz}$. Para marcação dos pontos a serem ensaiados utilizou-se uma régua e um giz. Antes de realizar os ensaios, aplicou-se acoplante em gel para homogeneizar a superfície e evitar a entrada de ar.

\subsubsection{Metodologia de ensaio}

Os transdutores foram colocados em diversos pontos da região de interesse (ligação entre mão francesa e aduela), sempre colocando um transdutor na mão francesa e outro transdutor na alma da aduela, conforme ilustra a Figura 3.54. 
Figura 3.54 - Aplicação do ensaio - um transdutor na aduela de concreto e o outro transdutor na mão francesa

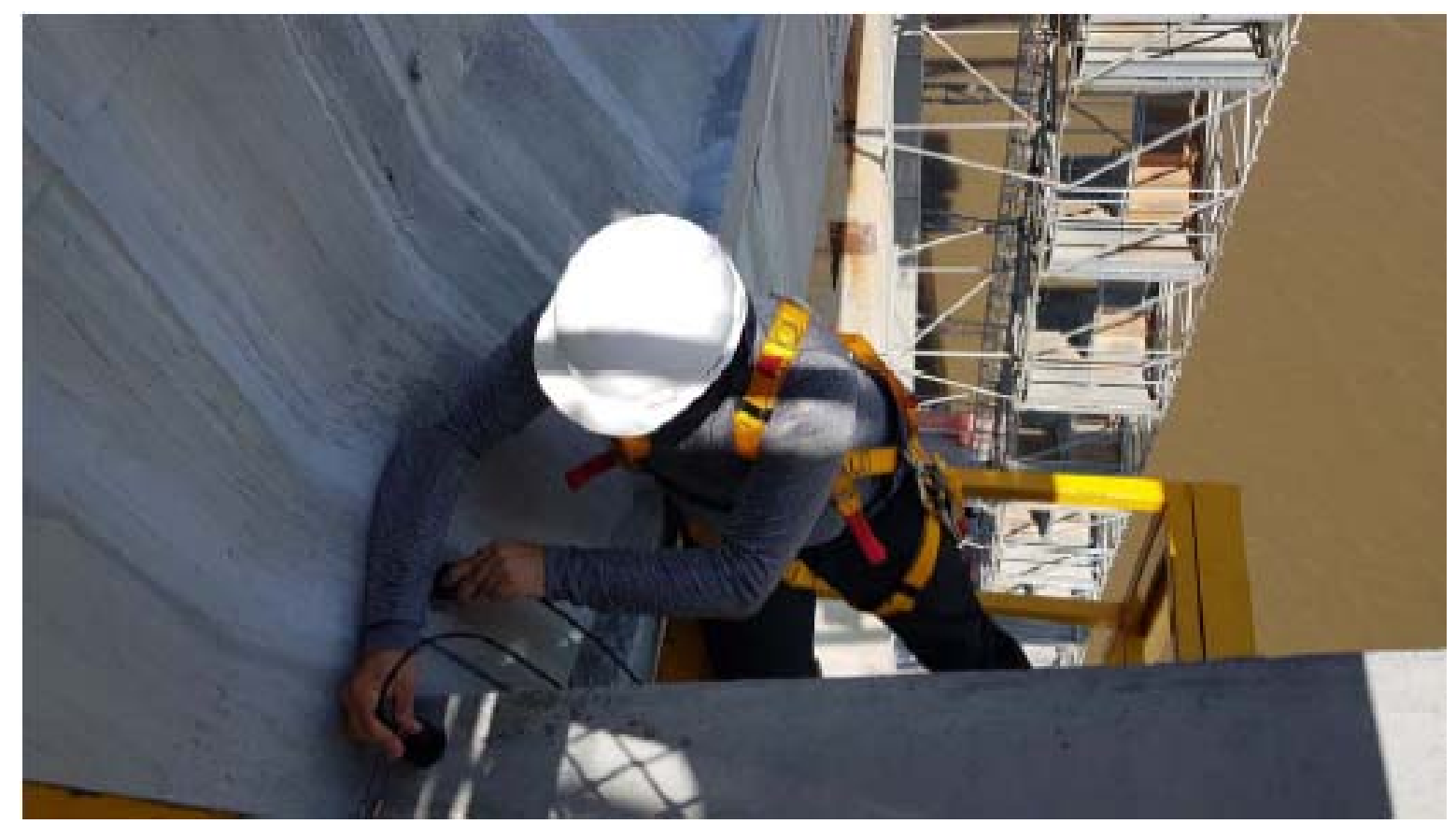

Fonte: Consórcio Ponte do Guaíba (2019)

Buscou-se sempre um caminho que atravessasse a camada de epóxi. Foram feitas diversas combinações. Os pontos ensaiados na mão francesa e na aduela estão apresentados em perspectiva e em elevação na Figura 3.55. 
Figura 3.55 - Localização dos pontos de ensaio
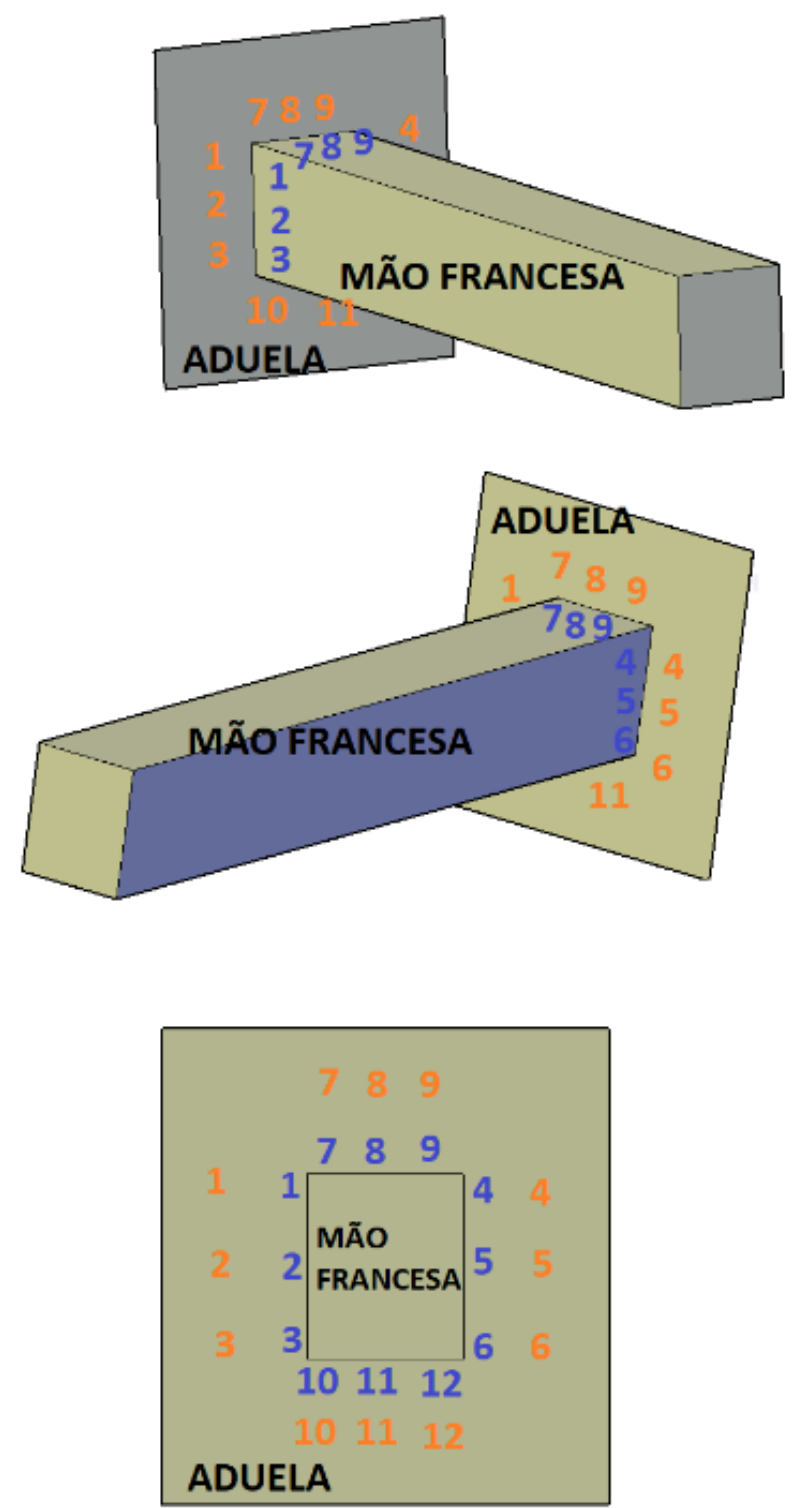

Fonte: Autoria própria

Para realizar os ensaios, primeiramente foi definida a velocidade de propagação do pulso para uma superfície de cada mão francesa ensaiada, posicionando os trandutores em faces opostas das mãos francesas.

Mediu-se o tempo de percurso e a distância entre transdutores e determinouse a velocidade de propagação. Estes valores de velocidades obtidos foram inseridos como referência nas leituras de cada região estudada. 
Após definida a velocidade de referência nas leituras, foram definidos os pontos a serem ensaiados, utilizando uma régua e um giz para tanto, e anotando as distâncias, conforme ilustra a Figura 3.56.

Figura 3.56 - Marcação dos pontos a serem ensaiados

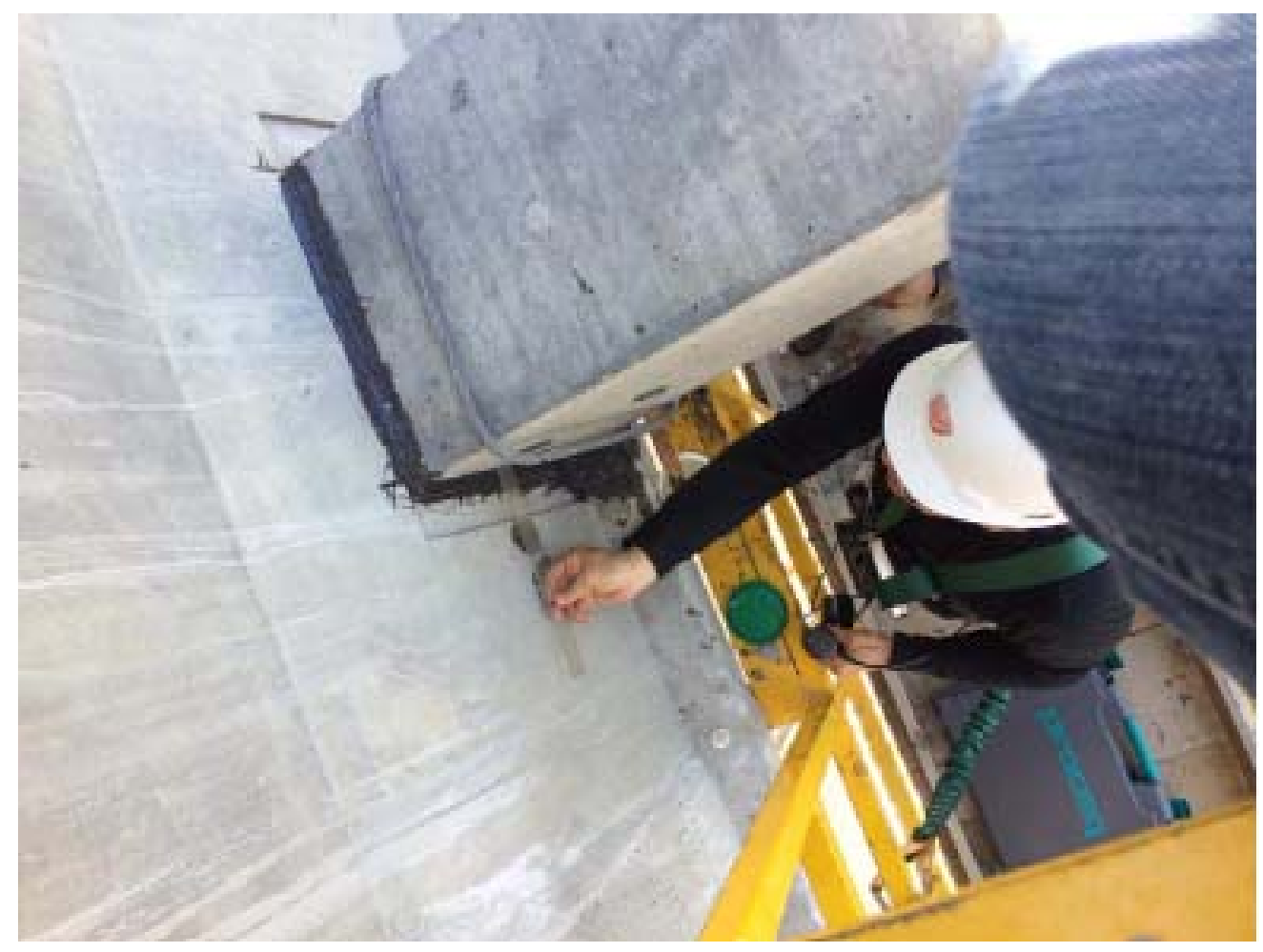

Fonte: Consórcio Ponte do Guaíba (2019)

Definidos os pontos a serem ensaiados, aplicou-se gel acoplante para homogeneizar a superfície e realizou-se o ensaio. Foram aplicadas diversas combinações, sempre com um transdutor na mão francesa e o outro na alma da aduela, de forma a atravessar o filme de epóxi, conforme ilustra a Figura 3.57 
Figura 3.57 - Realização do ensaio com um transdutor na aduela e o outro na mão francesa

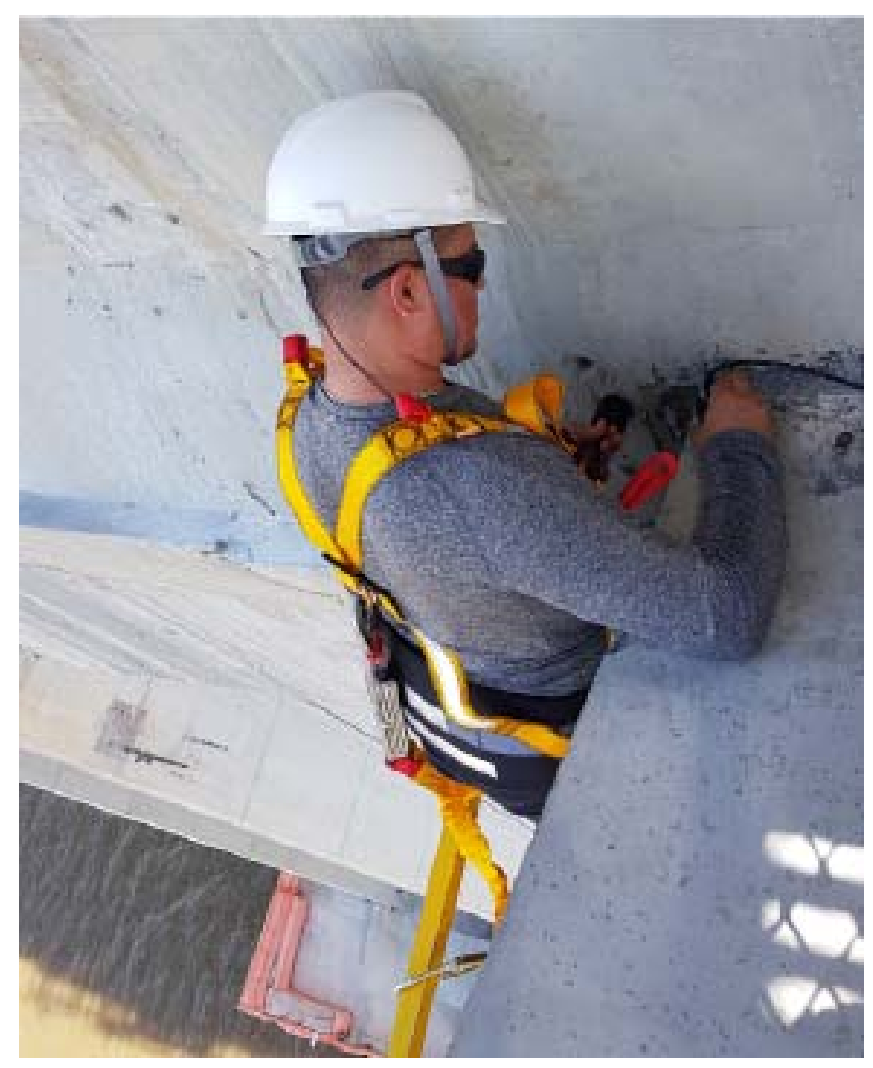

Fonte: Consórcio Ponte do Guaíba (2019)

No ensaio, foram medidos o tempo de percurso entre a emissão de um pulso por um transdutor e a recepção pelo outro transdutor. A distância entre transdutores foi determinada previamente, conforme ilustrado na Figura 3.56.

\subsubsection{Resultados e discussões}

A partir das diversas combinações feitas nos ensaios foram medidas as distâncias e o tempo de percurso entre a emissão de um pulso por um transdutor e a recepção pelo outro transdutor, conforme dados fornecidos pelo Consórcio Ponte do Guaíba (2019) e apresentados no ANEXO.

De posse desses dados para as diversas combinações, foram elaborados os gráficos de distância em função do tempo, para as diversas regiões estudadas, conforme é apresentado da Figura 3.58 a Figura 3.69. 
Figura 3.58 - Gráfico Distância x Tempo - Ligação Entre Aduela 2 e Mão Francesa 224

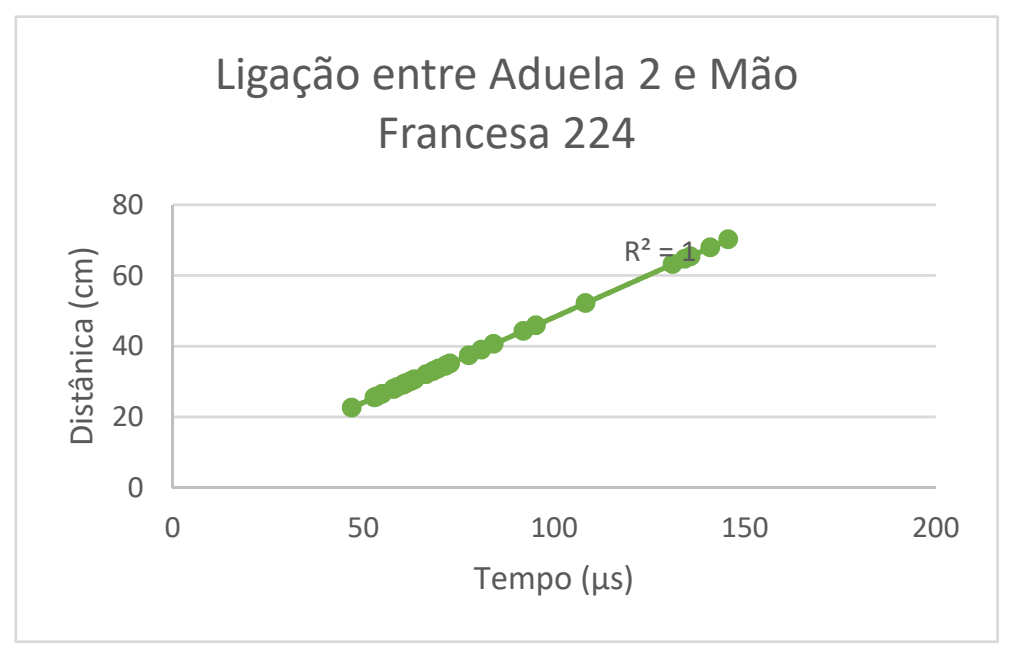

Fonte: Autoria Própria

Observa-se na Figura 3.58 que o coeficiente de correlação de Pearson é 1, indicando grande correlação entre os resultados obtidos no ensaio. A velocidade média de propagação do pulso entre a mão francesa 224 e a aduela 2 é de 4804,5 $\mathrm{m} / \mathrm{s}$ (inclinação da reta tangente). A velocidade obtida para calibração do equipamento, medida entre uma face da mão francesa e uma face oposta foi de $4770,0 \mathrm{~m} / \mathrm{s}$.

Figura 3.59 - Gráfico Distância x Tempo - Ligação Entre Aduela 2 e Mão Francesa 231

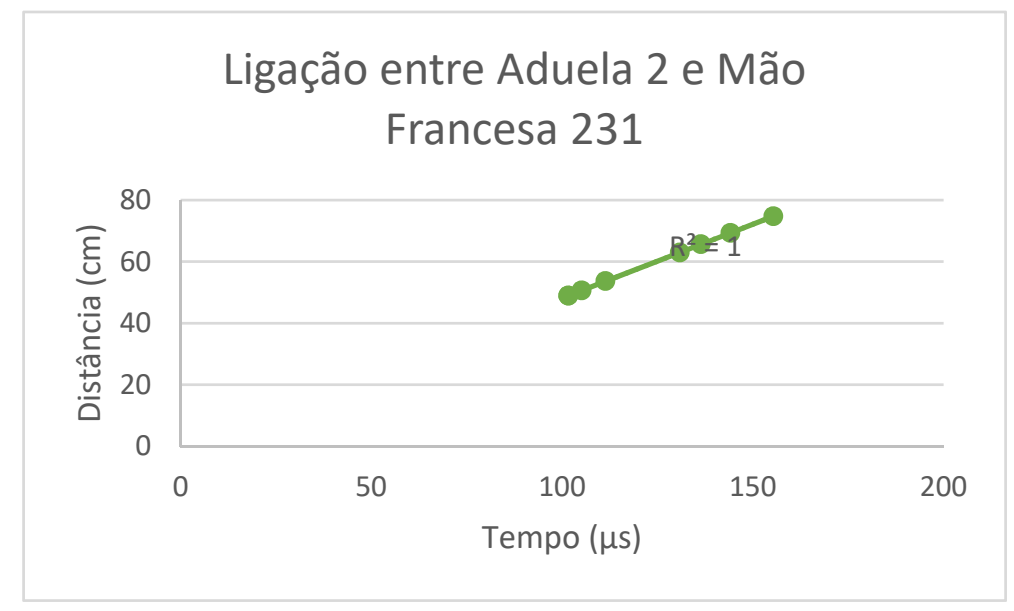

Fonte: Autoria Própria

Observa-se na Figura 3.59 que o coeficiente de correlação de Pearson é 1, indicando grande correlação entre os resultados obtidos no ensaio. A velocidade média de propagação do pulso entre a mão francesa 231 e a aduela 2 é de 4804,5 
$\mathrm{m} / \mathrm{s}$ (inclinação da reta tangente). A velocidade obtida para calibração do equipamento, medida entre uma face da mão francesa e uma face oposta foi de $4816,0 \mathrm{~m} / \mathrm{s}$.

Figura 3.60 - Gráfico Distância x Tempo - Ligação Entre Aduela 10 e Mão Francesa 254

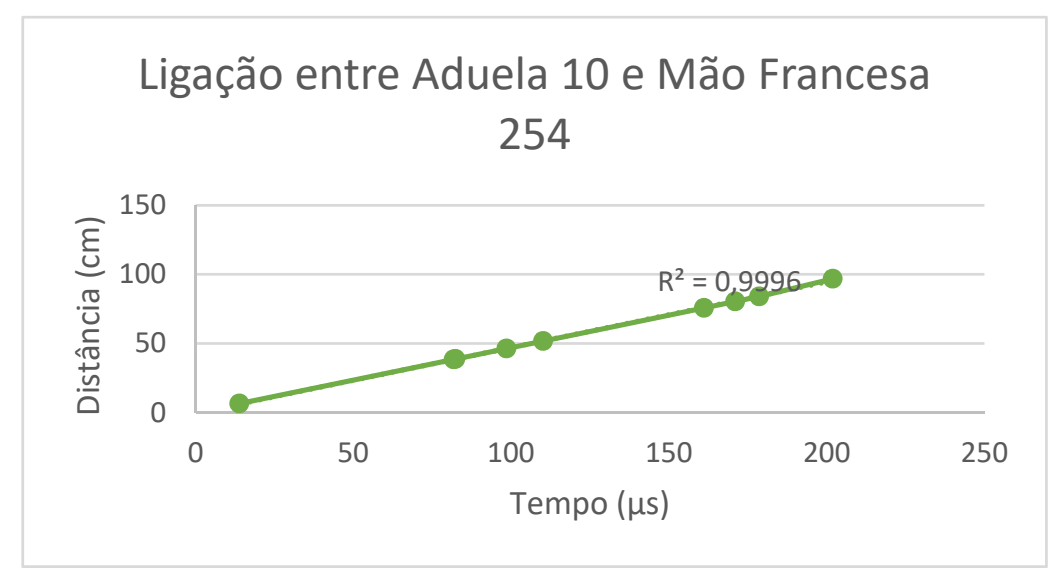

Fonte: Autoria Própria

Observa-se na Figura 3.60 que o coeficiente de correlação de Pearson é 0,9996, indicando grande correlação entre os resultados obtidos no ensaio. A velocidade média de propagação do pulso entre a mão francesa 254 e a aduela 10 é de $4702,7 \mathrm{~m} / \mathrm{s}$ (inclinação da reta tangente). A velocidade obtida para calibração do equipamento, medida entre uma face da mão francesa e uma face oposta foi de $4699,0 \mathrm{~m} / \mathrm{s}$.

Figura 3.61 - Gráfico Distância x Tempo - Ligação Entre Aduela 10 e Mão Francesa 258

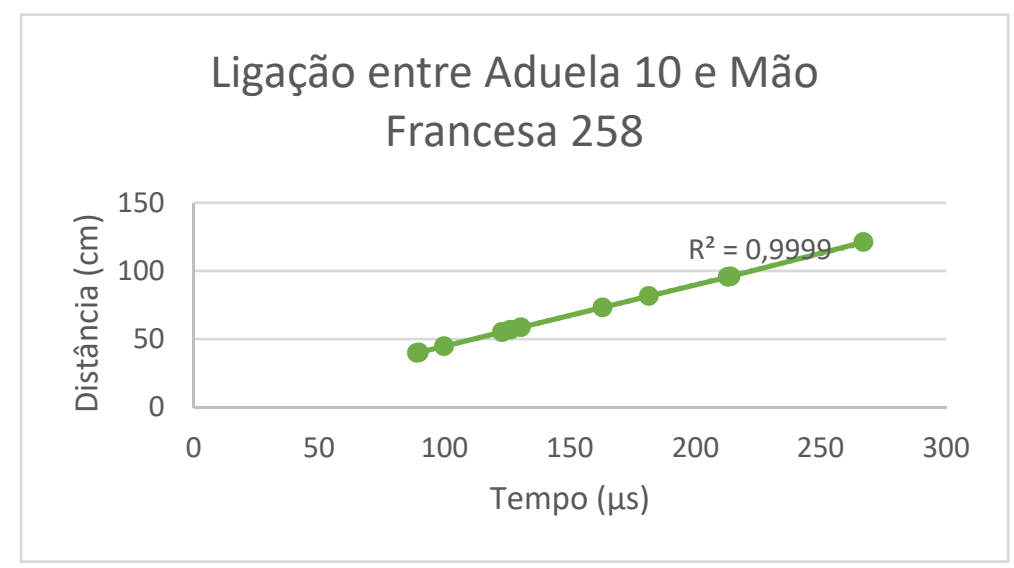

Fonte: Autoria Própria 
Observa-se na Figura 3.61 que o coeficiente de correlação de Pearson é 0,9999, indicando grande correlação entre os resultados obtidos no ensaio. A velocidade média de propagação do pulso entre a mão francesa 258 e a aduela 10 é de $4444,4 \mathrm{~m} / \mathrm{s}$ (inclinação da reta tangente). A velocidade obtida para calibração do equipamento, medida entre uma face da mão francesa e uma face oposta foi de $4430,0 \mathrm{~m} / \mathrm{s}$.

Figura 3.62 - Gráfico Distância x Tempo - Ligação Entre Aduela 16 e Mão Francesa 259

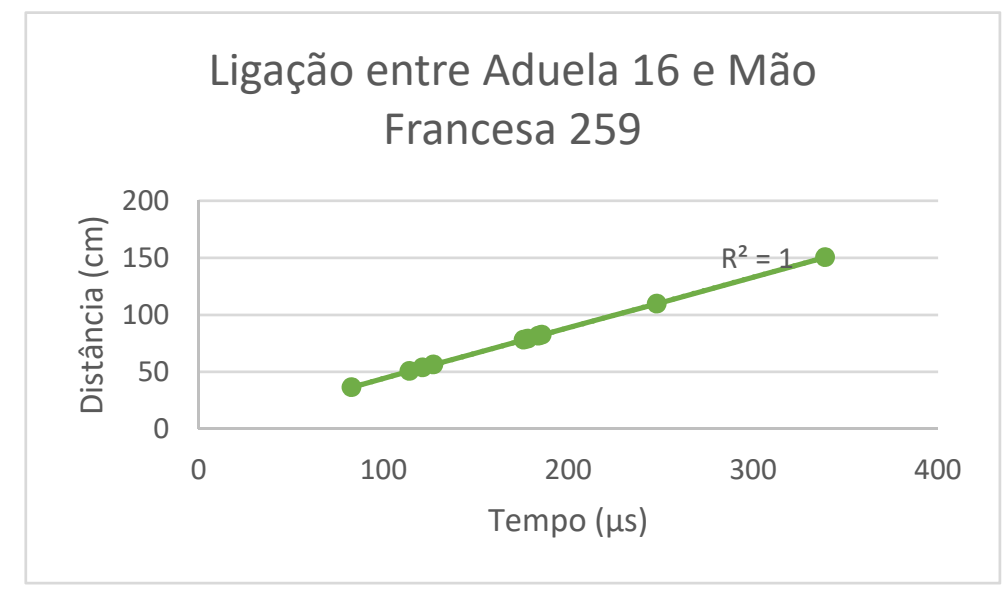

Fonte: Autoria Própria

Observa-se na Figura 3.62 que o coeficiente de correlação de Pearson é 1, indicando grande correlação entre os resultados obtidos no ensaio. A velocidade média de propagação do pulso entre a mão francesa 259 e a aduela 16 é de 4449,6 $\mathrm{m} / \mathrm{s}$ (inclinação da reta tangente). A velocidade obtida para calibração do equipamento, medida entre uma face da mão francesa e uma face oposta foi de $4441,0 \mathrm{~m} / \mathrm{s}$. 
Figura 3.63 - Gráfico Distância x Tempo - Ligação Entre Aduela 16 e Mão Francesa 255

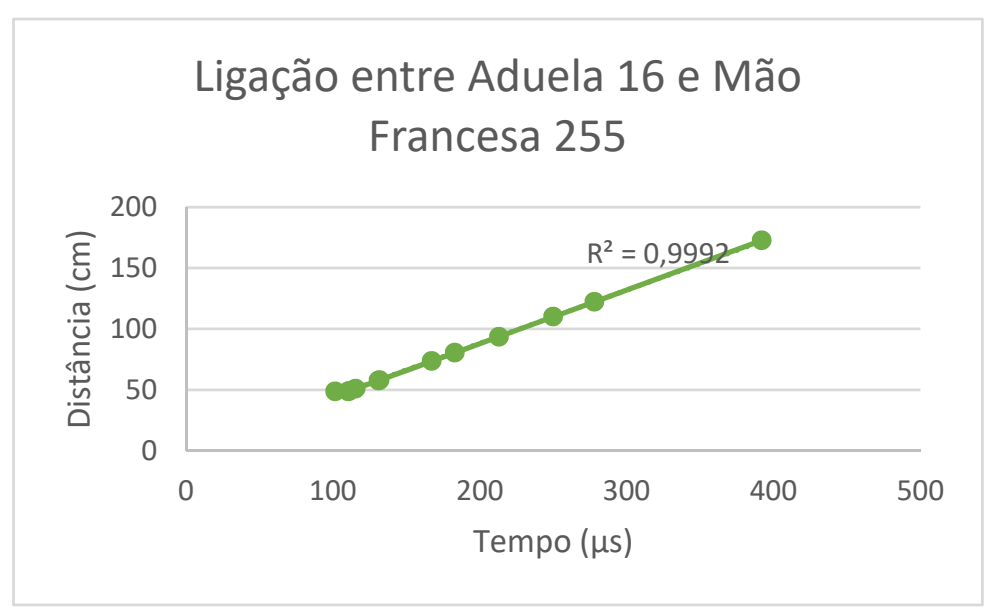

Fonte: Autoria Própria

Observa-se na Figura 3.63 que o coeficiente de correlação de Pearson é 0,9992, indicando grande correlação entre os resultados obtidos no ensaio. A velocidade média de propagação do pulso entre a mão francesa 255 e a aduela 16 é de $4405,0 \mathrm{~m} / \mathrm{s}$ (inclinação da reta tangente). A velocidade obtida para calibração do equipamento, medida entre uma face da mão francesa e uma face oposta foi de $4406,0 \mathrm{~m} / \mathrm{s}$.

Figura 3.64 - Gráfico Distância x Tempo - Ligação Entre Aduela 5A e Mão Francesa 192

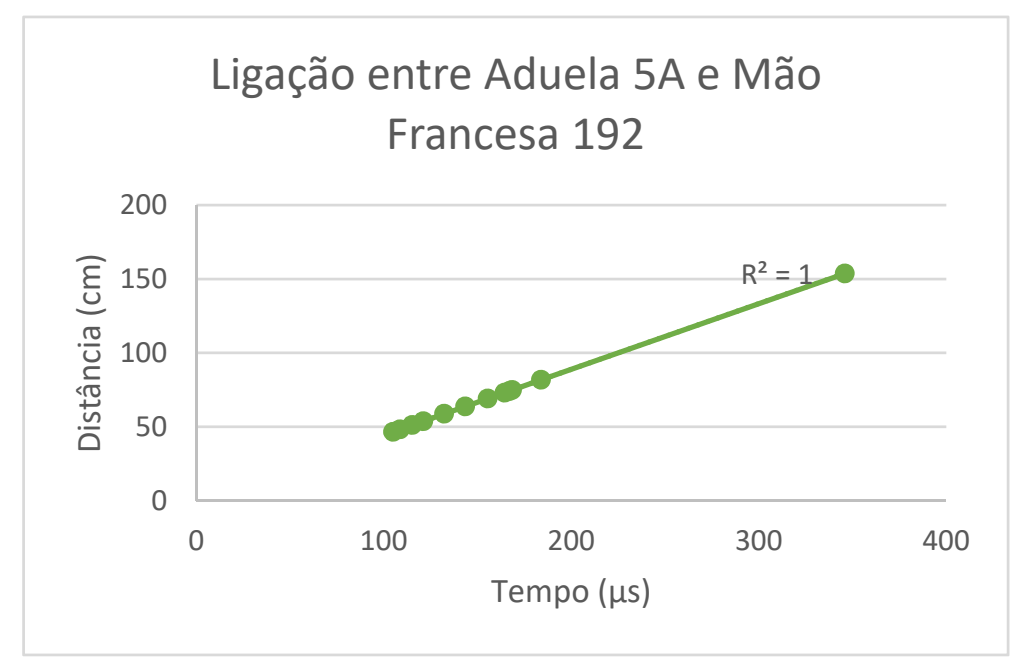

Fonte: Autoria Própria

Observa-se na Figura 3.64 que o coeficiente de correlação de Pearson é 1, indicando grande correlação entre os resultados obtidos no ensaio. A velocidade média de propagação do pulso entre a mão francesa 192 e a aduela 5A é de 4444,0 
$\mathrm{m} / \mathrm{s}$ (inclinação da reta tangente). A velocidade obtida para calibração do equipamento, medida entre uma face da mão francesa e uma face oposta foi de $4451,0 \mathrm{~m} / \mathrm{s}$.

Figura 3.65 - Gráfico Distância x Tempo - Ligação Entre Aduela 5A e Mão Francesa 202

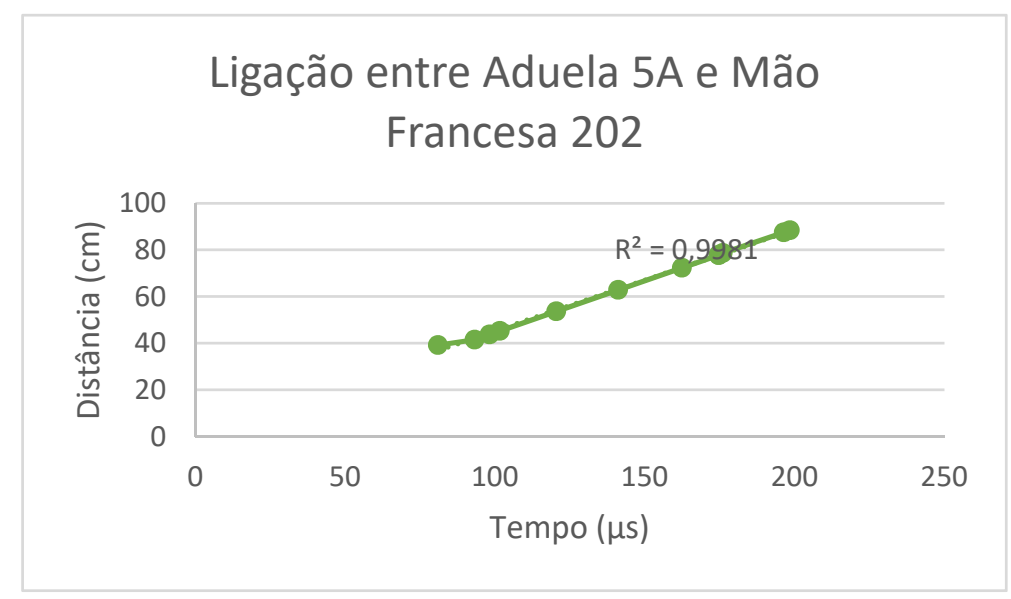

Fonte: Autoria Própria

Observa-se na Figura 3.65 que o coeficiente de correlação de Pearson é 0,9981, indicando grande correlação entre os resultados obtidos no ensaio. A velocidade média de propagação do pulso entre a mão francesa 202 e a aduela $5 \mathrm{~A}$ é de $4457,4 \mathrm{~m} / \mathrm{s}$ (inclinação da reta tangente). A velocidade obtida para calibração do equipamento, medida entre uma face da mão francesa e uma face oposta foi de 4453 $\mathrm{m} / \mathrm{s}$.

Figura 3.66 - Gráfico Distância x Tempo - Ligação Entre Aduela 11 e Mão Francesa 201

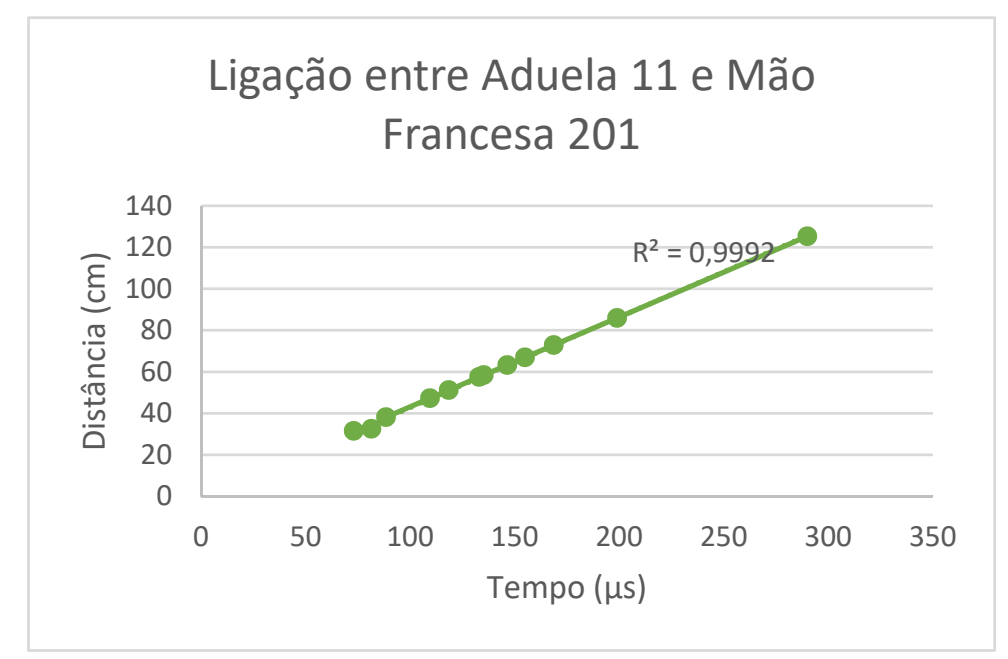

Fonte: Autoria Própria 
Observa-se na Figura 3.66 que o coeficiente de correlação de Pearson é 0,9992, indicando grande correlação entre os resultados obtidos no ensaio. A velocidade média de propagação do pulso entre a mão francesa 201 e a aduela 11 é de 4322,6 m/s (inclinação da reta tangente). A velocidade obtida para calibração do equipamento, medida entre uma face da mão francesa e uma face oposta foi de 4320 $\mathrm{m} / \mathrm{s}$.

Figura 3.67 - Gráfico Distância x Tempo - Ligação Entre Aduela 11 e Mão Francesa 197

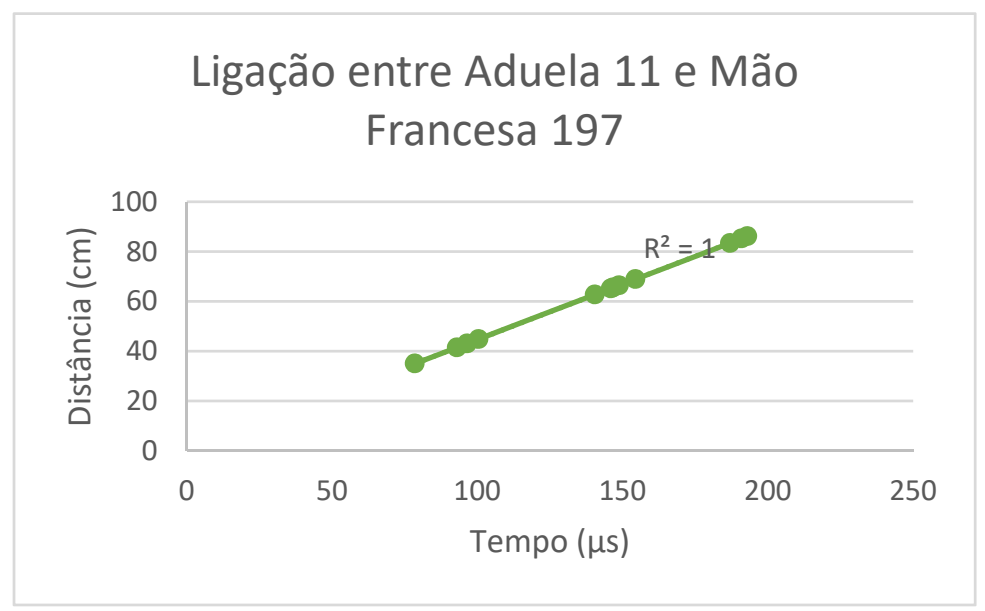

Fonte: Autoria Própria

Observa-se na Figura 3.67 que o coeficiente de correlação de Pearson é 1, indicando grande correlação entre os resultados obtidos no ensaio. A velocidade média de propagação do pulso entre a mão francesa 197 e a aduela 11 é de 4462,9 $\mathrm{m} / \mathrm{s}$ (inclinação da reta tangente). A velocidade obtida para calibração do equipamento, medida entre uma face da mão francesa e uma face oposta foi de $4467,0 \mathrm{~m} / \mathrm{s}$. 
Figura 3.68 - Gráfico Distância x Tempo - Ligação Entre Aduela 17 e Mão Francesa 232

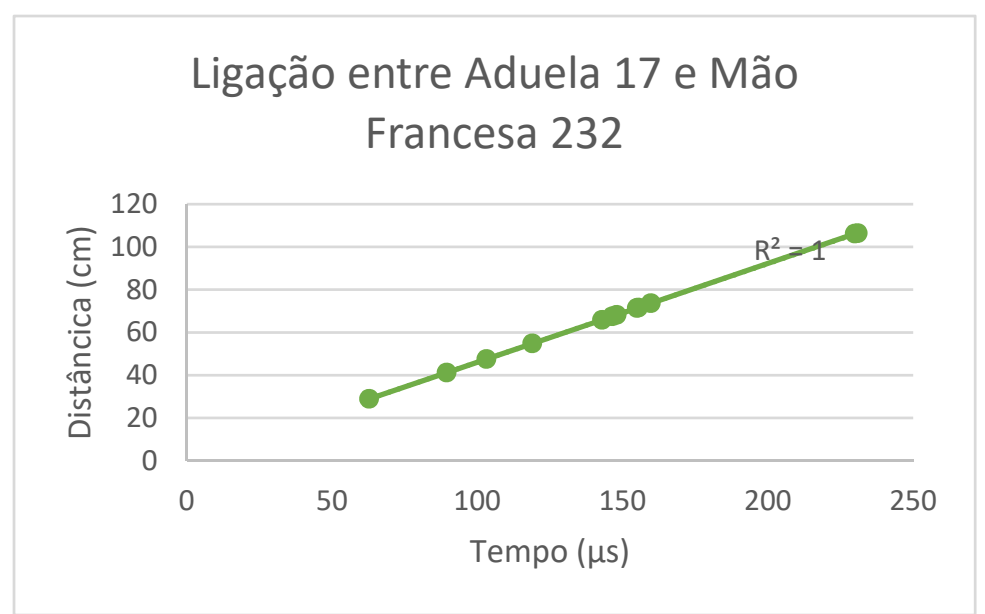

Fonte: Autoria Própria

Observa-se na Figura 3.68 que o coeficiente de correlação de Pearson é 1, indicando grande correlação entre os resultados obtidos no ensaio. A velocidade média de propagação do pulso entre a mão francesa 232 e a aduela 17 é de 4617,2 $\mathrm{m} / \mathrm{s}$ (inclinação da reta tangente). A velocidade obtida para calibração do equipamento, medida entre uma face da mão francesa e uma face oposta foi de $4611,0 \mathrm{~m} / \mathrm{s}$.

Figura 3.69 - Gráfico Distância x Tempo - Ligação Entre Aduela 17 e Mão Francesa 198

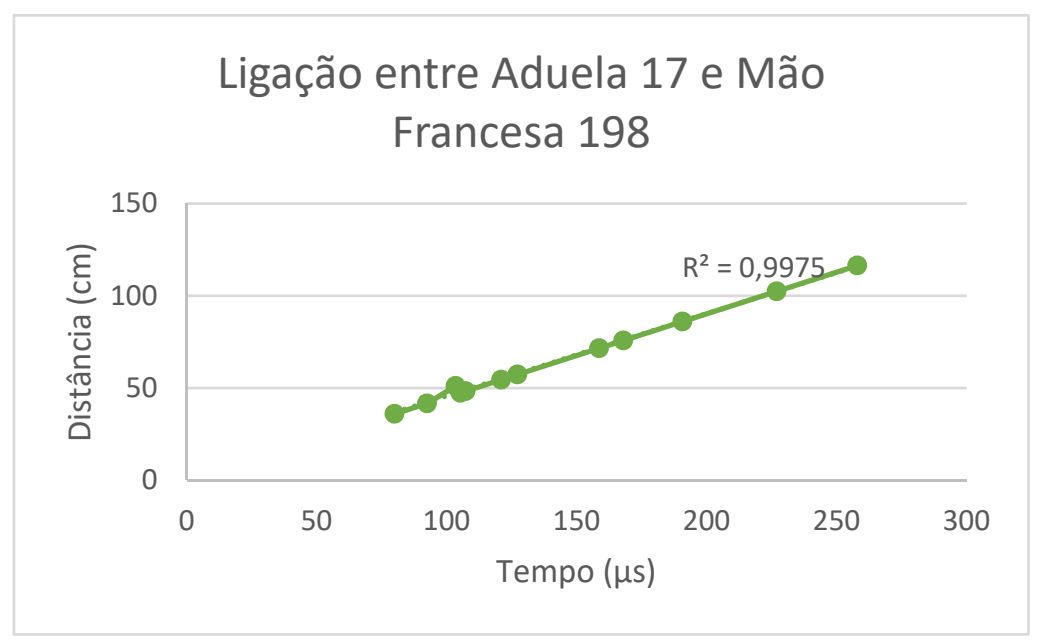

Fonte: Autoria Própria

Observa-se na Figura 3.69 que o coeficiente de correlação de Pearson é 0,9975, indicando grande correlação entre os resultados obtidos no ensaio. A velocidade média de propagação do pulso entre a mão francesa 198 e a aduela 17 é 
de $4512,1 \mathrm{~m} / \mathrm{s}$ (inclinação da reta tangente). A velocidade obtida para calibração do equipamento, medida entre uma face da mão francesa e uma face oposta foi de 4510 $\mathrm{m} / \mathrm{s}$.

A partir dos gráficos de distância em função do tempo para cada uma das ligações, obteve-se as velocidades médias de propagação do pulso. A velocidade corresponde à inclinação da reta tangente dos gráficos (variação do espaço no tempo). A Figura 3.70 apresenta um resumo das velocidades médias obtidas para as 12 ligações ensaiadas.

Figura 3.70 - Velocidades dos pulsos obtidas nas diferentes ligações

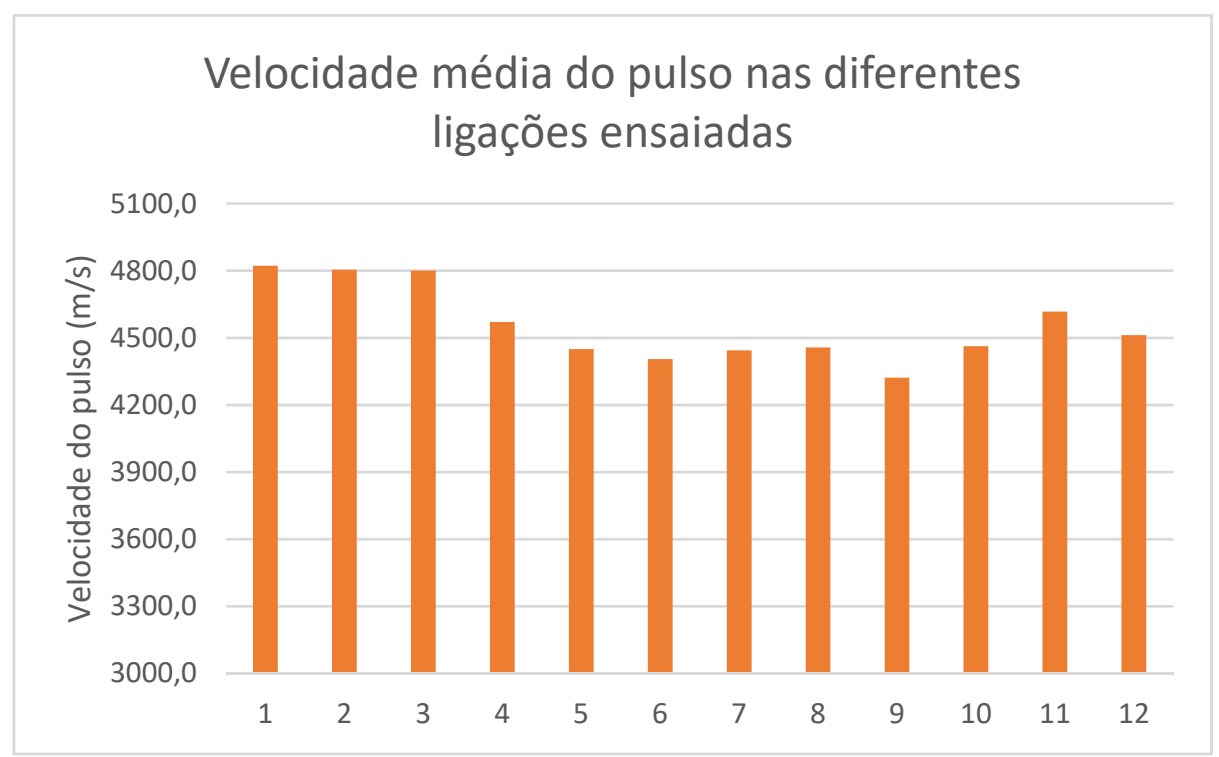

Fonte: Autoria Própria

Observa-se que a velocidade média foi de $4537,1 \mathrm{~m} / \mathrm{s}$. O desvio padrão foi de $154,9 \mathrm{~m} / \mathrm{s}$ e o coeficiente de variação resultante foi de $3,41 \%$, conforme indicado na Tabela 3.5. Bungey e Millard (2006) admitem que o coeficiente de variação possa ser de até $2,5 \%$. 
Tabela 3.5: Velocidades obtidas no ensaio de ultrassom (média, desvio padrão e coeficiente de variação das medidas)

\begin{tabular}{|c|c|}
\hline Ligação & $\begin{array}{c}\text { Velocidade medida } \\
\text { na ligação (m/s) }\end{array}$ \\
\hline $\mathbf{1}$ & 4822.7 \\
\hline $\mathbf{2}$ & 4804.5 \\
\hline $\mathbf{3}$ & 4702.7 \\
\hline $\mathbf{4}$ & 4444.4 \\
\hline $\mathbf{5}$ & 4449.6 \\
\hline $\mathbf{6}$ & 4405 \\
\hline $\mathbf{7}$ & 4444 \\
\hline $\mathbf{8}$ & 4457.4 \\
\hline $\mathbf{9}$ & 4322.6 \\
\hline $\mathbf{1 0}$ & 4462.9 \\
\hline $\mathbf{1 1}$ & 4617.2 \\
\hline $\mathbf{1 2}$ & 4512.1 \\
\hline Média & 4537.1 \\
\hline Desvio padrão & 154.9 \\
\hline Coef. De Variação & $3.41 \%$ \\
\hline
\end{tabular}

Fonte: Autoria Própria

Comparando as velocidades obtidas em cada ligação com as velocidades de calibração, que foram obtidas através do ensaio de duas faces opostas das mãos francesas, observa-se que as velocidades nos dois casos são muito próximas, conforme Tabela 3.6. 
Tabela 3.6: Comparação entre as velocidades obtidas nas ligações e as velocidades de calibração

\begin{tabular}{|c|c|c|c|}
\hline Ligação & $\begin{array}{c}\text { Velocidade medida } \\
\text { na ligação (m/s) }\end{array}$ & $\begin{array}{c}\text { Velocidade de } \\
\text { calibração (m/s) }\end{array}$ & $\begin{array}{c}\text { Diferença } \\
\text { Percentual }\end{array}$ \\
\hline $\mathbf{1}$ & 4822.7 & 4770 & $1.10 \%$ \\
\hline $\mathbf{2}$ & 4804.5 & 4816 & $-0.24 \%$ \\
\hline $\mathbf{3}$ & 4702.7 & 4699 & $0.08 \%$ \\
\hline $\mathbf{4}$ & 4444.4 & 4430 & $0.33 \%$ \\
\hline $\mathbf{5}$ & 4449.6 & 4441 & $0.19 \%$ \\
\hline $\mathbf{6}$ & 4405 & 4406 & $-0.02 \%$ \\
\hline $\mathbf{7}$ & 4444 & 4451 & $-0.16 \%$ \\
\hline $\mathbf{8}$ & 4457.4 & 4453 & $0.10 \%$ \\
\hline $\mathbf{9}$ & 4322.6 & 4320 & $0.06 \%$ \\
\hline $\mathbf{1 0}$ & 4462.9 & 4467 & $-0.09 \%$ \\
\hline $\mathbf{1 1}$ & 4617.2 & 4611 & $0.13 \%$ \\
\hline $\mathbf{1 2}$ & 4512.1 & 4510 & $0.05 \%$ \\
\hline
\end{tabular}

Fonte: Autoria Própria

A máxima variação percentual encontrada foi de 1,10\%. Desta forma, verificase que não houve diferença significativa na velocidade de propagação do pulso na região da junta se comparada a velocidade de propagação de uma região fora da junta. Conclui-se, portanto, que as regiões de ligação entre as mãos francesas e a alma das aduelas apresentam boa integridade.

A partir das Equações 2.4 e 2.6, estimou-se o módulo de elasticidade dinâmico e a resistência à compressão nas regiões ensaiadas, conforme apresentada na Tabela 3.7. 
Tabela 3.7 - Estimativa do módulo de elasticidade dinâmico e da resistência à compressão.

\begin{tabular}{|c|c|c|c|}
\hline Ligação & $\begin{array}{c}\text { Velocidade medida } \\
\text { na ligação (m/s) }\end{array}$ & Ed (G pa) & fc (Mpa) \\
\hline $\mathbf{1}$ & 4822.7 & 48.5 & 53.7 \\
\hline $\mathbf{2}$ & 4804.5 & 48.1 & 52.9 \\
\hline $\mathbf{3}$ & 4702.7 & 46.1 & 48.2 \\
\hline $\mathbf{4}$ & 4444.4 & 41.2 & 38.1 \\
\hline $\mathbf{5}$ & 4449.6 & 41.2 & 38.3 \\
\hline $\mathbf{6}$ & 4405 & 40.4 & 36.8 \\
\hline $\mathbf{7}$ & 4444 & 41.1 & 38.1 \\
\hline $\mathbf{8}$ & 4457.4 & 41.4 & 38.6 \\
\hline $\mathbf{9}$ & 4322.6 & 38.9 & 34.1 \\
\hline $\mathbf{1 0}$ & 4462.9 & 41.5 & 38.8 \\
\hline $\mathbf{1 1}$ & 4617.2 & 44.4 & 44.6 \\
\hline $\mathbf{1 2}$ & 4512.1 & 42.4 & 40.6 \\
\hline Média & 4537.1 & 42.9 & 41.9 \\
\hline Desvio padrão & 154.9 & 3 & 5.2 \\
\hline Coef. De Variação & $3.41 \%$ & $6.90 \%$ & $12.30 \%$ \\
\hline
\end{tabular}

Fonte: Autoria Própria

Observa-se que a estimativa média de resistência à compressão nas diversas regiões foi de 41,9 MPa e a estimativa média do módulo de elasticidade foi de 42,9 GPa. As estimativas para resistência à compressão apresentam coeficiente de variação de $12,3 \%$ e as estimativas para módulo de elasticidade dinâmico apresentam coeficiente de variação de 6,9\%. Bungey e Millard (2006) afirmam que o erro pode chegar a $20 \%$ na estimativa da resistência à compressão e de $10 \%$ na estimativa do módulo de elasticidade dinâmica, a partir do ensaio de ultrassom.

A Tabela 3.8 apresenta uma comparação entre as resistências à compressão estimadas no ensaio de ultrassom e as resistências à compressão obtidas no ensaio de compressão axial. Observa-se que o valor para resistência à compressão estimado no ensaio de ultrassom apresentou valores inferiores em relação aos valores obtidos no ensaio compressão axial. A diferença percentual média foi de 32,3\%. A diferença percentual apresentou menores valores na ligação 1, com diferença percentual de $12,1 \%$. A maior diferença foi encontrada na ligação 9 , com uma diferença percentual de $44,6 \%$. 
Tabela 3.8 - Comparação entre da resistência estimada pelo ultrassom com a resistência obtida no ensaio de compressão axial

\begin{tabular}{|c|c|c|c|c|}
\hline \multirow{2}{*}{ Ligação } & \multirow{2}{*}{$\begin{array}{c}\text { Velocidade medida } \\
\text { na ligação }(\mathbf{m} / \mathbf{s})\end{array}$} & Ultrassom & Compressão axial & \multirow{2}{*}{$\begin{array}{c}\text { Diferença } \\
\text { percentual }\end{array}$} \\
\cline { 3 - 4 } & $\mathbf{f c}$ (Mpa) & $\mathbf{f c}$ (Mpa) & \\
\hline $\mathbf{1}$ & 4822.7 & 53.7 & 61.1 & $-12.10 \%$ \\
\hline $\mathbf{2}$ & 4804.5 & 52.9 & 61.7 & $-14.30 \%$ \\
\hline $\mathbf{3}$ & 4702.7 & 48.2 & 61.6 & $-21.80 \%$ \\
\hline $\mathbf{4}$ & 4444.4 & 38.1 & 63.2 & $-39.70 \%$ \\
\hline $\mathbf{5}$ & 4449.6 & 38.3 & 63.2 & $-39.40 \%$ \\
\hline $\mathbf{6}$ & 4405 & 36.8 & 61.6 & $-40.30 \%$ \\
\hline $\mathbf{7}$ & 4444 & 38.1 & 59.3 & $-35.80 \%$ \\
\hline $\mathbf{8}$ & 4457.4 & 38.6 & 61.5 & $-37.20 \%$ \\
\hline $\mathbf{9}$ & 4322.6 & 34.1 & 61.5 & $-44.60 \%$ \\
\hline $\mathbf{1 0}$ & 4462.9 & 38.8 & 63.3 & $-38.70 \%$ \\
\hline $\mathbf{1 1}$ & 4617.2 & 44.6 & 61.7 & $-27.70 \%$ \\
\hline $\mathbf{1 2}$ & 4512.1 & 40.6 & 63.3 & $-35.90 \%$ \\
\hline Média & 4537.1 & 41.9 & 61.9 & $-32.30 \%$ \\
\hline Desvio padrão & 154.9 & 5.2 & 1.1 & \\
\hline Coef. De Variação & $3.41 \%$ & $12.30 \%$ & $1.82 \%$ & \\
\hline
\end{tabular}

Fonte: Autoria Própria

\subsection{Estudo de caso 4: Mapeamento com Laser Scanner e e avaliação da carbonatação na Ponte Eusébio Matoso.}

O quarto estudo de caso foi realizado na Ponte Eusébio Matoso, localizada na cidade de São Paulo / SP. Os dados utilizados no estudo foram fornecidos pela Secretaria de Obras de São Paulo. Com a intenção de fornecer informações para a análise estrutural da ponte, a secretaria de obras da cidade de São Paulo, contratou uma empresa terceirizada que realizou o mapeamento da ponte com laser scanner, além de realizar ensaio para verificação do nível de carbonatação das estruturas. Nesta seção será apresentada a metodologia desenvolvida para realização desses ensaios, os resultados obtidos e a análise crítica dos mesmos.

A Ponte Eusébio Matoso está localizada na Avenida Eusébio Matoso sobre as vias da Marginal Pinheiros e sobre o Rio Pinheiros, na região oeste da cidade de São Paulo / SP. Uma vista em planta da ponte está apresentada na Figura 3.71. 
Figura 3.71 - Vista em planta da Ponte Eusébio Matoso sobre o Rio Pinheiros.

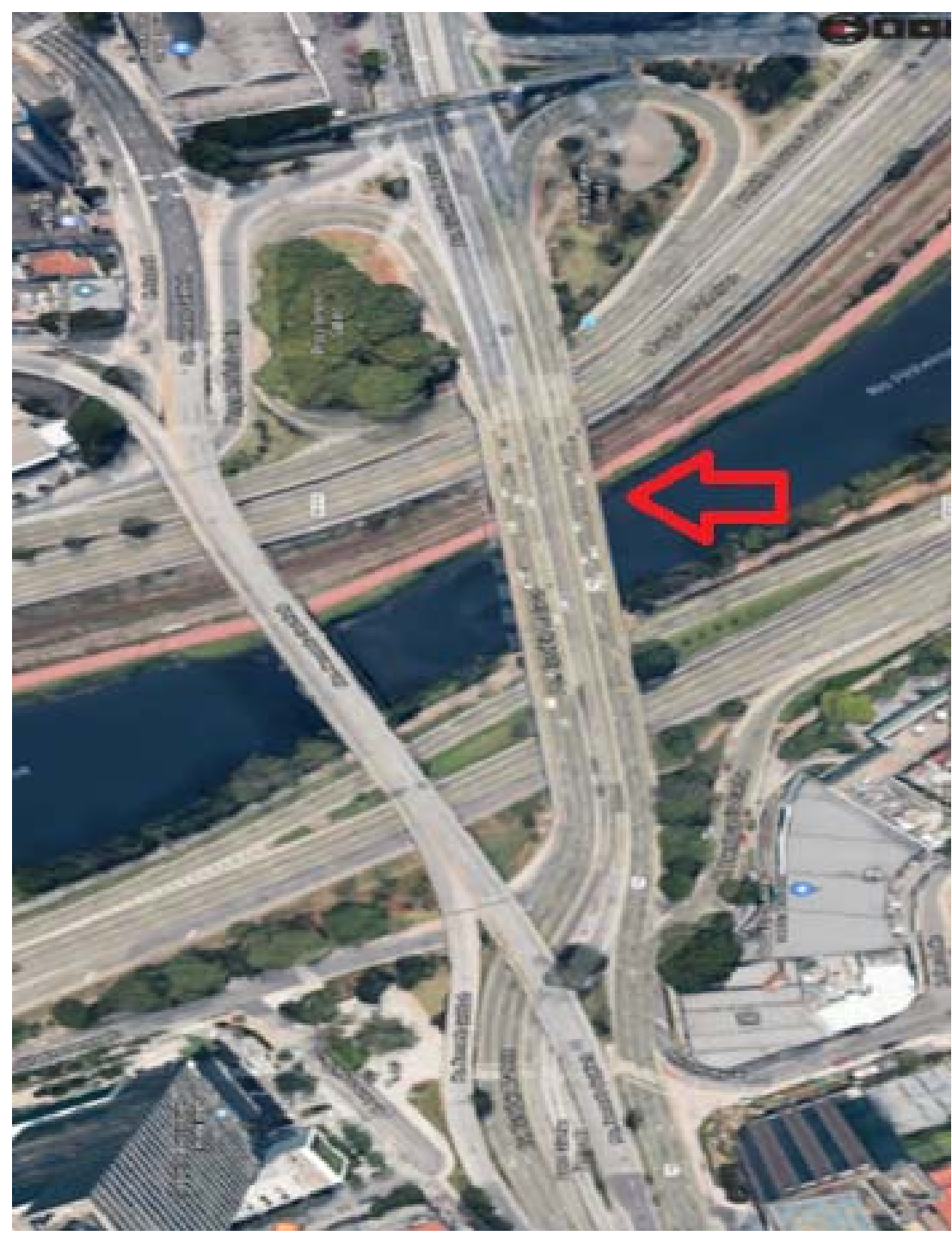

Fonte: GOOGLE MAPS (2019)

O comprimento total da estrutura é de aproximadamente 200 metros, com dois tabuleiros de 13,50 metros de largura, separados por uma junta longitudinal. Uma vista lateral da ponte está apresentada na Figura 3.72. 
Figura 3.72 - Vista lateral da Ponte Eusébio Matoso sobre o Rio Pinheiros.

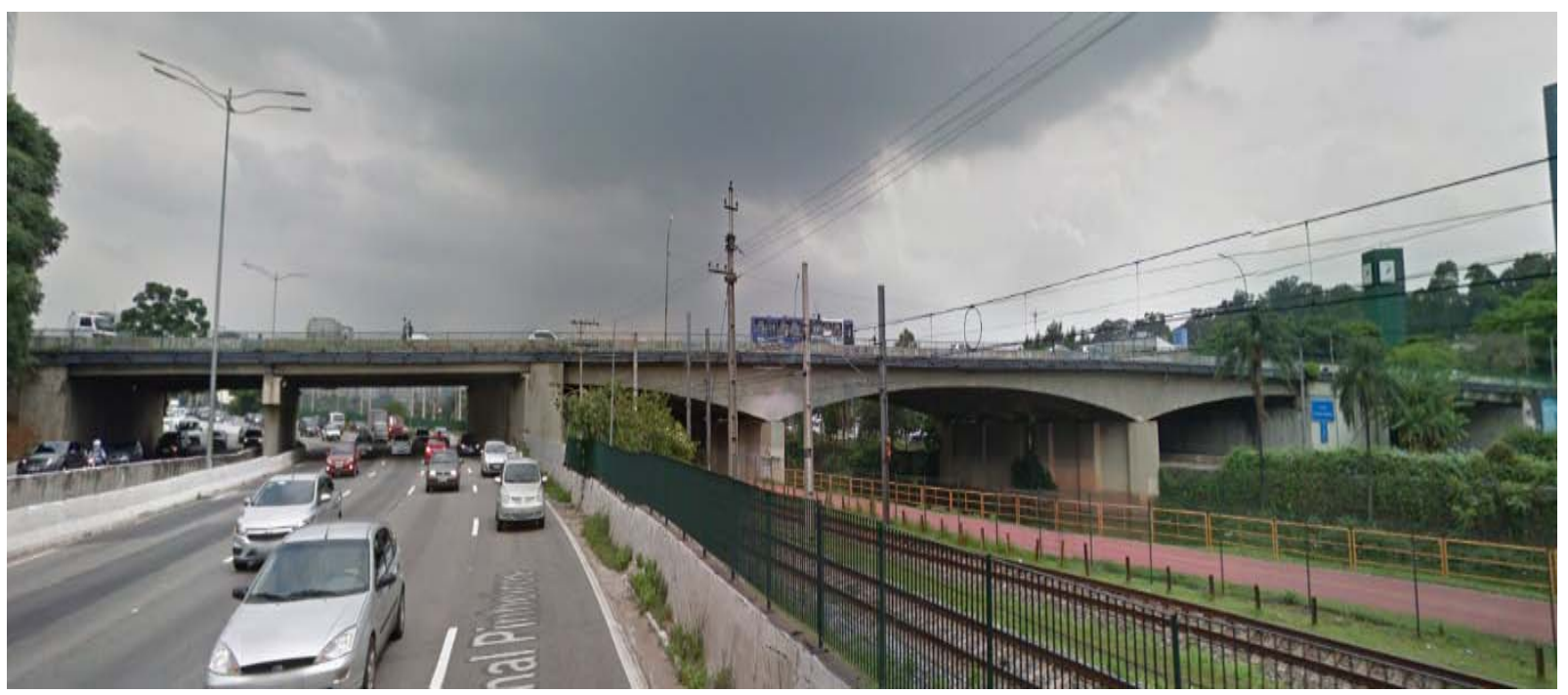

Fonte: GOOGLE MAPS (2019)

Uma vista lateral da parte central da Ponte está ilustrada na Figura 3.73.

Figura 3.73 - Parte central da Ponte Eusébio Matoso

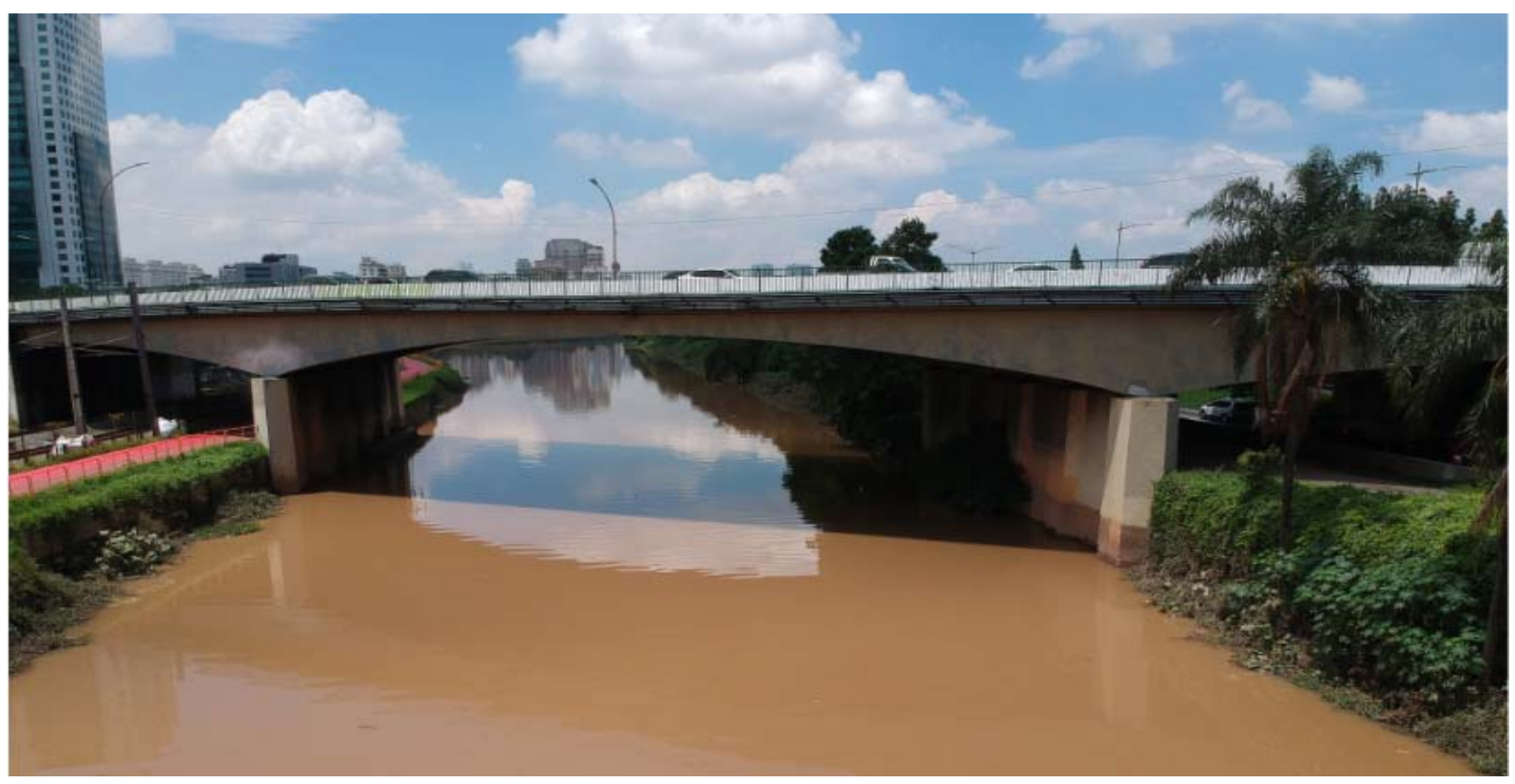

Fonte: GOOGLE MAPS (2019)

\subsubsection{Mapeamento com laser scanner}

O levantamento com laser scanner foi executado com o intuito de obter um modelo computacional tridimensional que contemplasse as dimensões reais da ponte. 
O modelo tridimensional gerado através do levantamento serviu como referência para a avaliação estrutural da ponte, no que diz respeito à geometria dos elementos.

\subsubsection{Equipamentos utilizados}

O equipamento utilizado nos levantamentos foi o laser Focus 3D X330, conforme ilustra a Figura 3.74. Segundo a fabricante, ele é capaz de coletar 976.000 pontos por segundo até uma distância máxima de 330 metros.

Figura 3.74 - Equipamento de ensaio: Focus 3D X330

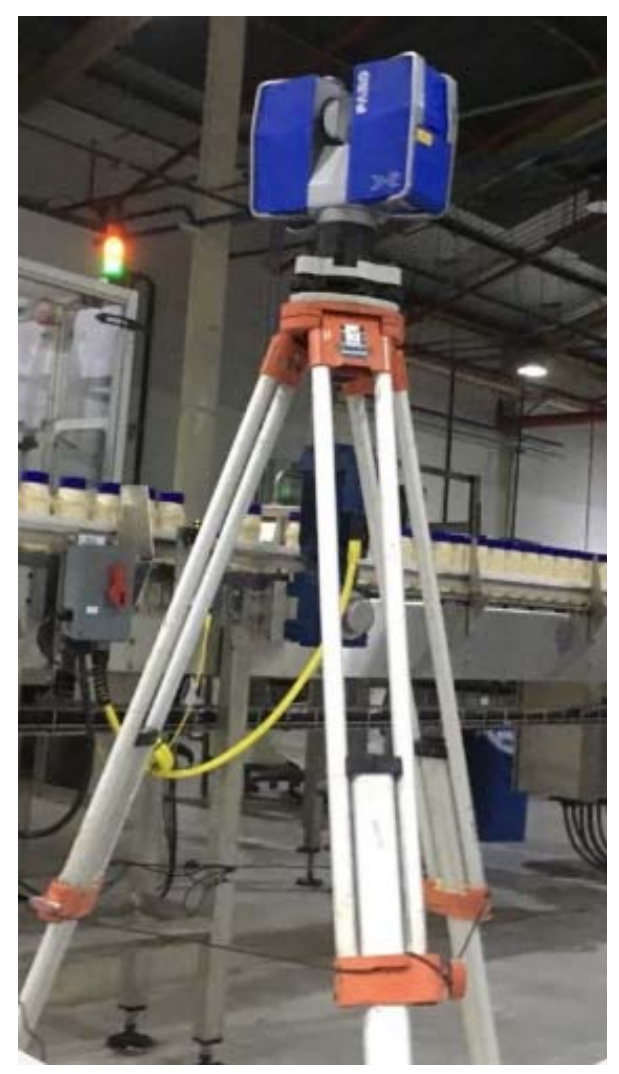

Fonte: FARO (2013)

\subsubsection{Metodologia de ensaio}

Para realização do mapeamento da estrutura com laser scanner, primeiramente definiu-se o posicionamento onde seria instalado o equipamento para coletar os dados. Devido ao tráfego local e restrições geométricas, como o rio Pinheiros e a linha do trem, instalou-se o equipamento em pontos que não causassem interferência, conforme ilustra a Figura 3.75. 
Figura 3.75 - Pontos de coleta de dados
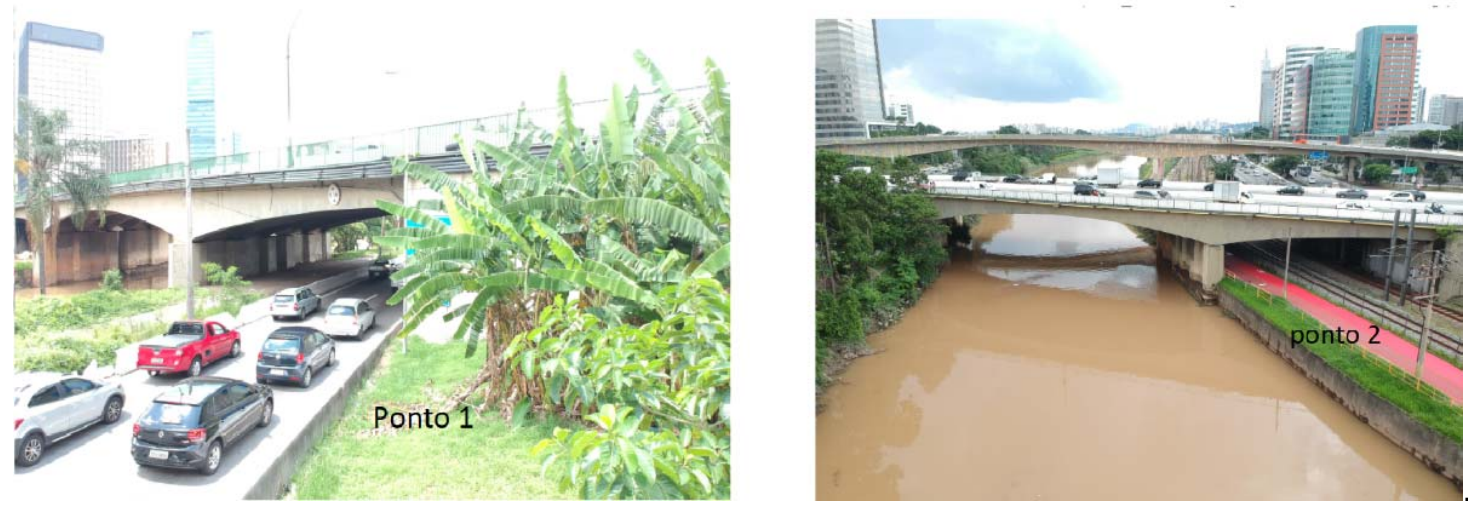

Fonte: Secretaria de Obras da cidade de São Paulo (2019)

No total, o laser scanner foi instalado em 12 posições distintas e foram gerados mais de 200 mil pontos. Gerou-se uma nuvem de pontos para cada posição que foi instalado o laser scanner. Essas 12 nuvens de pontos coletadas em campo, foram processadas no programa AutoCAD Recap, onde os pontos foram unidos, formando linhas que descrevem o esboço da estrutura da ponte e adjacências.

\subsubsection{Resultados e discussões}

Após executado o levantamento em campo foram geradas 12 nuvens de pontos (uma nuvem para cada posição de levantamento). Estes pontos foram exportados para um computador e foram processados no programa AutoCAD RECAP. No programa, as nuvens de pontos foram unidas e como resultado gerou-se a nuvem de pontos de toda a ponte, conforme ilustra a Figura 3.76 . 
Figura 3.76 - Nuvem de pontos

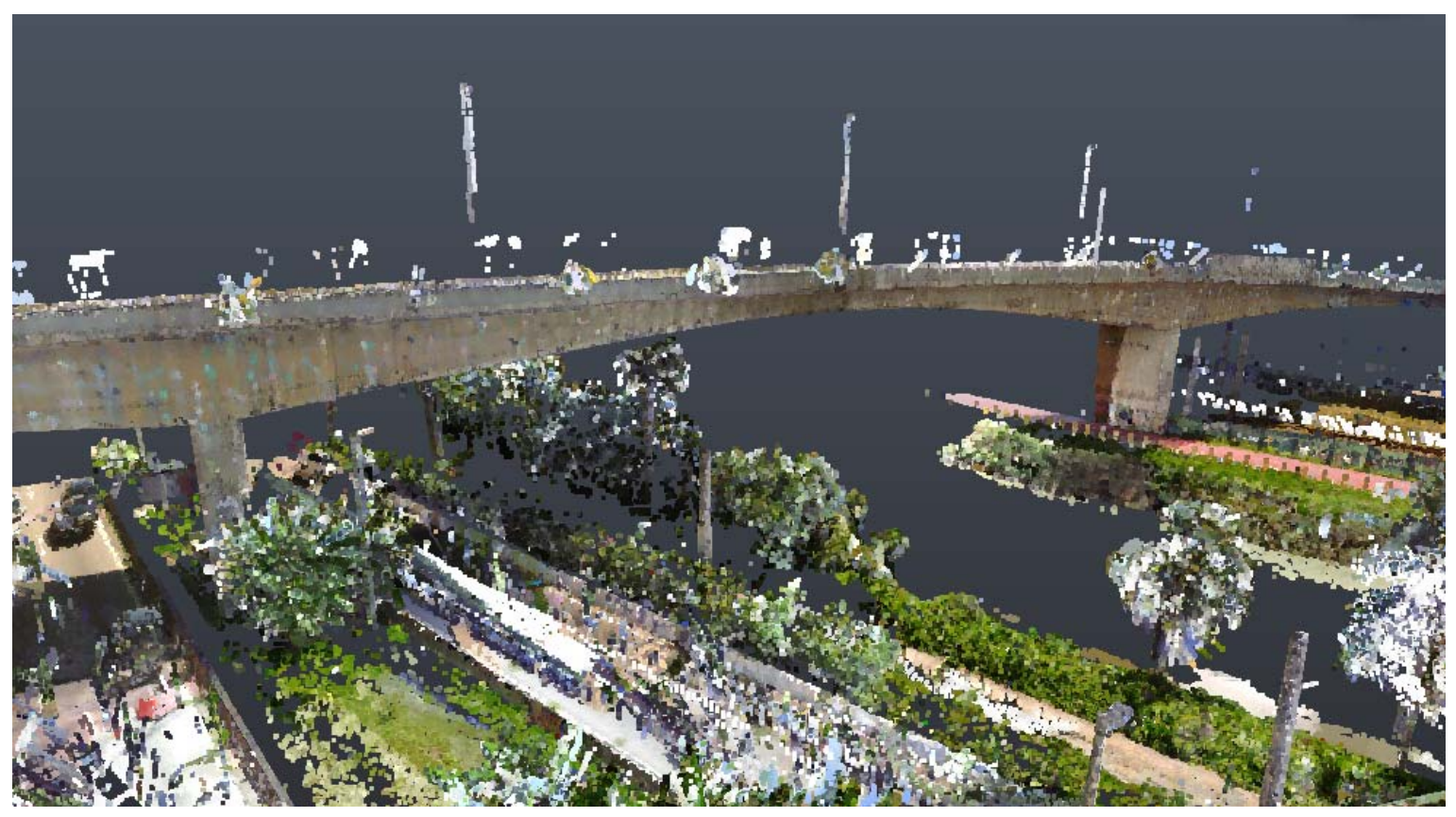

Fonte: Autoria própria.

Observa-se que a nuvem de pontos formada não apresenta visualização nítida. Porém, a partir da nuvem de pontos obtida, foi possível criar superfícies renderizadas no AutoCAD RECAP de acordo com a região de interesse, conforme ilustra a Figura 3.77 , onde foi gerada uma vista $3 d$ renderizada da ponte.

Figura 3.77 - Imagem 3d gerada a partir da nuvem de pontos

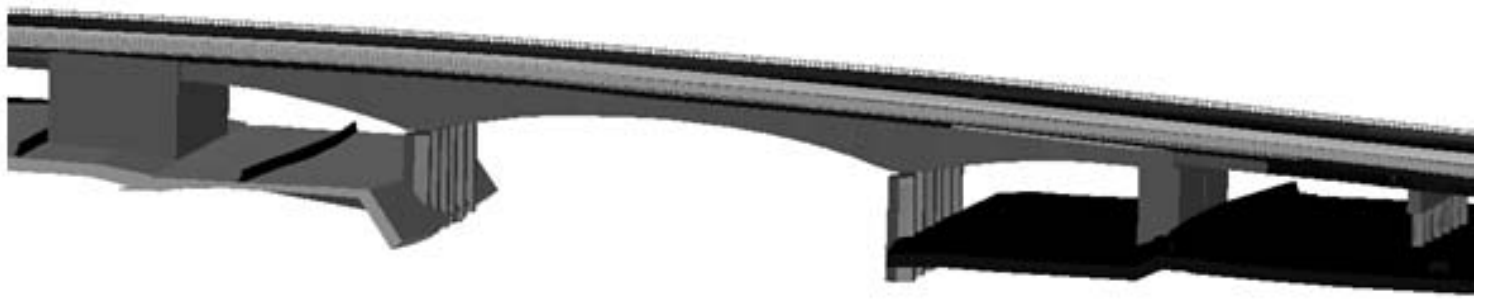

Fonte: Autoria própria.

Observa-se que o modelo gerado é tridimensional e contempla todas as medidas levantadas em campo, sendo possível obter medidas geométricas no AutoCAD e analisar as imperfeições da estrutura, conforme ilustra a Figura 3.78. 
Figura 3.78 - Imagem 3d gerada a partir da nuvem de pontos - Detalhe

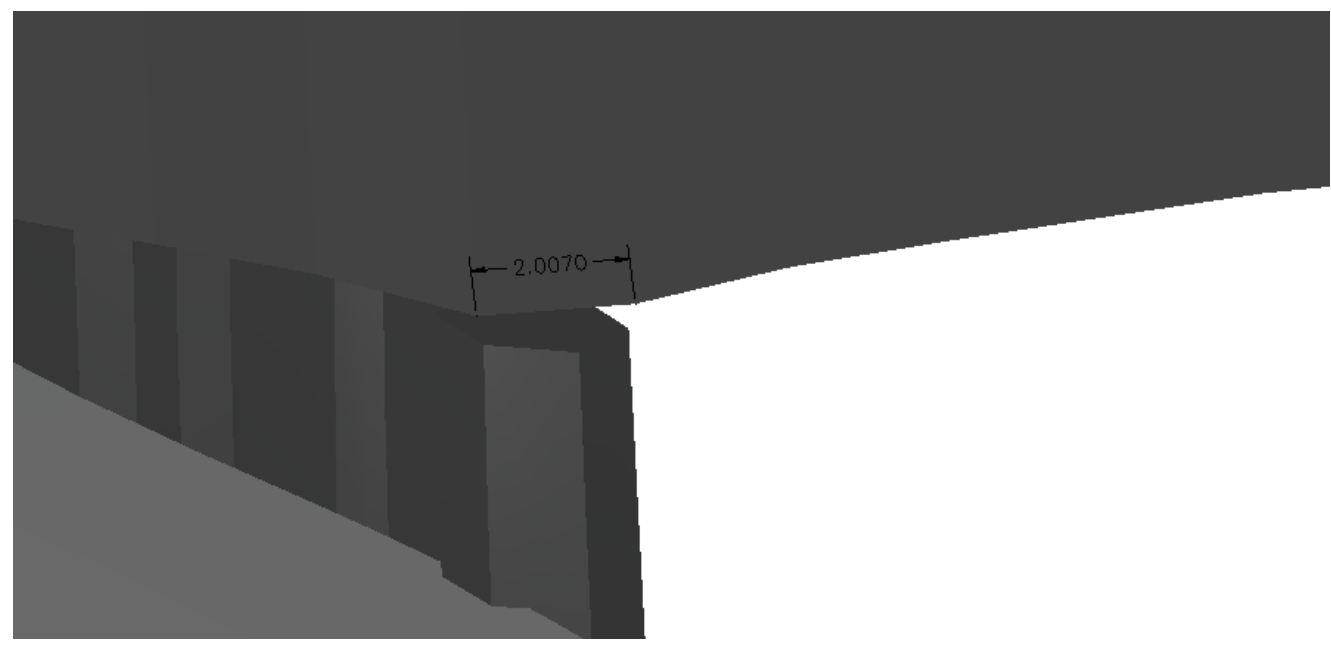

Fonte: Autoria própria.

A partir da nuvem de pontos também é possível gerar cortes transversais da estrutura, conforme ilustra a Figura 3.79.

Figura 3.79 - Imagem 3d gerada a partir da nuvem de pontos - Corte

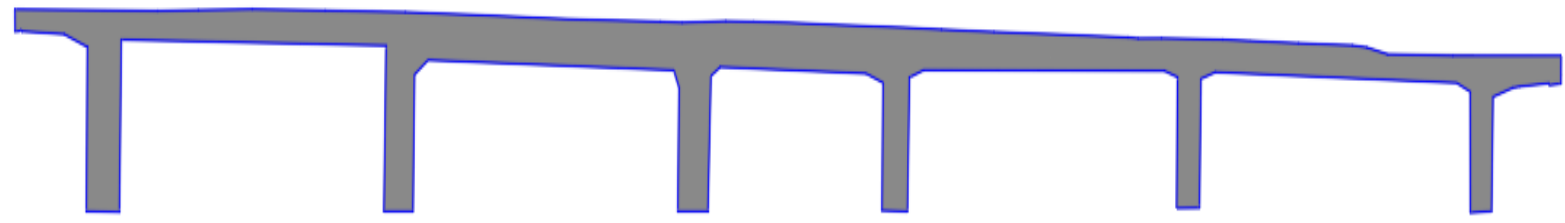

Fonte: Autoria própria.

Observa-se na Figura 3.79, que o corte gerado pelo programa determina as linhas de contorno da estrutura, porém não diferencia os elementos. Por exemplo, laje e pavimento são representados como se fossem um único elemento no corte. Desta forma, para determinar a espessura da laje foram extraídos alguns corpos de prova da estrutura (também serviram para ensaio de compressão axial). A espessura média encontrada para a laje através da medida dos corpos de prova foi de $16 \mathrm{~cm}$ (o projeto indicava $20 \mathrm{~cm}$ ). A Figura 3.80 apresenta o mesmo corte apresentado na Figura 3.79, porém diferenciando laje e pavimento, através das medidas obtidas dos testemunhos extraídos. 
Figura 3.80 - Imagem 3d gerada a partir da nuvem de pontos - Corte mostrando laje

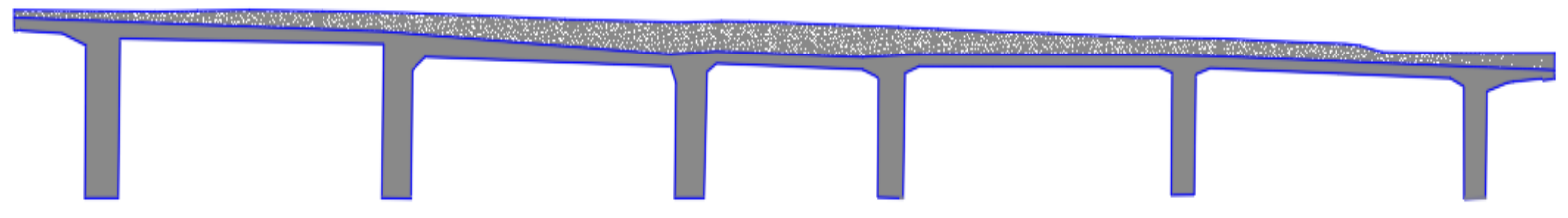

Fonte: Autoria própria.

Observou-se que a medida do pavimento chegava a $25 \mathrm{~cm}$ em alguns pontos (além da laje). Esta informação foi utilizada para composição de cargas na avaliação estrutural.

Foram realizadas algumas medidas de alguns pontos da estrutura com trena, por amostragem. Comparou-se essas medidas com as medidas apresentadas no modelo gerado no AutoCAD. Observou-se que as medidas apresentavam valores muito próximos.

\subsubsection{Ensaio para avaliar nível de carbonatação}

\subsubsection{Metodologia de ensaio}

O ensaio de verificação do nível de carbonatação foi aplicado em diversos pontos da estrutura. Algumas partes da estrutura da ponte, encontravam-se danificadas e com armadura exposta, como apresenta a Figura 3.81. Nestes pontos, não foi necessária a remoção da camada superficial de concreto para aplicação do ensaio. Em outros pontos, como no pilar ilustrado na Figura 3.82, foi necessária a remoção da camada superficial de concreto com o auxílio de uma picareta e uma marreta. 
Figura 3.81 - Partes da estrutura com armadura exposta

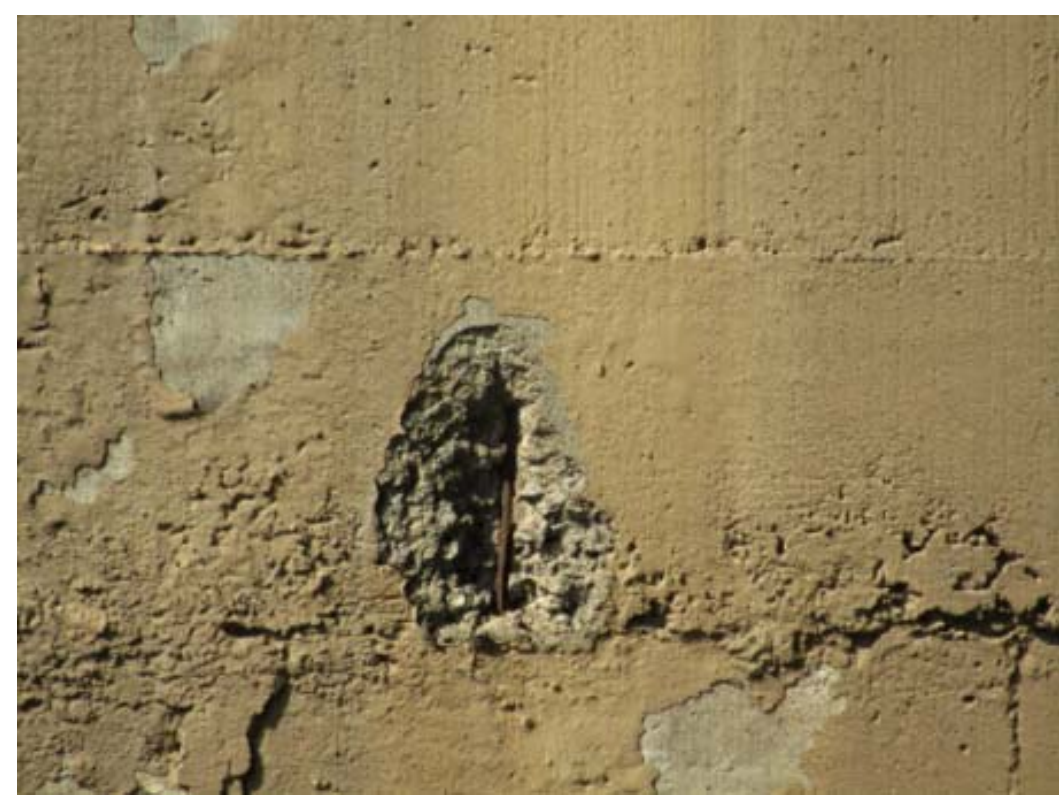

Fonte: Secretaria de Obras da cidade de São Paulo (2019)

Figura 3.82 - Ensaio de carbonatação em pilar

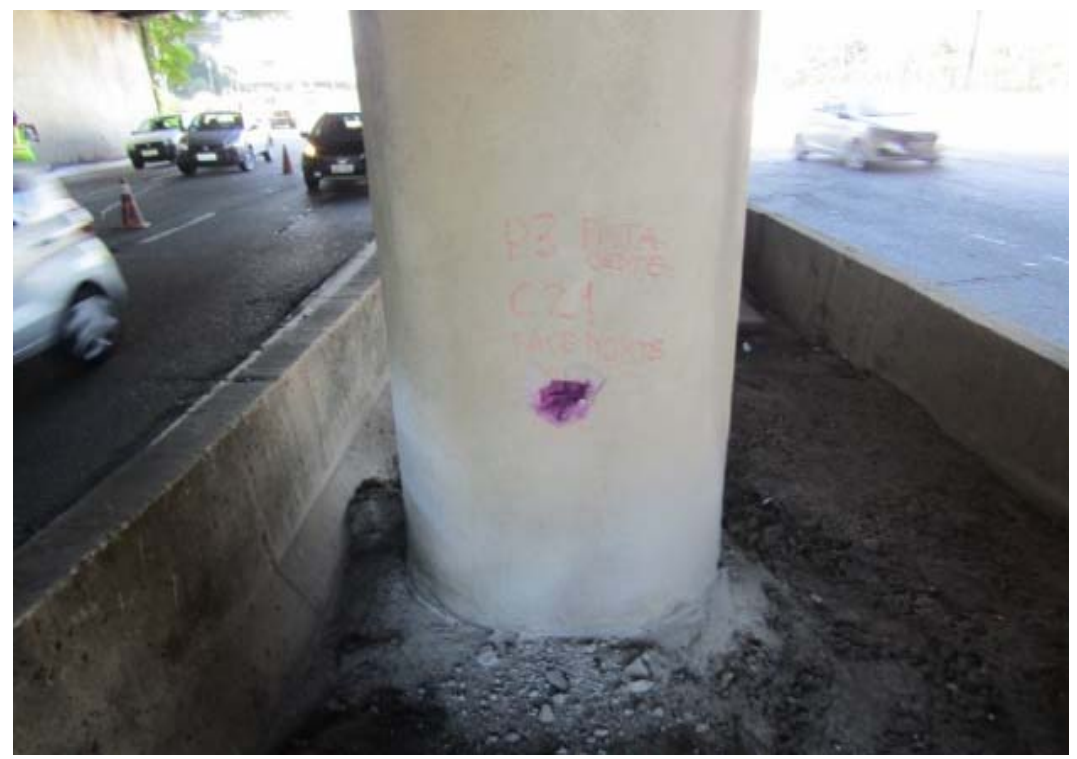

Fonte: Secretaria de Obras da cidade de São Paulo (2019)

Após removida a camada superficial de concreto, a metodologia para execução do ensaio consistiu em molhar a estrutura ensaiada com uma solução de fenolftaleína diluída em $1 \%$ de álcool e observar a coloração resultante. A fenolftaleína reage em meios com pH maiores que 9,5 ficando com coloração rósea a roxa. Em meios ácidos, ela não reage, e fica incolor. 


\subsubsection{Resultados e discussões}

São apresentados os resultados do ensaio aplicados em um pilar e uma viga da ponte. Para aplicar o ensaio no pilar, removeu-se uma parte do cobrimento do concreto com picareta e marreta para chegar na armadura e aplicar a solução de fenolftaleína. O resultado está apresentado na Figura 3.83. Observa-se que a solução de fenolftaleína apresentou coloração roxa intensa na região mais próxima da armadura e uma coloração rósea na região mais próxima da superfície, chegando a ficar incolor na região mais superficial. Estimou-se em $1 \mathrm{~cm}$ a profundidade de carbonatação (medindo com uma régua a profundidade onde a coloração rosa começava a aparecer).

Figura 3.83 - Detalhe do ensaio de carbonatação em pilar

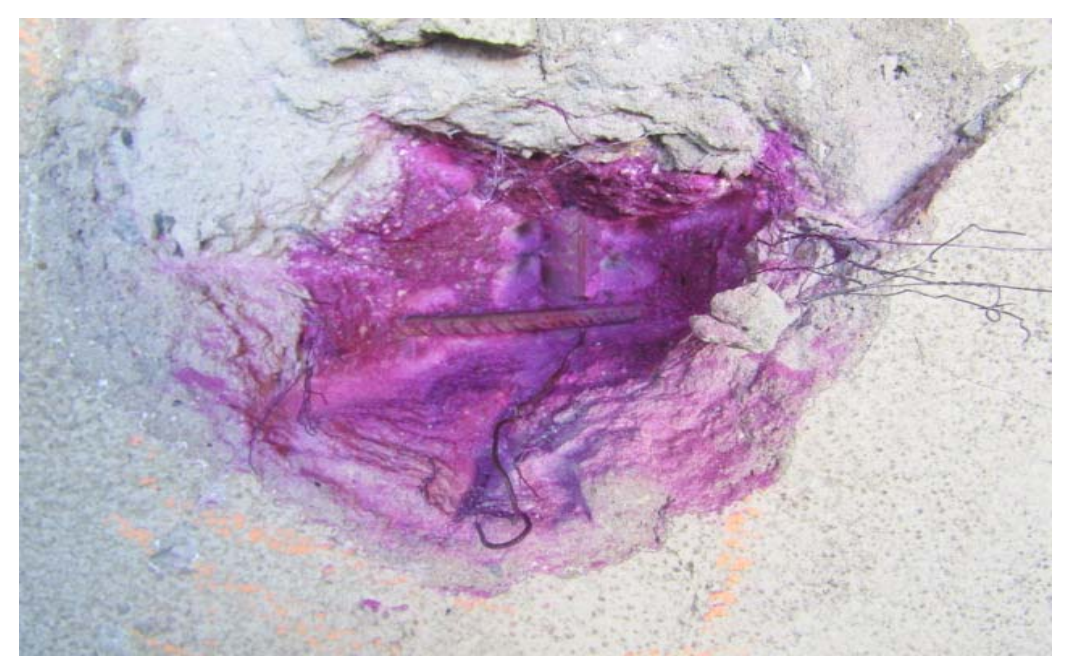

Fonte: Secretaria de Obras da cidade de São Paulo (2019)

Também aplicou-se o ensaio para verificação do nível de carbonatação em uma viga que apresentava danos superficiais (devido ao impacto de caminhões), conforme ilustra a Figura 3.84. Observa-se que a solução de fenolftaleína apresentou coloração roxa na região mais interna da viga e rósea na região mais próxima da superfície, chegando a ficar incolor na superfície. Estimou-se em $2 \mathrm{~cm}$ a profundidade da camada de carbonatação (medindo com uma régua a profundidade onde a coloração rosa começava a aparecer). 
Figura 3.84 - Detalhe do ensaio de carbonatação em viga

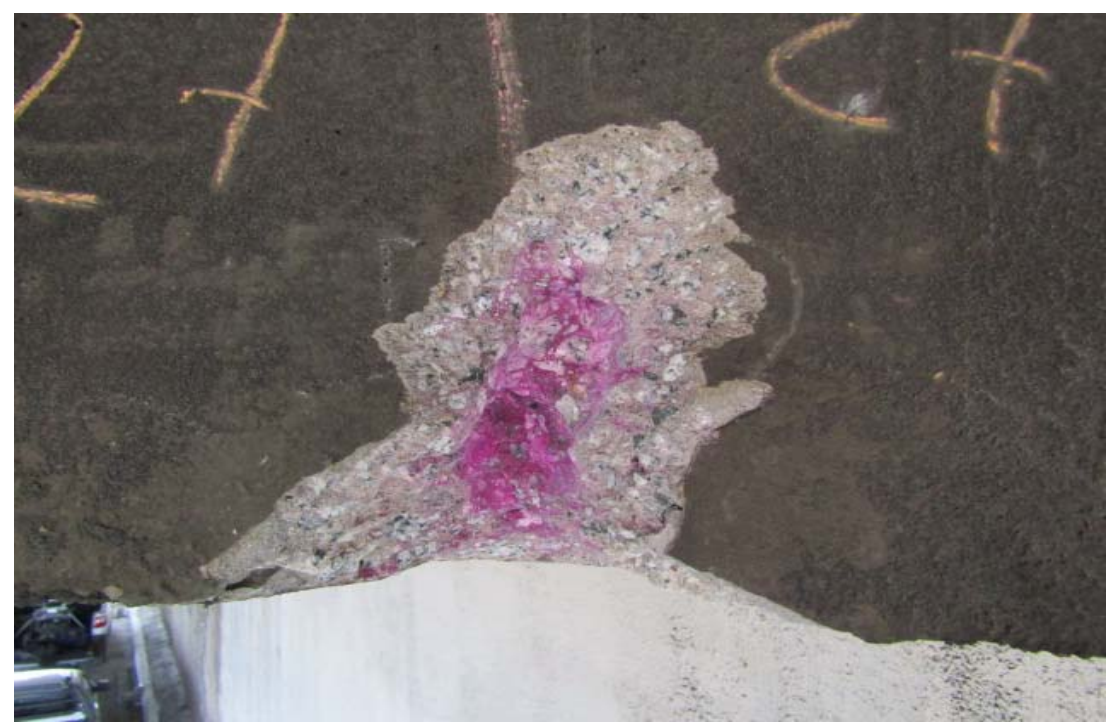

Fonte: Secretaria de Obras da cidade de São Paulo (2019) 


\section{CONCLUSÕES}

A utilização de ensaios não destrutivos aplicados na análise de estruturas de concreto, tem como principal vantagem o fato de ocasionarem pouco ou nenhum dano às estruturas ensaiadas. Ainda, permitem a detecção de anomalias e muitas vezes os ensaios são práticos e executados em poucos minutos. Por outro lado, muitos resultados obtidos através dos ensaios não destrutivos dependem de premissas e correlações para serem obtidas. O concreto é uma estrutura heterogênea e complexa, cuja composição é variável. Assim, essas correlações são muito difíceis de serem obtidas e muitas vezes se aplicam apenas a casos específicos de composição da estrutura ensaiada e condições de ensaio.

Dentro deste contexto, buscou-se no presente estudo, analisar diferentes métodos de ensaio não destrutivos que são aplicados às estruturas de concreto, apresentando suas aplicações, metodologias e particularidades através da revisão da bibliografia pertinente ao assunto e da análise de estudo de casos.

A técnica de ensaio utilizando o georadar GPR mostrou-se eficiente na determinação da largura das peças e na identificação da posição de vazios e elementos que compõem o interior de uma estrutura de concreto. No estudo de caso realizado, a técnica se mostrou eficaz principalmente na determinação do posicionamento dos elementos, mostrando com boa precisão a posição interna dos alvos e também do fundo da peça ensaiada. Salienta-se, porém, que a determinação do diâmetro dos alvos não foi possível de ser realizada utilizando a técnica. As respostas dadas pelas barras de ferro de diferentes diâmetros foram muito similares. Os resultados apresentados no ensaio com GPR realizado em estruturas de concreto são influenciados principalmente pela permissividade dielétrica do alvo. A identificação do tipo de alvo através dos radargramas exige experiência na análise dos resultados, uma vez que muitas vezes a diferença na resposta dada pelos diferentes materiais é mínima e a interpretação subjetiva.

A técnica de ensaio não destrutivo utilizando o ultrassom MIRA se mostrou eficaz, principalmente na determinação da largura das peças e na identificação do posicionamento de vazios e elementos no interior da estrutura. Os resultados do estudo de caso indicaram a reflexão do vazio da parede (furo longitudinal) em todos os pontos que apresentavam o furo. A estimativa realizada para o tamanho do furo, porém, apresentou resultados inferiores ao tamanho real do furo. Salienta-se que um 
correto levantamento deve abranger um mapeamento da estrutura contemplando pequenos espaçamentos, para conseguir mapear toda estrutura. No estudo de caso realizado, o mapeamento das regiões foi realizado a cada $25 \mathrm{~cm}$, e não foi possível identificar a reflexão das esferas de isopor. Identificou-se a reflexão das barras de ferro próximas à superfície ensaiada (não foi possível observar a reflexão das barras de ferro próximas a face do fundo). Essas reflexões foram influenciadas pelas ondas de superfície, e o padrão de reflexão não foi uniforme (esperava-se uma reflexão ao redor de cada barra isoladamente e, em alguns casos, as reflexões se juntavam). Desta forma, a estimativa do diâmetro das barras de ferro foi inviável de ser realizada. Comparando a estimativa média obtida para o valor do módulo de elasticidade através da velocidade da onda de cisalhamento obtido no ensaio com ultrassom MIRA com o valor médio do módulo de elasticidade obtido segundo a norma NBR 8522 (2017), observa-se que o valor médio obtido através do ensaio de ultrassom foi 12,3\% menor que o valor médio obtido através da a norma. Salienta-se que em muitos casos essa correlação fornece valores discrepantes, de acordo com a composição do material e dos parâmetros adotados na estimativa.

A técnica de ultrassom a partir de 2 transdutores se mostrou eficaz na avaliação da homogeneidade de um meio de concreto e apresentou valores discrepantes na estimativa da resistência à compressão. No estudo de caso 3 , realizando comparações através das velocidades da onda ultrassônica apresentadas nas regiões estudadas, foi possível verificar a integridade das ligações. O valor estimado para a resistência à compressão obtida a partir do ensaio de ultrassom de 2 transdutores apresentou valores discrepantes em relação aos valores obtidos no ensaio de compressão axial. A diferença percentual média foi de $32,3 \%$.

A técnica de esclerometria permite observar a homogeneidade da superfície ensaiada, através da comparação dos valores do índice esclerométrico obtidos nas regiões estudadas. No segundo estudo de caso, foram realizadas estimativas da resistência à compressão utilizando curvas de correlação fornecidas pelo fabricante do esclerômetro. Comparou-se estas estimativas com a resistência à compressão obtida no ensaio de compressão axial. As estimativas da resistência à compressão da parede através da correlação com o índice esclerométrico tiverem uma variação média de $8,9 \%$ em relação à média de resistência obtida no ensaio de compressão axial. Salienta-se, porém, que a correlação entre o índice esclerométrico e a 
resistência à compressão através do uso de curvas do fabricante do equipamento, pode apresentar valores discrepantes da realidade (uma vez que estas curvas foram elaboradas para um tipo específico de concreto). $O$ ideal para correlacionar o índice esclerômetro com a resistência à compressão, seria a moldagem de corpos de prova com diferentes relações água/cimento e a submissão destes corpos de prova aos ensaios de esclerometria e compressão axial e, assim, obter a curva de correlação (ao invés de usar a curva de correlação do fabricante).

A pacometria é uma técnica eficiente na determinação da localização das armaduras e do cobrimento. A partir dos resultados apresentados no estudo de caso, foi possível determinar o posicionamento das barras de ferro e do cobrimento das mesmas. Esta técnica tem grande importância para outros ensaios (como esclerômetria e carbonatação), identificando as barras de ferro e não comprometendo os resultados desses ensaios.

O mapeamento da estrutura através da técnica de laser scanner é baseado na criação de uma nuvem de pontos da estrutura ensaiada. Com esta nuvem de pontos, através de programas, como o AutoCAD, é possível criar um modelo físico tridimensional da estrutura, onde podem ser coletados dados com grande precisão. A técnica se mostrou eficaz na determinação de dimensões e ângulos, representando com grande precisão as dimensões físicas. Salienta-se que através desta técnica não é possível avaliar internamente a estrutura.

A técnica de medição da resistividade permite avaliar a durabilidade da estrutura, uma vez que concretos com alta resistividade elétrica apresentam menor pré-disposição para a corrosão das armaduras.

As técnicas de estimativa do teor de cloretos e da profundidade da camada de carbonatação, são técnicas importantes para avaliação da vida útil de uma estrutura, uma vez que tanto a carbonatação, quanto a presença de cloretos, fazem com que o $\mathrm{pH}$ da estrutura diminua, até o ponto em que a camada passivadora seja removida e se crie as condições propícias para o início da corrosão eletroquímica das armaduras. 


\section{REFERÊNCIAS BIBLIOGRÁFICAS}

ALMEIDA, L. C., TRAUTWEIN, L., BASAGLIA, C. Estudo das patologias de projeto e construção em uma estrutura de concreto armado. Anais do 10. Congresso Brasileiro de Patologia das estruturas. Foz do Iguaçu - PR, 2014.

AMERICAN CONCRETE INSTITUTE. ACI 228. In place methods for determination of the strength of concrete. Detroit, 2003.

AMERICAN SOCIETY FOR TESTING AND MATERIALS. ASTM C 597. Standard Test Method for Pulse Velocity Through Concrete. Philadelphia, 2016.

AMERICAN SOCIETY FOR TESTING AND MATERIALS. ASTM G 57. Standard Test Method for Field Measurement of Soil Resistivity Using the Wenner Four-Electrode Method. Philadelphia, 2012.

AMERICAN SOCIETY FOR TESTING AND MATERIALS. ASTM C 114. Standard Test Methods for Chemical Analysis of Hydraulic Cement Philadelphia, 2007.

AMERICAN SOCIETY FOR TESTING AND MATERIALS. ASTM C 1152. Standard Test Method for Acid-Soluble Chloride in Mortar and Concrete. Philadelphia, 2012

ANDRADE, M. D. C. Manual para diagnóstico de obras deterioradas por corrosão de armaduras. São Paulo, 1992.

ASSOCIAÇÃO BRASILEIRA DE NORMAS TÉCNICAS. NBR 8802. Concreto endurecido determinação da velocidade de propagação de onda ultra-sônica. Rio de Janeiro. 2019.

ASSOCIAÇÃO BRASILEIRA DE NORMAS TÉCNICAS. NBR 6118. Projeto de estruturas de concreto - Procedimento. Rio de Janeiro, 2014.

ASSOCIAÇÃO BRASILEIRA DE NORMAS TÉCNICAS. NBR 7584. Concreto endurecido avaliação da dureza superficial pelo esclerômetro de reflexão. Rio de Janeiro, 2012.

ASSOCIAÇÃO BRASILEIRA DE NORMAS TÉCNICAS. NBR 9204. Concreto endurecido Determinação da resistividade elétrico-volumétrica - Método de ensaio. Rio de Janeiro, 2012.

ASSOCIAÇÃO BRASILEIRA DE NORMAS TÉCNICAS. NBR 9917. Agregados para concretoDeterminação de sais, cloretos e sulfatos solúveis". Rio de Janeiro, 2009.

ASSOCIAÇÃO BRASILEIRA DE NORMAS TÉCNICAS. NBR 5739. Ensaio de compressão de corpos de prova cilíndricos. Rio de Janeiro, 2018.

ASSOCIAÇÃO BRASILEIRA DE NORMAS TÉCNICAS. NBR 8522. Concreto - Determinação dos módulos estáticos de elasticidade e de deformação à compressão. Rio de Janeiro, 2017.

BOMPAN, K. F.; HAACH, V.G. Ultrasonic tests in the evaluation of the stress level in concrete prisms based on the acoustoelasticity. Construction and Building Materials, v.162, 2018.

BUNGEY, J. H., The Influence of Reiforcement on Ultrasonic Pulse Velocity Testing, In Situ/Nondestructive Testing of Concrete, Special Publication SP-82, pp. 229-246, American Concrete Institute, Detroit 1984 
BUNGEY, J. H., The Testing of Concrete in Structures, 2 ed., London, Surrey University Press, 1989

BUNGEY, J. H.; MILLARD, S.G. Testing of concrete in structures. 4ed. Champan e Hall New York, USA, 2006

CASAGRANDE, E. et al. Utilização de GPR para Mapeamento Não Destrutivo de Estrutura de Concreto. Anais do $55^{\circ}$ CONGRESSO BRASILEIRO DO CONCRETO CBC2013 - 55CBC. Gramado- RS, 2013.

CASCUDO, O. Inspeção e diagnóstico de estrutura de concreto com problemas de corrosão de armaduras. Concreto: ensino, pesquisa e realizações. IBRACON. São Paulo, 2005.

CONSÓRCIO PONTE DO GUAÍBA. Consórcio CQG-EGT Ponte do Guaíba. Porto Alegre/RS, 2019

CHOI, P.; KIM, D. H.; LEE, B. H.; WON, M. C. Application of ultrasonic shear-wave tomography to identify horizontal crack or delamination in concrete pavement and bridge. Construction and building materials, v.121, 2016

CLEMEÑA, G. G. Short-pulse radar methods. In: Handbook on Nondestructive Testing of Concrete. 2 ed. CRC Press, 2004

DAVIS, J. L.; ANNAN, A. P. Ground-penetration radar for high-resolution mapping of soil and rock stratigraphy. Geophysical Prospecting, 1989.

DALMOLIN, Q.; SANTOS, D. R. Sistema Laserscanner: Conceitos e Princípios de Funcionamento. $3^{\mathrm{a}}$ Edição - UFPR - Curitiba/PR - Brasil. 97 pg - 2004.

DINH, K.; GUCUNSKI, N.; ZAYED, T. Automated visualization of concrete bridge deck condition from GPR. NDT \& E International, v.102, 2019.

ELBERN, A. W.; GUIMARÃES, L. Synthetic Aperture Focusing Technique for Image Restauration. - International Symposium on NDT Contribution to the Infrastructure Safety Systems, Torres, 1999 .

EVANGELISTA, A. C. J. Avaliação da resistência do concreto usando diferentes ensaios não destrutivos. Tese (Doutorado em Engenharia Civil) - COPPE, Universidade Federal do Rio de Janeiro, Rio de Janeiro, 2002.

FARO. FARO Laser Scanner Focus3D X 330: Features, Benefits \& Technical Specifications. Inc., 2013.

FRANCO, D. A. L. Avaliação das potencialidades do georadar em Engenharia Civil. Universidade de Aveiro. Aveiro, 2010.

GERMANN INSTRUMENTS. MIRA, Copenhagen, Denmark, 2012.

GMEC. Grupo de Modelagem de Estruturas de Concreto. Escola Politécnica da USP. São Paulo, 2019.

GSSI. Handbook for RADAR inspection of concrete: Geophysical Survey System, Inc., 2009 
GSSI. SIR System-3000. Salem: Geophysical Survey Systems, Inc., 2011a.

GSSI. UtilityScan: Quick Start Guide. [S.I.]: Geophysical Survey System, Inc.,2010.

GSSI. StructureScan Standard, Inc., 2013.

HAZA, A. O.; PETERSEN, C. G.; SAMOKRUTOV, A. Three Dimensional Imaging of Concrete Structures Using Ultrasonic Shear Waves. German Instruments SA, Denmark, 2011.

HOEGH, K. Ultrasonic Linear Array Evaluation of Concrete Pavements. Ph.D. Dissertation. University of Minnesota, Minneapolis, 2013

HOEGH, K.; KHAZANOVICH, L.; YU, T. Ultrasonic Tomography for Evaluation of Concrete Pavements. Transportation Research Record: Journal of the Transportation Research Board, v. 2232, p. 85 - 94, 2011.

HOPPE, T. F. Resistividade elétrica de concretos contendo diferentes teores de cinza de casca de arroz. Dissertação de mestrado - Universidade Federal de Santa Maria. Santa Maria / RS, 2005

KAPLANVURAL, I.; PEKSEN, E.; OZKAP, K. Volumetric water content estimation of C-30 concrete using GPR. Construction and Building Materials 166, 2018.

KAUR, N. P.;Shah J.K.;Majhi, S.; Mukherjee, A. Healing and simultaneous ultrasonic monitoring of cracks in concrete. Materials Today Communications, v.18, 2019.

LEVY, S. M. Contribuição ao estudo de durabilidade de concretos, produzidos com resíduos de concreto e alvenaria. 2001 208p. Tese (Doutorado) - Universidade de São Paulo, São Paulo, 2001.

MAIA, T. C. B. Estudo e Análise de Poligonais Segundo a NBR 13.133 e o Sistema de Posicionamento Global. Dissertação de Mestrado. Escola de Engenharia de São Carlos da Universidade de São Paulo - São Carlos/SP,1999.

MALHOTRA, V. M., "In Situ / Nondestructive Testing of Concrete - A Global Review", In Situ/Nondestructive Testing of Concrete, Special Publication SP-82, pp. 1-16.

American Concrete Institute, Detroit, 1984.

MALHOTRA V. M.; CARINO N. J. Handbook on Nondestructive Testing of Concrete. CRC Press, 2004.

MEHTA P. K.; MONTEIRO P. J. M. Concreto: Microestrutura, Propriedades e Materiais. São Paulo, Ibracon, 2008.

MENEGHETTI, L. C. Avaliação da resistência à compressão de concretos nas primeiras idades através do ultra-som, 163pp. Dissertação de Mestrado, Universidade Federal de Santa Catarina, Brasil, 1999.

NAIK, T. R.; MALHOTRA, V. M.; POPOVICS, J. S. The ultrasonic pulse velocity method. In: Handbook on Nondestructive Testing of Concrete, CRC Press, 2004.

NORMA MERCOSUL. NM 78. Concreto endureciddo - avaliação da dureza superficial pelo esclerômetro de reflexão. 1996. 
PAULETTI, C. Análise comparativa de procedimentos para ensaios acelerados de carbonatação. Dissertação de mestrado , Universidade Rio Grande do Sul, Porto Alegre / RS, 2004.

PEREIRA, L. F. L. C.; CINCOTTO, M. A. Determinação de cloretos em concreto de cimentos Portland: influência do tipo de cimento. Boletim técnico da Escola Politécnica da USP, São Paulo, 2001.

PORSANI, J. L., Ground Penetrating Radar (GPR): Proposta Metodológica de Emprego em Estudos Geológico-geotécnicos nas Regiões de Rio Claro e Descalvado -SP. Tese de Doutorado, Instituto de Geociências e Ciências Exatas, UNESP, 1999.

PROCEQ. Profoscope: INSTRUÇÕES DE OPERAÇÃO. Inc., 2014.

PROCEQ. Resipod family: INSTRUÇÕES DE OPERAÇÃO. Inc., 2017.

PROCEQ. SilverSchmidt: INSTRUÇÕES DE OPERAÇÃO. Inc., 2016.

RASHID, K.; WAQAS, R. Compressive strength evaluation by non-destructive techniques: An automated approach in construction industry. Journal of Building Engineering, 2017

RATHOD, H. et al. Applicability of GPR and a rebar detector to obtain rebar information of existing concrete structures. Case Studies in Construction Materials, v.11, 2019.

RESENDE, R. M. L. G. Avaliação dos efeitos da danificação e da acustoelasticidade sobre a velocidade de pulso ultrassônico em corpos de prova de concreto submetidos a compressão uniaxial. Dissertação de mestrado, Universidade de São Paulo, São Carlos, 2018.

REHMAN, S. K. U.; IBRAHIM, Z.; MEMON, S. A.; JAMEEL, M. Nondestructive test methods for concrete bridges: A review. Construction and building materials, 107 - 2016

RILEM. NDT 1.Testing of concrete by the ultrasonic pulse method". 1972.

RILEM. TC 154. Electrochemical techniques for measuring metallic corrosion. 2003.

RILEM. CPC 18. Measurement of hardened concrete carbonation depth. 1988.

SAHUINCO, M.H.C. Utilização de métodos não destrutivos e semi-destrutivos na avaliação de pontes de concreto. 170f. Dissertação (Mestrado em Engenharia Civil) Escola Politécnica da Universidade de São Paulo. São Paulo, 2011.

SALLES, L. S. Short continuously reinforced concrete pavement design recommendations based on non-destructive ultrasonic data and stress simulation. Tese de doutorado apresentada Universidade de São Paulo, São Paulo, 2017.

SANDMEIER, K.J. REFLEXW. Program for the processing of seismic, acoustic or electromagnetic reflection, refraction and transmission data. Manual do Software, Karlsruhe, Germany, 2010.

SANTOS, E. J. F. et al. CASAGRANDE, E. et al. Utilização de GPR para Mapeamento Não Destrutivo de Estrutura de Concreto. Anais do $57^{\circ}$ CONGRESSO BRASILEIRO DO CONCRETO , 2015. 
SILVA, L. A. Uso de georadar (GPR) e retroanálises de deflexões como suporte a análises probabilísticas de desempenho de pavimentos. Tese de doutorado apresentado a Universidade de Brasília, Brasília, 2014.

TUUTI, K. Corrosion of steel in concrete. Tese de Doutorado. Swedish Cement and Concrete Research Institue, Stockholm. 1982.

SINGH, M. P.; LIU, S. Structural control, advanced sensing systems and health monitoring: Past, present and future, 2002.

STURRUP, V. R.; VECCHIO, F. J.; CARATIN, H. "Pulse Velocity as a Mesuare of Concrete Compressive Strength", pp.201-228, In Situ/Nondestructive Testing of Concrete, Special Publication SP-82, American Concrete Institute, Detroit, 1984.

SUCHOCKI, C.; KATZER, J. Terrestrial laser scanning harnessed for moisture detection in building materials - Problems and limitations. Automation in Construction, V.94, 2018.

TOMMASELLI, A. M. G. Um Estudo Sobre as Técnicas de Varredura a Laser e Fotogrametria para Levantamentos 3D a Curta Distância. GEODÉSIA Online Revista da Comissão Brasileira de Geodésia. 4 / 2003.

VANCURA, M.; KHAZANOVICH, L.; BARNES, R. Concrete Pavement Thickness Variation Assessment with Cores and Nondestructive Testing Measurements. Transportation Research Record: Journal of the Transportation Research Board, v. 2347, p. 61 - 68, 2013

ZAJIKOVA, K.; CHUMAN, T. Application of ground penetrating radar methods in soil studies: A review. Geoderma 343, 2019. 
ANEXO

Tabela com dados fornecidos pelo Consórcio da Ponte do Guaíba (2019)

\begin{tabular}{|c|c|c|c|c|c|c|}
\hline \multirow{2}{*}{ № Aduela } & \multirow{2}{*}{ Lado } & \multirow{2}{*}{$\begin{array}{l}\text { № Mão } \\
\text { francesa }\end{array}$} & \multicolumn{2}{|c|}{ Pontos do ensaio } & \multirow{2}{*}{ Tempo ( $\mu$ seg) } & \multirow{2}{*}{ Distância (m) } \\
\hline & & & Aduela & Mão Francesa & & \\
\hline 2 & Esquerdo & 224 & 1 & 1 & 54,9 & 0,265 \\
\hline 2 & Esquerdo & 224 & 1 & 2 & 68,2 & 0,329 \\
\hline 2 & Esquerdo & 224 & 1 & 3 & 135,7 & 0,654 \\
\hline 2 & Esquerdo & 224 & 3 & 1 & 84,1 & 0,406 \\
\hline 2 & Esquerdo & 224 & 3 & 2 & 63,1 & 0,304 \\
\hline 2 & Esquerdo & 224 & 3 & 3 & 52,9 & 0,255 \\
\hline 2 & Esquerdo & 224 & 2 & 2 & 53,4 & 0,257 \\
\hline 2 & Esquerdo & 224 & 2 & 1 & 60,4 & 0,291 \\
\hline 2 & Esquerdo & 224 & 2 & 3 & 71,9 & 0,347 \\
\hline 2 & Esquerdo & 224 & 4 & 4 & 62,4 & 0,301 \\
\hline 2 & Esquerdo & 224 & 5 & 5 & 60,6 & 0,292 \\
\hline 2 & Esquerdo & 224 & 6 & 6 & 58,9 & 0,284 \\
\hline 2 & Esquerdo & 224 & 4 & 6 & 80,9 & 0,390 \\
\hline 2 & Esquerdo & 224 & 4 & 5 & 63,4 & 0,306 \\
\hline 2 & Esquerdo & 224 & 5 & 4 & 72,7 & 0,351 \\
\hline 2 & Esquerdo & 224 & 5 & 6 & 77,6 & 0,374 \\
\hline 2 & Esquerdo & 224 & 6 & 4 & 91,9 & 0,443 \\
\hline 2 & Esquerdo & 224 & 6 & 5 & 57,9 & 0,279 \\
\hline 2 & Esquerdo & 224 & 7 & 7 & 57,9 & 0,279 \\
\hline 2 & Esquerdo & 224 & 8 & 8 & 46,9 & 0,226 \\
\hline 2 & Esquerdo & 224 & 9 & 9 & 60,7 & 0,293 \\
\hline 2 & Esquerdo & 224 & 7 & 8 & 61,4 & 0,296 \\
\hline 2 & Esquerdo & 224 & 7 & 9 & 108,2 & 0,522 \\
\hline 2 & Esquerdo & 224 & 8 & 7 & 71,4 & 0,344 \\
\hline 2 & Esquerdo & 224 & 8 & 9 & 69,6 & 0,336 \\
\hline 2 & Esquerdo & 224 & 9 & 7 & 95,2 & 0,459 \\
\hline 2 & Esquerdo & 224 & 9 & 8 & 66,4 & 0,320 \\
\hline 2 & Esquerdo & 224 & 7 & 6 & 134,2 & 0,647 \\
\hline 2 & Esquerdo & 224 & 9 & 3 & 131,0 & 0,632 \\
\hline 2 & Esquerdo & 224 & 12 & 1 & 140,9 & 0,679 \\
\hline 2 & Esquerdo & 224 & 10 & 4 & 145,6 & 0,702 \\
\hline 2 & Direito & 231 & 12 & 1 & 144,2 & 0,694 \\
\hline 2 & Direito & 231 & 10 & 4 & 155,4 & 0,748 \\
\hline 2 & Direito & 231 & 7 & 6 & 136,4 & 0,657 \\
\hline 2 & Direito & 231 & 9 & 3 & 130,9 & 0,630 \\
\hline 2 & Direito & 231 & 8 & 5 & 101,7 & 0,490 \\
\hline
\end{tabular}




\begin{tabular}{|c|c|c|c|c|c|c|}
\hline 2 & Direito & 231 & 8 & 2 & 101,7 & 0,490 \\
\hline 2 & Direito & 231 & 11 & 5 & 111,4 & 0,537 \\
\hline 2 & Direito & 231 & 11 & 2 & 105,2 & 0,507 \\
\hline 10 & Esquerdo & 254 & 9 & 3 & 202,0 & 0,968 \\
\hline 10 & Esquerdo & 254 & 12 & 1 & 178,7 & 0,840 \\
\hline 10 & Esquerdo & 254 & 10 & 4 & 171,1 & 0,804 \\
\hline 10 & Esquerdo & 254 & 6 & 12 & 13,9 & 0,065 \\
\hline 10 & Esquerdo & 254 & 10 & 3 & 81,9 & 0,385 \\
\hline 10 & Esquerdo & 254 & 9 & 4 & 82,4 & 0,387 \\
\hline 10 & Esquerdo & 254 & 8 & 2 & 161,2 & 0,757 \\
\hline 10 & Esquerdo & 254 & 11 & 5 & 110,2 & 0,518 \\
\hline 10 & Esquerdo & 254 & 11 & 2 & 98,6 & 0,463 \\
\hline 10 & Direito & 258 & 1 & 7 & 102,0 & 0,454 \\
\hline 10 & Direito & 258 & 10 & 3 & 123,0 & 0,553 \\
\hline 10 & Direito & 258 & 8 & 2 & 214,0 & 0,960 \\
\hline 10 & Direito & 258 & 1 & 7 & 99,8 & 0,449 \\
\hline 10 & Direito & 258 & 9 & 3 & 267,0 & 1,212 \\
\hline 10 & Direito & 258 & 10 & 4 & 130,5 & 0,587 \\
\hline 10 & Direito & 258 & 6 & 12 & 89,8 & 0,402 \\
\hline 10 & Direito & 258 & 7 & 6 & 181,5 & 0,816 \\
\hline 10 & Direito & 258 & 12 & 1 & 163,0 & 0,733 \\
\hline 10 & Direito & 258 & 8 & 5 & 213,0 & 0,957 \\
\hline 10 & Direito & 258 & 11 & 2 & 123,0 & 0,553 \\
\hline 10 & Direito & 258 & 11 & 5 & 126,3 & 0,569 \\
\hline 10 & Direito & 258 & 9 & 4 & 89,0 & 0,400 \\
\hline 16 & Direito & 259 & 8 & 2 & 176,0 & 0,782 \\
\hline 16 & Direito & 259 & 9 & 3 & 185,8 & 0,825 \\
\hline 16 & Direito & 259 & 7 & 6 & 339,0 & 1,505 \\
\hline 16 & Direito & 259 & 12 & 1 & 248,0 & 1,099 \\
\hline 16 & Direito & 259 & 11 & 5 & 114,2 & 0,507 \\
\hline 16 & Direito & 259 & 11 & 2 & 121,3 & 0,539 \\
\hline 16 & Direito & 259 & 10 & 3 & 127,2 & 0,565 \\
\hline 16 & Direito & 259 & 10 & 4 & 184,0 & 0,817 \\
\hline 16 & Direito & 259 & 8 & 5 & 178,2 & 0,791 \\
\hline 16 & Direito & 259 & 12 & 6 & 82,8 & 0,365 \\
\hline 16 & Esquerdo & 255 & 12 & 1 & 213,0 & 0,936 \\
\hline 16 & Esquerdo & 255 & 7 & 1 & 111,0 & 0,491 \\
\hline 16 & Esquerdo & 255 & 8 & 2 & 183,0 & 0,806 \\
\hline 16 & Esquerdo & 255 & 11 & 2 & 131,0 & 0,577 \\
\hline
\end{tabular}




\begin{tabular}{|c|c|c|c|c|c|c|}
\hline 16 & Esquerdo & 255 & 10 & 3 & 115,5 & 0,509 \\
\hline 16 & Esquerdo & 255 & 9 & 3 & 278,0 & 1,223 \\
\hline 16 & Esquerdo & 255 & 9 & 4 & 110,5 & 0,487 \\
\hline 16 & Esquerdo & 255 & 10 & 4 & 392,0 & 1,727 \\
\hline 16 & Esquerdo & 255 & 8 & 5 & 167,2 & 0,737 \\
\hline 16 & Esquerdo & 255 & 11 & 5 & 131,7 & 0,580 \\
\hline 16 & Esquerdo & 255 & 7 & 6 & 250,0 & 1,102 \\
\hline 16 & Esquerdo & 255 & 12 & 6 & 101,5 & 0,487 \\
\hline $5 A$ & Direito & 192 & 12 & 1 & 184,0 & 0,819 \\
\hline $5 A$ & Direito & 192 & 7 & 1 & 108,7 & 0,484 \\
\hline $5 \mathrm{~A}$ & Direito & 192 & 8 & 2 & 115,3 & 0,513 \\
\hline $5 \mathrm{~A}$ & Direito & 192 & 11 & 2 & 155,5 & 0,692 \\
\hline $5 \mathrm{~A}$ & Direito & 192 & 10 & 3 & 105,0 & 0,467 \\
\hline $5 \mathrm{~A}$ & Direito & 192 & 9 & 3 & 166,8 & 0,742 \\
\hline $5 \mathrm{~A}$ & Direito & 192 & 9 & 4 & 164,5 & 0,732 \\
\hline $5 \mathrm{~A}$ & Direito & 192 & 10 & 4 & 168,5 & 0,750 \\
\hline $5 \mathrm{~A}$ & Direito & 192 & 8 & 5 & 143,5 & 0,639 \\
\hline $5 \mathrm{~A}$ & Direito & 192 & 11 & 5 & 132,3 & 0,589 \\
\hline $5 A$ & Direito & 192 & 7 & 6 & 346,0 & 1,538 \\
\hline $5 A$ & Direito & 192 & 12 & 6 & 121,2 & 0,539 \\
\hline $5 A$ & Esquerdo & 202 & 12 & 1 & 162,5 & 0,724 \\
\hline $5 A$ & Esquerdo & 202 & 7 & 1 & 93,3 & 0,415 \\
\hline $5 A$ & Esquerdo & 202 & 8 & 2 & 198,5 & 0,884 \\
\hline $5 A$ & Esquerdo & 202 & 11 & 2 & 196,5 & 0,875 \\
\hline $5 A$ & Esquerdo & 202 & 10 & 3 & 101,7 & 0,453 \\
\hline $5 A$ & Esquerdo & 202 & 9 & 3 & 174,7 & 0,778 \\
\hline $5 A$ & Esquerdo & 202 & 9 & 4 & 81,0 & 0,392 \\
\hline $5 A$ & Esquerdo & 202 & 10 & 4 & 176,1 & 0,787 \\
\hline $5 A$ & Esquerdo & 202 & 8 & 5 & 141,2 & 0,629 \\
\hline $5 A$ & Esquerdo & 202 & 11 & 5 & 120,5 & 0,537 \\
\hline $5 A$ & Esquerdo & 202 & 7 & 6 & 174,8 & 0,778 \\
\hline $5 A$ & Esquerdo & 202 & 12 & 6 & 98,3 & 0,438 \\
\hline 11 & Esquerdo & 201 & 12 & 1 & 168,7 & 0,729 \\
\hline 11 & Esquerdo & 201 & 7 & 1 & 81,5 & 0,325 \\
\hline 11 & Esquerdo & 201 & 8 & 2 & 133,0 & 0,575 \\
\hline 11 & Esquerdo & 201 & 11 & 2 & 135,2 & 0,584 \\
\hline 11 & Esquerdo & 201 & 10 & 3 & 146,5 & 0,633 \\
\hline 11 & Esquerdo & 201 & 9 & 3 & 155,0 & 0,670 \\
\hline 11 & Esquerdo & 201 & 9 & 4 & 73,0 & 0,315 \\
\hline 11 & Esquerdo & 201 & 10 & 4 & 199,0 & 0,860 \\
\hline
\end{tabular}




\begin{tabular}{|c|c|c|c|c|c|c|}
\hline 11 & Esquerdo & 201 & 8 & 5 & 109,5 & 0,473 \\
\hline 11 & Esquerdo & 201 & 11 & 5 & 118,5 & 0,512 \\
\hline 11 & Esquerdo & 201 & 7 & 6 & 290,0 & 1,253 \\
\hline 11 & Esquerdo & 201 & 12 & 6 & 88,5 & 0,382 \\
\hline 11 & Direito & 197 & 12 & 1 & 191,0 & 0,853 \\
\hline 11 & Direito & 197 & 7 & 1 & 93,0 & 0,415 \\
\hline 11 & Direito & 197 & 8 & 2 & 96,5 & 0,431 \\
\hline 11 & Direito & 197 & 11 & 2 & 193,0 & 0,862 \\
\hline 11 & Direito & 197 & 10 & 3 & 148,8 & 0,665 \\
\hline 11 & Direito & 197 & 9 & 3 & 146,8 & 0,656 \\
\hline 11 & Direito & 197 & 9 & 4 & 78,5 & 0,351 \\
\hline 11 & Direito & 197 & 10 & 4 & 187,0 & 0,835 \\
\hline 11 & Direito & 197 & 8 & 5 & 100,5 & 0,449 \\
\hline 11 & Direito & 197 & 11 & 5 & 146,0 & 0,652 \\
\hline 11 & Direito & 197 & 7 & 6 & 140,5 & 0,628 \\
\hline 11 & Direito & 197 & 12 & 6 & 154,5 & 0,690 \\
\hline 17 & Direito & 232 & 12 & 1 & 155,0 & 0,715 \\
\hline 17 & Direito & 232 & 7 & 1 & 103,2 & 0,476 \\
\hline 17 & Direito & 232 & 8 & 2 & 143,0 & 0,659 \\
\hline 17 & Direito & 232 & 11 & 2 & 146,5 & 0,676 \\
\hline 17 & Direito & 232 & 10 & 3 & 155,5 & 0,717 \\
\hline 17 & Direito & 232 & 9 & 3 & 159,8 & 0,737 \\
\hline 17 & Direito & 232 & 9 & 4 & 62,8 & 0,290 \\
\hline 17 & Direito & 232 & 10 & 4 & 231,0 & 1,064 \\
\hline 17 & Direito & 232 & 8 & 5 & 230,0 & 1,062 \\
\hline 17 & Direito & 232 & 11 & 5 & 119,0 & 0,549 \\
\hline 17 & Direito & 232 & 7 & 6 & 148,0 & 0,682 \\
\hline 17 & Direito & 232 & 12 & 6 & 89,5 & 0,413 \\
\hline 17 & Esquerdo & 198 & 12 & 1 & 158,7 & 0,716 \\
\hline 17 & Esquerdo & 198 & 7 & 1 & 92,5 & 0,417 \\
\hline 17 & Esquerdo & 198 & 8 & 2 & 103,5 & 0,512 \\
\hline 17 & Esquerdo & 198 & 11 & 2 & 107,3 & 0,484 \\
\hline 17 & Esquerdo & 198 & 10 & 3 & 127,3 & 0,574 \\
\hline 17 & Esquerdo & 198 & 9 & 3 & 258,0 & 1,164 \\
\hline 17 & Esquerdo & 198 & 9 & 4 & 105,3 & 0,475 \\
\hline 17 & Esquerdo & 198 & 10 & 4 & 168,0 & 0,758 \\
\hline 17 & Esquerdo & 198 & 8 & 5 & 190,8 & 0,861 \\
\hline 17 & Esquerdo & 198 & 11 & 5 & 121,0 & 0,546 \\
\hline 17 & Esquerdo & 198 & 7 & 6 & 227,0 & 1,024 \\
\hline
\end{tabular}

